\title{
IntechOpen
}

\section{Generation, Development and Modifications of Natural Fibers}

Edited by Mudassar Abbas and Han-Yong Jeon 



\title{
Generation, Development and Modifications of Natural Fibers
}

\author{
Edited by Mudassar Abbas \\ and Han-Yong Jeon
}



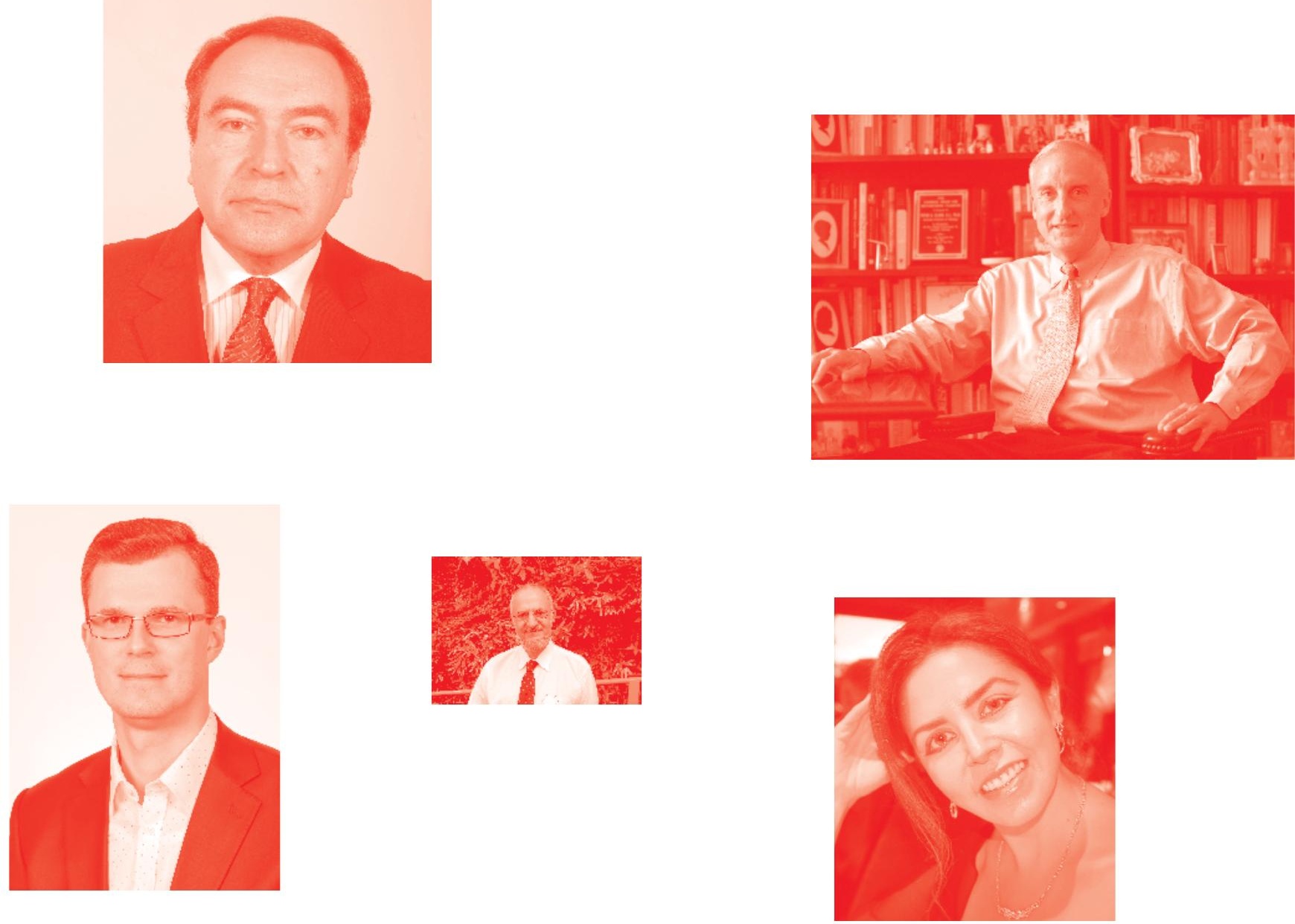

Supporting open minds since 2005

Generation, Development and Modifications of Natural Fibers

http : //dx . doi. org/10.5772/intechopen. 78111

Edited by Mudassar Abbas and Han-Yong Jeon

\section{Contributors}

Seungjin Kim, Hyun Ah Kim, Hem Raj Pant, Mahesh Kumar Joshi, Sareen Sheik, G.K. Nagaraja, Tayyaba Fatma, Nechita Petronela, Jatinder Singh Dhaliwal

(๑) The Editor(s) and the Author(s) 2020

The rights of the editor(s) and the author(s) have been asserted in accordance with the Copyright, Designs and Patents Act 1988. All rights to the book as a whole are reserved by INTECHOPEN LIMITED. The book as a whole (compilation) cannot be reproduced, distributed or used for commercial or non-commercial purposes without INTECHOPEN LIMITED's written permission. Enquiries concerning the use of the book should be directed to INTECHOPEN LIMITED rights and permissions department (permissions@intechopen.com).

Violations are liable to prosecution under the governing Copyright Law .

\section{(cc) BY}

Individual chapters of this publication are distributed under the terms of the Creative Commons Attribution 3.๑ Unported License which permits commercial use, distribution and reproduction of the individual chapters, provided the original author(s) and source publication are appropriately acknowledged. If so indicated, certain images may not be included under the Creative Commons license. In such cases users will need to obtain permission from the license holder to reproduce the material. More details and guidelines concerning content reuse and adaptation can be found at http : //www . intechopen . com/copyright-policy . html .

\section{Notice}

Statements and opinions expressed in the chapters are these of the individual contributors and not necessarily those of the editors or publisher. No responsibility is accepted for the accuracy of information contained in the published chapters. The publisher assumes no responsibility for any damage or injury to persons or property arising out of the use of any materials, instructions, methods or ideas contained in the book.

First published in London, United Kingdom, 2020 by IntechOpen IntechOpen is the global imprint of INTECHOPEN LIMITED, registered in England and Wales, registration number: 11086078 , 7th floor, 10 Lower Thames Street, London,

EC3R 6AF, United Kingdom

Printed in Croatia

British Library Cataloguing-in-Publication Data

A catalogue record for this book is available from the British Library

Additional hard and PDF copies can be obtained from orders@intechopen.com

Generation, Development and Modifications of Natural Fibers

Edited by Mudassar Abbas and Han-Yong Jeon

p. $\mathrm{cm}$.

Print ISBN 978-1-78984-672-0

Online ISBN 978-1-78984-673-7

eBook (PDF) ISBN 978-1-78985-688-0 


\section{We are IntechOpen, \\ the world's leading publisher of Open Access books}

\section{Built by scientists, for scientists}

\section{$4,600+$}

Open access books available

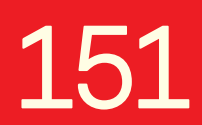

Countries delivered to

\section{$120,000+$}

International authors and editors

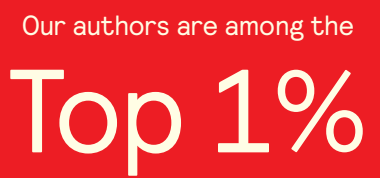

most cited scientists

Contributors from top 500 universities
$135 \mathrm{M}+$

Downloads
$12.2 \%$

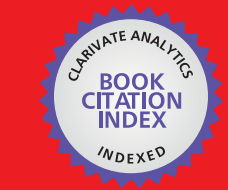

WEB OF SCIENCE ${ }^{\text {M }}$

Selection of our books indexed in the Book Citation Index in Web of Science ${ }^{\mathrm{TM}}$ Core Collection (BKCI)

\section{Interested in publishing with us? \\ Contact book.department@intechopen.com}

Numbers displayed above are based on latest data collected.

For more information visit www.intechopen.com 



\section{Meet the editor}

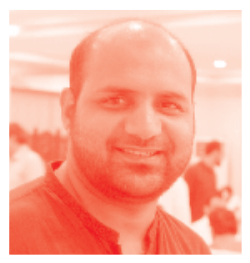

Dr. Mudassar Abbas is currently an associate professor in the School of Textile and Design at the University of Management and Technology, Lahore, Pakistan. He was also invited as a "guest professor" at Graz University of Technology, Graz, Austria, during summer 2017 after winning a scholarship under the Ernst March (EZA) fellowship program. His current area of research includes the findings of greener routes for the synthesis of applied materials containing nanoparticles and/or polymers. Dr. Abbas is also running an HEC-funded project (under NRPU, project No. 3422) for the development of silver nanoparticle-based functional materials for advanced biocidic applications.

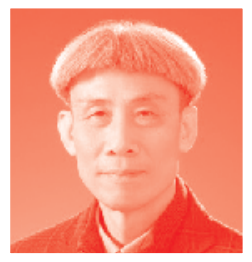

Dr. Han-Yong Jeon is a professor at Inha University, Incheon, Korea (South), and a geosynthetics/technical organic materials researcher. He was the 32nd President of the Korean Fiber Society (2014-2015) and the 6th President of the Korean Geosynthetics Society (2011-2013). He was also a Council Member of the International Geosynthetics Society (2008-2012). His research is focused on the manufacturing, application, and evaluation of technical organic materials/manufacturing, evaluation, standardization, and regulation of geosynthetics/environmental and structural polymeric composites, etc. He has written 24 texts, including Review of Long-Term Durable Creep Performance of Geosynthetics by Constitutive Equations of Reduction Factors (IntechOpen), ISBN 978-953-51-3724-5, IntechOpen (2018), and has also published 158 papers in domestic and international journals. He has published more than 943 proceedings and abstracts in domestic and international conferences. He was awarded the Marquis Who'sWho-Science and Engineering award in 2003-2019, the 33rd Academy Award of the Korean Fiber Society in 2006, the "Excellent Paper Award of 2012" by the Korean Federation of Science and Technology Societies, and "The Best Publication Award 2017" titled "Geosynthetics for Civil Engineers" from the Korea Association of Technical Textile Industry. 



\section{Contents}

Preface

Section 1

Generation, Development and Modification in Natural Fibres

Chapter 1

Development, Characterization and Properties of Silk Fibre and Grafted Silk Fibre Reinforced Polymer Composite Films by Sareen Sheik and Gundibasappa Karikannar Nagaraja

Chapter 2

Natural Fibers: Applications

by Jatinder Singh Dhaliwal

Chapter 3

Surface Modification of Bast-Based Natural Fibers through

Environment Friendly Methods

by Tayyaba Fatma

Chapter 4

Use of Recycled Cellulose Fibers to Obtain Sustainable Products

for Bioeconomy Applications

by Petronela Nechita

Section 2

Non-Woven Fabrics Technology

Chapter 5

Characteristics of Eco-friendly Kenaf Fiber-Imbedded Nonwoven for Automotive Application

by Seung Jin Kim and Hyun Ah Kim

Chapter 6

3D Nonwoven Fabrics for Biomedical Applications

by Mahesh Kumar Joshi, Rajeshwar Man Shrestha and Hem Raj Pant 



\section{Preface}

Natural fibers embrace a long history of serving mankind in a wide range of everyday life applications, and they compete and coexist in the twenty-first century with manmade fibers, especially as far as quality, sustainability, and economy of production are concerned. The present world has witnessed the importance of research, development, and innovation in the practical utilization of natural fibers. These fibers have been used for hundreds of years to meet human needs such as clothing and shelter. These practices were considerably reduced with the emergence of synthetic fibers toward the end of the 1900s. However, with the passage of time the alarming increase in environmental concerns and exhaustion of energy resources have revitalized the significance of natural fibers. Instead of the widespread usage of conventional synthetic fibers, researchers and the industry are now even more stimulated to utilize and generate the development and modification of sustainable fibers. The major advantages of using natural fibers in different applications is that they comprise several mechanical and physical properties such as good specific modulus values, low density, considerable toughness, low cost, recyclability, non-toxicity, and easy accessibility, and these attractive aspects give an opportunity to use natural fiber-reinforced composite products in various industries such as automotive, building, furniture, and so on. The book presents the latest research data on new and emerging areas in the generation, processing, development, and modification of natural fibers and their applications.

By definition, natural fibers are fibrous polymeric composite materials obtained from natural renewable sources, namely plants and animals. The ever-growing environmental, ecological, and economical concerns lead to increased acceptance of natural fibers as substitutes in almost every area of conventional synthetic material application. Applying natural fibers in various applications yields the benefits of biodegradability, non-toxicity, combustibility, easy availability, non-abrasiveness, light self-weight, low cost, good specific strength, and great corrosion, as well as fatigue resistance. Despite these advantages, there are huge drawbacks associated with the use of natural fibers, including great water sensitivity, poor melting temperature, and inferior adhesion to other materials. To combat these downsides, the surface modification of natural fibers has received vast research interest in recent developments.

The first chapter deals with different phases of development, characterization, and properties of silk fiber and grafted silk fiber-reinforced polymer composite films. The innumerable properties of silk fiber have proven its worth to be used by researchers both in the plastic and biomedical sectors. The extensive use of silk fibroin in the biomedical field, due to its robust properties, has made it a promising material suitable in tissue-engineering applications. Keeping this in view, the current chapter also focuses on retailoring the properties of silk fibers by grafting a natural polysaccharide. The results are useful in determining the practicality of silk fabric in the biomedical field.

The second chapter gives information on the structure and properties of common plants, which are used as natural fiber sources. Due to research and developmental 
work in the modification and treatment methods of natural fibers, utilization of natural fibers has observed a significant growth in various applications. The chapter addresses the potential applications of natural fibers in various commercial sectors for the development of environmentally friendly products with the aim of replacing synthetic fibers or inorganic fillers with cost-effective and efficient products.

The next chapter looks at the topic of surface modification of bast-based natural fibers through environmentally friendly methods. Bast fibers play a significant role in producing natural products that are extracted from the stems of various plants. Besides being environmentally friendly in nature, bast fibers have several benefits, e.g., they can improve the livelihood of poor farmers involved in the cultivation of plants and the extraction and processing of the fibers. Therefore, surface modification of established natural fibers (such as hemp, flax, jute, kenaf, urena, nettle, and ramie) and explored natural fibers are momentous areas for research. The most important aspect of the current research is the exploration of environmentally friendly methods, such as plasma treatment, and utilization of enzymes, bacteria, and fungi to acquire these modifications.

The last chapter deals with a review of the valorization of cellulose fibers to obtain sustainable products for bioeconomy applications. Over the past decade, natural fibers have received considerable research interest as a reinforcement for the generation of polymer composites due to their high-performance profile and environmental sustainability. Cellulose fibers can be used as functionalized products for several applications cost effectively.

Being convinced of the value of the topics covered in the book, owing to the significance of the sustainable approach in the generation, development and modification of natural fibers for the industrial world, as well as for developing countries, I was myself delighted to collaborate on this book focusing on different aspects of natural fibers applications. I hope that readers become aware of the complexity, the interaction, interconnections and the challenges of this field, and that they will help to communicate the importance of topics covered.

Dr. Mudassar Abbas

School of Textile and Design of University of Management and Technology, Lahore, Pakistan 
The non-woven fabrics industry can play a leading role in the convergence and commercialized production of industrial textiles as a front- and rear-linked industry for industrial textile applications. In general, non-woven fabrics are used as representative intermediate materials or final products of composite materials. For this purpose, new fibers for the production of non-woven fabrics have been developed and new manufacturing technologies for making differentiated intermediate products or final products have been introduced to consider the application of non-woven fabrics expanding from intermediate products to hybrid products.

To review the position of non-woven fabrics as one of the important convergence materials, its future vision is introduced, including from raw materials to final composite products. The applicability of non-woven fabrics is also introduced based on the new advanced embedded intermediate materials using general-purpose synthetic fibers as well as special fibers such as nanofibers and carbon fibers.

The core technology of non-woven fabrics manufacturing is to improve and control the uniformity of the dispersed phase of the constituent fibers. In addition, since the weight and thickness of the web are directly related to the weight and thickness of non-woven fabrics, it is possible to predict the mechanical performance of nonwoven fabrics prepared by controlling uniformity and weight through optimization of the manufacturing process.

This book describes the current state of technology and product trends of nonwoven fabrics that have an important effect on the manufacturing technology and product development of industrial textiles. Hybrid technology from new and advanced fibers to final products is included for its specialized end-use application. Especially, nanofiber and related non-woven fabrics are newly introduced from the point of view of nanofiber assembly technology.

Finally, we expect this text to be a meaningful guide and reference for non-woven fabrics technology and sincerely thank all the authors for their precious manuscripts. Also, we deeply appreciate the effort of Author Service Manager Ms. Lada Bozic at IntechOpen.

Han-Yong Jeon Professor, GeoSynthetics Research Laboratory, Technical Organic Materials Research Laboratory, Department of Chemical Engineering, Inha University, Inha-ro, Michuhol-gu, Incheon, South Korea 

Section 1

\section{Generation, Development and Modification in Natural Fibres}





\title{
Development, Characterization and Properties of Silk Fibre and Grafted Silk Fibre Reinforced Polymer Composite Films
}

\author{
Sareen Sheik and Gundibasappa Karikannar Nagaraja
}

\begin{abstract}
The use of natural fibres over synthetic fibres is gaining widespread importance due to its availability; renewability, low density and satisfactory mechanical properties making them an ecological alternative to synthetic fibres. The innumerable properties of silk fibre have made it superior to be used by researchers both in the plastic and biomedical sector. Silk fibre reinforced PVA (polyvinylalcohol) and PVA/PVP (polyvinyl pyrrolidone) films were prepared via solution casting technique. The effect of silk fibre concentration, on the structural, thermal, mechanical, bio-degradable and the morphological properties of the composite films was assessed. The results indicated that the addition of silk fibres improved the thermal, morphological, mechanical and biodegradable properties of the films. The extensive use of silk fibroin in the biomedical field, due to its robust properties has made it a promising material, suitable in tissue engineering applications. Keeping this in view, the current study also focuses on re-tailoring the properties of silk fibres by grafting a natural polysaccharide like chitosan and thereby fabricate composite films of PVA reinforced with this grafted fibre. The films were tested for their potential applications in tissue engineering, by subjecting them to in vitro biocompatibility tests. The films were also tested for their antibacterial properties. The results thus obtained indicated that the films were non-toxic in all concentrations and were found to be suitable for biomaterial applications.
\end{abstract}

Keywords: silk fibre, chitosan, grafting, tissue-engineering, biodegradation

\section{Introduction}

With the advent of polymer technology and large scale production of synthetic fibre reinforced composites, natural fibres as reinforcements have gained greater insights due to ecological concerns, accessibility, relatively low cost and biodegradability. This thrust for green products has empowered the mankind to consider these natural fibres, to be an alternative over conventional glass and carbon fibres [1]. Natural fibres are however considered far more superior over synthetic fibres as they are known to possess good relative mechanical properties, flexibility during processing, biodegradability and minimum health hazards [2]. 
Among the natural fibres, silk, a natural animal fibre is widely used due to its enormous applications. Silk is a strong and filamentous fibre produced by the larva of silkworm, during metamorphosis [3]. Of the many varieties of silk fibres, the best known is the Bombyx mori, which is essentially recognized for its strength and lustre [4].

It is structurally made up of a protein called fibroin which is composed of amino acids like glycine, alanine and serine, with a crystallinity in the order of 70-75 and 25-30\% amorphous in nature. Besides, polypeptide chains in silk lie close enough to each other, to form a network of hydrogen bonds. As a result, bond formation is enabled with other hydrogen atoms of the polymer matrix resulting in higher thermal stability $[3,5]$. The vast properties of silk fibres are mainly due to its high ultimate tensile strength which is about $208.45 \mathrm{MPa}$, elongation at break: $19.55 \%$, modulus of $6.10 \mathrm{GPa}$ and density of $1.33 \mathrm{~g} / \mathrm{cm}^{3}$ [6]. Furthermore, silk also exhibits high softening temperature and decomposes at a higher temperature [3]. Moreover, it is a potential candidate in the field of medical, pharmaceutical and agricultural areas and is also known to possess properties, like microbial resistance, oxygen permeability, biocompatibility, water absorbability [7-9]. Due to these properties, the emphasis lies on the study of silk based fibre reinforced polymer composites.

The surface modification of biomaterials using biomolecules is known to improve blood compatibility [10] or to enhance cell attachment and proliferation [11]. Over the centuries, grafting of silk fibres using vinyl monomers was performed to improve properties of the fibre to make it equally competent over manmade fibres $[12,13]$. Although, grafting of vinyl monomers improves the properties of fibres, it however has a major limitation, due to the damaging products released by slow degradation [14]. Therefore, environmental surface modification of fibres was a technique introduced in an attempt to retain the properties of silk by grafting natural polysaccharides such as chitin and chitosan. Chitosan, is a derivative of chitin and is prepared through the deacetylation of chitin. It is a major component present in marine invertebrates such as crustacean shells (shrimps, crabs etc.), exoskeleton of insects and a few fungi [15]. Chitosan and silk fibroin are natural biopolymers that are applied in tissue engineering and biomedical fields. Chitosan has been proposed as a biomaterial for biomedical applications mainly due to its biocompatibility $[16,17]$. The properties of chitosan including easy availability, biodegradability, bioactivity and nontoxicity, as well as bio-adhesion and antimicrobial properties are the major reasons for its applications widely considered by researchers [18].

Glycosaminoglycans (GAGs), which are native components of the extracellular matrix (ECM), are known to structurally resemble chitosan, making it one of the promising biomaterials, for cartilage repair [19, 20]. Furthermore, it accelerates wound healing $[21,22]$ and amends the immune system by macrophage activation [23] to generate cytokines thus, inhibiting infections [24]. In view of this, the grafting of silk fibres using chitosan was adopted for the current study.

The best route to successfully graft chitosan over silk is via acylation as it provides an enhanced surface area for grafting. Chitosan grafting over silk and via acylation has been successfully performed by researchers to enhance the properties of silk in the textile industry $[25,26]$. However, the application of grafted silk fibres in the field of tissue engineering remains unexplored. Therefore, the current chapter focuses on the preparation and properties of silk fibre reinforced PVA and PVA/PVP composite films and thereafter study the effect of surface modification of silk fibre by grafting a natural polysaccharide like chitosan and thus explore the potential of these fibre reinforced composites for packaging and biomedical applications respectively. 


\section{Sillk fibre reinforced PVA and PVA/PVP composite films}

\subsection{Preparation}

Silk fibre reinforced PVA (SF-PVA) and PVA/PVP (SF-PVA/PVP) films were prepared as follows. The degummed silk fibres were rinsed with distilled water to remove any impurities/solid dust particles sticking to the fibres. Further, the fibres were dried completely and then incised into small particles and powdered. This powdered silk was used for the preparation of films. Using the solution-casting technique, SF-PVA and SF-PVA/PVP films were prepared by mixing different weights of silk fibre and the polymer. For the blend composites, the weight of PVP was kept constant and the weight of silk fibres and PVA was varied. The solvent used for the preparation of films was double distilled water. The SF-PVA and SF-PVA/PVP solutions were mixed, for about 8 hours at $80^{\circ} \mathrm{C}$. Further, to avoid agglomeration of fibres and to enhance its dispersion in the polymer matrix, the solutions were ultra-sonicated. The solutions were finally poured to a petri-dish and subjected to evaporation and final drying in an oven at $50^{\circ} \mathrm{C}[27,28]$.

\subsection{Characterization of the composite films}

\subsubsection{Morphological properties}

The morphology of the films was observed using field emission scanning electron microscopy (FESEM) [27, 28]. The surface morphology and cross sections depicting thickness of a few selected films is as depicted in Figure 1. The thickness of the film corresponds to $27.53 \mu \mathrm{m}$. PVA film, without the fibre shows a homogenous and continuous matrix throughout without cracks. Similarly, in case of blend film, the compatibility of both PVA and PVP was clearly observed due to the smooth and homogenous surface resulting from the interaction between the two polymers. In both the cases, when the film is reinforced with $9 \mathrm{wt} \%$ silk, the smoothness of the surface is however lost and appears rough. The images depict that the fibres are randomly distributed and embedded well in the matrix indicating proper mixing of fibres. This could possibly be due to the interaction of the polar functional groups of the fibre with that of the matrix. When the fibre concentration is further increased to $15 \mathrm{wt} \%$, the fibres seem to be less adhered to the matrix phase and tend to agglomerate indicating phase discontinuity [29] resulting in loss of film homogeneity.

\subsubsection{Thermal properties}

Thermogravimetric analysis (TGA) was performed for both SF-PVA and SF-PVA/PVP films as depicted in Figure 2. For SF-PVA films, the pristine PVA film exhibited three decomposition steps. The initial decomposition, due to the loss of water from the sample occurred at $80-150^{\circ} \mathrm{C}$ with a mass loss of $7.6 \%$. The maximum degradation occurred from $250-400^{\circ} \mathrm{C}$ accompanied by a major weight loss of about $62.1 \%$. This was due to the structural degradation followed by scissions of polymer chains in PVA. Further decomposition occurred from $450^{\circ} \mathrm{C}$. This was due to the breakdown of $\mathrm{C}-\mathrm{C}$ bonds in the polymer backbone. The addition of silk fibre (3-15 $\mathrm{wt} \%)$ reduced the percentage mass loss (59.7-45.5\%) [27]. This decrease in mass loss and the resultant increase in thermal stability is attributed to the higher thermal stability of silk fibres, which on interaction with the polymer matrix act as barriers for better heat insulation and lower the rate of degradation of the polymer [30]. 


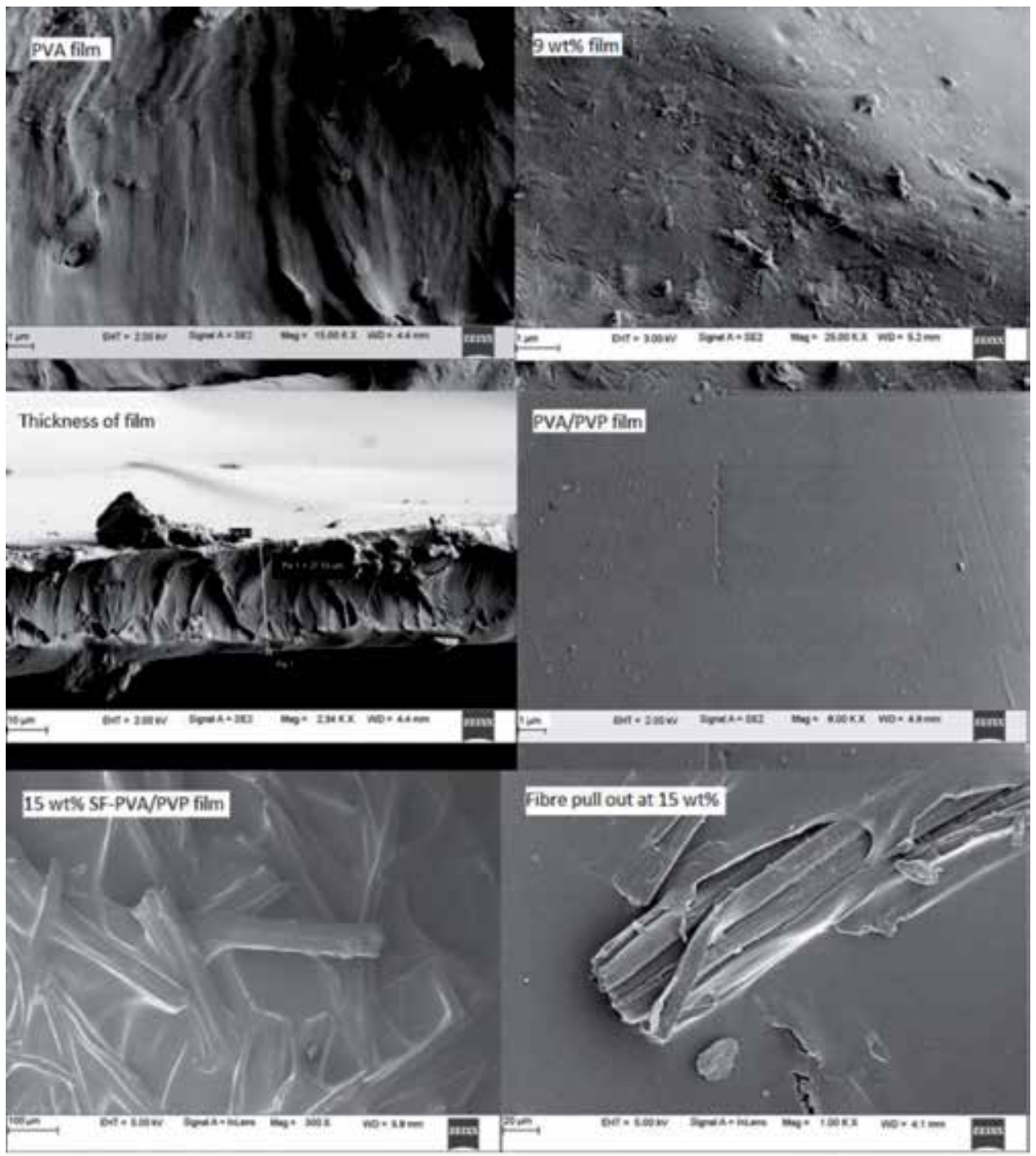

Figure 1.

FESEM images of SF-PVA and SF-PVA/PVP films.
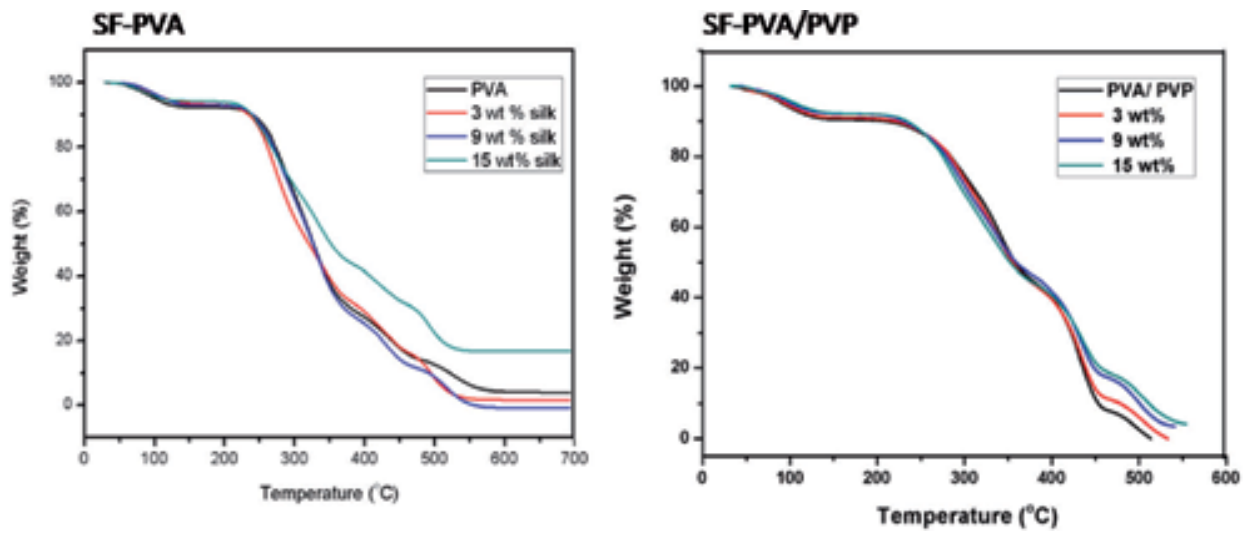

Figure 2.

TGA curves for SF-PVA and SF-PVA/PVPfilms. 
The TGA of PVA/PVP film (Figure 2) and the film composites showed three decomposition steps. For the pure blend, the initial decomposition, with a mass loss of $7.4 \%$, occurred at $70-140^{\circ} \mathrm{C}$ which was due to the loss of bound water molecules and acetic acid in the polymer [31]. Major degradation, due to the melting and breakdown of the blend segments, occurred between 200 and $365^{\circ} \mathrm{C}$ followed by a major weight loss of about $42 \%$. Further decomposition and degradation of the sample resulted in a mass loss of $36 \%$ which occurred from 370 to $460^{\circ} \mathrm{C}$. This was mainly due to the condensation and cyclization of the polyaromatic PVP [32]. With the addition of silk fibres, the percentage weight loss was slightly reduced to $40 \%$, followed by an additional decrease to $36 \%$ ( $15 \mathrm{wt} \%$ ) with a maximum residual content. It is quite obvious that due to the presence of amide groups, silk is known to possess a higher thermal stability as indicated by its high melting temperature, than PVA. The existence of a strong intermolecular hydrogen bonding interaction between hydroxyl groups of PVA and amide groups of silk in the composites resulted in an improved thermal stability and mechanical strength.

To further explain, after a thermal analysis, the final residual mass of a composite (char) is a measure of its flame resistance. This residual char, when exposed to a higher temperature can thermally insulate the undecomposed polymer from degrading [28]. The high varying nitrogen content in silk fibres (about 15-18\%), has provided the fibre with a self-extinguishing property and hence a higher flame resistance. Therefore, it can thus be concluded that the decrease in mass loss with increasing fibre concentration, is mainly due to the thermal stability and flame resistance properties of silk fibres in the composites [33, 34].

From differential scanning calorimetry (DSC), the melting temperature, glass transition $\left(\mathrm{T}_{\mathrm{g}}\right)$ and enthalpy values $\left(\Delta \mathrm{H}_{\mathrm{m}}\right)$ were assessed and summarized in Table 1 and depicted in Figure 3. The melting temperature values for PVA and SF-PVA films were to a certain extent close to each other. The $T_{g}$ for pure PVA film observed was $85.89^{\circ} \mathrm{C}$ [27]. Substantial increase in the $\mathrm{T}_{\mathrm{g}}$ and $\Delta \mathrm{H}_{\mathrm{m}}$ values was observed with the addition of silk fibres, as compared to the PVA film. The addition of silk reinforcements hinders the chain mobility, thus shifting the $\mathrm{T}_{\mathrm{g}}[30]$.

For SF-PVA/PVP films, a single glass transition temperature was observed. The occurrence of a single glass transition temperature $\left(\mathrm{T}_{\mathrm{g}}\right)$ indicates the miscibility between the two polymers [35]. For the blend films, this endothermic transition appeared at a temperature of $93^{\circ} \mathrm{C}$. Glass transition temperature $\left(\mathrm{T}_{\mathrm{g}}\right)$ was further increased to higher temperatures $\left(97,101\right.$, and $105^{\circ} \mathrm{C}$ for 3,9 and $15 \mathrm{wt} \%$

\begin{tabular}{lcccc}
\hline Silk fibre content $(\mathbf{w t} \%)$ & $\mathbf{T}_{\mathbf{g}}\left({ }^{\mathbf{o}} \mathbf{C}\right)$ & $\mathbf{T}_{\mathbf{m}}\left({ }^{\mathbf{o}} \mathbf{C}\right)$ & $\mathbf{\Delta} \mathbf{H}_{\mathbf{m}}(\mathbf{J} / \mathbf{g})$ & Mass loss $(\%)$ \\
\hline SF-PVA films & & & & \\
\hline 0 & 85.9 & 222.7 & 21.9 & 62.1 \\
\hline 3 & 101.9 & 223.04 & 23.5 & 59.7 \\
\hline 9 & 106.7 & 221.9 & 28.7 & 58.7 \\
\hline 15 & 93.9 & 221 & 29.8 & 45.5 \\
\hline SF-PVA/PVP films & & & 27.4 & 42 \\
\hline 0 & 93 & 215 & 21.6 & 41.4 \\
\hline 3 & 97 & 217 & 23.3 & 40 \\
\hline 9 & 101 & 219 & 28.6 & 36 \\
\hline 15 & 105 & 220 & & \\
\hline
\end{tabular}

Table 1.

Thermal properties of SF-PVA and SF-PVA/PVP films. 
SF-PVA

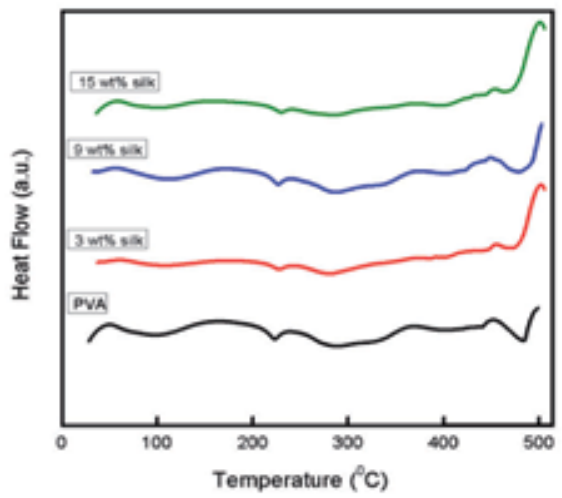

SF-PVA/PVP

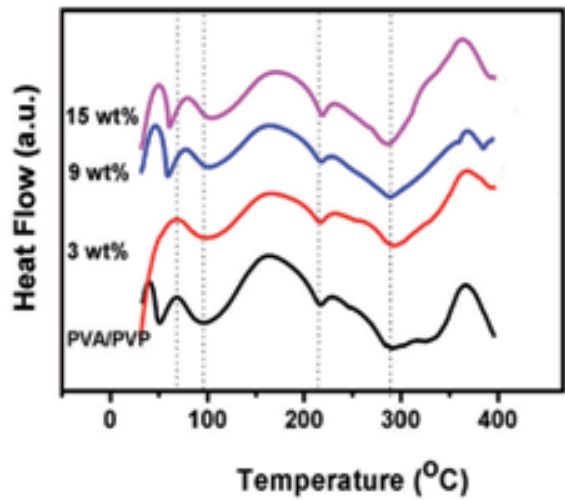

Figure 3.

DSC curves for SF-PVA and SF-PVA/PVP films.

respectively) with the increased amounts of silk fibre [28]. This increase in $\mathrm{T}_{\mathrm{g}}$ along with the increase in the concentration of silk is due to the interaction of the silk fibre with the PVA/PVP matrix, thus, hindering chain mobility as previously discussed [30].

\subsubsection{Mechanical properties}

Tensile strength, Young's modulus and percentage elongation at break of the SF/ PVA films was assessed and illustrated in Figure 4. For the SF-PVA film, the tensile strength and Young's modulus values effectively increased up to a fibre concentration of $12 \mathrm{wt} \%$ and thereafter decreased. The maximum values recorded for tensile strength and Young's modulus were $41.87 \pm 2.08$ and 202.08 $\pm 2.53 \mathrm{MPa}$ respectively [27]. This was probably due to the hydrogen bonding interactions between the PVA and silk fibre that resulted in an increased mechanical property. When the fibre concentration was relatively low $(3 \mathrm{wt} \%)$, the matrix was not restrained by adequate fibres and thus a remarkably high strain occurred which was confined to a small area in the matrix. This can cause rupturing in the bonds between the matrix and the fibre ensuing in an insufficient mechanical strength [36]. When the fibre concentration was increased, the load was shared between the fibres and the matrix, wherein the maximum load was taken by the fibres by the stress transfer mechanism. At a high fibre concentration, the $-\mathrm{NH}_{2}$ and $\mathrm{CO}-$ groups of silk have a tendency to entangle and agglomerate among each other thus failing to interact with PVA [37] and hence a resulting decrease in the mechanical strength. The interfacial adhesion of the fibre and matrix plays a pivotal role in understanding the strength of a composite [36]. Highest percentage elongation at break was seen in PVA film, while the films reinforced with silk fibre, showed lower values due to the decrease in the concentration of PVA. This resulted in a fragile character and less ductile nature of the films.

For the SF-PVA/PVP films, the tensile strength and Young's modulus values increased up to $9 \mathrm{wt} \%$, and subsequently decreased at a fibre concentration of $12 \mathrm{wt} \%$. The maximum values for $9 \mathrm{wt} \%$ film, recorded a tensile strength of $30.3 \pm 1.58 \mathrm{MPa}$ and Young's modulus of $276.5 \pm 4.05 \mathrm{MPa}$ [28].

It is obvious that when a polymer matrix is reinforced with short fibres such as silk, the mechanical keying effects between the polymer chains and the fibre primarily restricts the segmental motion of the polymer matrix. Further, as previously 

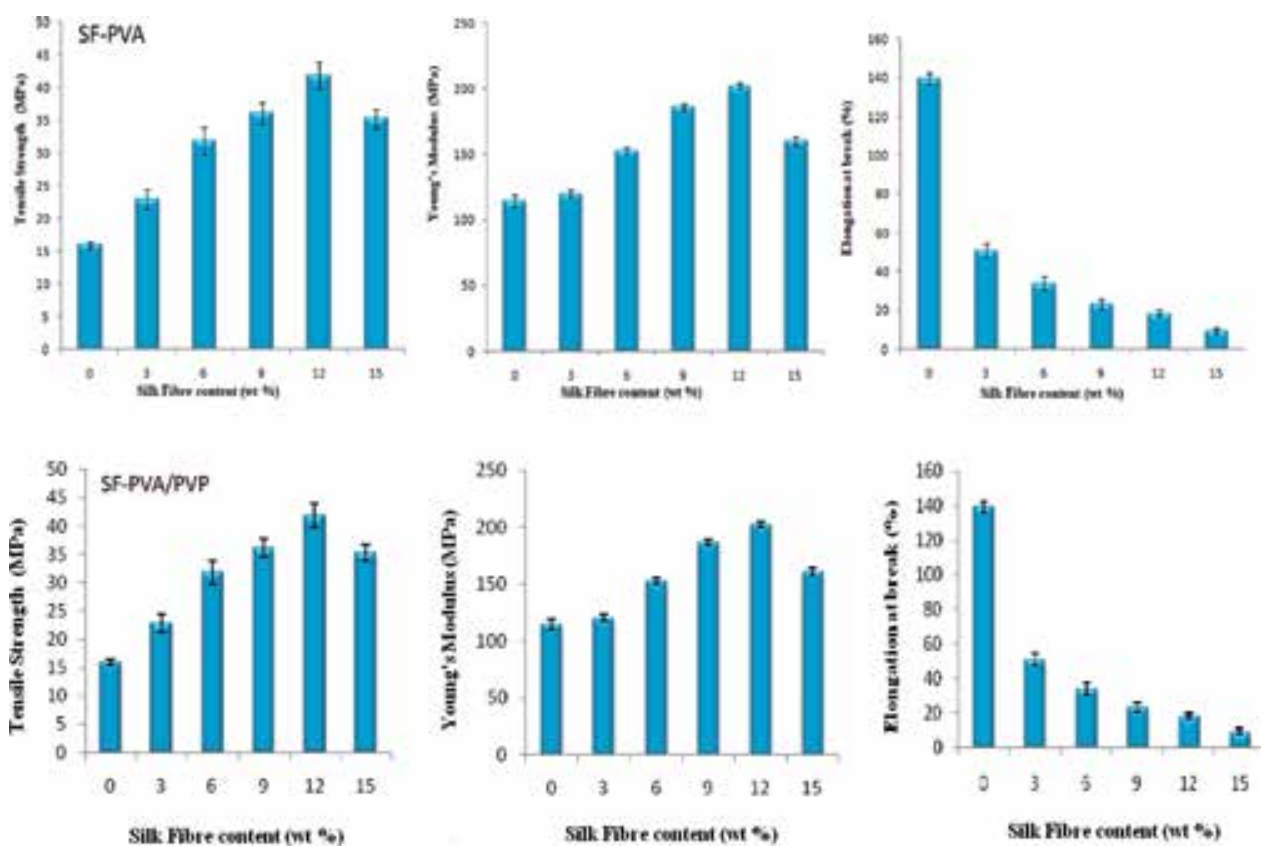

Figure 4.

Mechanical properties of the composite films.

discussed, the chemical interactions such as hydrogen bonding between the matrix and fibre, improves the strength of the composite.

In short fibre reinforced composites; the matrix plays a dynamic role as it provides a cushioning effect to the embedded fibres, although the load is shared by both fibre and matrix. When the concentration of the matrix is decreased, followed by a relatively increase in the concentration of the fibres, the increased load results in more strain resulting in breaking, thus leading to de-bonding between the fibre and matrix [38]. In addition to this, as evident from FESEM analysis (Figure 1) the silk fibres were less adhered to the matrix at the surface of the film (15 wt $\%$ fibre concentration) [28].

The trend observed in the percentage elongation at break was similar to that observed in the case of SF-PVA films. This decrease was again ascribed to the associated decrease in the concentration of the matrix [28].

\subsubsection{Biodegradation by soil burial tests}

The biodegradability of the film samples was evaluated using the weight loss method [39] and depicted in Figure 5. For a period of 8 days, the average weight decrease was $5 \%$ and the weight of the films further gradually decreased as the time increased. For SF-PVA/PVP films, for a period of 8 days, the average weight decrease was found to be $12 \%$ and as time increased, the weight of the films also gradually decreased. After 64 days the average weight decrease was approximately 36 and $32 \%$ for SF-PVA and SF-PVA/PVP respectively. It was observed that, as the percentage of silk fibre increased there is enhancement in the rate of bio-degradation of the films when compared to the pure PVA and blend film without the fibre. As the soil microbes attack, structural deformations in the film composites occurred resulting in the brittleness of the films. Therefore the films became hard and fragile in nature. When this protein based silk fibre, is buried in soil, it tends to undergo degradation 


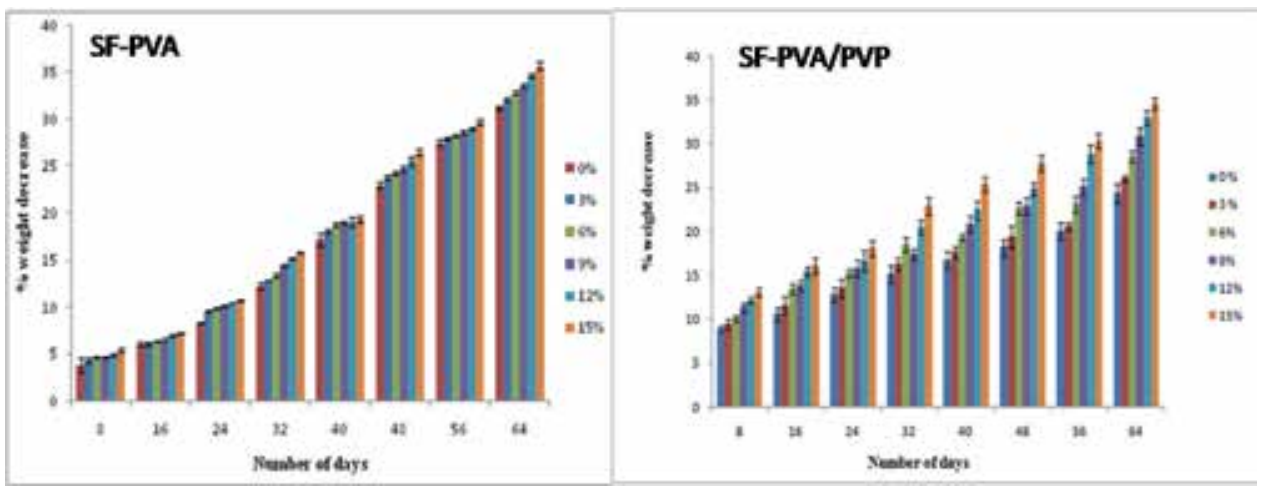

Figure 5.

Graphs depicting soil burial degradation tests for composite films.

which could be attributed to the penetration of water from the cut edges of the composite films, resulting in loosening of the complex structure and consequently results in the weight loss of the films [40].

\section{Surface modification of silk by grafting chitosan}

The grafting of chitosan over silk was performed using the optimized procedure with slight modifications, reported by Davarpanah et al. [26, 41]. Briefly, degumming of silk was performed using sodium dodecyl sulphate and sodium carbonate. The material mass to liquor ratio maintained was 1:25. The fibres were further washed with warm and cold distilled water and dried. Acylation of the degummed fibres was performed using succinic anhydride in N,N-dimethyl formamide (DMF). The fibre samples were washed with DMF followed by acetone, to remove unreacted anhydrides. Grafting of chitosan was carried out in acetic acid media followed by drying. In Figure 6, the images of the fibres before and after surface modification are shown. Total percentage fibre weight gain was calculated by the difference in weight gain of the acylated and the grafted silk fibre and was found to be $17 \%$ [42].

\subsection{Preparation of grafted silk fibre reinforced PVA composite films}

Post grafting, the fibres were dried completely and incised into small particles and finely powdered. Fibre reinforced PVA films were prepared by mixing different weight percentages of grafted silk and PVA, followed by the solution-casting technique [42] as described previously under Section 2.1.

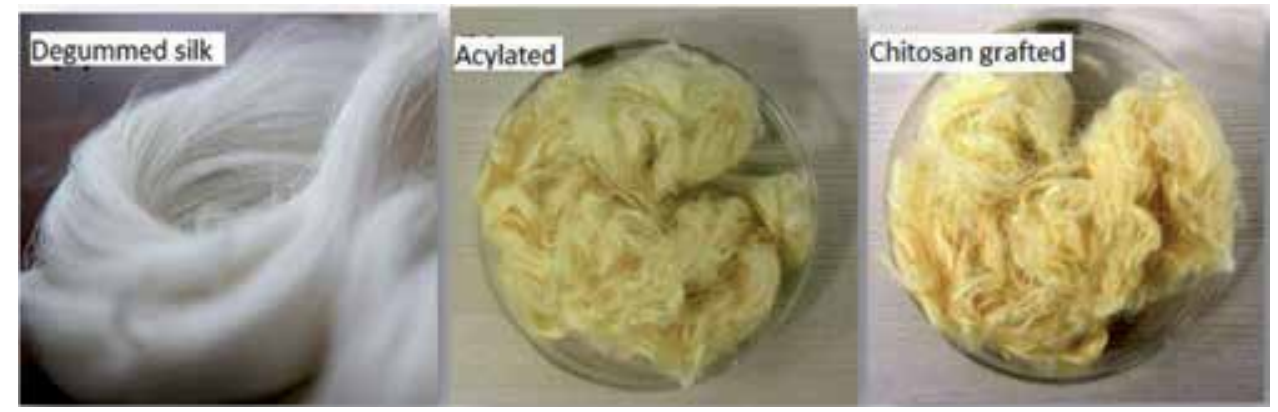

Figure 6.

Image depicting degummed, acylated and chitosan grafted silk fibres. 
Development, Characterization and Properties of Silk Fibre and Grafted Silk Fibre Reinforced... DOI: $h$ ttp://dx.doi.org/10.5772/intechopen.85022

\subsection{Characterization and in vitro biocompatibility studies}

\subsubsection{Morphological properties}

From scanning electron microscopy the chemically treated and grafted fibres were examined. Figure 7 depicts the surface of degummed silk fibre and thus appears smooth. The acylated fibres were characterized by a uniform surface with few foreign particles and the roughness of the fibres further increased due to grafting of chitosan, which clearly shows the presence of particles firmly attached on the fibre.

The surface topography and roughness of the pristine film as well as the fibre reinforced composites was studied using atomic force microscopy (AFM). Atomic force microscopy (AFM) images for PVA and composite film samples are depicted in Figure 8. The AFM of PVA film appeared smooth and the surface roughness (RMS) value obtained for PVA film was $86.32 \pm 58 \mathrm{~nm}$. For the composite films, AFM revealed the presence of grafted silk fibres randomly scattered along the matrix. The roughness values substantially increased with the addition of the fibres and the films appeared corrugated and irregular. It is apparent that, a fibre, when added to a polymer matrix and later casted to form a film, a repulsive interaction is known to exist between the two phases (matrix + fibre), which eventually results in changes in surface roughness. This is mainly due to the microphase separation and changes in the alignment of the polymer chains [43] that results in changes in the topography.

\subsubsection{Thermal properties}

TGA curves showed three decomposition steps for PVA film as depicted in Figure 9. The trend in decomposition observed for PVA was similar to that observed previously. The initial decomposition for PVA occurred at $80-150^{\circ} \mathrm{C}$. The

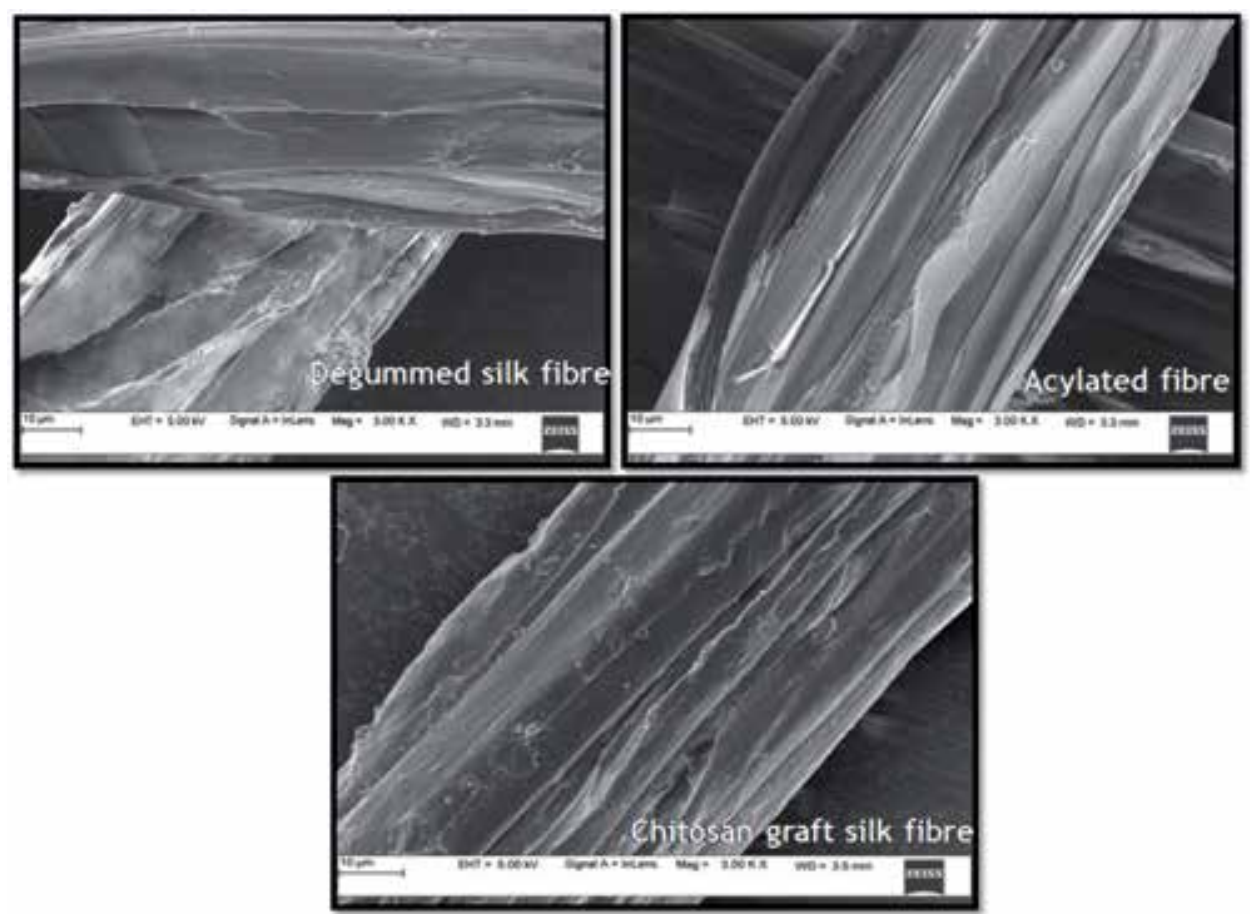

Figure 7.

FESEM images of degummed, acylated and chitosan grafted silk fibres. 


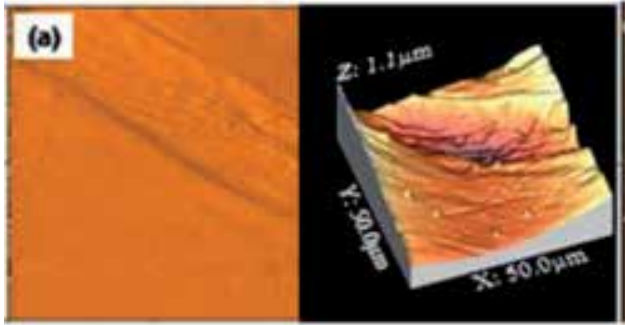

RMS $=86.3 \pm 58 \mathrm{~nm}$

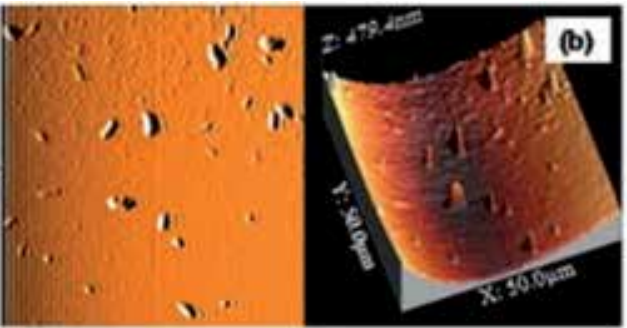

RMS $=112.65 \pm 37 \mathrm{~nm}$

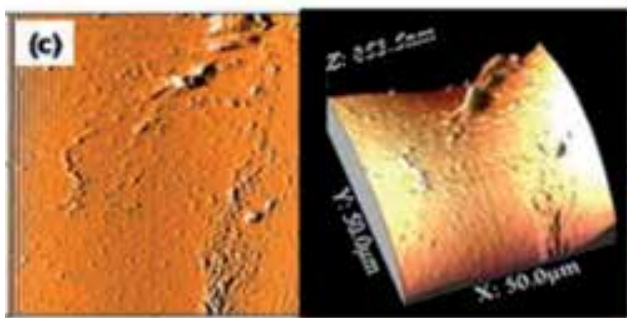

RMS $=131.47 \pm 50 \mathrm{~nm}$

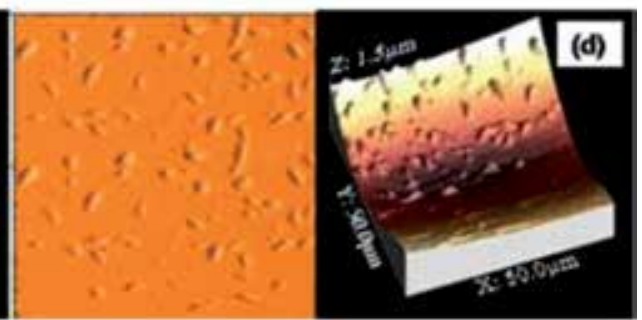

RMS $=248.35 \pm 25 \mathrm{~nm}$

Figure 8.

AFM images of (a) PVA film (b) 3 wt\% film (c) 9 wt\% film (d) 15 wt\% film.
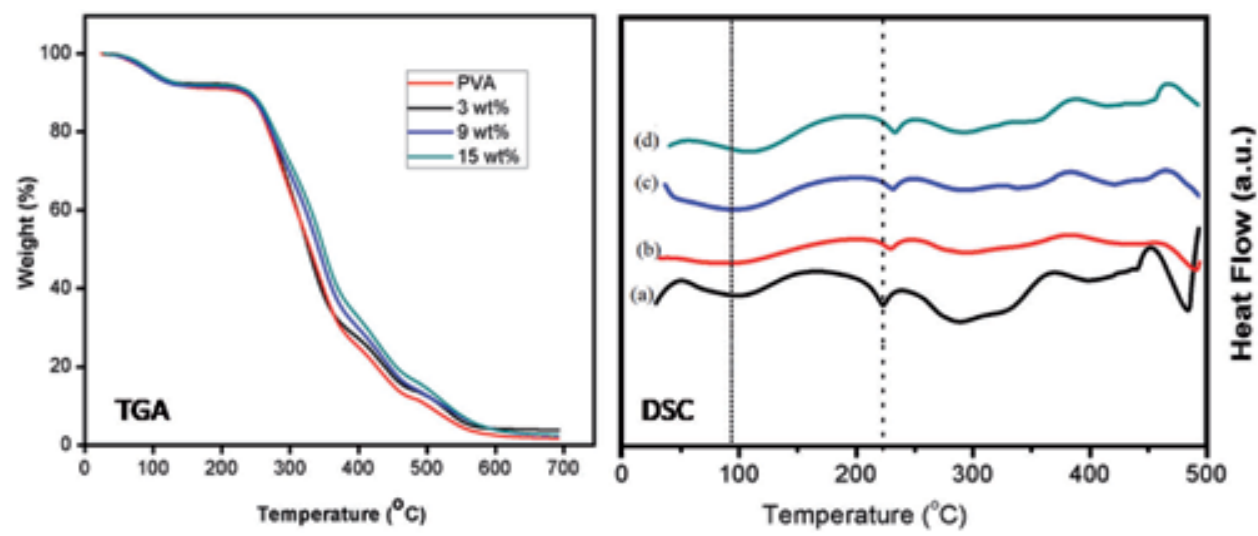

Figure 9.

TGA and DSC curves for grafted fibre reinforced composite films.

weight loss of about $8 \%$ was observed which was due to the loss of bound water from the sample. The maximum degradation occurred from 250 to $400^{\circ} \mathrm{C}$ accompanied by a major weight loss of about $59.4 \%$. As previously discussed, this was due to the structural degradation along with the chain scissions in PVA [42]. Further decomposition followed by the decrease in the weight of sample was observed from $450^{\circ} \mathrm{C}$. This was due to the breakdown of $\mathrm{C}-\mathrm{C}$ bonds in the polymer backbone [44].

Incorporation of chitosan onto the silk fibres did not affect its thermal properties. As a result, the higher thermal stability of silk fibre was retained. The higher thermal stability of silk fibres reduced the percentage weight loss to about 58\%, followed by further reduction in weight to about 54.9 and $50 \%$ for 3,9 and $15 \mathrm{wt} \%$ incorporated grafted fibres respectively [42]. Thus, the hydrogen bonding interaction of PVA, with the functional groups of silk fibre was still observed.

DSC analysis showed a substantial increase in $\mathrm{T}_{\mathrm{g}}$ and a slight increase in melting temperatures indicating better thermal stability as depicted in Table 2 and Figure 9. 
Development, Characterization and Properties of Silk Fibre and Grafted Silk Fibre Reinforced... DOI: http://dx.doi.org/10.5772/intechopen.85022

\begin{tabular}{lcccc}
\hline Silk fibre content $(\mathbf{w t} \%)$ & $\mathbf{T}_{\mathbf{g}}\left({ }^{\circ} \mathbf{C}\right)$ & $\mathbf{T}_{\mathbf{m}}\left({ }^{\mathbf{o}} \mathbf{C}\right)$ & $\mathbf{\Delta}_{\mathbf{m}}(\mathbf{J} / \mathbf{g})$ & Mass loss (\%) \\
\hline 0 & 98.8 & 222.6 & 22.8 & 59.4 \\
\hline 3 & 101.9 & 222.3 & 23.5 & 58 \\
\hline 9 & 106.7 & 224.6 & 26.62 & 54.9 \\
\hline 15 & 109.9 & 224.8 & 28.9 & 50 \\
\hline
\end{tabular}

Table 2.

Thermal properties of grafted silk fibre composites.

The $\mathrm{T}_{\mathrm{g}}$ for the PVA film observed was $98.8^{\circ} \mathrm{C}$. The grafted silk when added to the matrix, further increased the $\mathrm{T}_{\mathrm{g}}$, and $\Delta \mathrm{H}_{\mathrm{m}}$ values. Thus, the mobility of polymer chains was hindered by further addition of silk; thereafter resulting in a substantial increase in $\mathrm{T}_{\mathrm{g}}$ values $[30,42]$.

\subsubsection{Biodegradation by soil burial tests}

The prepared film composites turned brittle and lost their flexibility when exposed to soil, after a certain period of time. For a period of 8 days the weight decrease was found to be approximately $8 \%$ and as the time increased the percentage decrease in the weight of the samples also increased. After 64 days the weight decrease was approximately $40 \%$. Compared to our previous results as discussed, the trend observed in this study as depicted in Figure 10, was that the weight decrease slightly increased due to the incorporation of chitosan grafted silk fibres. Although chitosan is known to be antibacterial in nature, it is however known to be an efficient soil amendment material and shows degradation in soil. This is due to the fact that certain microbes are known to possess an enzyme chitosanase that promotes degradation of chitosan. Berkeley [45] reported that chitosan-hydrolyzing enzymes (chitosanases) are produced by the genera Arthrobacter, Bacillus, Streptomyces, Aspergillus, and Penicillium. Besides, the increased surface roughness with the addition of silk fibres is also known to enhance the rate of biodegradation.

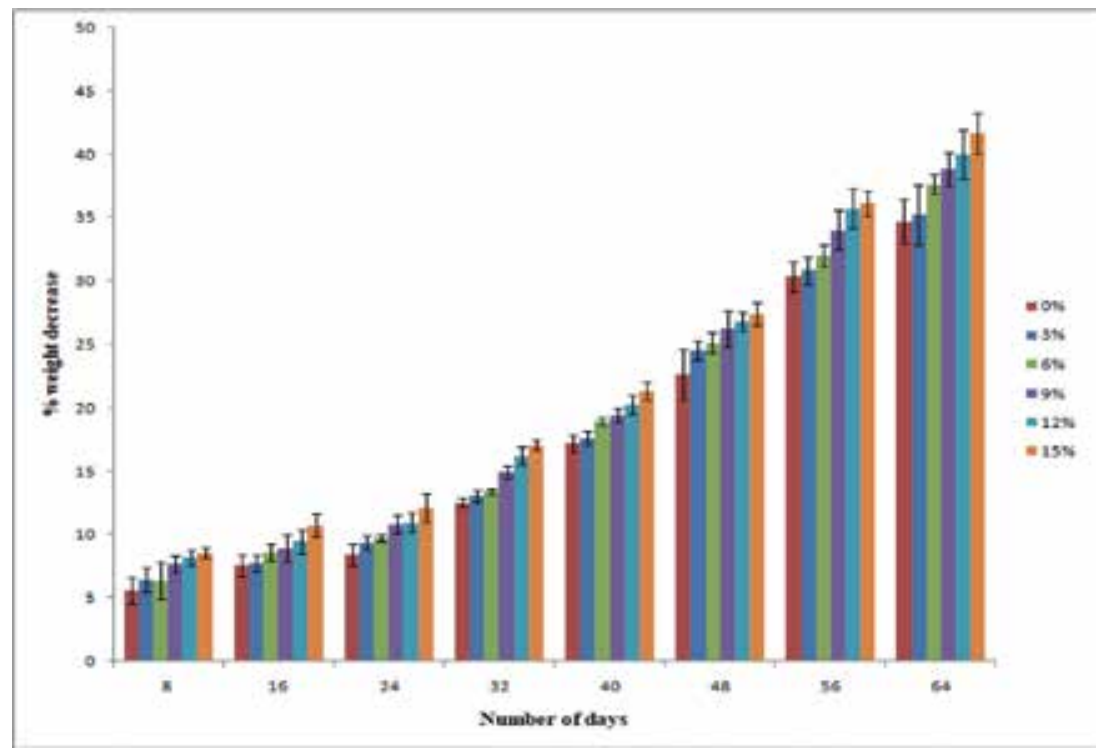

Figure 10.

Graph depicting soil burial degradation test. 
Higher surface roughness increases biodegradation by providing more sites for bacterial colonies to settle and proliferate [46].

\subsubsection{Antibacterial tests}

In vitro antibacterial studies were performed for $2 \mathrm{~g}$ negative and $2 \mathrm{~g}$ positive bacterial strains. PVA film did not show any activity on all four bacterial strains. The positive control streptomycin showed highest antibacterial activity. Table 3 shows the zone of inhibition calculated for the films and the activity against the bacterial strains. Due to the lower concentrations of the chitosan grafted silk fibre ( 3 and $6 \mathrm{wt} \%$ ), the films showed little or no activity. However as the fibre concentration was increased, the films showed good activity and consequently at $15 \mathrm{wt} \%$ concentration, due to a relatively high concentration of chitosan, significant activity was seen against $S$. aureus and $E$. coli the reason being the bacteriostatic as well as bactericidal activity of chitosan towards pathogenic strains of bacteria. It is believed that the polycationic nature of chitosan, due to the positively charged $-\mathrm{NH}_{3}{ }^{+}$groups of glucosamine, might be a crucial factor contributing to its interaction with the negatively charged surface components of many fungi and bacteria. Consequently, this leads to extensive cell surface alterations, leakage of intracellular substances, and impairment of vital bacterial activities [47-50].

\subsubsection{In vitro hemocompatibility}

Hemolysis is a phenomenon that occurs, when the cells swell to the critical bulk and results in the lysis of cell membranes. The resulting broken red blood cells can release adenosine diphosphate, which escalates the assembly of blood platelets, thereby accelerating the formation of clotting and thrombus. It is an additional setback associated with the biocompatibility of material [51]. It is quite obvious that when red blood cells (RBC's) come in contact with water, they tend to hemolyse and when an incompatible material comes in contact with these cells, this problem intensifies. The membrane stability of the RBC's was studied for PVA and film composites, in relation with the standard drug diclofenac sodium [52]. Percentage inhibition of hemolysis for test samples was studied and calculated as follows

$$
\text { Percentage inhibition of haemolysis }(\%)=\frac{\text { Control }- \text { Test sample }}{\text { Control }} \times 100
$$

\begin{tabular}{lcccc}
\hline Zone of inhibition $(\mathbf{m m})$ & & & \\
\hline Sample films & S. aureus & Bacillus subtilis & E. coli & K. pneumoniae \\
\hline Control & - & - & - & - \\
\hline $3 \mathrm{wt} \%$ & $8 \pm 1$ & - & - & - \\
\hline $6 \mathrm{wt} \%$ & $8 \pm 1$ & - & $11 \pm 0.00$ & - \\
\hline $9 \mathrm{wt} \%$ & $9.00 \pm 0.00$ & $9 \pm 0.00$ & $13.66 \pm 0.57$ & $9 \pm 0.00$ \\
\hline $12 \mathrm{wt} \%$ & $12 \pm 0.00$ & $12.66 \pm 0.57$ & $14.66 \pm 1.15$ & $10 \pm 0.00$ \\
\hline $15 \mathrm{wt} \%$ & $17.33 \pm 1.15$ & $13.33 \pm 0.57$ & $15.33 \pm 1.15$ & $12.66 \pm 0.57$ \\
\hline Chitosan & $22 \pm 0.57$ & $19.33 \pm 1.15$ & $21 \pm 0.57$ & $22 \pm 0.57$ \\
\hline Streptomycin & $25 \pm 1$ & $22 . \pm 1$ & $28.66 \pm 0.57$ & $19.33 \pm 0.57$ \\
\hline
\end{tabular}

Table 3.

Antibacterial activity of composite films reinforced with grafted fibre. 
A higher percentage inhibition was observed for all composite films in comparison with the pristine PVA film as depicted in Figure 11. The highest percentage value obtained was for $15 \mathrm{wt} \%$ films $(79.0 \pm 1.8)$, which were almost similar to the standard diclofenac $(82.5 \pm 1.2)$ [52]. Previous reports suggest that chitosan promoted surface induced hemolysis, which can be ascribed in part to the electrostatic interactions $[53,54]$. When the concentration of chitosan was increased to about $100 \mathrm{mg} / \mathrm{ml}$, traces of haemolytic activity was observed and the largest haemolytic activity observed was less than $10 \%$, signifying a wide safety margin suitable for blood contact applications [55]. Thus, on comparing the low hemolytic activity with the high erythrocyte agglutination, it can be seen that, chitosan only induces the surface adhesion of erythrocytes and does not critically damage the cell membrane $[56,57]$. The results thus obtained for the films, did not rupture the cell membrane, subsequently making them hemocompatible.

\subsubsection{Cell proliferation studies by trypan blue assay}

The principle underlying the trypan blue dye exclusion assay is that a dead or a dying cell possesses a membrane that happens to be permeable to the dye trypan blue and thus will stain blue. On the contrary, the viability of the cells can be determined as the viable cells are capable of repelling the dye and hence do not stain [58]. Figure 12 denotes the cultured mouse fibroblast cells growing on PVA and composite films. The cells displayed spindle shaped morphology, rapidly proliferated and grew into small colonies by strongly attaching on the film substrates as compared to the control (Dubecco's Modified Eagle's Medium) and PVA film. It was observed that the composite films of all concentrations supported cell growth and were thus non-toxic. These results when further corroborated with AFM investigations, demonstrated that the enhanced surface roughness of the films provided a larger surface area for the cells to adhere. As a result, cell growth was facilitated when compared to the comparatively smooth pristine film, signifying that surface roughness of the substrate played a huge role in regulating cell adhesion and growth [52].

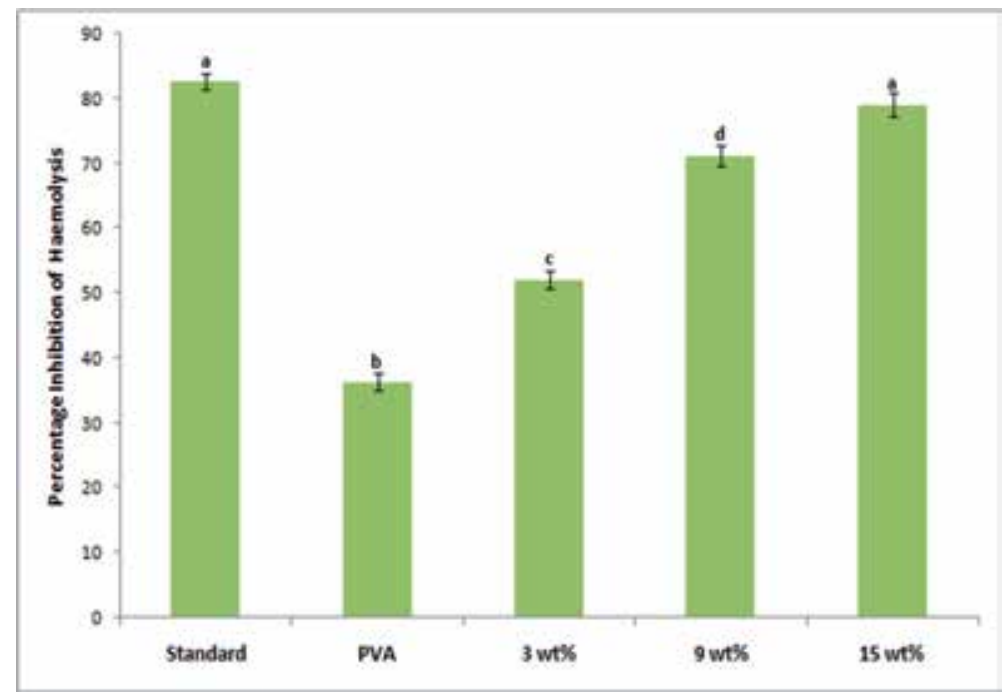

Figure 11.

Graph depicting percentage inhibition of haemolysis. Values expressed as Means \pm SD of triplicate measurements $(n=3)$. Means with different letters in each column is significantly different $(p<0.05$, ANOVA, Bonferroni). 


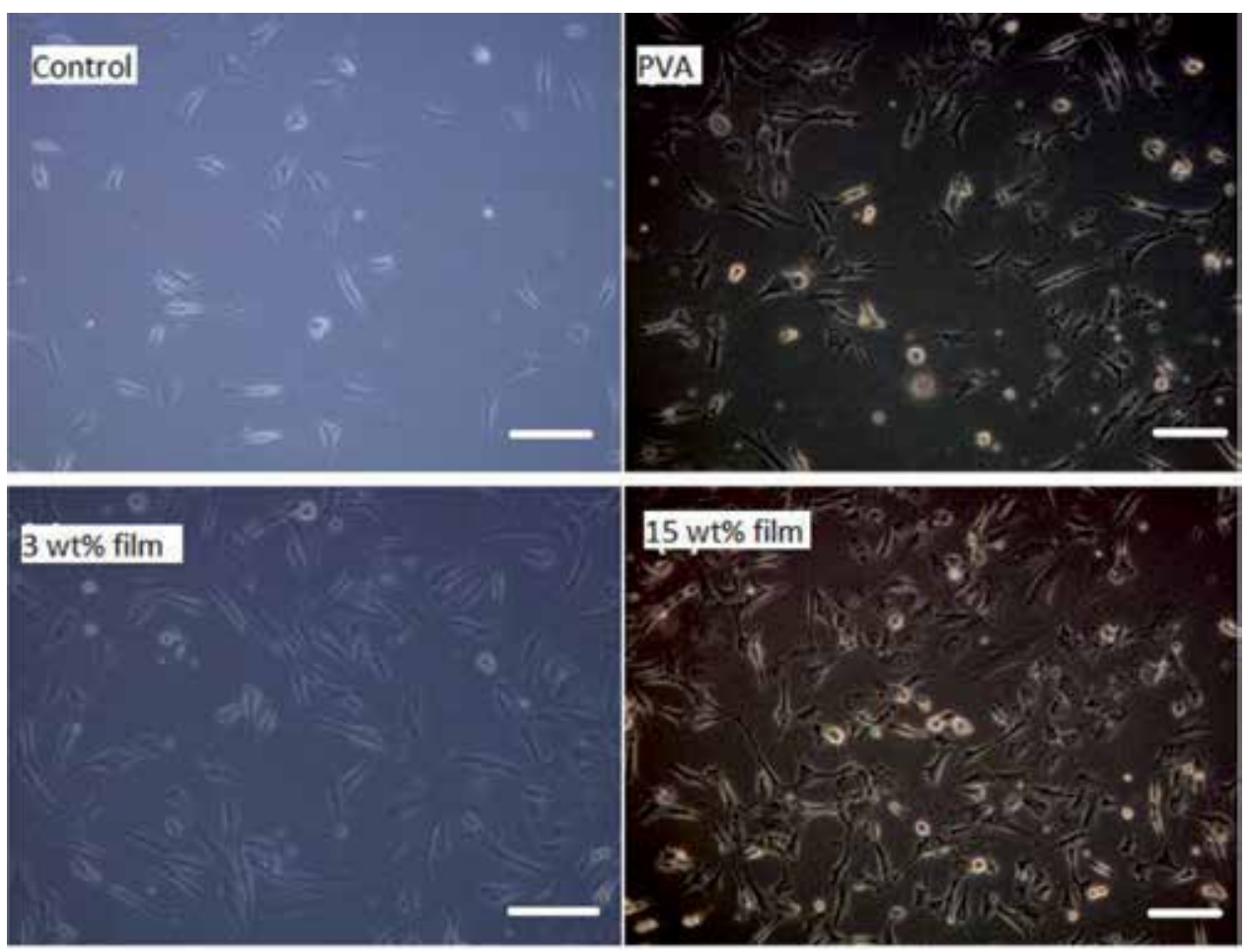

Figure 12.

Pictomicrographs of attachment of fibroblast cells (Scale bar-50o $\mu \mathrm{m}$ ).

\subsubsection{MTT assay}

The mitochondrial activity of cells is measured by a colorimetric assay (MTT assay) that can reduce MTT to a purple coloured product called formazan. The number of viable cells is related to the amount of colour produced. Yellow MTT (3-(4,5-dimethylthiazol-2-yl)-2,5-diphenyltetrazolium bromide, a tetrazole) is reduced to purple coloured product called formazan in viable cells [59]. This insoluble purple formazan is dissolved using a solvent such as dimethyl sulphoxide (DMSO), so as to form a coloured solution [60]. Solubilization of the cells results in liberation of the purple product, which can be detected using a colorimetric measurement. The resulting purple solution is spectrophotometrically measured [61]. The increase in the absorbance is related to the amount of formazan formed resulting due to rapid proliferation of cells, thus indicating the mitochondrial activity of cells.

The cellular activity on the substrate was studied using cultured mouse astrocytes. The results demonstrated cell viability values higher than $80 \%$ for all film samples (Figure 13). This enhanced viability is ascribed to the initial time taken by the cells to adapt to the nature of the substrate [62]. Although there was no huge difference in the cell activity of all test samples, highest activity observed was for $3 \mathrm{wt} \%$ films $(103.25 \pm 13.23)$. The films were thus nontoxic and supported cell growth [52].

\subsubsection{Micronucleus cytome assay}

The in vitro cytokinesis-blocked micronucleus cytome (CBMN-cytome) assay is a modified CBMN assay which is based on the assessment of micronucleus (MN) 
Development, Characterization and Properties of Silk Fibre and Grafted Silk Fibre Reinforced... DOI: http://dx.doi.org/10.5772/intechopen.85022

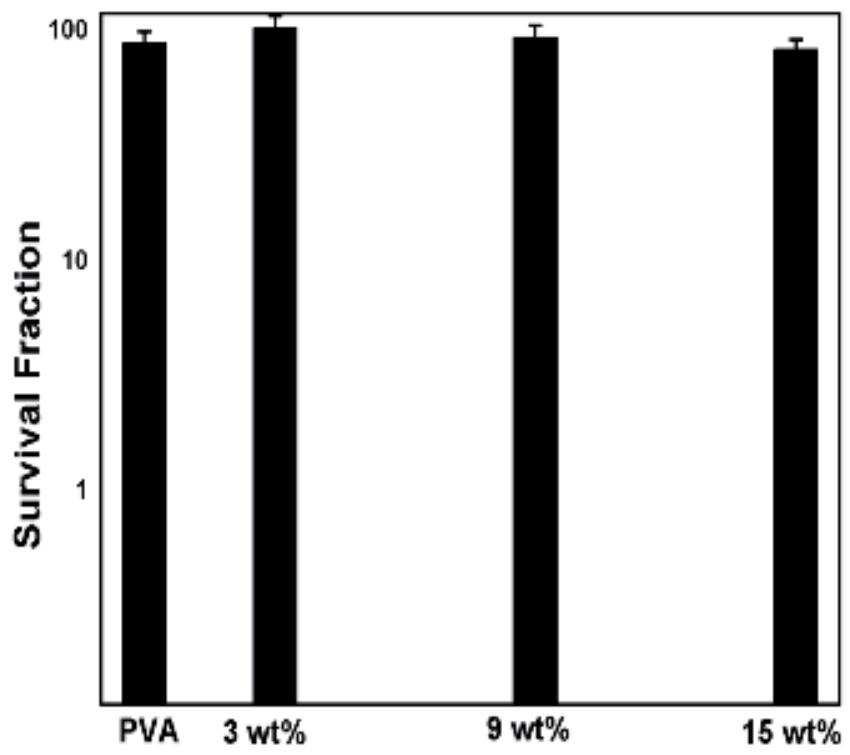

Figure 13.

Cell viability by MTT assay. Results are expressed in percentage survival fraction.

in nucleated cells that have completed only one nuclear division. The $\mathrm{MN}$ assay is a simple and rapid method that is perfectly suitable to elicit the biocompatibility of the samples and thus study the genotoxicity of the polymer composite samples. The CBMN cytome assay is not only restricted to micronucleus measurement, but also assists in the assessment of relevant markers like nucleoplasmic bridges (NPBs), nuclear buds (NBUDs), apoptotic and necrotic cells [63]. Figure 14 reveals the presence of micronucleus, NPBs, NBUDs, and necrotic cells. The MN refer to small nuclei formed from acentric fragments or whole chromosomes, which lag behind and does not get included in either of the daughter nuclei, formed during cell division [64]. Hence, MN provides an indication of both chromosome breakage and chromosome loss.

MN cytome assay as described by Fenech [63], with slight modifications was used in the study. The cells used for the study were cultured normal lung cells

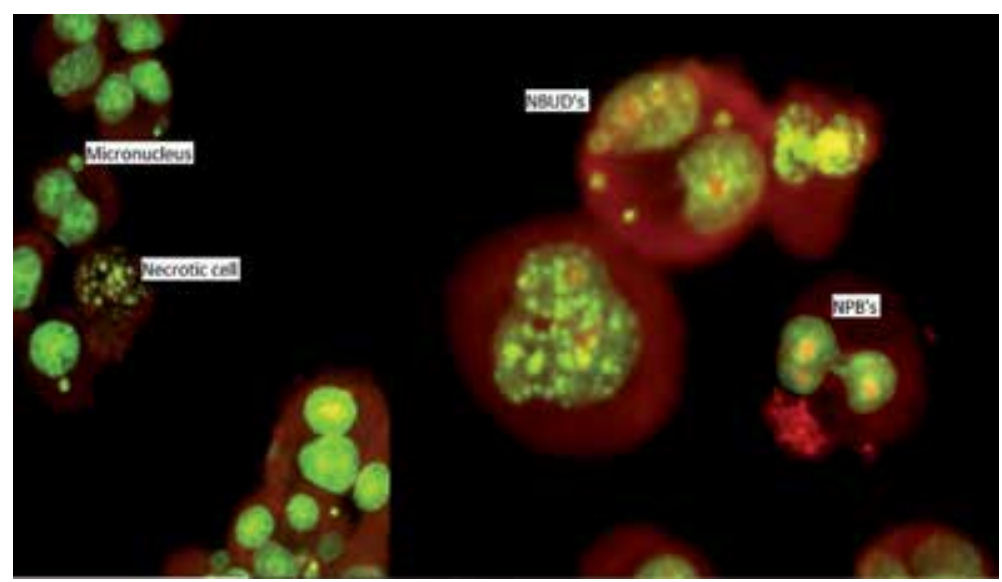

Figure 14 .

Image depicting typical L132 cells. 
(L132) cells. Only binucleated cells (BNC) with intact cytoplasm were considered for scoring micronuclei (MNi) by ignoring cells with broken cytoplasm and cells with fused nuclei [65]. No significant difference in the $\mathrm{MN}$ yield of micronuclei was observed between the cultures treated with PVA, 3, 9 and $15 \mathrm{wt} \%$ silk fibre reinforced films when compared to the negative control, revealing the lack of genotoxic effect. In relation to nuclear division index values, no significant differences were observed between the different composite films and negative control, demonstrating the absence of cytotoxicity.

\section{Conclusions}

The surging interest towards silk fibres due to its innumerable properties was the motivation of this study. A comprehensive study on the use of silk fibres as reinforcements, for the development of biocompatible and biodegradable composites was conducted. The composite films were developed by solution casting and the effect of silk fibre concentration on the properties of the composite films was assessed.

Biocomposite films of PVA and PVA/PVP; reinforced with degummed short silk fibres were prepared and showed enhanced properties. The results showed that increasing the fibre concentration, diminished the mechanical properties and the optimum concentration was found to be 12 and $9 \mathrm{wt} \%$ respectively. The added short silk fibres, improved the thermal properties of the composite films as confirmed by DSC/TGA. Morphological properties of the film composites indicated a poor fibre matrix adhesion (FESEM) at the fibre concentration of 12 and $15 \mathrm{wt} \%$ respectively. The prepared films were found to biodegradable and the biodegradation was aided by the presence of soil microbes.

The properties of silk fibres were re-tailored by grafting a natural polysaccharide like chitosan, thereby fabricating films of PVA, suitable for biomedical applications. Films of PVA reinforced with grafted silk showed improved properties as a result of fibre-matrix interactions and hence prove to be effective to be used as scaffolds for tissue engineering applications. Besides, the composite films also showed enhanced biodegradable characteristics with increasing concentrations of grafted silk fibres. The efficacy of the films to exhibit antimicrobial activity was undoubtedly due to the presence of chitosan on silk. The films were further evaluated for their blood compatibility, cytotoxicity and genotoxicity studies and proved to be nontoxic in almost all concentrations.

\section{Acknowledgements}

The authors are grateful to DST PURSE, Mangalore University for providing the necessary facilities for the characterization of the samples.

\section{Conflict of interest}

The authors of this manuscript declare that they do not hold any conflicts of interest that might have any bearing on research reported in their submitted manuscript. 
Development, Characterization and Properties of Silk Fibre and Grafted Silk Fibre Reinforced... DOI: http://dx.doi.org/10.5772/intechopen.85022

\section{Author details}

Sareen Sheik ${ }^{1,2}$ and Gundibasappa Karikannar Nagaraja ${ }^{2 *}$

1 P.A. College of Engineering and Technology, Mangaluru, India

2 Department of Chemistry, Mangalore University, Mangalagangothri, India

*Address all correspondence to: nagarajagk@gmail.com

\section{IntechOpen}

(C) 2019 The Author(s). Licensee IntechOpen. This chapter is distributed under the terms of the Creative Commons Attribution License (http://creativecommons.org/licenses/ by/3.0), which permits unrestricted use, distribution, and reproduction in any medium, provided the original work is properly cited. (cc) BY 


\section{References}

[1] Saheb DN, Jog JP. Natural fiber polymer composites: A review. Advances in Polymer Technology: Journal of the Polymer Processing Institute. 1999;18(4):351-363.

DOI: $10.1002 /(S I C I) 1098-$ 2329(199924)18:4<351::AIDADV6>3.0.CO;2-X

[2] Shalwan A, Yousif BF. In state of art: Mechanical and tribological behaviour of polymeric composites based on natural fibres. Materials \& Design. 2013;48:14-24. DOI: 10.1016/j. matdes.2012.07.014

[3] Hatch KL. Textile Science. 1st ed. New York: West Group Publishing; 1993 472 p. ISBN: 0314904719

[4] Rockwood DN, Preda RC, Yücel T, Wang X, Lovett ML, Kaplan DL. Materials fabrication from Bombyx mori silk fibroin. Nature Protocols. 2011;6(10):1612. DOI: 10.1038/ nprot.2011.379

[5] Gupta P, Nayak KK. Characteristics of protein-based biopolymer and its application. Polymer Engineering \& Science. 2015;55(3):485-498. DOI: 10.1002/pen.23928

[6] Cheung HY, Lau KT, Ho MP, Mosallam A. Study on the mechanical properties of different silkworm silk fibers. Journal of Composite Materials. 2009;43(22):2521-2531. DOI: $10.1177 / 0021998309345347$

[7] Okhawilai M, Rangkupan R, Kanokpanont S, Damrongsakkul S. Preparation of Thai silk fibroin/gelatin electrospun fiber mats for controlled release applications. International Journal of Biological Macromolecules. 2010;46(5):544-550. DOI: 10.1016/j. ijbiomac.2010.02.008

[8] Vepari C, Kaplan DL. Silk as a biomaterial. Progress in Polymer
Science. 2007;32(8-9):991-1007. DOI: 10.1016/j.progpolymsci.2007.05.013

[9] Lei C, Zhu H, Li J, Li J, Feng X, Chen J. Preparation and characterization of polyhydroxybutyrate-cohydroxyvalerate/silk fibroin nanofibrous scaffolds for skin tissue engineering. Polymer Engineering \& Science. 2015;55(4):907-916. DOI: 10.1002/pen.23958

[10] Zhu A, Zhang M, Wu J, Shen J. Covalent immobilization of chitosan/ heparin complex with a photosensitive hetero-bifunctional crosslinking reagent on PLA surface. Biomaterials. 2002;23(23):4657-4665. DOI: $10.1016 /$ S0142-9612(02)00215-6

[11] Guarnieri D, De Capua A, Ventre M, Borzacchiello A, Pedone C, Marasco D, et al. Covalently immobilized RGD gradient on PEG hydrogel scaffold influences cell migration parameters. Acta Biomaterialia. 2010;6(7):2532-2539. DOI: $10.1016 /$ j.actbio.2009.12.050

[12] Prachayawarakorn J, Khanchaiyapoom K. Dyeing properties of Bombyx mori silks grafted by 2-hydroxyethyl methacrylate (HEMA). Fibers and Polymers. 2010;11(7): 1010-1017. DOI: 10.1007/s12221-010-1010-z

[13] Chen G, Guan J, Xing T, Zhou X. Properties of silk fibers modified with diethylene glycol dimethacrylate. Journal of Applied Polymer Science. 2006;102(1):424-428. DOI: $10.1002 /$ app. 24064

[14] Khanchaiyapoom K, Prachayawarakorn J. Physical and dyeing properties using natural dyes of degummed silks (Bombyx mori) grafted by 2-hydroxyethyl methacrylate. Journal of Metals, Materials and Minerals. 2008;18(2):237-240

[15] Badawy ME, Rabea EI. A biopolymer chitosan and its derivatives as promising 
antimicrobial agents against plant pathogens and their applications in crop protection. International Journal of Carbohydrate Chemistry. 2011;2011: 1-29. DOI: $10.1155 / 2011 / 46038$

[16] Li Q, Dunn ET, Grandmaison EW, Goosen MF. Applications and properties of chitosan. Journal of Bioactive and Compatible Polymers. 1992;7(4): 370-397.DOI: $10.1177 / 088391159200700406$

[17] Shigemasa Y, Minami S. Applications of chitin and chitosan for biomaterials. Biotechnology and Genetic Engineering Reviews. 1996;13(1):383-420. DOI: $10.1080 / 02648725.1996 .10647935$

[18] Dutta PK, Dutta J, Tripathi VS. Chitin and chitosan: Chemistry, properties and applications. Journal of Scientific and Industrial Research. 2004;63(1):20-31

[19] Nishikawa H, Ueno A, Nishikawa $\mathrm{S}$, Kido JI, Ohishi $\mathrm{M}$, Inoue $\mathrm{H}$, et al. Sulfated glycosaminoglycan synthesis and its regulation by transforming growth factor- $\beta$ in rat clonal dental pulp cells. Journal of Endodontics. 2000;26(3):169-171. DOI: 10.1097/00004770-200003000-00010

[20] Barud HO, Barud HD, Cavicchioli M, do Amaral TS, de Oliveira Junior OB, Santos DM, et al. Preparation and characterization of a bacterial cellulose/ silk fibroin sponge scaffold for tissue regeneration. Carbohydrate Polymers. 2015;128:41-51. DOI: 10.1016/j. carbpol.2015.04.007

[21] Ishihara M, Ono K, Sato M, Nakanishi K, Saito Y, Yura H, et al. Acceleration of wound contraction and healing with a photocrosslinkable chitosan hydrogel. Wound Repair and Regeneration. 2001;9(6):513-521. DOI: 10.1046/j.1524-475x.2001.00513.x

[22] Muxika A, Etxabide A, Uranga J, Guerrero P, De La Caba K. Chitosan as a bioactive polymer: Processing, properties and applications.

International Journal of Biological

Macromolecules. 2017;105:1358-1368.

DOI: 10.1016/j.ijbiomac.2017.07.087

[23] Peluso G, Petillo O, Ranieri M, Santin M, Ambrosic L, Calabró D, et al. Chitosan-mediated stimulation of macrophage function. Biomaterials. 1994;15(15):1215-1220. DOI: 10.1016/0142-9612(94)90272-0

[24] Nishimura K, Nishimura S, Nishi N, Saiki I, Tokura S, Azuma I. Immunological activity of chitin and its derivatives. Vaccine. 1984;2(1):93-99. DOI: 10.1016/S0264-410X(98)90039-1

[25] Hosseini M, Montazer M, Damerchely R. Enhancing dye-ability and antibacterial features of silk through pre-treatment with chitosan. Journal of Engineered Fibers and Fabrics. 2013;8(3):155892501300800313

[26] Davarpanah S, Mahmoodi NM, Arami M, Bahrami H, Mazaheri F. Environmentally friendly surface modification of silk fiber: Chitosan grafting and dyeing. Applied Surface Science. 2009;255(7):4171-4176. DOI: 10.1016/j.apsusc.2008.11.001

[27] Sheik S, Nagaraja GK, Naik J, Bhajanthri RF. Development and characterization study of silk fibre reinforced poly (vinyl alcohol) composites. International Journal of Plastics Technology. 2017;21(1):108-122. DOI: $10.1007 / \mathrm{s} 12588-017-9174-7$

[28] Sheik S, Nagaraja GK, Prashantha K. Effect of silk fiber on the structural, thermal, and mechanical properties of PVA/PVP composite films.

Polymer Engineering \& Science. 2018;58(11):1923-1930. DOI: 10.1002/ pen. 24801

[29] Sanchez-Garcia MD, Gimenez E, Lagaron JM. Morphology and barrier properties of solvent cast composites of thermoplastic biopolymers and purified 
cellulose fibers. Carbohydrate Polymers. 2008;71(2):235-244. DOI: $10.1016 /$ j. carbpol.2007.05.041

[30] Cheung HY, Lau KT, Tao XM, Hui D. A potential material for tissue engineering: Silkworm silk/PLA biocomposite. Composites Part B: Engineering. 2008;39(6):1026-1033. DOI: 10.1016/j.compositesb.2007.11.009

[31] Ramesan MT, Athira VK, Jayakrishnan P, Gopinathan C. Preparation, characterization, electrical and antibacterial properties of sericin/poly (vinyl alcohol)/poly (vinyl pyrrolidone) composites. Journal of Applied Polymer Science. 2016;133(24):43535-43545. DOI: 10.1002/app.43535

[32] Budrugeac P. Kinetics of the complex process of thermo-oxidative degradation of poly (vinyl alcohol). Journal of Thermal Analysis and Calorimetry. 2008;92(1):291-296. DOI: 10.1007/s10973-007-8770-8

[33] Ramesan MT. Thermogravimetric analysis, flammability and oil resistance properties in natural rubber and dichlorocarbene modified styrene butadiene rubber blends. Reactive and Functional Polymers. 2004;59(3):267-274. DOI: 10.1016/j. reactfunctpolym.2004.02.005

[34] Horrocks AR, Price D. Advances in Fire Retardant Materials. USA: Elsevier; 2008

[35] Abdelrazek EM, Elashmawi IS, Labeeb S. Chitosan filler effects on the experimental characterization, spectroscopic investigation and thermal studies of PVA/PVP blend films. Physica B: Condensed Matter. 2010;405(8):2021-2027. DOI: 10.1016/j. physb.2010.01.095

[36] Ho MP, Lau KT, Wang H, Bhattacharyya D. Characteristics of a silk fibre reinforced biodegradable plastic. Composites Part B: Engineering. 2011;42(2):117-122. DOI: 10.1016/j. compositesb.2010.10.007

[37] Sriupayo J, Supaphol P, Blackwell J, Rujiravanit R. Preparation and characterization of $\alpha$-chitin whiskerreinforced poly (vinyl alcohol) nanocomposite films with or without heat treatment. Polymer. 2005;46(15):5637-5644. DOI: 10.1016/j. carbpol.2005.07.013

[38] Kuchaiyaphum P, Punyodom W, Watanesk S, Watanesk R. Composition optimization of polyvinyl alcohol/rice starch/silk fibroin-blended films for improving its eco-friendly packaging properties. Journal of Applied Polymer Science. 2013;129(5):2614-2620. DOI: 10.1002/app.38977

[39] Laxmeshwar SS, Madhu Kumar DJ, Viveka S, Nagaraja GK. Preparation and properties of biodegradable film composites using modified cellulose fibre-reinforced with PVA. ISRN Polymer Science. 2012;2012:1-8. DOI: 10.5402/2012/154314

[40] Shubhra QT, Saha M, Alam AK, Beg MD, Khan MA. Effect of matrix modification by natural rubber on the performance of silk-reinforced polypropylene composites. Journal of Reinforced Plastics and Composites. 2010;29(22):3338-3344. DOI: $10.1177 / 0731684410375640$

[41] Arai T, Freddi G, Innocenti R, Kaplan DL, Tsukada M. Acylation of silk and wool with acid anhydrides and preparation of water-repellent fibers. Journal of Applied Polymer Science. 2001;82(11):2832-2841. DOI: 10.1002/ app. 2137

[42] Sheik S, Sheik S, Nagaraja GK, Chandrashekar KR. Thermal, morphological and antibacterial properties of chitosan grafted silk fibre reinforced PVA films. Materials Today: 
Development, Characterization and Properties of Silk Fibre and Grafted Silk Fibre Reinforced... DOI: http://dx.doi.org/10.5772/intechopen.85022

Proceedings. 2018;5(10):21011-21017.

DOI: $10.1016 /$ j.matpr.2018.06.493

[43] Rajput M, Bhandaru N, Barui A, Chaudhary A, Paul RR, Mukherjee R, et al. Nano-patterned honey

incorporated silk fibroin membranes for improving cellular compatibility. RSC Advances. 2014;4(84):44674-44688. DOI: 10.1039/C4RA05799F

[44] George J, Ramana KV, Bawa AS. Bacterial cellulose nanocrystals exhibiting high thermal stability and their polymer nanocomposites. International Journal of Biological Macromolecules. 2011;48(1):50-57. DOI: 10.1016/j.ijbiomac.2010.09.013

[45] Berkeley RCW. In: Proceedings of the International Conference on Chitin/ Chitosan; MIT Sea Grant Report; 1977. pp. 570

[46] Re GL, Morreale M, Scaffaro R, La Mantia FP. Biodegradation paths of Mater-Bi ${ }^{\circledR} /$ kenaf biodegradable composites. Journal of Applied Polymer Science. 2013;129(6):3198-3208. DOI: 10.1002/app.39027

[47] Helander IM, Nurmiaho-Lassila EL, Ahvenainen R, Rhoades J, Roller S. Chitosan disrupts the barrier properties of the outer membrane of gram-negative bacteria. International Journal of Food Microbiology. 2001;71(2-3):235-244. DOI: $10.1016 /$ S0168-1605(01)00609-2

[48] Je JY, Kim SK. Chitosan derivatives killed bacteria by disrupting the outer and inner membrane. Journal of Agricultural and Food Chemistry. 2006;54(18):66296633. DOI: 10.1021/jf061310p

[49] Zakrzewska A, Boorsma A, Brul S, Hellingwerf KJ, Klis FM. Transcriptional response of Saccharomyces cerevisiae to the plasma membrane-perturbing compound chitosan. Eukaryotic Cell. 2005;4(4):703-715. DOI: 10.1128/ EC.4.4.703-715.2005
[50] Wu T, Zivanovic S, Draughon FA, Conway WS, Sams CE. Physicochemical properties and bioactivity of fungal chitin and chitosan. Journal of Agricultural and Food Chemistry. 2005;53(10):3888-3894. DOI: 10.1021/ jf048202s

[51] Singhal JP, Ray AR. Synthesis of blood compatible polyamide block copolymers. Biomaterials. 2002;23(4):1139-1145. DOI: 10.1016/ S0142-9612(01)00228-9

[52] Sheik S, Sheik S, Nairy R, Nagaraja GK, Prabhu A, Rekha PD, et al. Study on the morphological and biocompatible properties of chitosan grafted silk fibre reinforced PVA films for tissue engineering applications. International Journal of Biological Macromolecules. 2018;116:45-53. DOI: 10.1016/j. ijbiomac.2018.05.019

[53] Hirano S, Zhang M, Nakagawa M, Miyata T. Wet spun chitosan-collagen fibers, their chemical $\mathrm{N}$-modifications, and blood compatibility. Biomaterials. 2000;21(10):997-1003. DOI: 10.1016/ S0142-9612(99)00258-6

[54] Amiji MM. Platelet adhesion and activation on an amphoteric chitosan derivative bearing sulfonate groups. Colloids and Surfaces B: Biointerfaces. 1998;10(5):263-271. DOI: 10.1016/ S0927-7765(98)00005-8

[55] Wang QZ, Chen XG, Li ZX, Wang S, Liu CS, Meng XH, et al. Preparation and blood coagulation evaluation of chitosan microspheres. Journal of Materials Science: Materials in Medicine. 2008;19(3):1371-1377. DOI: 10.1007/s10856-007-3243-y

[56] Jumaa M, Furkert FH, Müller BW. A new lipid emulsion formulation with high antimicrobial efficacy using chitosan. European Journal of Pharmaceutics and Biopharmaceutics. 2002;53(1):115-123. DOI: 10.1016/ S0939-6411(01)00191-6 
[57] Richardson SW, Kolbe HJ, Duncan R. Potential of low molecular mass chitosan as a DNA delivery system: Biocompatibility, body distribution and ability to complex and protect DNA. International Journal of Pharmaceutics. 1999;178(2):231-243. DOI: $10.1016 /$ S0378-5173(98) 00378-0

[58] Dankers PY, van Beek DJ, ten Cate AT, Sijbesma RP, Meijer EW. Novel biocompatible supramolecular materials for tissue engineering. Polymeric Materials Science and Engineering. 2003;88:52-53

[59] Mosmann T. Rapid colorimetric assay for cellular growth and survival: Application to proliferation and cytotoxicity assays. Journal of Immunological Methods. 1983;65(1-2):55-63. DOI: 10.1016/0022-1759(83)90303-4

[60] Altman FP. Tetrazolium salts and formazans. Progress in Histochemistry and Cytochemistry. 1976;9(3):III-I51. DOI: 10.1016/S0079-6336(76)80015-0

[61] Denizot F, Lang R. Rapid colorimetric assay for cell growth and survival: Modifications to the tetrazolium dye procedure giving improved sensitivity and reliability. Journal of Immunological Methods. 1986;89(2):271-277. DOI: 10.1016/0022-1759(86)90368-6

[62] Gopinathan J, Mano S, Elakkiya V, Pillai MM, Sahanand KS, Rai BD, et al. Biomolecule incorporated poly$\varepsilon$-caprolactone nanofibrous scaffolds for enhanced human meniscal cell attachment and proliferation. RSC Advances. 2015;5(90):73552-73561. DOI: 10.1039/C5RA14315B

[63] Fenech M. Cytokinesis-block micronucleus cytome assay. Nature Protocols. 2007;2(5):1084

[64] Maluf SW, Erdtmann B. Follow-up study of the genetic damage in lymphocytes of pharmacists and nurses handling antineoplastic drugs evaluated by cytokinesis-block micronuclei analysis and single cell gel electrophoresis assay. Mutation Research, Genetic Toxicology and Environmental Mutagenesis. 2000;471(1):21-27. DOI: $10.1016 /$ S1383-5718(00)00107-8

[65] Heddle JA. A rapid in vivo test for chromosomal damage. Mutation Research: Fundamental and Molecular Mechanisms of Mutagenesis. 1973;18(2):187-190. DOI: 10.1016/0027-5107(73)90035-3 


\title{
Chapter 2
}

\section{Natural Fibers: Applications}

\author{
Jatinder Singh Dhaliwal
}

\begin{abstract}
Fibers derived from bio-based sources such as vegetables and animal origin are termed as natural fibers. This definition includes all natural cellulosic fibers (cotton, jute, sisal, coir, flax, hemp, abaca, ramie, etc.) and protein-based fibers such as wool and silk. There are also man-made cellulose fibers (e.g., viscose rayon and cellulose acetate) that are produced with chemical procedures from pulped wood or other sources (cotton, bamboo). Natural fibers being cost effective and abundantly available yields high potential in various industrial and commercial applications such as in the interior applications of the passenger cars, panels for partition and false ceiling, partition boards, roof tiles, coir fibers in packaging, furniture applications, as insulating materials in low energy houses, geo-textiles for soil protection and erosion control, enhancing barrier properties, composites etc. Due to research and developmental work in modification and treatment methods of natural fibers, utilization of natural fibers has observed a significant growth in various applications. The chapter addresses the potential applications of natural fibers in various commercial sectors for the development of environment-friendly products with an aim to replace synthetic fibers or inorganic fillers with cost-effective and efficient products.
\end{abstract}

Keywords: natural fibers, polymers, composites, applications, modification

\section{Introduction}

The transition toward a bio-based economy and sustainable developments as a consequence of the Kyoto protocols on greenhouse gas reduction and $\mathrm{CO}_{2}$ neutral production offers high perspectives for natural fiber markets. Changing to a biobased economy requires substitution of common raw materials that are currently largely produced from fossil (petrochemical) or mineral resources, by-products produced from renewable (plant and animal based) resources [1]. The development of a sustainable global economy, which permits improving purchasing power and living standards without exhaustion of resources for future generations, requires a fundamental change in attitude. On ecological grounds products should then be preferred that are based on photosynthetic CO2 fixation [1]. The benefit of those sustainable resources is that they can be regrown within the foreseeable future, without negative side effects on global biodiversity. Therefore, competitive products based on renewable resources need to be developed to have high quality, show excellent technical performance, and harm the environment less than current products based on petrochemical materials [2, 3]. Table 1 below shows the major natural fiber producers in the world, their potential applications and associated by products. 


\begin{tabular}{|c|c|c|c|}
\hline $\begin{array}{l}\text { Natural } \\
\text { fiber }\end{array}$ & Main producers & Fiber market & By-product \\
\hline Cotton & $\begin{array}{l}\text { China, USA, India, } \\
\text { Pakistan }\end{array}$ & $\begin{array}{l}\text { Textile fabric: apparel, home furnishing, } \\
\text { upholstery, non-wovens, specialty paper, } \\
\text { cellulose, medical and hygienic supplies } \\
\text { (hydrophilic absorbents) }\end{array}$ & $\begin{array}{l}\text { Linter, cottonseed, } \\
\text { stalks }\end{array}$ \\
\hline Kapok & Indonesia & Pillow, mattress & Seeds, wood \\
\hline Jute & India, Bangladesh & Hessian, sacking, carpet backing & Stalks (sticks) \\
\hline Kenaf & $\begin{array}{l}\text { China, India, } \\
\text { Thailand }\end{array}$ & & \\
\hline Flax & $\begin{array}{l}\text { China, France, } \\
\text { Belgium, Belarus, } \\
\text { Ukraine }\end{array}$ & $\begin{array}{l}\text { Textile fabric, composites non-woven, } \\
\text { insulation mats, specialist paper }\end{array}$ & Seeds, shives \\
\hline Hemp & China & & \\
\hline Ramie & China & Textile fabric & Leaves, stem \\
\hline Abaca & $\begin{array}{l}\text { Philippines, } \\
\text { Ecuador }\end{array}$ & Specialty paper, tea bags & Leaves, juice \\
\hline Sisal & $\begin{array}{l}\text { Brazil, China, } \\
\text { Tanzania, Kenya }\end{array}$ & Twine and ropes & $\begin{array}{l}\text { Short fiber, juice, } \\
\text { poles, stem }\end{array}$ \\
\hline Henequen & Mexico & & \\
\hline Coir & India, Sri Lanka & $\begin{array}{l}\text { Twine, ropes, carpets, brushes, mattress, } \\
\text { geotextiles, horticultural products }\end{array}$ & $\begin{array}{l}\text { Copra, water, } \\
\text { shell, pith, wood, } \\
\text { leaves }\end{array}$ \\
\hline Wool & $\begin{array}{l}\text { Australia, China, } \\
\text { New Zealand }\end{array}$ & Knitted wear & Lamb meat, cheese \\
\hline Silk & China, India & Fine garments, veils, handkerchiefs & $\begin{array}{l}\text { Worms, cocoons, } \\
\text { fruits, wood }\end{array}$ \\
\hline
\end{tabular}

Table 1.

Natural fiber type, producers and markets [4].

In 2017, global fiber production exceeded 100 million mt resulting in the largest fiber production volume ever. Global fiber production saw a 10 -fold increase from 1950 to 2017 from < 10 million mt to over 100 million mt. Synthetic fibers have dominated the fiber market since the mid-1990s when they overtook cotton and became the dominant fiber. With around 65 million mt of synthetic fibers, this fiber category made up approximately $60 \%$ of the global fiber production in 2017. Polyester has a market share of around $51 \%$ of the total global fiber production. More than 53 million mt of polyester is produced annually. Cotton is the second most important fiber since synthetics took the lead in the mid-1990s [4]. With around 26 million $\mathrm{mt}$, it has a market share of approximately $25 \%$ of global fiber production. An increasingly important fiber category is man-made cellulosics (MMCs) with a global production volume of around 6.5 million $\mathrm{mt}$ and a market share of around $6-7 \%$ in 2017 . Wool has a market share of around $1 \%$ with a global production volume of a little over one million mt. Other plant-based fibers, including jute, linen, and hemp, together have a market share of about 5\%. Silk and down have market shares of less than $1 \%$. The need to decouple growth from resource consumption gets more urgent every year. The significant growth in fiber production results in a significant use of natural resources and a huge production of textile waste. There is a growing awareness of the urgent need for a more responsible use of resources, enabling growth without increased resource consumption. 
An innovation toward a circular economy and dematerialization can be seen in almost all fiber categories. Accelerating such initiatives will help to reduce the overall fiber footprint on the planet [4].

Natural fibers have three main components lignin, cellulose and hemi-cellulose, percent of each vary with each type of natural fiber. Hemicellulose is strongly tied to cellulose fibrils presumably by hydrogen bonds. Hemicellulose polymers are branched and fully amorphous and have a significantly lower molecular weight than cellulose. Because of its open structure containing many hydroxyl and acetyl groups, hemicellulose is partly soluble in water and hygroscopic. Lignin is amorphous, highly complex, and mainly aromatic polymer of phenyl propane units but had the least water absorption of the natural fiber components. Amorphous lignin matrix helps in the combination of helically arranged cellulose microfibrils, which results in the formation of composite fiber. Lignin plays a very important role in the plant fiber such as water holding capacity, provide protection against biological attacks, and strengthened the stem against wind and gravity forces. Hemicellulose found in the plant fibers is believed to be a compatibilizer between cellulose and lignin [5].

However, the quality of natural fibers is greatly influenced by various factors like the age of the plant, species, growing environment, harvesting, humidity, quality of soil, temperature, and processing steps, and there is a move to reduce the on-field processing to improve consistency and reduce costs [6].

\section{Applications of natural fibers}

\subsection{Wind turbine blade}

For centuries different sources like wood, oil, coal and currently materials like coke, natural gas, nuclear materials etc. are used for energy generation. With the significant increase in population, civilization, and industrialization, the consumption of energy has increased many folds. In today's scenario due to this imbalance of ecological system, more ecological awareness and stringent country law and policies have led to the increased interest on renewable and sustainable energy sources. There is a continuous search for sustainable development with minimum pollution and better efficiencies for reduction in energy consumption which have led to the development of wind energy. It is a prominent renewable energy source available to mankind which can be part of the solution of the global energy problem [7]. Currently the wind energy sector is growing, and highly efficient systems capable for converting the kinetic energy of the wind into mechanical or electrical energy are available. Generally the wind turbines consist of three rotor blades that rotate around a horizontal hub and convert the wind energy into mechanical energy and are the key component of the wind turbine. However the design aspect of these wind blades plays a major role in conversion process, the aerodynamic shape, the length of blades, and the material of construction used by the manufacturer.

Based upon the design of orientation of the shaft and rotational axis, wind turbines can be classified into two types (Figure 1). A turbine with a shaft mounted horizontally parallel to the ground is known as a horizontal-axis wind turbine (HAWT), and turbine with shaft normal to the ground is called vertical-axis wind turbine (VAWT). Today's leading large-scale turbine manufacturers favor HAWTtype turbines because of attributes like increased rotor control through pitch and yaw control [8-10].

Fiber-reinforced composite materials have been the choice for the commercial production of large-scale wind turbine rotor blades especially glass and carbon 

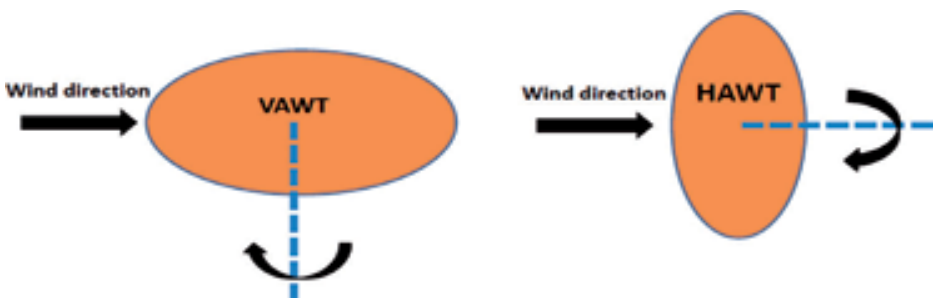

Figure 1.

Alternative configurations of shaft and rotor [8].

fibers. Carbon fibers are preferred over glass fibers because they provide superior mechanical strength due to their lower density and higher fatigue ratio which extends the life of the blades. The high cost of the carbon fibers which start with the expensive poly-acrylonitrile polymer (PAN) precursor and due to the environmental concerns and stringent laws, these are not considered as first choice since the commercial production of these types of fibers is highly dependent upon petroleum-based resources [11]. Because of these and similar reasons, researchers around the globe have shifted their focus on replacing these man-made fibers with natural fibers. Some of the main requirements for the wind turbine blade are

(a) high strength, (b) high fatigue resistance and reliability, (c) low weight, and (d) high stiffness [12].

There is a huge potential to reduce the overall manufacturing cost of the wind turbine blades and replace the man-made fibers with natural fiber-reinforced composite materials. Balsa, flax, hemp, coir, abaca, alpaca, bamboo, and jute fibers have been marketed as potential and prospective substitutes to the traditional composite reinforcements. Lignin which is an aromatic biopolymer and abundantly available and can be sourced from plants and wood can be used as a precursor for production of carbon fibers. Low cost and easy availability can have a saving of 37-49\% in the production cost of carbon fibers. However lignin has to be modified so as to be spun, stretched/aligned, and spooled into fibers, and these fibers can also be used in manufacturing of blades. Generally wind turbine blades are made up of array of sandwich panel strips and panels. Because of its light in weight and stiffness relative to density, balsa wood is being studied and used for making wind turbine interior panels and sandwich components $[11,12]$.

The performance of NFC-based wind turbine blades depend upon the following factors [10]:

1. Matrix selection-Matrix plays an important role in fiber-reinforced composites. It acts as a barrier against environment and protects the surface exposed from mechanical abrasion. Most commonly used matrices are polymeric in nature as they hold certain advantages being light in weight and easy to fabricate, can be designed to withstand harsh temperatures, etc. Thermoplastic

(e.g., polypropylene, polyethylene, nylon, polycarbonate, etc.) and thermoset (e.g., polyurethanes, polyester, epoxy etc.) polymers are being used with natural fibers [13].

2. Fiber selection-All the plant-based fibers hold cellulose as the major structural component. Choice of the fiber depends upon the country or region and size of the wind turbine blade. It is important to know the availability of the fiber since it varies from country to country. The size of the blade governs the nature of mechanical performance requirements; therefore one particular fiber might not provide adequate strength for a particular size blade. Generally 
better performance can be achieved with fibers having higher cellulose content and cellulose microfibrils aligned more in fiber direction. Typical examples are flax, hemp, kenaf, jute, and ramie fibers. The properties of the natural fibers do vary depending upon the chemical structure and composition, growing conditions, treatment procedures, harvesting time, extraction method, and storage procedures [14].

3. Fiber orientation-Orientation of fibers in polymer matrix ultimately governs the performance of the composite material which is best achieved when the fibers are aligned in parallel to the direction of applied load, however it's difficult to achieve in reality. Some alignment can be achieved during injection molding process and manual placement of long fibers [15-18].

4. Interference strength-Though the natural fibers are obtained from renewable resources and the composite materials will be environment-friendly, there are certain disadvantages also associated with unmodified or raw natural fibers. Some of the major problems can be high moisture uptake, low thermal stability, poor adhesion, poor mechanicals, etc. However, the majority of these can be overcome by employing suitable treatment/modification procedures [19-21].

\subsection{Hydrogel production}

Hydrogels are polymers having a three-dimensional cross-linked hydrophilic structure produced by simple reaction of one or more monomers which renders them capability of absorbing, storing, and releasing water molecules. Hydrogels have been researched considerably over the past decades due to their promising application in various fields. Some of the application areas of hydrogels include the manufacture of personal hygiene products, medical devices, environmental, agricultural, drug delivery systems, pharmaceuticals, biomedical, tissue engineering and regenerative medicines, wound dressing, biosensor, separation of biomolecules or cells and barrier materials to regulate biological adhesions, etc. [22-26].

Hydrogels can be classified based upon the following [22]:

1. Source-Based upon the source, hydrogels can be categorized into two groups: natural and synthetic.

2. According to the polymeric composition-Preparation method leads to different class of hydrogels. (a) Homopolymeric hydrogels are formed using single monomer. Cross-linking will depend upon the nature of monomer and polymerization technique. (b) Copolymeric hydrogels are formed using two or more monomer species having at least one hydrophilic component. (c) Multipolymer interpenetrating polymeric network (IPN) is formed of two independent cross-linked natural or synthetic polymer components. In semi-IPN hydrogel, one is cross-linked, while the other component is non-cross-linked.

3. Type of cross linking-Based upon the chemical or nature of cross-linking junctions, hydrogels can be classified into two categories. Chemical crosslinked having permanent junctions and hydrogels with physical networks arising from physical entanglements or interactions [27].

4. Configuration-Based upon the chemical composition and physical structure, the hydrogels can be amorphous, semicrystalline, and crystalline. 
5. Physical appearance-It is governed by the polymerization technique used for preparation. Hydrogels can be in form of matrix, films, microsphere, etc.

6. Network electrical charge-On the basis of the presence or absence of electrical charge located on the cross-linked chains, hydrogels are divided into four groups: nonionic, ionic, amphoteric, and zwitterionic (polybetaines) electrolytes.

\subsubsection{Modification methods of natural fibers for hydrogel production}

Lignin, hemicellulose, and cellulose are the major constituents of natural fibers. Lignin which coats or covers the cellulose part shows lower tendency to react with other molecules and poor adhesion with polymer matrix. Therefore the natural fibers most of the time have to undergo through treatment or modifications to improve the reactivity, interaction, and better adhesion with polymer matrix or other molecules [28].

For the hydrogel production, the natural fibers are modified in two stages:

- Pretreatment step-It is a very common step even used when NF are used in composite material production also. The main objective of this step is the removal of lignin which is nonreactive toward other molecules and is achieved by alkaline treatment [29].

- Chemical modification-The step involves insertion of molecules into active sites of natural fibers of cellulose [30].

Collectively these steps increase the water absorption and retention capacity throughout with the help of modifying agents and active site generation.

\subsubsection{Hydrogel synthesis from plant fibers}

Hydrogel synthesis methods are mass polymerization, solution, and reverse suspension (use of initiator and a crosslinking agent). Generally hydrogel synthesis based upon the plant fibers uses solution polymerization method [28]. Figure 2 shows general hydrogel preparation process.

Table 2 shows the different polymerization techniques, method employed, and type of characterization required during hydrogel synthesis. Solution polymerization is typically the preferred method for synthesis.

As reported by [29], during hydrogel synthesis, increase in the fiber content increased the swelling and elastic modulus, whereas Liang et al. showed change in $\mathrm{pH}$, temperature, and salts leads to change in swelling behavior. In acidic environment, hydronium ions interacts with hydroxyl groups of cellulose to form hydrogen

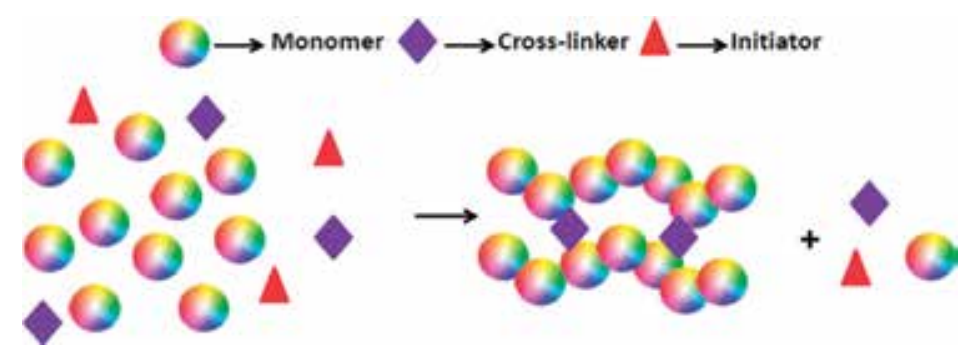

Figure 2.

Schematic for hydrogel preparation [22]. 


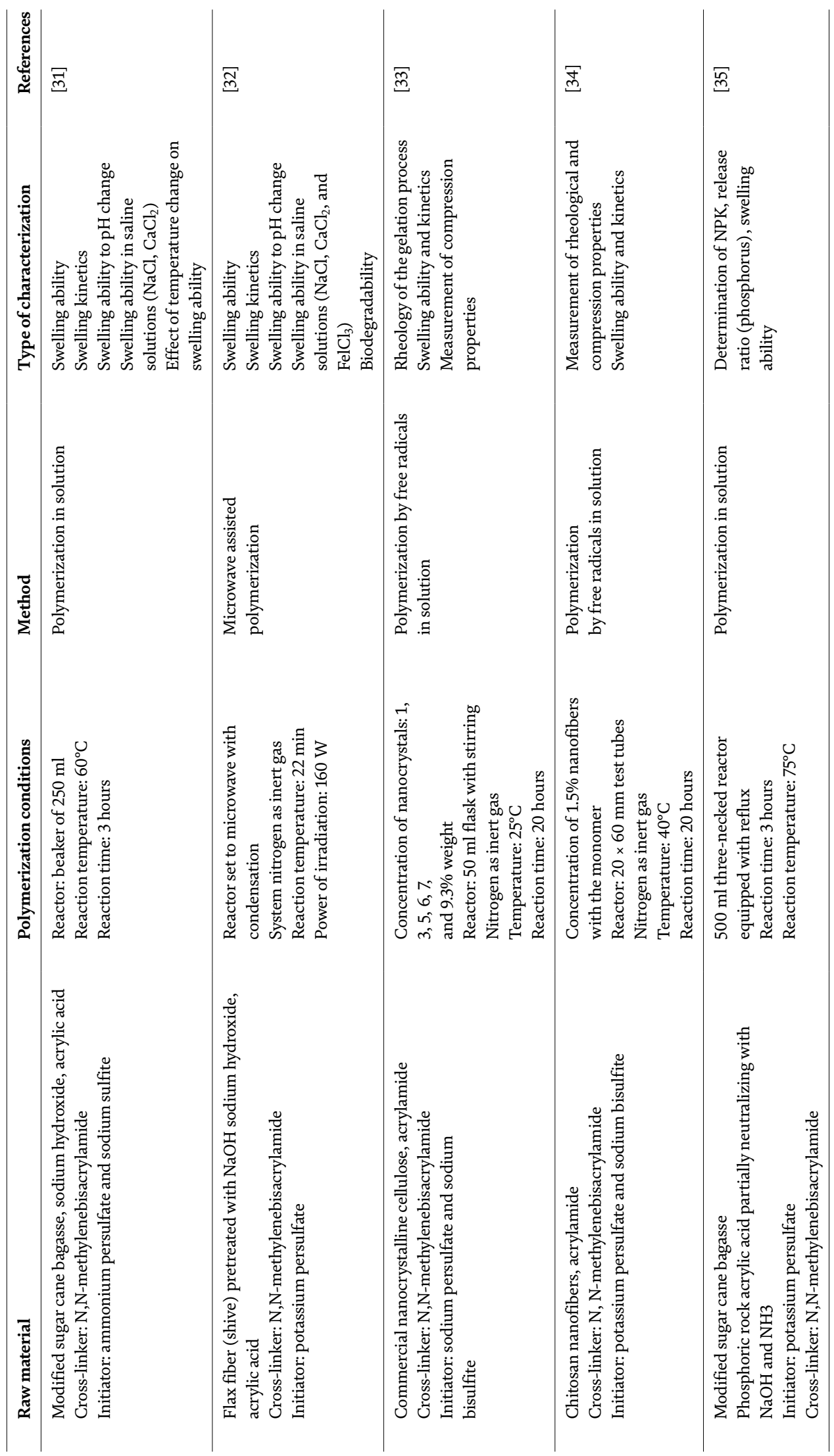




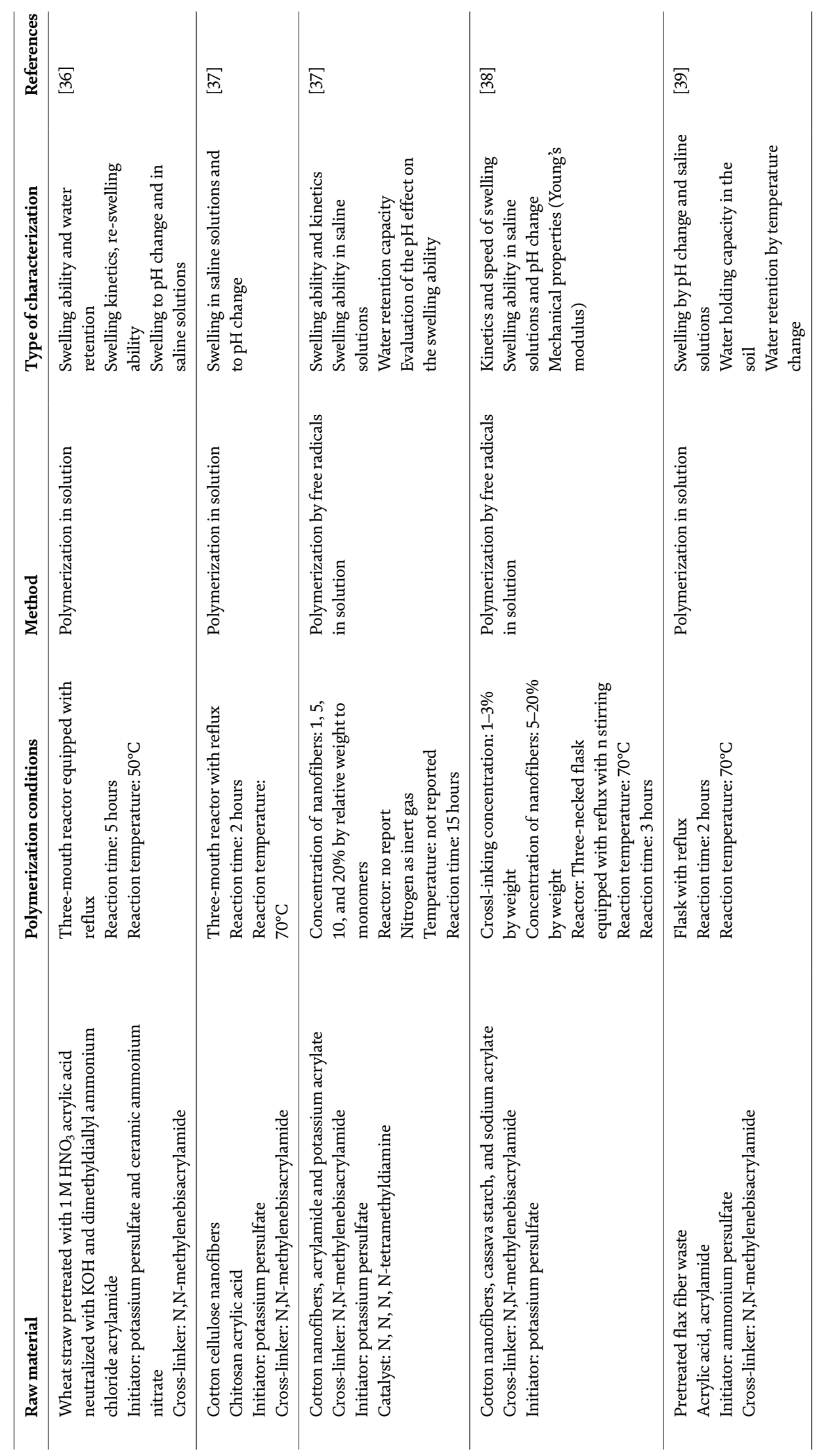




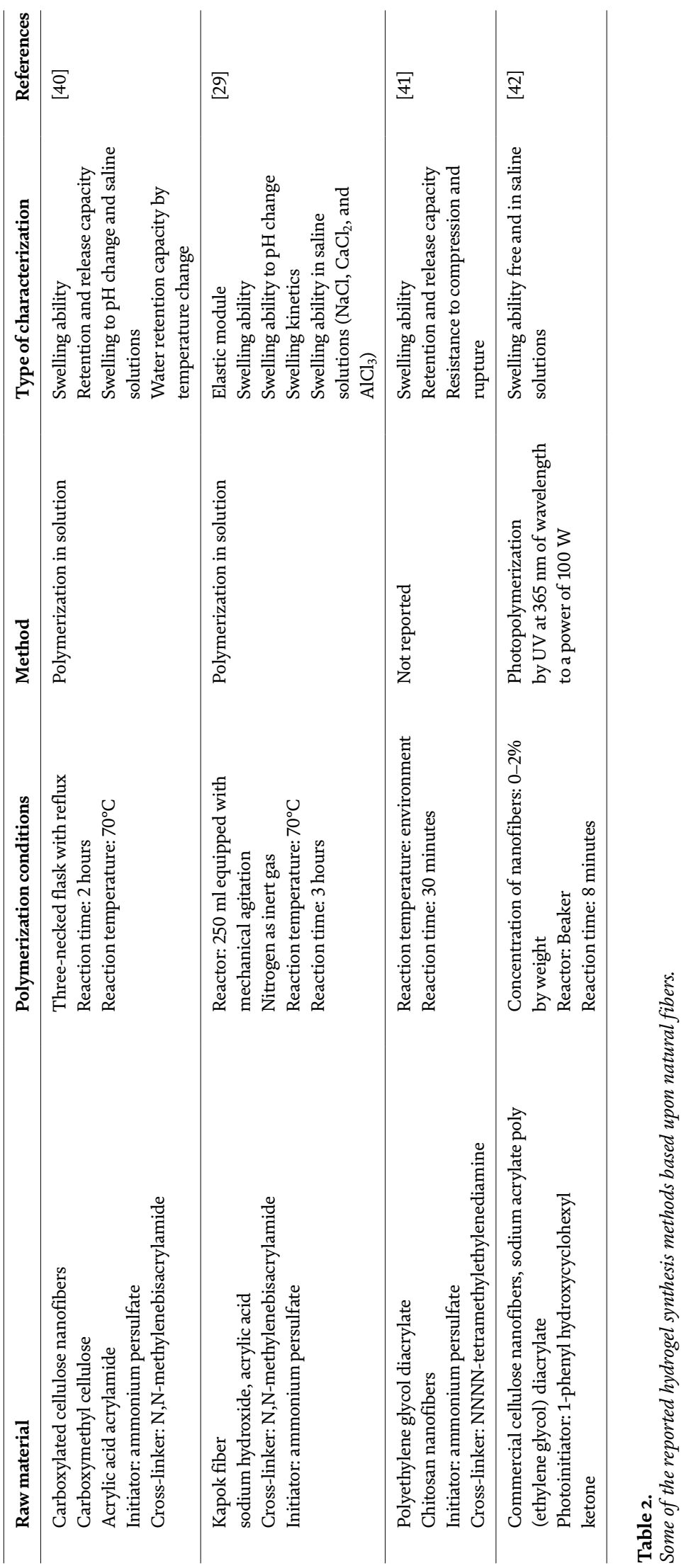


linking forces resulting in increasing chain cross-linking and decreasing absorption capacity, whereas in basic media due to the neutralization of active sites, the swelling ability decreased. A temperature between 0 and $50^{\circ} \mathrm{C}$ is reported to have positive effect on the swelling ability. Zhong et al. [35] found the inclusion of the phosphoric rock in polymer matrix results into better swelling ability and water release rate.

The effect of use of natural fibers at nanoscale level in the hydrogels also has been studied, and few of the advantages found are the following:

- Better mechanical strength of hydrogels

- Improvement in the swelling ability

- Increase the density of cross-linking points

- Promotes the formation of porous morphology

Hydrogels can be tailored and designed as per the requirements and needs for different applications. Natural fibers as part of hydrogels synthesis can provide an eco-friendly alternative and fulfill the potential.

\subsection{Automotive application}

Today more than $50 \%$ of the vehicles' interior constitutes different polymeric materials. Automotive manufacturers and associations are under tremendous pressure to improve on fuel efficiency and lower emissions. One of the best ways is to reduce the overall weight of the vehicle which can be possible in replacing metal with lightweight composite materials [43]. Automakers have taken initiatives to design and utilize natural renewable resources as part of composite materials, though the use of natural biomaterials like natural fibers in automotive dates back to 1940s when Henry Ford produced the first composite component using hemp fiber. Similarly many other automotive manufacturers started following the same path down the line. Natural fiber-based composites hold great potential especially in automotive industry where studies have reported NFRC can contribute to cost and weight reduction by 20 and 30\%, respectively [44]. Natural fiber-reinforced composite materials are generally utilized in interior parts like door panels, dashboard parts, parcel shelves, seat cushions, backrests, cable linings, etc. Applications to exterior are limited due to the high demand of mechanical strength [45-48]. Finished automotive door produced from hemp fiber is shown in Figure 3.
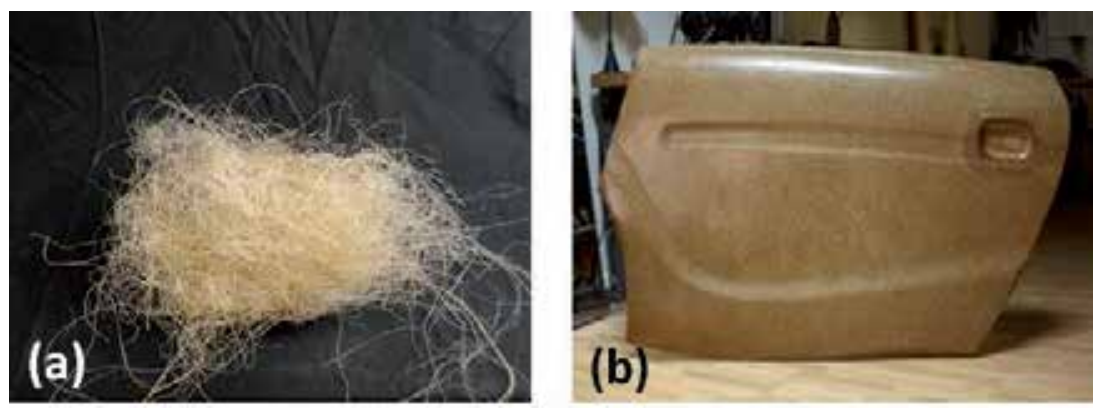

Figure 3.

Schematic of (a) hemp fiber and (b) automotive part produced using hemp fiber. 
The properties of the natural fiber-reinforced composite materials depend upon the interfacial compatibility of the polymer matrix. The inherent characteristics and properties of natural fibers, generally issues like poor adhesion, moisture absorption, poor wet ability, etc., cause lower bonding with the polymer matrix. Therefore, modification or pretreatment of natural fibers is done prior to composite preparation. Several techniques and processes have been studied and reported. Few of them are stretching, calendaring, and production of hybrid yarns which result into change in physical attributes of natural fibers. Corona treatment (electrical discharge) method is another method used which makes surface rough resulting in better adhesion with polymer. The use of oxidizing agents such as sodium/calcium hypochlorite and hydrogen peroxide for removal of dust and oil from natural fibers has been reported. Alkali treatment of natural fibers also have been extensively studied and found to improve wet ability and improve adhesion significantly. Further improvement can be made by the use of grafted polymers like polypropylene/polyethylene-grafted maleic anhydride as compatibilizers and the use of coupling agents. These specialty products facilitate in the introduction and formation of covalent bonds and cross-linking effect [49-53].

In a report published by SABIC Innovative Plastics, wood flour and curaua fiber-based composites have been developed. Results are shown in the table below. The company claims that the composites developed are more resistant to fungi growth and have good dimensional stability, lower moisture absorption, and intended mechanical properties as required for the application. Table 3 shows the comparison of unfilled PP and PA6 with filled natural fibers, glass fibers, and talc at similar loading level. Density advantage can be observed with NFRC as compared to other composite materials. Most of the mechanical properties of PP filled with NFs are almost similar to the talc-filled PP. Glass fiber-filled PP possess advantage in terms of tensile and flexural strength over NFRC and talc-filled PP materials. However, in automotive interior applications, composite materials with mild to high mechanical properties can serve the purpose. Mechanical properties of natural fiber-reinforced polymer composite are comparable to polypropylene talc and glass fiber composites (Table 3).

\begin{tabular}{|c|c|c|c|c|c|c|c|c|}
\hline Property & $\mathbf{P P}$ & $\begin{array}{c}P P+30 \% \\
W P\end{array}$ & $\begin{array}{c}P P+30 \% \\
\text { GF }\end{array}$ & $\begin{array}{c}P P+30 \% \\
\text { talc }\end{array}$ & PA6 & $\begin{array}{c}\text { PA6 + 20\% } \\
\text { curaua }\end{array}$ & $\begin{array}{c}P P+20 \% \\
\text { GF }\end{array}$ & $\begin{array}{c}\mathrm{PP}+20 \% \\
\text { talc }\end{array}$ \\
\hline $\begin{array}{l}\text { Density } \\
\left(\mathrm{g} / \mathrm{cm}^{3}\right)\end{array}$ & 0.91 & 1.04 & 1.13 & 1.15 & 1.14 & 1.18 & 1.27 & 1.27 \\
\hline $\begin{array}{l}\text { Tensile } \\
\text { strength } \\
\text { (Mpa) }\end{array}$ & 19 & 28 & 65 & 25 & 63 & 83 & 101 & 73 \\
\hline $\begin{array}{l}\text { Tensile } \\
\text { modulus } \\
\text { (Gpa) }\end{array}$ & 1.4 & 2.3 & 4.5 & 2.2 & 1.4 & 5.5 & 6.5 & 6.5 \\
\hline $\begin{array}{l}\text { Elongation at } \\
\text { break (\%) }\end{array}$ & 50 & 2.5 & 3.0 & 5.0 & $>60$ & 3.0 & 3.0 & 6.0 \\
\hline $\begin{array}{l}\text { Izod impact } \\
\text { strength } \\
\left(\mathrm{KJ} / \mathrm{m}^{2}\right)\end{array}$ & 5.0 & 9.0 & 9.5 & 8.0 & 10 & 9.0 & 9.0 & 9.0 \\
\hline $\begin{array}{l}\text { Flexural } \\
\text { strength } \\
\text { (Mpa) }\end{array}$ & 50 & 78 & 115 & 65 & 95 & 115 & 160 & 115 \\
\hline
\end{tabular}

Table 3.

Mechanical properties of filled and unfilled PP and PA6 composites [43]. 


\begin{tabular}{|c|c|c|}
\hline Natural fibers & Component description & Polymer matrix \\
\hline $\begin{array}{l}\text { Bast fibers (hemp, } \\
\text { flax, jute, sisal, } \\
\text { etc.) }\end{array}$ & $\begin{array}{l}\text { Carrier for door panel, covered inserts, carrier for hard } \\
\text { and soft arm insert, backseat panel, door bolsters, side } \\
\text { and back walls, rear deck tray, center console, trunk trim, } \\
\text { pillars, load floors, etc. }\end{array}$ & $\begin{array}{l}\text { Polypropylene and } \\
\text { polyester }\end{array}$ \\
\hline Abaca & Under floor panel and body panel & - \\
\hline Coconut & $\begin{array}{l}\text { Seat bottom, back cushions, interior trim, seat } \\
\text { cushioning, seat surfaces/backrests, etc. }\end{array}$ & Natural rubber \\
\hline Coir & Seat covers, doormats, rugs & - \\
\hline Cotton & Sound proofing, trunk panels, insulation & $\mathrm{PP} / \mathrm{PET}$ \\
\hline $\begin{array}{l}\text { Fibrowood } \\
\text { recycled }\end{array}$ & Plastic retainer for backseat panel & $\mathrm{PP}$ \\
\hline Flax & $\begin{array}{l}\text { Backseats, covers, rear parcel shelves, other interior } \\
\text { trims, floor trays, pillar panels, central consoles, etc. }\end{array}$ & Mat with PP \\
\hline Flax/hemp & Carrier for covered door panels & Epoxy resin \\
\hline Flax/sisal & Door linings and panels & Thermoset resins \\
\hline Kenaf & Door inner panel & $\mathrm{PP}$ \\
\hline Kenaf/flax & Package trays and door panel inserts & - \\
\hline Kenaf/hemp & $\begin{array}{l}\text { Door panel, rear parcel shelves, interior trims, luxury } \\
\text { package shelves, door panels }\end{array}$ & - \\
\hline Wood & $\begin{array}{l}\text { Carrier for door panels, covered door panels, instrument } \\
\text { panels, covered inserts and components, covered } \\
\text { backseat panels, etc. }\end{array}$ & $\begin{array}{l}\text { Acrylic resin or } \\
\text { synthetic fibers }\end{array}$ \\
\hline Wood flour & Carrier for door panels, arm rest, and covered inserts & $\begin{array}{l}\text { PP or polyolefin } \\
\text { (POE) }\end{array}$ \\
\hline Wool & Upholstery, seat cover & Leather \\
\hline
\end{tabular}

Table 4.

Applications of natural fibers in automotive industry [54-59].

Now different regions across globe opt for different natural fibers depending upon their availability and ease of use. European automotive industry prefers flax and hemp, whereas in Asian country India prefers jute and kenaf. Banana fibers are preferred in the Philippines, whereas sisal fibers are used majorly in the USA, Brazil, and South Africa. Table 4 shows the use of natural fibers in various automotive components.

The use and development of natural fiber-based composite materials in automotive are going on good pace, and in time better composite materials with mechanical performance similar to synthetic fibers will be developed. Continuous development in fiber modification techniques, compounding machines, additives, polymers, etc. will yield a promising future ahead.

\subsection{Barrier properties and applications}

Cellulose is the primary component of green plants and is the most abundant organic compound derived from biomass. Due to its characteristic chemical and physical properties, it has been investigated and applied to variety of products and materials for many decades $[60,61]$. Cellulose material exists in four different polymorphs $[62,63]$ : 
- Type I-Native cellulose, the form in which cellulose occurs in nature.

- Type II-Regenerated cellulose, formed after recrystallization or mercerization with aqueous sodium hydroxide.

- Type III-This type of cellulose is produced by ammonia treatment of types I and II.

- Type IV-Heat treatment of type III yield type IV.

Type II is the most stable crystalline form of cellulose. The major difference between the type I and type II is the layout of their atoms. Chains in type I are layered in parallel fashion, whereas in type II they are in antiparallel.

About 36 individual cellulose molecules collectively form into a larger unit called elementary fibrils. Figure 4 depicts the details of cellulose fibers and microfibrils. Depending upon the dimensions, functions, and preparation methods, nanocellulose can be subdivided into three main types: (a) microfibrillated cellulose (MFC), (b) nanocrystalline cellulose (NCC), and (c) bacterial nanocellulose (BNC) [64], as shown in Figure 5.

Various petroleum-based materials are widely used for packaging application to prevent food, drinks, cosmetic goods, consumer goods, etc. against physical

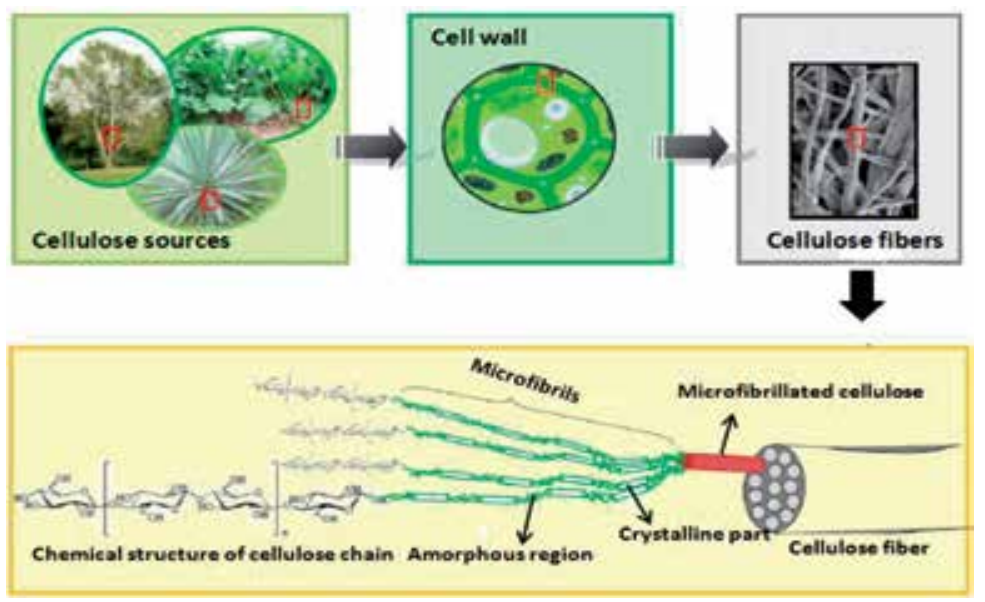

Figure 4.

From cellulose sources to cellulose molecules. Details of cellulose fiber structure with emphasis on cellulose fibrils $[64,65]$.
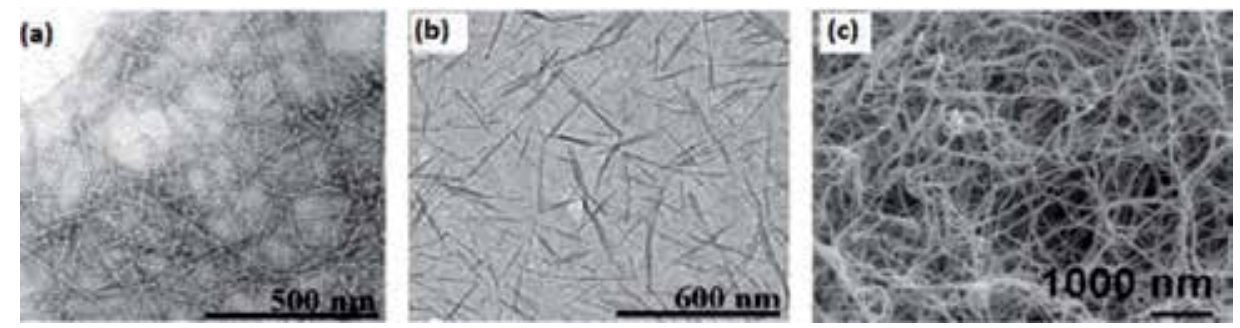

Figure 5 .

TEM images of (a) microfibrillated cellulose, (b) nanocrystalline cellulose, and (c) bacterial cellulose. 


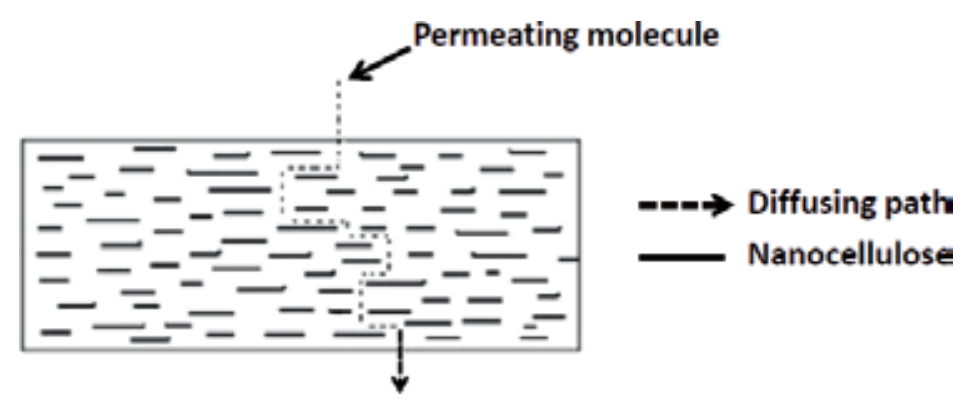

Figure 6.

Schematic representation of increased diffusion path within nanocellulose film [70].

and microbiological degradation and deterioration. These polymeric materials provide a layer of barrier against water vapor, oxygen, grease, and microorganisms. Packaging industry is one of the fastest-growing industries in the world. Now with the increased concerns due to the impact of these polymeric and other packaging materials like paper, glass, and metal on environment, materials derived from the renewable resources are strongly advocated. Recent research in more efficient and reliable preparation techniques for cellulose nanofibers and microfibrils synthesis, has attracted significant interest as potential barrier materials in packaging films. Cellulose nanomaterials have large surface area and diameter in range of 2-50 nm. Their ability to form hydrogen bonds results into strong network formation making it difficult for gas or water molecules to pass through it, thus providing excellent barrier properties [66-69].

Microfibrillated cellulose (MFC) films have better gas barrier property than cellulose nanocrystals (CNCs) because of the crystalline and amorphous regions in CNCs. Oxygen transmission rate (OTR) of 25 micron MFC film was found to be competitive with films of similar thickness made from ethylene vinyl alcohol $(\mathrm{EVOH})$ and polyvinylidene fluoride (PVDF). OTR of MFC film was found to be lower than EVOH and PVDF films [71, 72]. Figure 6 represents the kind of torturous path for permeating molecule because of nanocellulose. As reported, the barrier properties of MFC films can be tuned further. Rodionova et al. [73] in his work showed that oxygen permeability of MFC acetylated and carboxymethylated films can be further reduced. Carboxymethylated films had very low oxygen permeability of 0.009 and $0.0006 \mathrm{~cm}^{3} \mathrm{~m}^{-2} /$ day $\mathrm{kPa}-1$. Further the oxygen permeability can further be modified by using thermal treatment technique. Table 5 shows the OTR and WVTR values of commercial polymer films and MFC film.

MFC film have poor water vapor barrier property as compared to PVDF film due to hydrophilic nature of cellulose molecules however it can be improved thereby using different pre and post treatments during production process.

Cellulose nanocrystals have been studied as potential fillers for natural polymers to enhance their barrier properties. Results reported as in Saxena et al. [74] showed that nanocomposite film made by casting aqueous solution containing xylan,

\begin{tabular}{lcccr}
\hline Barrier material & Thickness & OTR $\left(\mathbf{c m}^{3} / \mathbf{m}^{2} / \mathbf{d}\right)$ & WVTR $\left(\mathbf{g} / \mathbf{m}^{2} / \mathbf{d}\right)$ & Sources \\
\hline EVOH & $24 \mu \mathrm{m}$ & $0.16-1.86$ & NA & {$[69]$} \\
\hline MFC & $25 \mu \mathrm{m}$ & $0.5-2.347$ & $47-55$ & {$[70]$} \\
\hline PVDF & $24 \mu \mathrm{m}$ & 8 & 0.3 & {$[69]$} \\
\hline
\end{tabular}

Table 5 .

Barrier properties of polymers and MFC. 
sorbitol, and cellulose nanocrystals had low oxygen permeability of $0.1799 \mathrm{~cm}^{3} \mu \mathrm{m} /$ $\mathrm{m}^{2} \mathrm{~d} \mathrm{kPa}$. As other reports $[75,76]$ also indicate that cellulose nanocrystals when used in other polymer matrix like PLA and PVOH improved in OTR and WVTR values. Studies based upon the use of microfibrillated and nanocrystals of cellulose in polymeric materials have opened possibilities in films, composites, and coatings to substantially reduce especially the oxygen permeation rate. Microfibrillated cellulose and its nanocrystals have oxygen-barrier efficiency better some of the commercially available polymers.

\subsection{Other applications}

\subsubsection{Composites}

There are considerable enhancement and suggestions for the natural fibers that can be implemented in order to enhance their mechanical properties resulting in high strength and structure so that it can be used as fillers and reinforcement agents instead of conventional materials like talc, calcium carbonate, mica, glass fibers, etc. After selecting the appropriate fiber and method of modification for the target application, the polymer matrix properties can be improved. Few of the parameters that effect the composite performance are the (a) orientation of fibers, (b) strength of fibers, (c) physical properties of fibers, (d) interfacial adhesion property of fibers, and many more [77-80]. Natural fiber-reinforced composite materials have shown better properties than pure polymer matrix in many cases. $75.8 \%$ of PLA's tensile strength was improved by the introduction of jute fibers. Properties of PP composites were improved by the incorporation of kenaf, cotton, and hemp fibers [77]. Ishagh et al. [81] investigated effects of azodicarbonamide (AZD) and nanoclay (NC) content on the physico-mechanical and foaming properties of HDPE/ wheat straw flour (WSF) composites. With the increase of AZD, the average cell size and density increased, whereas with addition of nanoclay up to $5 \mathrm{phr}$, the cell size and density increased. Idicula et al. [82] investigated thermophysical properties of banana sisal hybrid-reinforced composites. Increase in the thermal conductivity by $43 \%$ was observed in fibers which were subjected to mercerization and polystyrene maleic anhydride treatments. Chensong dong et al. [83] reported flexural properties of wheat straw polyester composites. Natural fiber-reinforced composites due to their certain advantages such as high stiffness to weight ratio, lightweight, and biodegradability gave them suitability in different applications in building industries. Sisal fiber reinforced composite have shown good tensile and compression strength making it suitable for wide area of applications, for instance, structural building members, permanent formwork, tanks, facades, long span roofing elements, and pipes strengthening of existing structures [84]. On the other hand, bamboo fiber can be used in structural concrete elements as reinforcement, while sisal fiber and coir fiber composites have been used in roofing components in order to replace asbestos. Natural fiber-reinforced concrete products in construction applications like sheets (both plain and corrugated) and boards are light in weight and are ideal for use in roofing, ceiling, and walling for the construction of low-cost houses.

\subsubsection{Silk fiber applications}

Silk which is a natural fiber and produced in more than 20 countries finds application in various sectors. Silk proteins are used as special diet for cardiac and diabetic patients due to its low sugar content, easy digestibility, and low cholesterol [83, 84]. The Japan Aerospace Exploration Agency (JAXA) has released a recipe as astronauts' food. Silk biopolymer is used in tissue regeneration for treating burn victims and as 
matrix for wound healing. Silk fibroin peptides are used in cosmetics due to their glossy, flexible, elastic powder coating; easy spreading; and good adhesion properties $[89,90]$. Silk is reported to be used to fight various health-related diseases like edema, cystitis, impotence, adenosine augmentation therapy, epididymitis, and cancer [91]. Derivatives of silk fibers are reported to be used as nonsteroidal antiinflammatory agents for treating rheumatoid arthritis $[85,86]$. Silk fibers are used as surgical sutures and as biodegradable microtubes for repair of blood vessels and as molded inserts for bone, cartilage, and teeth reconstruction [90, 93]. Due to the phenomenal mechanical properties of silk as a biopolymer, it is suitable for biomedical applications.

\subsubsection{Natural fiber-reinforced building material}

Various natural fibers have been exploited to be used as reinforcements for building/construction industry. Bamboo due to its lightweight and strength is a very popular construction material. Bamboo-based material has been developed to make eco-friendly roofing product. Other such products such as bamboo mat board (BMB), bamboo mat veneer composites (BMVC), and bamboo mat corrugated sheets (BMCS) have been developed. Sisal fiber-based roofing sheets also have been under development as economical alternative. Rice husk and rice straw are nowadays used to manufacture medium density fiberboards, particle boards, straw bales, cement-bonded boards, etc. Ground nutshell is used for manufacturing building panels, building blocks, chip boards, roofing sheets, particle boards, etc. Cotton stalk fiber is used for making panel, door shutters, roofing sheets, autoclaved cement composite, paper, plastering of walls, etc. Coir fiber is a highly durable fiber used in all types of matrices like fly ash-lime, polymers, bitumen, cement, mud, gypsum, etc. Jute coir composites are seen as cheap and economical alternative to wood for construction industry. Jute coir boards are used for the production of boards which are more resistant than teakwood against rooting under wet and dry conditions with better tensile strength. Jute with rubber, wood, and coir is considered as good alternative to plywood [94].

\subsubsection{Geotextiles for soil protection and erosion control}

Soil protection using natural fibers and other bio-based materials includes leaves, straws, and plant residues for the mulching of unprotected soil. Nowadays woven and nonwoven textiles and blankets made from wheat straw, rice straw, long wood shavings, coir, and jute are used as soil protection products. These products are categorized under two subgroups of the rolled control product (RECP) category. These can be open-weave geotextiles made using coir and jute fibers termed as erosion control
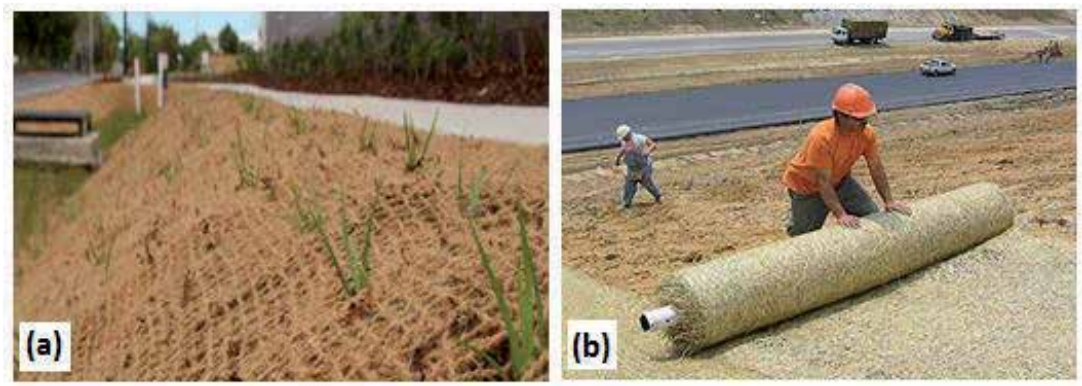

Figure 7 .

Showing (a) coir fiber-made erosion control mesh and (b) coconut fiber-made erosion control blanket. 
meshes (ECM) or nonwoven from natural fibers or synthetic fibers glued or bonded by nets or meshes called as erosion control blankets (ECB) as shown in Figure 7.

Natural fibers are also commonly used in rolls stuffed with straw or coir fiber bundles held together by nets which further can be used as slope interruption devices or sediment retention fiber rolls [95].

\section{Summary}

Natural fibers and the products designed around these materials possess many distinctive advantages: cost-effective, low coefficient of friction, ease of availability, exhibit good thermal and dimensional stability, environmental friendly, etc. Because of these and many more reasons, the popularity of natural fibers is on increase, and a lot of scientific data and research is being done around the globe. However for effective utilization of natural fibers in various potential applications, all the aspects associated with them has to be studied and presented: (a) target application, advantages, and disadvantages of using natural fibers; (b) product design, studies to be carried out on the development of prototype and other engineering software; (c) preparation and fabrication technique, particular technique, or process to be identified which should reduce possibility of failure, etc.; (d) commercial production, should be cost effective and eco-friendly; (e) marketing and sales, product should be marketed to show case its potential benefits toward society and environment with good after-sale service.

Despite of current prevailing aforementioned issues, several commercial products has been launched by various manufacturers, automotive industry the most active and leading the development of natural fibers based products. Gradually other sectors related to sports, furniture, medical, etc. are catching up.

\section{Author details}

Jatinder Singh Dhaliwal

Research and Development Center, Indian Oil Corporation Ltd., Faridabad, Haryana, India

*Address all correspondence to: singhj4@indianoil.in

IntechOpen

(C) 2019 The Author(s). Licensee IntechOpen. This chapter is distributed under the terms of the Creative Commons Attribution License (http://creativecommons.org/licenses/ by/3.0), which permits unrestricted use, distribution, and reproduction in any medium, provided the original work is properly cited. (cc) BY 


\section{References}

[1] Jan EGVDA. Environmental benefits of natural fiber production and use. In: Proceedings of the Symposium on Natural Fibers. 2008. pp. 3-17

[2] Ho M-p, Hao W, Joong-Hee L, Chun-kit H, Kin-Tak L, Jinsong L, et al. Critical factors on manufacturing processes of natural fiber composites. Composites Part B Engineering. 2012;43:3549-3562

[3] Sathishkumar TP, Navaneethakrishnan P, Shankar S. Tensile and flexural properties of snake grass natural fiber reinforced isophthallic polyester composites. Composites Science and Technology.

2012;72:1183-1119

[4] Textile Exchange. Preferred Fiber \& Materials Market Report. 2018;1-96

[5] Hansen CM, Bjorkman A. The ultrastructure of wood from a solubility parameter point of view. Holzforschung. 1998;52:335-344

[6] Velde KV, Kiekens P. Thermoplastic pultrusion of natural fiber reinforced composites. Composite Structures. 2001;54:355-360

[7] Debnath K, Singh I, Dvivedi A, Kumar P. Natural fibre-reinforced polymer composites for wind turbine blades: Challenges and opportunities. Chapter 2. In: Recent Advances in Composite Materials for Wind Turbine Blades. The World Academic Publishing Co. Ltd.; 2013. pp. 25-39

[8] Peter JS, Richard JC. Wind turbine blade design. Energies. 2012;5:3425-3449

[9] Dominy R, Lunt P, Bickerdyke A, Dominy J. Self-starting capability of a Darrieus turbine. The Journal of Power and Energy, Part A of the Proceedings of the Institution of Mechanical Engineers. 2007;221:111-120
[10] Holdsworth B. Green Light for Unique NOVA Offshore Wind Turbine. 2009. Available online: http://www. reinforcedplastics.com

[11] Felipe S, Veronica C, Nei P Jr. Lignin-based carbon fiber: A current overview. Materials Research Express. 2018;5(7):1-55

[12] Ganesh RK, Rajashekar P, Narayan N. Natural fiber reinforced polymer composite materials for wind turbine blade applications. International Journal of Scientific Development and Research. 2016;1(9):28-37

[13] Marion P, Andréas R, Marie HM. Study of wheat gluten plasticization with fatty acids. Polymer. 2003;4:115-122

[14] Sinha E, Panigrahi S. Effect of plasma treatment on structure, wettability of jute fiber and flexural strength of its composite. Journal of Composite Materials. 2009;43(17):1791-1802

[15] Avella M, Bogoeva-Gaceva G, Bužarovska A, Errico ME, Gentile G, Grozdanov A. Poly (lactic acid)-based biocomposites reinforced with kenaf fibers. Journal of Applied Polymer Science. 2008;108(6):3542-3551

[16] Kang JT, Park SH, Kim SH. Improvement in the adhesion of bamboo fiber reinforced polylactide composites. Journal of Composite Materials. 2013;48(21):2567-2577

[17] Bledzki AK, Mamun AA, JaszkiewiczA,ErdmannK.Polypropylene composites with enzyme modified abaca fibre. Composites Science and Technology. 2010;70(5):854-860

[18] Sanadi AR, Caulfield DF, Jacobson RE. Agro-fiber thermoplastic composites. In: Paper and Composites from Agro-Based Resources. Boca Raton, FL: CRC; 1997. pp. 377-401 
[19] Rowel RM, Sanadi AR, Caulfield DF, Jacobson RE. In: Leao A, Carv-Alho FX, Frollini E, editors. Utilization of Natural Fibers in Composites: Problems and Opportunities in Ligno-CellulosicPlastic Composites. USP/UNESP Publishers: Sao Paulo; 1997. pp. 23-51

[20] Mishnaevsky JL, Branner K, Petersen HN, Beauson J, McGugan M, Sørensen BF. Materials for Wind Turbine Blades: An Overview. 2017;10(1285):1-24

[21] Maldas D, Kokta BV, Daneault C. Composites of polyvinyl chloridewood fibers. IV. Effect of the nature of fibers. Journal of Vinyl Technology. 1989;1:90-99

[22] Enas MA. Hydrogel: Preparation, characterization, and applications: $\mathrm{A}$ review. Journal of Advanced Research. 2015;6:105-121

[23] Ahmed EM, Aggor FS, Awad AM, El-Aref AT. An innovative method for preparation of nanometal hydroxide superabsorbent hydrogel. Carbohydrate Polymers. 2013;91:693-698

[24] Buchholz FL, Graham AT. Modern Superabsorbent Polymer Technology. New York: Wiley-VCH; 1998. chapters 1-7

[25] Brannon-Peppas L, Harland RS. Absorbent polymer technology. Journal of Controlled Release. 1991;17(3):297-298

[26] Yuhui L, Guoyou H, Xiaohui Z, Baoqiang L, Yongmei C, Tingli L, et al. Magnetic hydrogels and their potential biomedical applications. Advanced Functional Materials. 2013;23(6):660-672

[27] Hacker MC, Mikos AG.

Chapter-33. Synthetic polymersprinciples of regenerative medicine. In principles of regenerative medicines. 2nd edition. Academic Press, Elsevier; 2011:587-622
[28] Serna Cock L, GuanchaChalapud MA. Natural fibers for hydrogels production and their applications in agriculture. Acta Agronomica. 2017;66(4):495-505

[29] Shi X, Wang W, Zheng Y, Wang A. Utilization of hollow kapok fiber for the fabrication of a $\mathrm{pH}$-sensitive superabsorbent composite with improved gel strength and swelling properties. RSC Advances. 2014;4(92):50478-50485

[30] Thomas S, Paul SA, Pothan LA, Deepa B. Chapter 1: Natural fibres: Structure, properties and applications. In Cellulose fibers: Bio-and NanoPolymer Composites. Springer; 2011:3-42

[31] Liang X, Huang Z, Zhang Y, Hu H, Liu Z. Synthesis and properties of novel superabsorbent hydrogels with mechanically activated sugarcane bagasse and acrylic acid. Polymer Bulletin. 2013;70(6):1781-1794

[32] Feng H, Li J, Wang L. Preparation of biodegradable flax shive cellulosebased superabsorbent polymer under microwave irradiation. BioResources. 2010;5(3):1484-1495

[33] Chen W, Yu H, Liu Y, Chen P, Zhang M, Hai Y. Individualization of cellulose nanofibers from wood using high-intensity ultrasonication combined with chemical pretreatments. Carbohydrate Polymers. 2011;83(4):1804-1811

[34] Chang C, Zhang L. Cellulosebased hydrogels: Present status and application prospects. Carbohydrate Polymers. 2011;84(1):40-53

[35] Zhong K, Zheng XL, Mao XY, Lin ZT, Jiang GB. Sugarcane bagasse derivative based superabsorbent containing phosphate rock with waterfertilizer integration. Carbohydrate Polymers. 2012;90(2):820-826 
[36] Li Q, Ma Z, Yue Q, Gao B, Li W, $\mathrm{Xu} \mathrm{X}$. Synthesis, characterization and swelling behaviour of superabsorbent wheat straw graft copolymers. Bioresource Technology. 2012;118:204-209

[37] Spagnol C, Rodrigues F, Pereira A, Fajardo A, Rubira A, Muniz E. Superabsorbent hydrogel composite made of cellulose nanofibrils and chitosan-graft-poly(acrylic acid). Carbohydrate Polymers. 2012;87(3):2038-2045

[38] Spagnol C, Rodrigues F, Pereira A, Fajardo A Rubira A, Muniz E. Superabsorbent hydrogel nanocomposites based on starch-g-poly (sodium acrylate) matrix filled with cellulose nanowhiskers. Cellulose. 2012;19:1225-1237

[39] Wu CS. Preparation, characterization, and biodegradability of renewable resource-based composites from recycled polylactide bioplastic and sisal fibers. Journal of Applied Polymer Science. 2012;123(1):347-4556

[40] Mohan YM, Murthy PSK, Raju KM. Preparation and swelling behavior of microporous poly (acrylamide-co-sodium methacrylate) superabsorbent hydrogels. Journal of Applied Polymer Science.

2006;101:3202-3214

[41] Nitta S, Kaketani S, Iwamoto H. Development of chitosan-nanofiberbased hydrogels exhibiting high mechanical strength and $\mathrm{pH}$-responsive controlled release. European Polymer Journal. 2015;67:50-56

[42] Wen Y, Zhu X, Gauthier DE, An X, Cheng D, Ni Y, et al. Development of poly (acrylic acid)/nanofibrillated cellulose superabsorbent composites by ultraviolet light induced polymerization. Cellulose. 2015;22(4):2499-2506

[43] Santos PAD, Amarasekera J, Moraes G. Natural fibers plastic composites for automotive applications. Sabic Innovative Plastics. 2008:1-9

[44] Juaska C, Gearhart J, Griffith C. Automotive plastic card-The policies and practices of eight leading automakers. USA: Ecology center. 2006

[45] Kozłowski RM. Handbook of Natural Fibres: Processing and Applications. Woodhead Publishing Limited; 2012. p. 221

[46] Holbery J, Houston D. Naturalfiber-reinforced polymer composites in automotive applications. Journal of Mineral, Metals and Material Society. 2006;58(11):80-86

[47] Ali LMA, Ansari MNM, Pua G, Jawaid M, Islam MS. A review on natural fiber reinforced polymer composite and its applications. International Journal of Polymer Science. 2015:1-15

[48] Chandramohan D, Bharanichandar J. American. Journal of Environmental Sciences. 2013;9(6):494-504

[49] Ramesh M, Palanikumar K, Reddy KH. Plant fibre based biocomposites: Sustainable and renewable green materials. Renewable and Sustainable Energy Reviews. 2017;79:558-584

[50] Le Moigne N, Otazaghine B, Corn S, Angellier-Coussy H, Bergeret A. Chapter-Modification of the interface/ interphase in natural fibre reinforced composites: Treatments and processes. In: Surfaces and Interfaces in Natural Fibre Reinforced Composites. 2018. pp. $35-70$

[51] Azam A, Khubab S, Nawab Y, Madiha J, Hussain T. Hydrophobic treatment of natural fibers and their composites-A review. Journal of Industrial Textiles. 2016:1-31 
[52] Ferrero F, Periolatto M. Modification of surface energy and wetting of textile fibers. In: Wetting and Wettability. Chapter 6. London, UK: InTechopen; 2015:139-168

[53] Sood M, Dwivedi G. Effect of fiber treatment on flexural properties of natural fiber reinforced composites: A review. Egyptian Journal of Petroleum. 2017

[54] Huda MS, Drzal LT, Ray D, Mohanty AK, Mishra M. Natural-Fiber Composites in the Automotive Sector. In Properties and Performance of Natural-Fibre Composites. Oxford, UK: Woodhead Publishing; 2008

[55] Witayakran S, Smitthipong W, Wangpradid R, Chollakup R, Clouston PL. Natural fiber composites: Review of recent automotive trends. In: Reference Module in Materials Science and Materials Engineering. Amherst, MA, USA: Elsevier Publishing; 2017

[56] Food and Agriculture Organization of the United Nations. Unlocking the Commercial Potential of Natural Fibres. Rome, Italy: Food and Agriculture Organization of the United Nations; 2012

[57] Holbery J, Houston D. Naturalfiber-reinforced polymer composites in automotive applications. Journal of Metals. 2006;58:80-86

[58] Ramdhonee A, Jeetah P. Production of wrapping paper from banana fibres. Journal of Environmental Chemical Engineering. 2017

[59] Food and Agriculture Organization of the United Nations. Common fund for commodities. In: Proceedings of the Symposium on Natural Fibres, Rome, Italy. 2008

[60] Azizi Samir AF, Dufresne A. Review of recent research into cellulosic whiskers, their properties and their application in nanocomposite field.

Biomacromolecules. 2005;6(2):612-626

[61] Simon J, Muller HP, Koch R, Muller V. Thermoplastic and biodegradable polymers of cellulose. Polymer Degradation and Stability. 1998;59:107-115

[62] Aulin C. Novel Oil Resistant Cellulosic Materials (pulp and Paper Technology). Stockholm, Sweden, KTH Chemical Science and Engineering; 2009

[63] Siqueira G, Bras J, Dufresne A.

Cellulosic bio nanocomposites: A review of preparation, properties and applications. Polymer. 2010; 2(4):728-765

[64] Habibi Y, Lucia LA, Rojas OJ. Cellulose nanocrystals: Chemistry, selfassembly, and applications. Chemical Reviews. 2010;110(6):3479-3500

[65] Nathalie L, Isabelle D, Alain D, Julien B. Microfibrillated cellulose-Its barrier properties and applications in cellulosic materials: A review. Carbohydrate Polymers. 2012;90:735-764

[66] Stelte W, Sanadi AR. Preparation and characterization of cellulose nanofibers from two commercial hardwood and softwood pulps. Industrial and Engineering Chemistry Research. 2009;48:11211-11219

[67] Nair SS, Zhu JY, Deng Y, Ragauskas AJ. Hydrogels prepared from cross-linked nanofibrillated cellulose. ACS Sustainable Chemistry \& Engineering. 2014;2:772-780

[68] Hoeger IC, Nair SS, Ragauskas AJ, Deng Y, Rojas OJ, Zhu JY. Mechanical deconstruction of lignocellulose cell walls and their enzymatic saccharification. Cellulose. 2013;20:807-818 
[69] Syverud K, Stenius P. Strength and barrier properties of MFC films. Cellulose. 2009;16:75-85

[70] Syverud K, Stenius P. Strength and barrier properties of MFC films. Cellulose. 2009;17:15-25

[71] Platt D. The Future of Specialty Films: Market Forecasts to 2018. Smithers Pira; 2013

[72] Kumar V, Bollström R, Yang A, Chen Q, Chen G, Salminen P, et al. Comparison of nano- and microfibrillated cellulose films. Cellulose. 2014;21(5):3443-3456

[73] Rodionova G, Lenes M, Eriksen O, Gregersen O. Surface chemical modification of microfibrillated cellulose: Improvement of barrier properties for packaging applications. Cellulose. 2011;18:127-134

[74] Saxena A, Elder TJ, Kenvin J, Ragauskas AJ. High oxygen nanocomposite barrier films based on xylan and nanocrystalline cellulose. Nano-Micro Letters. 2010;2:235-241

[75] Fortunati E, Peltzer M, Armentano I, Torre L, Jimenez A, Kenny JM. Effects of modified cellulose nanocrystals on the barrier and migration of PLA nano-composites. Carbohydrate Polymers. 2012;90:948-956

[76] Fortunati E, Peltzer M, Armentano I, Jimenez A, Kenny JM. Combined effects of cellulose nanocrystals and silver nanoparticles on the barrier and migration properties of PLA nano-biocomposites. Journal of Food Engineering. 2013;118:117-124

[77] Shalwan A, Yousif BF. In state of art: Mechanical and tribological behaviour of polymeric composites based on natural fibers. Materials and Design. 2013;48:14-24
[78] Shinoj S, Visvanathan R, Panigrahi S, Kochubabu M. Oil palm fiber (OPF) and its composites: A review. Industrial Crops and Products. 2011;33:7-22

[79] Benezet JC, StanojlovicDavidovic A, Bergeret A, Ferry L, Crespy A. Mechanical and physical properties of expanded starch, reinforced by natural fibres. Industrial Crops and Products. 2012;37(1):435-440

[80] Kakroodi AR, Cheng S, Sain M, Asiri A. Mechanical, thermal, and morphological properties of nanocomposites based on polyvinyl alcohol and cellulose nanofiber from Aloe vera rind. Journal of Nanomaterials. 2014

[81] Babaei I, Madanipour M, Farsi M, Farajpoor A. Physical and mechanical properties of foamed HDPE/wheat straw flour/nanoclay hybrid composite. Composites Part B: Engineering. 2014;56:163-170

[82] Idicula M, Boudenne A, Umadevi L, Ibos L, Candau Y, Thomas S. Thermophysical properties of natural fiber reinforced polyester composites. Composites Science and Technology. 2006;66(15):2719-2725

[83] Chensong D, Davies IJ. Flexural properties of wheat straw reinforced polyester composites. American Journal of Materials Science. 2011;1(2):71-75

[84] Weyenberg VDI, Ivens J, De Coster DA, Kino B, Baetens E, Verpoest I. Influence of processing and chemical treatment of flax fibres on their composites. Composites Science and Technology. 2003;63(9):1241-1246

[85] Ramesh S, Kumar CS, Seshagiri SV, Basha KI, Lakshmi H, Rao CGP, et al. Silk filament its pharmaceutical applications. Indian Silk. 2005;44(2):15-19 
[86] Manohar R. Value addition span of silkworm cocoon-time for utility optimization. International Journal of Industrial Entomology. 2008;17(1):109-113

[87] Kumaresan P, Sinha RK, Urs SR. Sericin-a versatile by-product. Indian Silk. 2007;45(12):11-13

[88] Federico S, Maja KL, Isabelle G, Godelieve V, Erik V, Dirk DR, et al. Tensile strength and host response towards silk and type 1 polypropylene implants used for augmentation of facial repair in a rat model. Gynecologic and Obstetric Investigation.

2007;63(3):155-162

[89] Dandin SB, Kumar SN. Bio-medical uses of silk and its derivatives. Indian Silk. 2007;45(9):5-8

[90] Wang Y, Blasioli DJ, Kim HJ, Kim HS, Kaplan DL. Cartilage tissue engineering with silk scaffolds and human articular chondrocytes. Biomaterials. 2006;27(25):4434-4442

[91] Meinel L, Betz O, Fajardo R, Hofmann S, Nazarian A, Cory E, et al. Silk based biomaterials to heal critical sized femur defects. Bone. 2008;39(4):922-931

[92] Makaya K, Terada S, Ohgo K, Asakura T. Comparative study of silk fibroin porous scaffolds derived from salt/water and sucrose/ hexafluoroisopropanol in cartilage formation. Journal of Bioscience and Bioengineering. 2009;108(1):68-75

[93] Sofia S, McCarthy MB, Gronowicz G, Kaplan DL. Functionalized silk-based biomaterials for bone formation. Journal of Biomedical Materials Research. 2001;54(1):139-148

[94] Pravin VD, Viveka DM. Natural fiber reinforced building materials. Journal of Mechanical and Civil Engineering. 2015;12(3):104-107
[95] Jorg M. Industrial Applications of Natural fibers. A John Wiley and Sons Ltd. Publication; 2010. pp. 509-522 



\title{
Surface Modification of Bast-Based Natural Fibers through Environment Friendly Methods
}

\author{
Tayyaba Fatma
}

\begin{abstract}
Nowadays, natural products are extremely preferred among the people. These natural products are produced by environment friendly sources. In case of textiles, bast fibers play significant role in producing natural products that are extracted from the stem of various plant and environment friendly in nature. The bast fibers can also improve the livelihood of the poor farmers who are involved in the cultivation of the plants and extraction and processing of the fibers. Therefore, surface modification of established natural fibers (such as hemp, flax, jute, kenaf, urena, nettle, and ramie) and explored natural fibers are momentous area for doing research. And, these modifications can be done through environment friendly methods such as plasma treatment, and utilization of enzymes, bacteria, and fungi.
\end{abstract}

Keywords: natural fibers, surface modification, environment friendly methods, physical and mechanical properties of fibers

\section{Introduction}

At global level, $58 \%$ of synthetic fibers is used in clothing in which $77 \%$ polyester, $9 \%$ nylon, $6 \%$ acrylic, and $7 \%$ cellulosic fibers take place. Hence, the utilization of synthetic fibers is higher as compared to natural fibers. The synthetic fibers are generally made from polymers that have been synthetically produced from chemical compounds, which create lot of air, land, and water pollutions. These synthetic fibers are more harmful for health of the human being as well as environment because these cannot easily degrade after its use.

To overcome health-related problems and also for environmental safety, people are gradually attracted toward more and more use of natural products in both developed and developing countries. Thus, increasing concerns toward natural products have led to the search for ecological safe, biodegradable, and recyclable characters in their production. Though in case of textiles, production of natural products from natural fibers play a significant role. Natural fibers obtained from natural resources are one of the proficient fibers that replace the synthetic fibers. Numerous natural fibers such as cotton, wool, silk, and jute are used at commercial level and established as the conventional fibers. Apart from these fibers, some other plant-based natural fibers are also used that are introduced as bio-fibers or vegetable fibers.

The utility of vegetable fibers for preparation of textiles started prior to recorded history. Since the dawn of history to present day, the world is being endowed with 
an abundant availability of vegetable fibers such as flax, jute, hemp, ramie, kenaf, urena, nettle, coir, sisal, pineapple, bamboo, and banana.

Globally, cotton is the leading natural fiber which is produced 25 million tons. It is an estimated average production of cotton. Wool and silk fibers are produced around 2.20 and 0.10 million tons per year, respectively. Other vegetable fibers including jute, flax, kenaf, coir, sisal, ramie, hemp, abaca, kapok, and henequen are produced in considerably 4.61 million tons $[1,2]$. On the basis of morphological classification, vegetable fibers are categorized into several sub-categories such as bast fibers, leaf fibers, and seed fibers.

\section{Bast fibers introduced as a natural fiber}

The bast fibers are usually very long and relatively strong. For this reason, the bast fiber is considered to be the most important fraction of any plant [3].

The bast fibers are referred to as "soft" fibers, which are obtained from the stems of plants. Generally, the stem of fiber-yielding plant consists of bark layer, bast layer, and stem core. The bark layer is the outermost thin skin, that is, cuticle of stem that holds the bast fibers and protects the whole stem. The bast layer occurs between the bark layer and stem core, which is introduced as a fibrous layer of plant. The stem core has two parts, that is, woody tissue (xylem) and pith (Figure 1).

The fibrous layers are introduced as forms of primary and secondary fiber layers, which run parallel to the stem of dicotyledonous plants between the nodes. These fiber layers are referred to as bast or phloem or soft fibers, and their bundles vary from stem to stem and in different parts of the stem. There may be as few as 15 bundles to 35 or greater than 35. Each fiber bundle contains 10-40 individual fiber cells that are pointed. The number of cells in the bundle depends on the position of bundle in the stem, which means the largest number being found at the middle of the stem. The size of ultimate fiber cells also varies according to their position in the stem, which means the cells at the bottom of the stem being about three times as thick and longer as those at the top of the stem.

The molecular structure of bast fibers is formed by chains of cellulose molecules and an amorphous matrix of hemicellulose, lignin, pectin, and other substances in a single fiber unit. Therefore, all bast fibers are cellulosic in nature $[4,5]$. The large

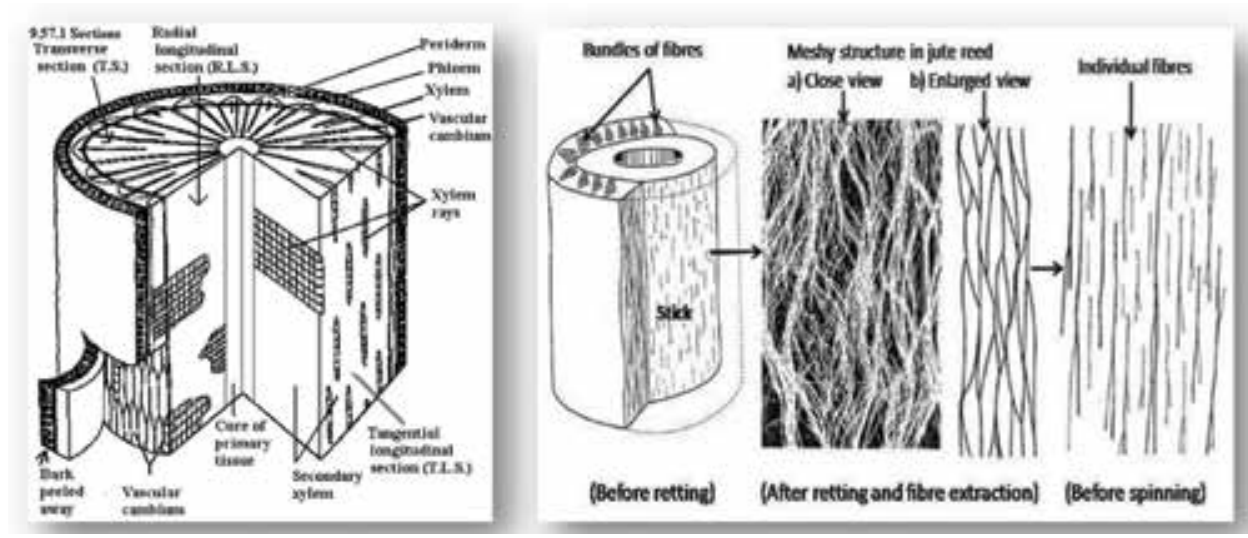

Figure 1.

Microscopic view (cross sectional and longitudinal) of bast fibers. Source: https://textilestudycenter.com/jutefibre-properties-and-end-uses/ [Accessed: 09-02-2019]. 
Surface Modification of Bast-Based Natural Fibers through Environment Friendly Methods DOI: http://dx.doi.org/10.5772/intechopen.85693

\begin{tabular}{|c|c|c|c|}
\hline S. no. & Order & Family & Botanical name (genus and species) \\
\hline 1 & Asterales & Compositae & Eupatorium cannabinum \\
\hline 2 & Gentianales & Apocynaceae & $\begin{array}{l}\text { Apocynum cannabinum, A. venetum, Chonemorpha } \\
\text { macrophylla }\end{array}$ \\
\hline 3 & & Asclepiadaceae & $\begin{array}{l}\text { Asclepias syriaca, } \text { A. fruticosa and } A \text {. incarnate } \\
\text { Calotropis gigantea } \\
\text { Cryptostegia grandiflora } \\
\text { Marsdenia tenacissima }\end{array}$ \\
\hline \multirow[t]{2}{*}{4} & Geraniales & Euphorbiaceae & Euphorbia gregaria and E. gummifera \\
\hline & & Linaceae & Linum angustifolium and L. usitatissimum \\
\hline 5 & Laminales & Labiatae & Phlomis lychnitis \\
\hline 6 & Loasales & Datiscaceae & Datisca cannabina \\
\hline \multirow[t]{5}{*}{7} & Malvales & Malvaceae & $\begin{array}{l}\text { Abutilon angulatum, A. indicum, A. bedfordianum, } \\
\text { A. incanum, A. graveolens } \\
\text { Adansonia digitata } \\
\text { Hibiscus abelmoschus, H. cannabinus, and H. furcatus } \\
\text { Lavatera arborea and L. maritime } \\
\text { Malachra capitata and M. radiate } \\
\text { Pavonia velutina and P. schimperiana } \\
\text { Paritium elatus } \\
\text { Plagianthus betulinus and P. pulchellus } \\
\text { Pseudabutilon spicatum } \\
\text { Sida acuta and S. cordifolia } \\
\text { Sphaeralcea umbellata } \\
\text { Thespesia macrophylla and T. populnea } \\
\text { Urena lobata and U. sinuate }\end{array}$ \\
\hline & & Moraceae & $\begin{array}{l}\text { Artocarpus elastic } \\
\text { Broussonetia papyrifera } \\
\text { Cannabis sativa } \\
\text { Ficus benghalensis and F. nekbudu }\end{array}$ \\
\hline & & Sterculiaceae & $\begin{array}{l}\text { Abroma augusta } \\
\text { Commersonia fraseri and C. echinata } \\
\text { Dombeya buettneri and D. cannabina } \\
\text { California fremontia } \\
\text { Helicteres isora and H. viscid } \\
\text { Sterculia acerifolia, S. diversifolia, S. lurida and S. villosa }\end{array}$ \\
\hline & & Tiliaceae & $\begin{array}{l}\text { Cephalonema polyandrum } \\
\text { Corchorus acutangulus (syn. fuscus), C. aestuans, } \\
\text { C. capsularis, C. hirsutus, C. olitorius, and C. siliquosus } \\
\text { Grewia occidentalis and G. oppositifolia } \\
\text { Honckenya ficifolia } \\
\text { Sparmannia africana } \\
\text { Tilia americana, T. europaea and T. japonica } \\
\text { Triumfetta cordifolia, T. pentandra (syn neglecta), } \\
\text { T. semitriloba, T. bartramia and T. rhomboidea }\end{array}$ \\
\hline & & Urticaceae & $\begin{array}{l}\text { Boehmeria cylindrical, B. nivea, and B. tenacissima } \\
\text { Debregeasia hypoleuca } \\
\text { Girardinia palmata } \\
\text { Laportea gigas } \\
\text { Maoutia puya } \\
\text { Pouzolzia hypoleuca and P. viminea } \\
\text { Sarcochlamys pulcherrima } \\
\text { Touchardia latifolia } \\
\text { Urtica dioica, U. urens and U. pilulifera } \\
\text { Villebrunea integrifolia and V.rubescens }\end{array}$ \\
\hline
\end{tabular}




\begin{tabular}{|c|c|c|c|}
\hline S. no. & Order & Family & Botanical name (genus and species) \\
\hline \multirow[t]{2}{*}{8} & Myrtales & Onagraceae & Epilobium angustifolium and E. hirsutum \\
\hline & & Lecythidaceae & Couratari tauari \\
\hline 9 & Polygalales & Polygalaceae & Securidaca longipedunculata \\
\hline 10 & Rosales & Leguminosae & $\begin{array}{l}\text { Acacia leucophloea } \\
\text { Bauhinia racemosa and B. vahli } \\
\text { Brachystegia spicaeformis and B. tamarindoides } \\
\text { Crotalaria juncea (syn. tenuifolia) } \\
\text { Cytisus scoparius } \\
\text { Pueraria thunbergiana and P. phaseoloides } \\
\text { Sesbania exaltata } \\
\text { Lonchocarpus sericeus } \\
\text { Spartium junceum } \\
\text { Vigna sinensis } \\
\text { Wisteria floribunda }\end{array}$ \\
\hline 11 & Sapindales & Anacardiaceae & Rhus typhina \\
\hline 12 & Thymelaeales & Thymelaeaceae & $\begin{array}{l}\text { Aquilaria agallocha and A. malaccensis } \\
\text { Daphnopsis guacacoa and D. occidentalis } \\
\text { Dirca palustris } \\
\text { Lagetta lintearia }\end{array}$ \\
\hline
\end{tabular}

Sources: Mauersberger, Herbert R. Mathew's Textile Fibers: Their Physical, Microscopic and Chemical Properties. 6th ed. New York: John Wiley \& Sons, Inc. and Landon, Chapman and Hall Limited; 1954.

Table 1.

List of potential plant sources of bast fibers.

number of plants included in the bast fiber group, which represents in relation to the number that are cultivated and processed on a commercial scale. This group is a very rich potential supply in the field of textiles fibers (Table 1).

\section{Background information}

The history of bast fibers is not clearly defined. But the several evidences indicate that the bast fibers were used by prehistoric people. The ancient people started their nomadic life by using plant materials for covering and protecting their body, thatched leaf for shelter, and mats for household and other day to day activities. So, the bast fibers were specially cultivated by people to fulfill their needs.

Fragments of linen fabric have been found in excavations at the prehistoric lake regions of Switzerland, which date back to about 10,000 B.C. [6]. The actual samples of woven linen fabric have been recovered from Egyptian tombs dating from 4000 B.C. [7]. The early cultivation of kenaf fiber goes back to 4000 B.C. in West Africa [8]. Ramie has been cultivated for hundreds of years in China, Taiwan and to some extent in Egypt [6]. Hemp is the oldest fiber giving plant, which originated in Southeast Asia and spread to China. The cultivation date of hemp reports back to about 4500 B.C. In 3400 B.C., the skill of spinning and weaving of linen fabric was also well developed in Egypt that indicates the flax was cultivated sometime before that date. According to historical interest, the best known bast fibers include hemp, flax, jute, and ramie and minor fibers are kenaf, urena, and nettle [7].

\section{Physico-chemical properties of bast fibers}

To evaluate the quality of natural fibers, the fiber length and fineness are two important dimensions which are considered. The length of fiber must be several 
hundred times to the width, which enables fibers to be twisted together to form a yarn or thread. The length of fiber can be infinitely long but it should not be shorter than $6-12 \mathrm{~mm}(1 / 4-1 / 2$ inch) because it may not hold together for spinning. The width of the fiber can vary between considerable limits. The natural fibers vary in fineness from place to place on an individual fiber.

In addition, the fiber must be strong and flexible. Strength is needed to enable the spinning and weaving processes and to provide strength in the final cloth. Flexibility gives draping to a textile due to its unique characteristics. Many experts consider a single fiber strength of $5.0 \mathrm{~g} / \mathrm{D}$ to be necessary for a fiber suitable in most textile applications, although certain fibers with strengths as low as $1.0 \mathrm{~g} / \mathrm{D}$ have been found suitable for few applications. The elasticity is an important because the individual fibers in textiles are often subjected to sudden stresses, and the textile must be able to give and recover without significant overall deformation of the textile.

The density of a fiber is related to its inherent chemical structure and the packing of the molecular chains within its structure. The density of a fiber will have a noticeable effect on its esthetic appeal and its usefulness in given applications. Fiber density may be used as an aid in fiber identification [9-12].

The cross-sectional shape is important in luster, bulk, body, texture, and hand or feel of a fabric. The cross-sectional shape may be round, dog-bone, triangular, lobal, bean-shaped, flat, or straw like. The natural fibers derive their shape from the way by which the cellulose is built up during plant growth [13].

The estimation of chemical composition is needed for better understanding regarding the nature of fiber and for making different value-added products. The main constituent of the vegetable fiber cell is cellulose and represented by the general formula $\mathrm{C}_{6} \mathrm{H}_{10} \mathrm{O}_{5}$. Apart from cellulose, vegetable fibers also contain significant amounts of other chemicals such as hemicellulose, lignin, pectin, resin, mineral matter, fats, and waxes $[14,15]$.

Traditionally, bast fibers were used for making carpets, hessian or burlap, sacks, brooms, and wrapping purposes.

Now-a-days, representative of various industries and research institutes are producing range of textile and non-textile products in different fields such as automotive, packaging, horticulture, building, and construction. The bast fibers are suitable in building and construction as a form of geo-textiles, fiber board materials, insulation materials, reinforcement, filler, light-weight concrete, and bricks. High quality thermoplastic and thermosetting composite materials such as door panels, dashboards, seat backs, package trays, headliners and boot liners are produced with the help of bast fibers in automotive. Automotive and aircrafts industries have been actively developing different kinds of natural fibers, mainly on hemp, flax, and sisal and bio-resin systems for their interior components. High specific properties with lower prices of natural fiber composites are making it attractive for various applications.

The bast fibers are also used to produce non-woven fibers that are applied in various forms and products such as tissues and hygienic products, sorbents in diapers and disposables, insulation mat, filling material in mattresses, and geo-textiles. Biodegradable pots for plants, mulching materials, packing cloth for agriculture products, ship towing ropes, tea bags, currency notes, thermal under wears, stationeries, reusable containers, laboratory equipment, and loudspeakers are also manufactured by bast fibers. Therefore, it may face a renaissance, not only for old industrial products but also for the manufacturing of new type of products in the various fields such as technical textiles, industrial products, paper, and building materials [16-20].

Current annual requirement of jute, kenaf, and allied fibers distribute in various sectors such as food grade jute bags, packing materials, family need jute bags, jute 
geo-textiles, and automobiles. It provides work for more than 12 million of farmers, 1 million of industrial workers, and 0.6 million of jute artisans in more than 18 countries from Asia and Africa directly or indirectly.

The bast fibers have played a significant role for both consumer and manufacturer. Through dyes and finishes, the manufacturer can enhance the appeal and functionality of bast fibers, which ultimately increases the demand and sale of their end products. The bast fibers are also an important for consumers in term of wide range of value-added natural products. Apart from this, bast fibers can improve livelihood of the poor farmers who are involved in the cultivation of the plants, extraction, and processing of the fibers, which play a very important part for their economic life [21].

\section{Advantages and drawbacks of bast fibers}

The bast fibers have various properties such as comparable specific strength, heat, electrical, and sound insulating properties, good moisture absorbency, air permeability, comfort, low density, low energy requirement, lower pollutant emission, wide availability, better reactivity, and biodegradability. All these properties of the bast fibers are strongly influenced with various factors such as chemical composition, internal fiber structure, micro-fibril angle, and cell dimensions. These factors differ from plant to plant as well as from different parts of a plant. The properties of the bast fibers (cellulosic fibers) also depend on their type of cellulose, because each type of cellulose has its own crystalline organization. Due to their properties, the bast fibers cover a wide range of application from apparel and household fabrics to industrial materials.

One of the most important properties of bast fibers is their eco-friendly nature. Bast fibers are more environment-friendly in term of production and disposal of their products. So, we can say that the bast fibers have been introduced as an emerging "green" economy.

Few drawbacks of bast fibers are also available such as high moisture absorption, poor dimension stability, low thermal stability, low hygroscopicity, low surface energy, and rough structure along with high impurities content in bast fibers. Despite the drawbacks of bast fibers, they have been successfully used in certain applications in the field of insulation, composite, and geotextiles. But these drawbacks inhibit the growth of its applications [22].

However, to increase their applications and achieve better interface of bast fibers, the appropriate environment friendly surface modification methods can be utilize instead of physical and chemical methods for surface modification $[1,23-25]$.

\section{Environment friendly methods for surface modification}

Surface modification may be defined as the treatment to modify the surface of materials using physical, chemical, and biological methods for improving their properties [26].

By keeping the point in mind, world has also turned its attention to renewable and sustainable resources or environmental sustainability. Therefore, environment friendly methods for surface modification of bast fibers can be utilized. These methods introduced as green surface methods indicate to environment friendly processes, which are as follows: 


\subsection{Plasma treatment}

Plasma treatment is introduced as a novel dry technique that significantly decreases toxic pollutant in the environment. This technique is suitable to modify the chemical structure along with topography of the surface of the bast fibers.

Basically, plasma is a type of ionized gas consisting of electrons $(0-10 \mathrm{eV})$, ions (10-30 eV), photons, atoms, and molecules and is called as the fourth state of matter. Free electrons, photons, and ion clouds begin to be formed, and some atoms continue to remain neutral and the mixture of atoms, ions, and electrons form the plasma. Two different types of plasma are available for industrial purposes:

i. Thermal plasma: formed direct or alternating current or radio-frequency (RF) or microwave sources at high pressure.

ii. Cold or non-equilibrium plasma: specified by an electron temperature higher than the ion temperature.

The basic function of plasma is to exploit surface of a material by using different type gases. After treatment, reactive free radicals and groups are produced, surface energy is increased or decreased and surface crosslinking are introduced [27-29]. There are two types of interactions which are present on the surface of fibers in the case of plasma treatment.

i. Application of non-polymerizing gases such as helium, oxygen, air, and nitrogen, which creates chain scission on the surface that results in surface etching, cleaning, or activation.

ii. Application of polymerizing gases and precursors such as fluorocarbons, hydrocarbons, and silicon containing monomers, which creates plasmainduced polymerization or grafting.

\subsubsection{Mechanism}

In the mechanism of plasma treatment, energetic particles and photons generate on the surface of fibers and interact strongly with other substrates by using freeradicals, though various types of changes occur like changes in physical and chemical properties along with changes in the chemical structure of polymers. These changes become due to cleaning, ablation or etching, cross-linking, and grafting modification of surface chemical structure. All these processes, alone or in synergistic combination, improve the functionality of fibers [27].

\subsection{Treatment with bacteria}

Bacterial cellulose (unlike from the plant cellulose) is natural renewable polymer, synthesized from the bacteria in appropriate culture medium. Certain bacteria which belong to the genera such as Acetobacter, Agrobacterium, Alcaligenes, Pseudomonas, Rhizobium, or Sarcina are used for treatment of plant cellulosic materials. And, the most efficient bacteria for production of bacterial cellulose are Acetobacter xylinum. After treatment, the bacterial cellulose is endowed with unique properties such as high crystallinity index, high tensile strength, good chemical stability, and high water-holding capacity. Due to these properties, it is emerging as a biomaterial that has superior structural aspect to the plant cellulose. 


\subsubsection{Mechanism}

In the optimum culture medium, the bacteria produces about $50-80$ cellulose microfibrils ranging from 3.0 to $3.5 \mathrm{~mm}$ thickness, which are free from lignin, hemicellulose, and other substances [30].

\subsection{Treatment with nanocellulose}

Nanocellulose is defined as nanosized cellulose fibril that is a light solid substance obtained from plant resources. It is a pseudo-plastic in nature and also available as a fluids or gels form in standard conditions. The cross dimensions of nanocellulose are starting from 5 to $20 \mathrm{~nm}$, and the longitudinal dimension ranges from a few tens of nanometers to several microns.

The specific properties of nanocellulose are light weight, high strength, and transparency. Hence, this nanocellulose is applicable in a wide variety of areas. Nanocellulose is commonly produced from wood pulp of any plant sources by using mechanical shearing methods such as pulverisette and cryo-crushing or combination of chemical and mechanical method.

\subsubsection{Mechanism}

Application of nanocellulosic is performed on the surface of bast fibers for enhancing their properties [31,32].

\subsection{Fungal treatment}

This treatment ultimately increases the interfacial adhesion between fiber and matrix. Fungal treatment is done by the sterilization of bast fibers at $121.8^{\circ} \mathrm{C}$ for $15 \mathrm{~min}$. Subsequently, the fibers treated with incubated culture of fungi for 2 weeks at $27.8^{\circ} \mathrm{C}$. And then, the fibers were washed and dried. The species of fungi used were Phanerochaete sordida (D2B), Pycnoporus species (Pyc), and Schizophyllum commune (S. com) of the basidiomycetes group, Ophiostoma floccosum (F13) of the ascomycetes group, and Absidia (B101), a zygomycete. Fungal treatment gave higher crystallinity index as compared to the untreated fibers. Fungi treatment can provide low cost, highly efficient, and environmentally friendly alternatives to surface treatment of bast fibers.

\subsubsection{Mechanism}

Fungal treatment causes the formation of holes (pits) on the surface of fibers, which creates roughness on the surface of fibers by removing the lignin content and increasing the solubility of hemicellulose content.

\subsection{Enzymatic treatment}

Bio-grafting through enzymes is a comparatively novel modification method that includes grafting of organic molecules onto bast fibers. The purpose of biografting is to enhance the performance of bast fibers by improving the properties such as strength and stiffness, hydrophobicity, assistance to moisture, and microbial attack. Various enzymes such as laccases, lipases, and peroxidases are used surface functionalization of bast fibers. 


\subsubsection{Mechanism}

The enzymes can oxidize in extensive range of natural polymers and generate reactive species such as phenoxy radicals, thereby increasing the reactivity of polymers [2].

\section{Analysis of bast fibers}

The molecular and morphological structure of bast fibers (before and after treatment) is analyzed by using the following:

1. SEM analysis: the SEM constitutes one of the oldest and most widely used instruments for surface analysis. It provides a three-dimensional visual image, and thus, the quantitative analysis is relatively straight forward [33].

2. FTIR analysis: it is another technique to examine the nature of molecular chains, crystallinity as a form of high crystallinity index, and their correlations with various bonds [34].

\section{Future prospective}

Lot of researches may be conducted at various levels such as production and extraction of plasma, bacterial cellulose, nanocellulose, fungi, and enzymes from natural resources, way of application on the surface of bast fibers and other related fibers, and defining its end products.

Development of new bio-composite materials with added functional properties such as in active and smart packaging system has created further scope for expansion of materials technology. Much research is expected for such biodegradable nano-composite materials to replace or reduce the use of the existing petro-based products. Another new approach is GM modification toward higher productivity, better quality, and higher application areas of natural bast fiber [35].

\section{Conclusion}

It can be concluded that these environment friendly methods are green approaches for modifying the surface of bast fibers. Through these methods, drawback of bast fibers can be improved and also the demand for application of bast fiber at commercial level can be increased. So, we can say that it is green concept-based approach toward sustainability of natural resources as a form of surface modified bast fibers. 


\section{Author details}

Tayyaba Fatma

Department of Clothing and Textiles, College of Home Science, G.B.P.U.A. and T., Pantnagar, Uttarakhand, India

*Address all correspondence to: tfansari.ct@gmail.com

\section{IntechOpen}

(C) 2019 The Author(s). Licensee IntechOpen. This chapter is distributed under the terms of the Creative Commons Attribution License (http://creativecommons.org/licenses/ by/3.0), which permits unrestricted use, distribution, and reproduction in any medium, provided the original work is properly cited. (cc) BY 


\section{References}

[1] Gopalakrishnan D. Reviews on Perception of Sustainable Green Consumption Practicesand it's Impact on Greener Lifestyles [Internet]. Available from: http:// www.academia.edu/34432113/ reviews_on_perception_of_sustainable_ green_consumption_practices_and_its_ impact_on_greener_lifestyles [Accessed: 06-02-2019]

[2] India. Ministry of Textiles

(Government of India) on other Natural Fibres: Section VI [Internet]. Available from: http://texmin.nic.in/policy/ Fibre_Policy_Sub_\%20Groups_Report_ dir_mg_d_20100608_6.pdf [Accessed: 03-07-2015]

[3] Tahir PM, Ahmad AB, Saiful A, Sayeed OA, Ahmad Z. Review of bast fibre retting. BioResources. 2011;6(4):5260-5281

[4] Klaus F, Breuer Ulf.

Multifunctionality of Polymer Composites: Challenges and New Solution. William Andrew Applied Science [Internet]. 2015. Available from: https://www.sciencedirect.com/science/ article/pii/B9780323264341000040?via \%3Dihub [Assessed: 01-02-2019]

[5] NIIR Board of Consultants \& Engineers. Natural Fibres: Handbook with Cultivation \& Uses. Delhi: National Institute of Industrial Research; 2006

[6] Joseph ML. Introductory Textile Science. 5th ed. New York: Holt, Rinehart and Winston; 1986

[7] Tortora PG. Understanding Textiles. New York: Macmillan Publishing Co. Inc.; 1982

[8] Chen JY, Liu F. Bast Fibres: From plants to products. In: Singh BP, editor. Industrial Crops and Uses. UK: CAB International; 2010
[9] Angappan P, Gopalakrishnan R. Textile Testing. Komarapalayam: S.S.M. Institute of Textile Technology; 2002

[10] Cook JG. Handbook of Textiles Fibers: Natural Fibres. Cambridge England: Woodhead Publishing Limited; 2005

[11] Labarthe J. Textiles: Origins to Usage. London: The Macmillian Company \& Collier Macmillian Limited; 1969

[12] Needles HL. Textile Fibers, Dyes, Finishes, and Processes. Park Ridge, New Jersey, U.S.A.: Noyes Publication; 1986

[13] Hollen N, Saddler J. Textiles. 3rd ed. London: The Macmillan Company/ Collier Macmillan Limited; 1968

[14] Kirby RH. Vegetable Fibres: Botany, Cultivation and Utilization. Londaon: Leonard Hill [Books] Limited and New York, Interscience Publishers, Inc.; 1963. p. 9

[15] Pan NC, Day A, Mahalanabis KK. Chemical composition of jute and its estimation. Man-Made Textiles in India. 1999;42:467-473

[16] Kholiya R, Goel A, Kholiya

D. Unconventional fibre plants: A source of sustainable livelihood. International Journal of Science Technology \& Management. 2011;2(1):27-35

[17] Marques G, Rencoret J, Gutiérrez A, del Río JC. Evaluation of the chemical composition of different non-Woody Plant Fibres used for pulp and paper manufacturing. The Open Agriculture Journal. 2010;4:93-101

[18] Mitra BC. Commercial Fibre Crops and their Utilisation. New Delhi: Directorate of Information and Publication of Agriculture; 2008 
[19] Mohanty AK, Misra M, Drzal LT. Surface modifications of natural fibres and performance of resulting biocomposites: An overview. Composite Interfaces. 2001;8(5):313-343

[20] Sanjay MR, Arpitha GR, Naik LL, Gopalakrishna K, Yogesha B.

Applications of natural Fibres and its composites: An overview. Natural Resources. 2016;7:108-114. DOI: 10.4236/nr.2016.73011. [Assessed: 01-02-2019]

[21] International Jute Study Group. Report on World Jute \& Kenaf Statistics: At a Glance (Jute, Kenaf other Bast and Hard Fibres: Farm to Fashion). Dhaka, Bangladesh [Internet]. 2012. Available from: http://jute.org/IJSG\%20 Publications/Jute\%20\&\%20kenaf\%20 Stat\%20at\%20a\%20glance_ijsg.pdf [Accessed: 13-07-2015]

[22] Sadrmanesh V, Chen Y. Bast fibres: Structure, processing, properties, and applications. International Materials Reviews. 2019;64(7):381-406. DOI: 10.1080/09506608.2018.1501171

[23] Kalia S, Vashishta S. Surface modification of sisal fibres (Agave sisalana) using bacterial cellulose and methyl methacrylate. Journal of Polymers and the Environment. 2012;20:142-152

[24] Kalia S, Thakur K, Celli A, Kiechel MA, Schauer CL. Surface medication of plant fibres using environment friendly methods for their application in polymer composites, textile industry and antimicrobial activities: A review. Journal of Environmental Chemical Engineering. 2013;1:97-112

[25] Khoshnava SM, Rostami R, Ismai $\mathrm{M}$, Valipour A. The using fungi treatment as green and environmentally process for surface modification of natural Fibres. Applied Mechanics and Materials. 2014;554:116-122
[26] Khan A, Bhawani SA, Asiri AM, Khan I. Thermoset Composites: Preparation, Properties and Applications. Material Research Forum LLC: Millersville, PA; 2018

[27] Senthilkumar P. Surface modification of bast fibres by plasma treatment. Chemical Fibres International. 2017;67(2):94-95

[28] Shanmugasundaram OL. Application of plasma in textile industries. Textile Asia. 2006;38(5):44

[29] Zille A, Oliveira FR, Souto AP. Plasma treatment in textile industry. Plasma Processes and Polymers. 2014;12(2)

[30] Lustri Wilton R, de Oliveira Barud HG, da Silva Barud H, Peres Maristele FS, Junkal G, Agniezka T, et al. Microbial Cellulose-Biosynthesis Mechanisms and Medical Applications [Internet]. 2015. Available from: https://www.intechopen.com/ books/cellulose-fundamentalaspects-and-current-trends/ microbial-cellulose-biosynthesismechanisms-and-medical-applications [Accessed: 09-12-2015]

[31] Halib N, Perrone F, Cemazar M, Dapas B, Farra R, Abrami M, et al. Potential applications of Nanocellulosecontaining materials in the biomedical field. Materials. 2017;10:977

[32] Jawaid M, Salit MS, Alothman OY. Green Biocomposites: Design and Applications. Green Energy and Technology [Internet]. 2017. Available from: https://books.google.co.in/book s?id=e6gbDgAAQBAJ\&pg=PA280\&lp $\mathrm{g}=\mathrm{PA} 280 \& \mathrm{dq}=$ future + scope + of + envir onment+friendly+surface+modificatio $\mathrm{n}+$ method + for + bast + fibres \& source $=\mathrm{b}$ 1\&ots=N8e5s0pJH2\&sig=ACfU3U2jqM V0KQhMo9cK_3I4XOqGBl2C7w\&hl=e $\mathrm{n} \& \mathrm{sa}=\mathrm{X} \& \mathrm{ved}=2 \mathrm{ahUKEwjD7tX3p6fgA}$ hWJso8KHdVCn8Q6AEwCnoECAcQA $\mathrm{Q} \# \mathrm{v}=$ onepage $\& \mathrm{q}=$ future $\% 20$ scope $\% 20$ 
Surface Modification of Bast-Based Natural Fibers through Environment Friendly Methods DOI: http://dx.doi.org/10.5772/intechopen.85693

of $\% 20$ environment $\% 20$ friendly $\% 20$

surface $\% 20$ modification $\% 20$

method $\% 20$ for $\% 20$ bast $\% 20$

fibres\&f=false [Assessed: 01-02-2019]

[33] Ugbolue SC. Fiber and yarn

identification. In: Fan Q, editor.

Chemical Testing of Textiles. Woodhead

Publishing in Textiles; 2005. pp. 6-7, 14

[34] Bakar NA, Sultan MTH, Azni ME, Hazwan MH, Ariffin AH. Extraction and surface characterization of novel bast fibers extracted from the Pennisetum purpureum plant for composite application. Materials Today: Proceedings. 2018;5(10). (Part 2):21926-21935

[35] Mitra BC. Contemporary environment friendly composite materials: Biocomposites and green Co. Defence Science Journal. 2014;64(3):244-261. DOI: 10.14429/ dsj.64.7323 



\title{
Use of Recycled Cellulose Fibers to Obtain Sustainable Products for Bioeconomy Applications
}

\author{
Petronela Nechita
}

\begin{abstract}
Knowing the negative impact of plastic materials from agriculture sources on the environmental pollution, in this chapter, some of research activities carried on the utilization of secondary cellulose fibers (from recovered papers and boards) and other lignocellulosic materials on obtaining of sustainable composite materials are presented. The aim was to obtain the (bio)composite materials with applications in manufacturing processes of biodegradable nutritive pots used in the production of vegetable seedlings. The tests were developed on a pilot plant designed to obtain the pots from a mixture of secondary cellulose fibers, red peat, and other additives. These materials were characterized in terms of biodegradability and growth and development of tomatoes and lettuce seedlings. For all the compositional versions studied, the specific indicators of seedlings growth and development have recorded values that allow a normal growth of plants similar to the use of plastic pots or biodegradable pots available on the import market.
\end{abstract}

Keywords: biodegradable nutritive pots, cellulose fibers, peat, recovered papers, seedling, biodegradable potential, biodegradable rate, wet strength, dry strength, bioeconomy

\section{Introduction}

In the most technological processes, current trends are geared toward the identification of alternative solutions for the rational use of raw materials by replacing the petroleum-based materials with negative environmental impact with those from renewable resources, biocompatibles, and highly recyclables in order to obtain sustainable products according to the circular economy concept.

The negative impact on the environment of plastic pots used in agriculture has convinced many consumers that this is an unsustainable practice and has determined them to explore and identify the "green" alternatives to obtain the new materials, biodegradable, eventually recyclable and based on renewable resources with low pollution for soils and plants [1,2].

Nowadays, the plastic pots, containers, and trays are widely used in industrial greenhouse and private farms. In 2002, there were 1.678 billion pounds of plastics used in the agricultural sector [3].

After their utilization, these are dumped in landfills where they are very slowly degraded. The total flow of agricultural plastic waste reaches ca. 400,000 tonnes per year, and plastic pots and trays constitute about 16,000 tonnes 
(www.greenfacts.org). In this respect, the biodegradable pots represent a good alternative to plastic materials [4].

Generally, the plastic pots are light, cheap, and durable, and their walls are relatively impermeable. The last feature contributes to reducing the water consumption by the plants cultivated in such pots. Nevertheless, the salts and nutritive elements in their walls are not concentrated, and the recycling of the used plastic pots is still an unsolved problem [5].

Recently, alternative containers based on natural raw materials, impregnated with various components, such as slow-releasing fertilizers, fungicides, insecticides, and plant growth regulators that are released during plant growth, are gaining entry to the market and could enhance the efficiency of the production system. Industry and researchers are continuously working together to develop and fine-tune sustainable alternative containers to suit emerging grower and customer requirements $[6,7]$.

The researches in the field of biodegradable pots are focused into groups:

- biodegradable plastic pots; and

- cellulose fibers pots

The researches in the field of biodegradable plastic materials are very intense and generally are economically stimulated to become alternatives to nondegradable materials [8]. Nevertheless, biocontainers are considerably more expensive and their cost ranges from 10 to $40 \%$, which is more than their plastic counterparts [9]. Furthermore, these are only partially degradable and their degradation products do not exhibit the ecological safety $[10,11,12]$.

In particular case of seedling biodegradable pots, it is required that beside the lack of toxicity, their degradation products should have nutritive properties for plants and contribute to soil quality improvement [13].

In this context, when the reuse and recycling are the first options in the concerns of sustainable management of production processes, cellulose fibers (primary and secondary) are considered to be the raw materials with great availability between the existing vegetal and renewable resources, presenting the important advantages compared with synthetic, inorganic, or mineral fibers.

The use of cellulose fibers has been explosive over the last decades, being directed both to the production of paper products (paper and cardboard) but, more and more as auxiliaries in many economical fields, such as: obtaining of (bio) composite materials with applicability in the construction materials industry, automobiles, aeronautics, electronics, agriculture, etc., medicine, pharmaceutical applications, or the food industry.

Considerable progress has been reported in the development of nano or microfibrilated cellulose with large-scale applications in medicine (cardiovascular implants, prostheses, etc.), and also in the field of biorefinery, the concept and basic process of the future of the cellulose and paper industry, which provides integrated solutions for the complex exploitation of plant biomass for energy production and the extraction of chemicals based on "green chemistry" concept.

The biodegradable pots based on cellulose fibers are composite materials obtained from mixtures of cellulose fibers and peat on wire or vacuum dewatering process using specials molds [14].

The main drawback of these materials is their low strength, especially wet strength. However, the researches in this field are focused on increasing the dry and wet strength without affecting their biodegradation capacity $[15,16]$. 
This chapter highlights the use of cellulose fibers in composite materials with application in agriculture to obtain the biodegradable nutritive pots for seedling manufacturing.

\section{Utilization of cellulose fibers to obtain the biodegradable nutritive pots with applications in the seedlings production}

The cellulose is the most available polymer in nature that can be converted into (bio) composite materials or (bio)chemicals as alternative to petroleum-based products [17].

Among the biodegradable and nutritive pots, the pots based on peat and cellulose fibers are most widely used. They can be either embedded into soil together with plants or digested $[18,19]$. The advantages of using the nutritive pots in the seedling manufacturing process are based on the fact that, comparing with existing plastic pots, these are biodegradable, have good water and air permeability and high ability of plant roots to penetrate the pot walls. Furthermore, these types of pots do not generate the waste after use and their degradation products are adequately fertilizers that contribute to soil bioremediation [20]. In their walls, the nutritional and biostimulative elements can be incorporated. These have an important role for improving the plant prophylaxis.

The other advantages are presented as follows:

- increasing the work productivity in the seedling production by elimination of collecting, selection, storage, cleaning and sterilization stages that exist for the plastic pots;

- reducing the costs for seedlings production-due to the fact that these are planted in soil together with biodegradable pots;

- improving the seedling quality — the walls of biodegradable pots have incorporated all the nutritive elements necessary for growing of plant roots (i.e. cellulose fibers, peat, protective and stimulative additives) and allow water retention and air penetration; these are very important parameters to ensure the oxygen flow;

- reducing the duration of seedling production with about 14-21 days comparing with existing conditions, which contribute to obtain a better production efficiency;

- obtaining $100 \%$ biodegradable fully organic products (cellulose fibers, peat, etc.);

- eliminating recycling and waste management totally—at soil contact, these pots are converted in humus that improves the soil fertility.

The applications of nutritive and biodegradable pots in seedling manufacturing are varied, starting with vegetables and flowers, medicinal plants, ornamental shrubs, or various forest species until the production of vine cuttings [21].

The nutritive biodegradable pots belong to new generation of transplantation media being designed to fulfill the following functions:

- resilient support of seedling for a variable period depending on the cultivated plant; 
- biologically active material that releases nutrients and biostimulators during germination and seedling growth;

- support with a structure that is totally degradated during a life cycle of plants transplanted in soil, and the degradation products must be nontoxic for soil, biodegradable, and can to contribute to soil bioremediation.

Therefore, obtaining biodegradable nutritive pots is based on the principles of sustainable development, considering the entire life cycle of the product [22]:

- utilization of natural raw materials, renewables and recyclables (recycled cellulose fibers, lignocellulosic waste);

- using of additives for strength properties of composite structures, based on natural polymers, biodegradables, and nontoxic;

- all of these additives ensure the adequate level of nutrients for plants growth and their the degradation products of the nutritive and biodegradable pots are good soil fertilizers.

As a result of these aspects and in the context of integration of the horticultural production with other industrial fields (i.e., processing and recycling of cellulosic fibers), the experimental programs were managed to obtain the biodegradable nutritive supports (pots) based on peat and secondary cellulose fibers. These pots were tested with promising results for obtaining tomatoes and lettuce seedlings [23].

\subsection{The composition of biodegradable nutritive pots}

The properties of composite structure are highly influenced by the distribution and interactions between raw materials during wet forming and fibrous network consolidation by pressing and drying.

The mechanical strength properties are most important for a composite structure because indifferently by their use, this must meet specific characteristics such as shape, stiffness, and strength.

The fibrous materials are the main raw material for the biodegradable nutritive pots, having a decisive role to obtain the composite structure with adequate strength properties without compromising their biodegradability.

In this context, the most used fibrous materials are: kraft pulp for achieving the structure strength; secondary cellulose fibers from different types of recycled papers as fine material for forming and reinforcing the structure; peat consisting of vegetal materials, including wood fibers, in different stages of degradation, which gives the structure porosity, absorption, and water retention capacity as well as the nutritional properties.

Therefore, the characteristics of composite material may vary depending on the levels and properties of the fibrous raw materials.

After the analysis of the sources of fibrous materials based on their utilization in the composition of biodegradable and nutritive pots, for our experimental program, the following fibrous components have been identified: secondary cellulose fibers (from recycling of corrugated board boxes) and surface peats.

Based on the laboratory tests performed on the choice of the ratio between fibrous components, a value of 70/30 peat/secondary cellulose fiber ratio was identified as optimal.

This ratio allows obtaining: 
- a product with a proper strength of the support for a variable period depending on the cultivated plant;

- a high content of biologically active material, which releases the nutrients and biostimulators during germination and plant growing;

- a pot with permeable structure for water and oxygen and penetrable by the plant roots, which is completely degradated over a life cycle of plants transplanted in soil.

A content over $80 \%$ peat has as a result decreased the dewatering rate as well as the dry and wet strength of nutritive biodegradable pots.

Regarding the cellulose fiber quality, it is recommended to have a high content of long fiber fraction that ensures a better bonding capacity and reinforcement of the pot structure.

The physical-mechanical properties that are important for seedling pots are bursting and tensile strength (bursting index and breaking length). These properties are recommended to be evaluated in dry and wet state [24]. Another important property is the structure porosity that is determined by air permeability measurement. All these characteristics of composite material were tested on hand sheets $\left(400 \mathrm{~g} / \mathrm{m}^{2}\right)$ obtained in the laboratory by Rapid-Köthen method with different percent of fibrous components (peat and cellulose fibers). The values of dry and wet strength of laboratory hand sheets with different contents of peat are presented in the Figures $\mathbf{1}$ and 2.

It is important to mention that the optimization of these strength parameters is very difficult to obtain only from fibrous composition, because some requirements on resistance indexes are somewhat in opposite; for example, to obtain the composite material as pot shape, high resistance indexes (both for tensile and bursting strength) are necessary; during seedling manufacturing, a high wet strength for composite materials is necessary; after soil transplantation of seedling and pot, a lower bursting strength as the plant roots to easily penetrate the composite material structure is necessary.

The tensile and bursting strength in dry state are influenced by total interfiber bonding energy and fiber length. Therefore, at high grammage, it is difficult to

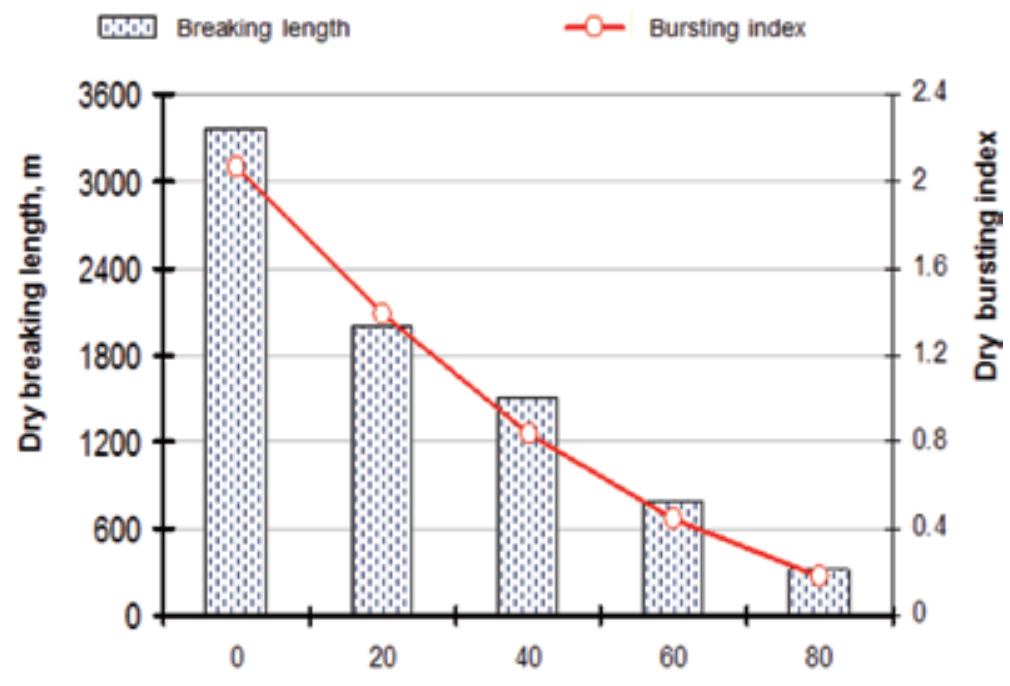

Peat content, \%

Figure 1.

The influence of peat content on dry breaking length and dry bursting index for the laboratory hand sheets of composite material $\left(23^{\circ} \mathrm{C}\right.$ and $\left.50 \% \mathrm{RH}\right)$. 


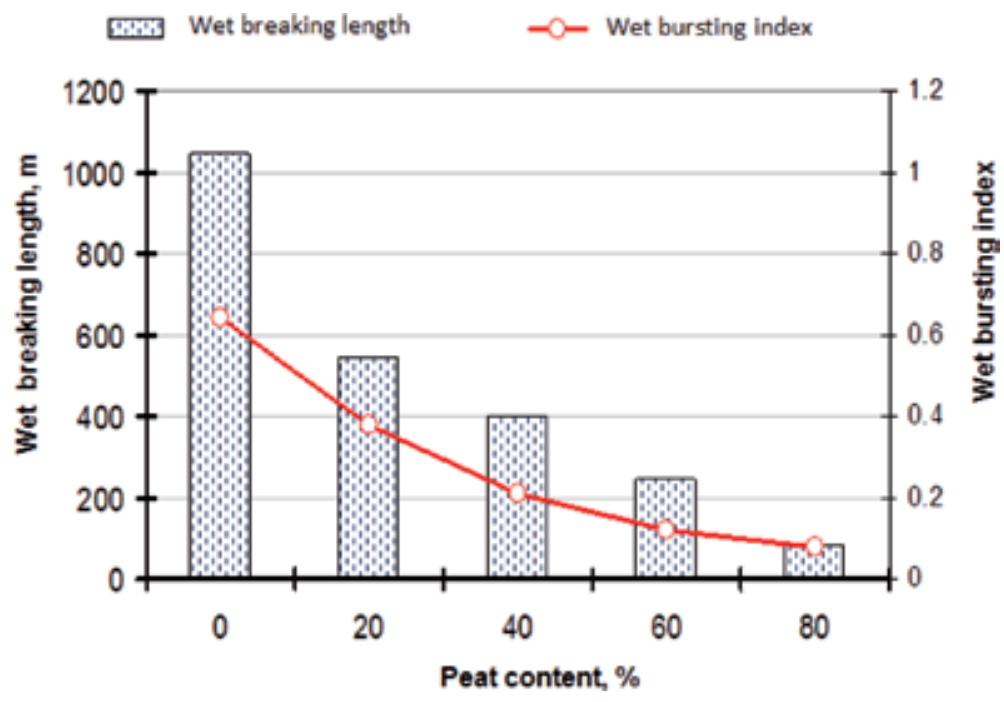

Figure 2.

The influence of peat content on wet breaking length and wet bursting index for laboratory hand sheets of composite material.

obtain a fibrous structure with better breaking length than bursting strength. In this context, the solution is to exploit the fact that long and rigid peat fibers reduce the interfiber bonding energy. This will have a higher impact on the bursting strength that is more influenced by the fibers length (Figures 1 and 2).

The wet strength retention of fibrous composite structures (percent of fraction from dry strength that remains when the structure is saturated with water) is obtained by introducing, in the composite structure, the specific additives that protect the interfiber bonds by blocking the access of water when this is wetted for different durations. The wet strength retention (\%) can be at different levels $(10-40 \%)$, and mechanical wet strength of the composite structure is directly influenced by dry strength and level of wet strength retention [25].

Aiming to obtain the appropriate wet strength retention of composite structure, a polyamide-polyamine-epichlorohydrin (Kymene 611) resin was used in the fibrous composition. This additive has a high efficiency for improving wet strength and a good degradation capacity. Furthermore, this resin, in accordance with environmental safety, is being used in the composition of tissue papers or cellulosic food packaging.

Breaking length and wet strength retention: At different contents of Kymene 611, the dry breaking length increases linearly with resin content (approx. $150 \mathrm{~m} / 1 \%$ ). The optimum content of resin for $40 \%$ value of wet strength retention is between 4 and $6 \%$ (Figure 3 ).

Based on these experiments, the content of Kymene resin was considered as optimum at $6 \%$, when the wet strength retention level is over $35 \%$.

Bursting index and wet strength retention: Dry bursting strength increases linearly with the content of Kymene (approx.10\%/1\%) (Figure 4).

Unlike the wet strength retention reported as breaking length that starts to decrease at $4 \%$ Kymene content, the wet strength retention reported as bursting strength starts to decrease at $6 \%$ Kymene content.

The dry bursting index for the tested samples has a maximum value for $6 \%$ Kymene content. The wet tensile and bursting strength of the composite material are directly influenced by their values in dry state as well as by wet strength retention level. 
Use of Recycled Cellulose Fibers to Obtain Sustainable Products for Bioeconomy Applications DOI: $h$ ttp://dx.doi.org/10.5772/intechopen.86092

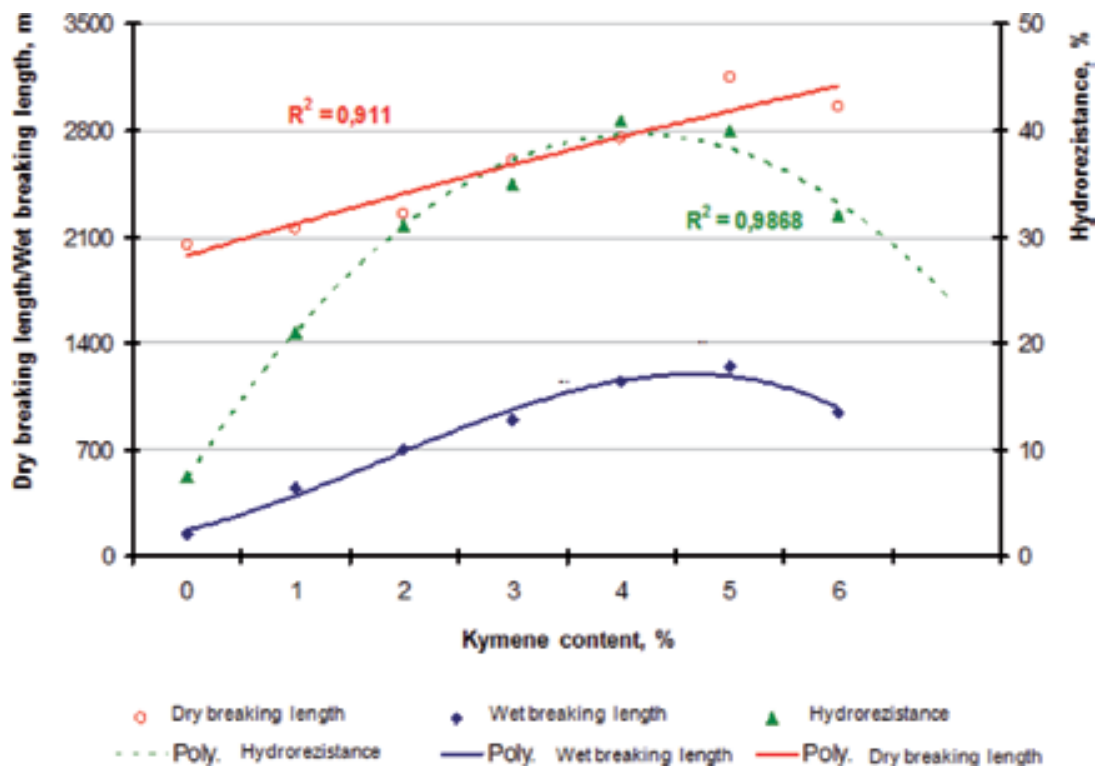

Figure 3.

Breaking length and wet strength retention at different contents of polyamide-polyamine-epichlorohydrin resin.

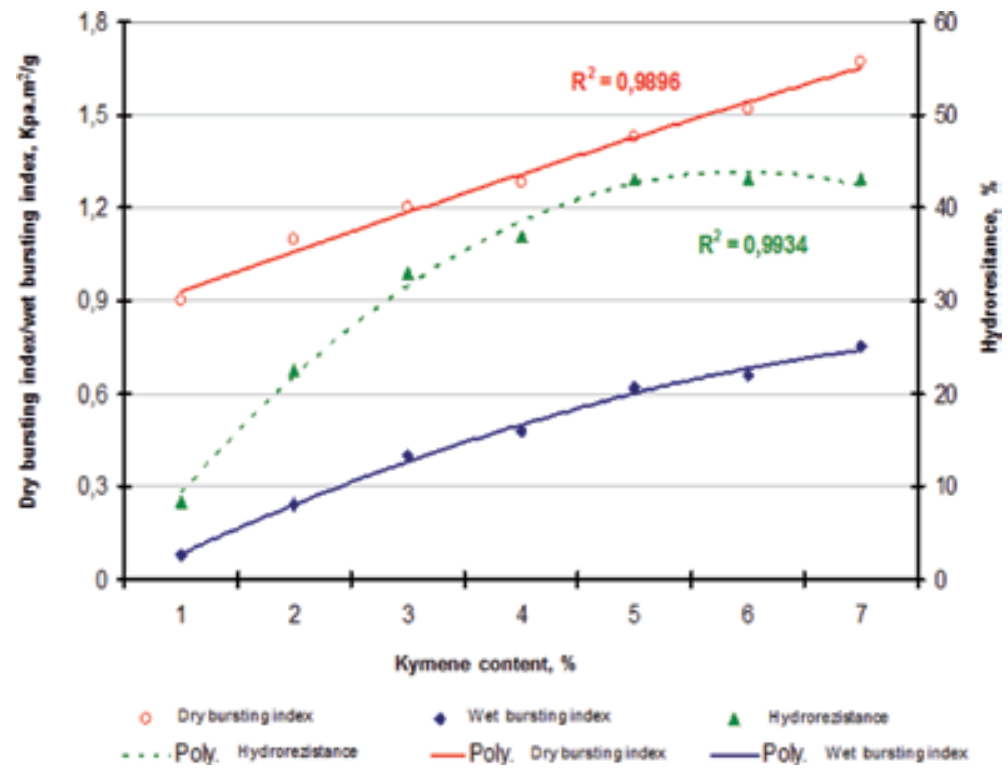

Figure 4.

Bursting index and wet strength retention at different contents of Kymene 611.

The dosage of resin for wet strength can be a means for retention of the components control, contributing also to increase of the additive efficiency as nutrient intake.

\subsection{The influence of fibrous composition and additive content on the structure of nutritive biodegradable pots}

Generally, the porosity is an important property that characterizes the structure of fibrous composites. This property influences the other characteristics of 
composites such as air permeability, liquids filtering, and water absorption. The porosity of composite structure was evaluated by air permeability measurement, which means the air volume that passes through a sample with known surface, under given time and pressure. The moisture content at equilibrium was evaluated beside air permeability.

The increasing peat content as a result has increased the porosity of the composite structure, evaluated by air permeability. Due to the high capacity of water retention of peat, the composite structure exhibits an increased moisture content (Figure 5).

The permeability of the composite structure is mainly influenced by the peat content. A lower influence is obtained with the increase of the resin content, also (Figure 6).

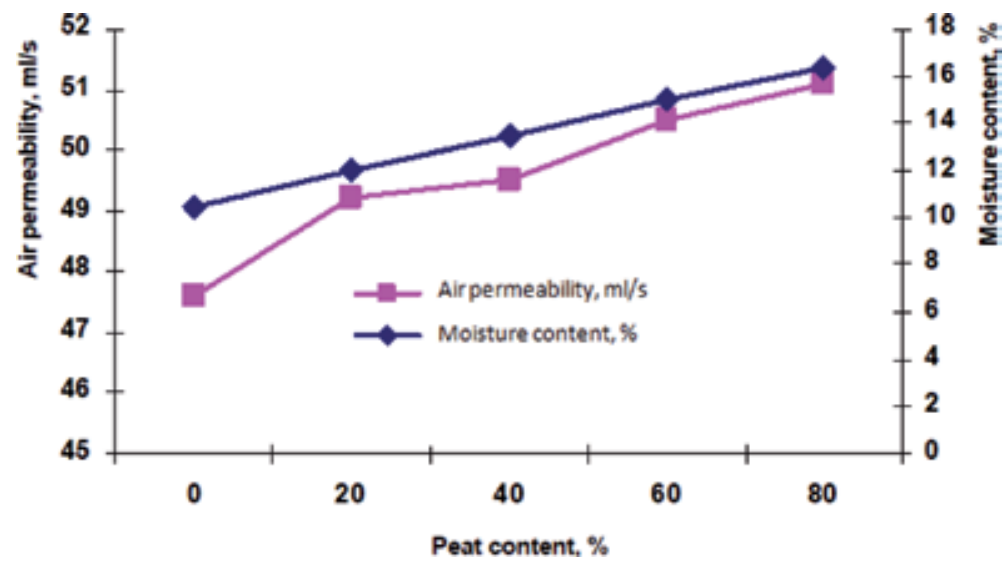

Figure 5.

The influence of peat content on air permeability and equilibrium moisture of composite structures.

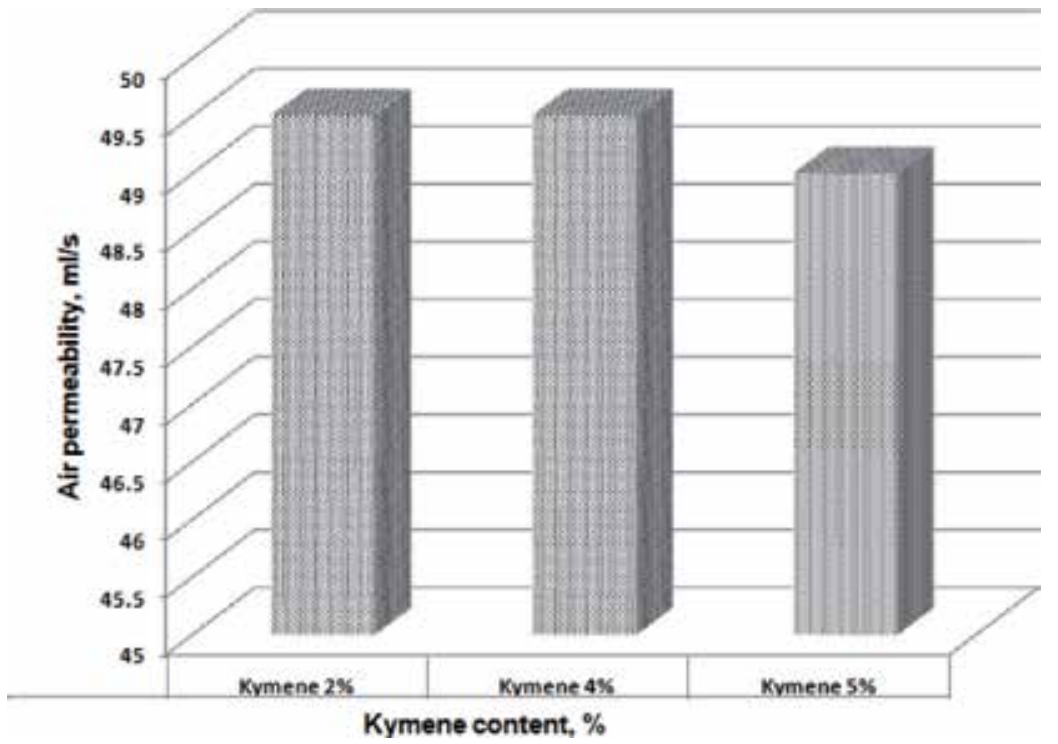

Figure 6.

The effect of resin content on the air permeability. 


\subsection{The level of nutrients in composition of biodegradable nutritive pots}

A high content of peat in the composition of biodegradable pots involves an ideal medium for development of seedling roots, while providing a nutritional reserve. This fibrous component allows circulation of air and water ensuring the oxygen flow. The peat cannot be a permanent source of nutrients for a long time. In this respect, the ways of retaining nitrogen from urea or ammonium phosphates, phosphorus from potassium or ammonium phosphate, potassium and microelements such as molybdenum, boron, manganese, copper, and zinc, were analyzed.

For an additional contribution of mineral salts and nutrients in the composition of biodegradable pots, it was established that a part of the peat to be replaced with a mixture of waste from grape processing (skins and bunches of grapes, dried and ground), keeping the proportion of peat in the range of $50-70 \%$.

All of these additives were introduced in the mass of composite materials aiming to obtain an optimal ratio of nutritive elements $(\mathrm{N}, \mathrm{P}, \mathrm{K})$.

The chemical and natural auxiliaries identified to be introduced into the composite material structure are:

- urea and dibasic ammonium phosphate-for nitrogen and phosphorus release;

- borax and ammonium molybdate-for release of boron and molybdenum microelements;

- zinc sulfate and copper sulfate for zinc and copper release;

- potassium nitrate for the release of potassium;

- mixture of waste from grape processing (peelings and bunches) for additional mineral salts.

The nutritional properties of biodegradable composites are improved by incorporating bioactive substances in their structure (walls). Furthermore, a peat content of about $50-70 \%$ contributes to accelerating biodegradation rate of composite pots. A content of $70 \%$ peat in the composite structure facilitates the accessibility of seedling roots toward nutritive elements within the optimum range of $\mathrm{pH}$. Exceeding the proportion of peat in the composition of the nutritive pots (over 70\%) raises high problems during the formation process of their fibrous structure.

\section{Experimental program for obtaining the biodegradable nutritive pots}

In our experiments, three compositional versions (M1, M2, and M3) of biodegradable nutritive pots dedicated to produce seedling material were obtained using the formation and dewatering system through die molding. The obtained nutritive pots were dried in a laboratory oven at $105^{\circ} \mathrm{C}$ temperature [26].

\subsection{Materials preparation}

The composition of those three versions of nutritive pots is presented in the Table 1 and their preparing stages in Figure 7.

After separation of coarse materials, the peat was dried at $105^{\circ} \mathrm{C}$ and defibrated using a homogenization device (Lhomargy type) for 4-5 min at $2000 \mathrm{rpm}$. Recycled 


\begin{tabular}{lccc}
\hline Materials & M1 (\%) & M2 (\%) & M3 (\%) \\
\hline Peat & 70 & 55 & 70 \\
\hline Waste from grapes processing & - & 15 & - \\
\hline Secondary cellulose fibers & 30 & 30 & 30 \\
\hline Wet strength resin (Kymene 611) & 6 & 6 & 6 \\
\hline Chemical additives & 2 & 2 & - \\
\hline
\end{tabular}

Table 1.

The compositional versions of nutritive pots obtained in the experimental program.

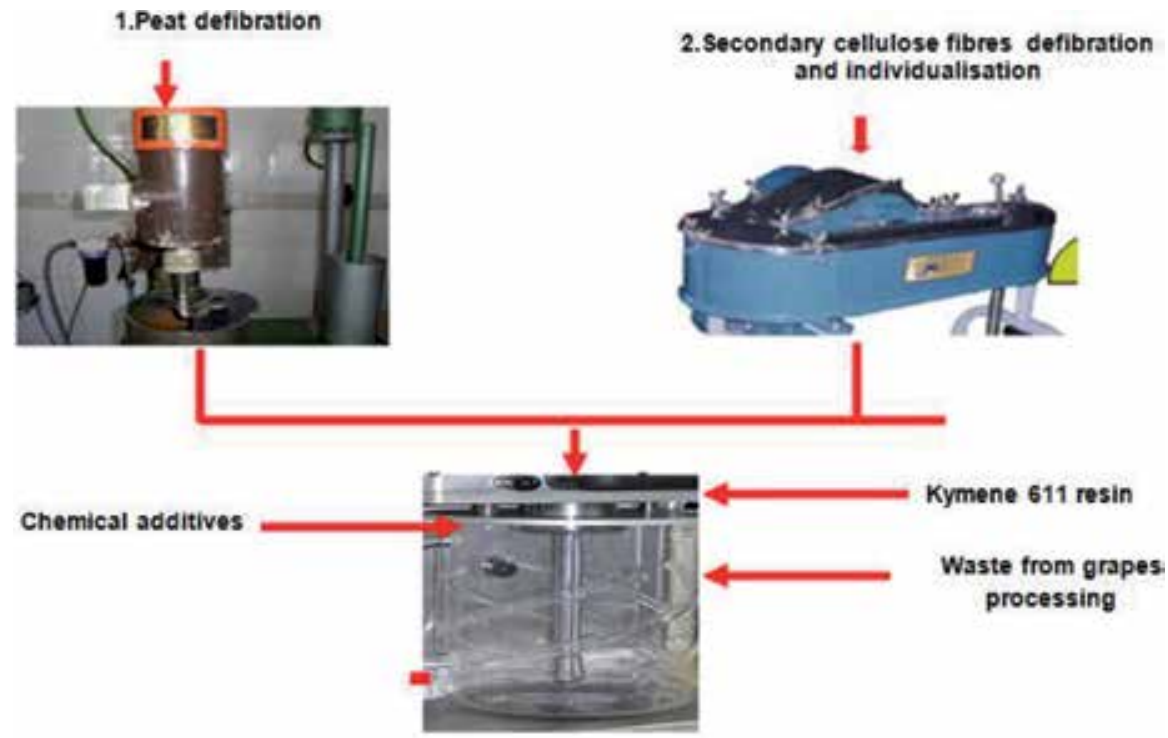

3. Homogenization and addition of components

Figure 7.

The stages of fibrous material preparing.

papers from corrugated board boxes were defibrated in a laboratory Hollander until $35-40^{\circ} \mathrm{SR}$. The fibrous components (peat and cellulose fibres) are mixed using a homogenizer where the Kymene 611 resin is added. The consistency of the fibrous mixture is adjusted at $0.8-1.0 \%$.

\subsection{Formation and dewatering of biodegradable nutritive pots}

Fibrous suspension corresponding to each compositional version was transferred to a laboratory pilot plant where the die molding and dewatering of biodegradable nutritive pots took place as is described in Figure 8.

For each compositional version, about 150 pieces of nutritive pots have been obtained, and technical parameters during formation and dewatering processes are presented in the Table 2 .

All composite structures have an adequate wet strength and fibrous network integrity (after formation and dewatering). This allowed manual take-up of nutritive pots and their introduction into drying equipment, where free-air drying was carried out. 


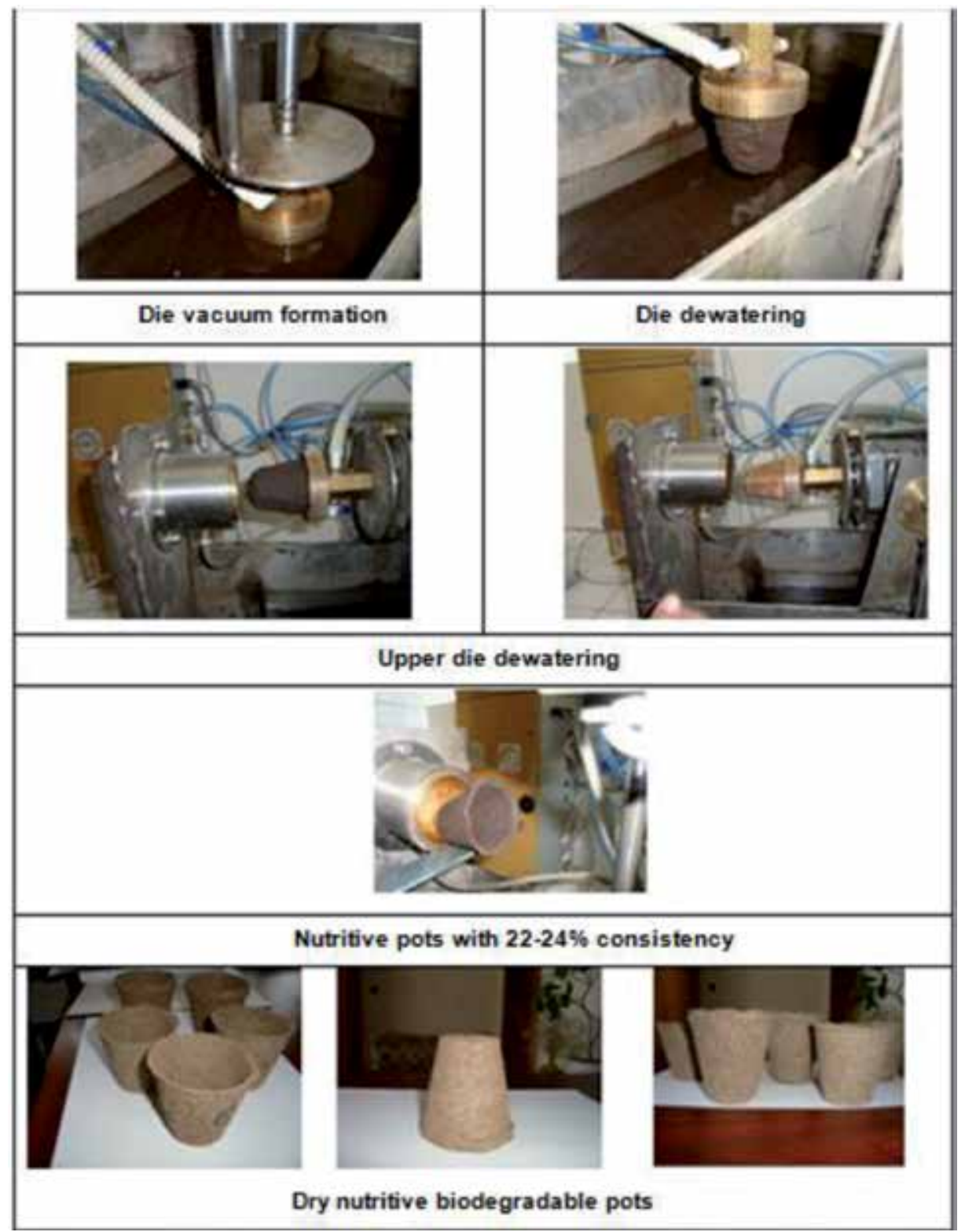

Figure 8.

Formation and dewatering of biodegradable nutritive pots [27].

\subsection{Drying of nutritive pots}

The nutritive pots were dried at $105^{\circ} \mathrm{C}$ for $60-80 \mathrm{~min}$ in a laboratory oven (Figure 9).

\subsection{Assessment of mechanical strength properties of nutritive biodegradable pots}

The mechanical strength properties were measured using a specific device for strength evaluation, whose construction was developed to simulate the specific shape and individual stresses to which biodegradable nutritive pots are subjected [27]. 


\begin{tabular}{lcccc}
\hline \multirow{2}{*}{ Parameter } & \multicolumn{3}{c}{ Value } & Observations \\
\cline { 2 - 4 } & M1 & M2 & M3 & \\
\hline Consistency of fibrous material, \% & $1.2-1.4$ & $1.2-1.4$ & $0.9-1.1$ & \\
\hline Formation consistency, \% & $22-24$ & $22-24$ & $22-24$ & After die formation \\
\hline Weight of wet pot, $g$ & $32-34$ & $34-36$ & $24-28$ & After die formation \\
\hline Weight of dry pot, $g$ & $7.5-8.0$ & $8.0-9.0$ & $6.5-7.5$ & After drying at $105^{\circ} \mathrm{C}$ \\
\hline Time of die formation, $\mathrm{s}$ & $12-15$ & $15-16$ & $15-17$ & \\
\hline Dewatering time, $\mathrm{s}$ & 60 & 60 & 60 & \\
\hline Consistency of white water, \% & 0.0397 & 0.0351 & 0.0320 & \\
\hline Ash content of white water, \% & 41.43 & 30.34 & 21.72 & \\
\hline Number of nutritive pots & 150 pcs. & 150 pcs. & 150 pcs. & \\
\hline
\end{tabular}

Table 2.

Technical parameters during formation and dewatering of nutritive biodegradable pots.
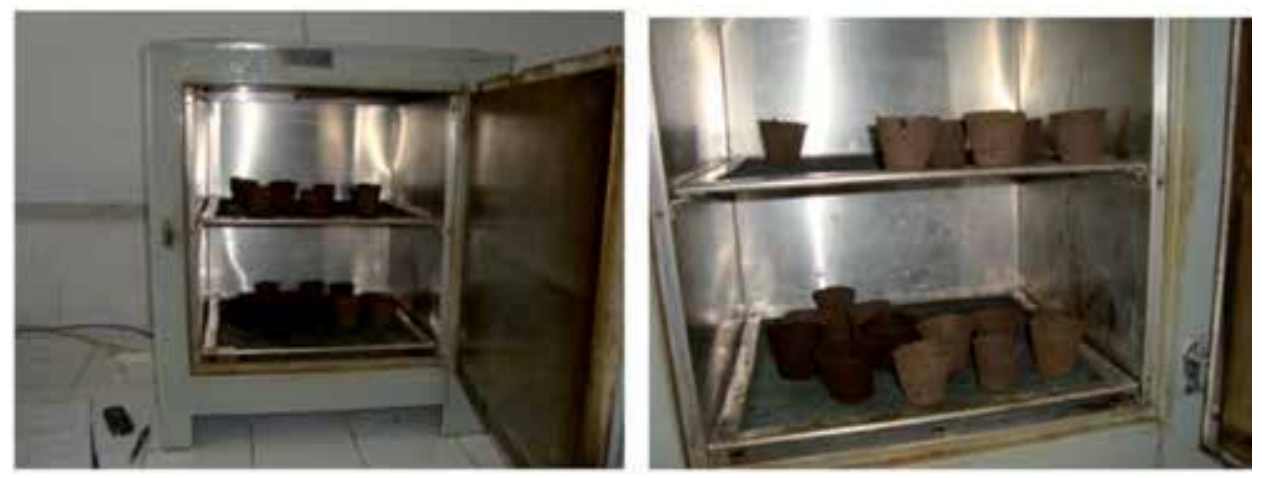

Figure 9.

Drying of biodegradable nutritive pots.

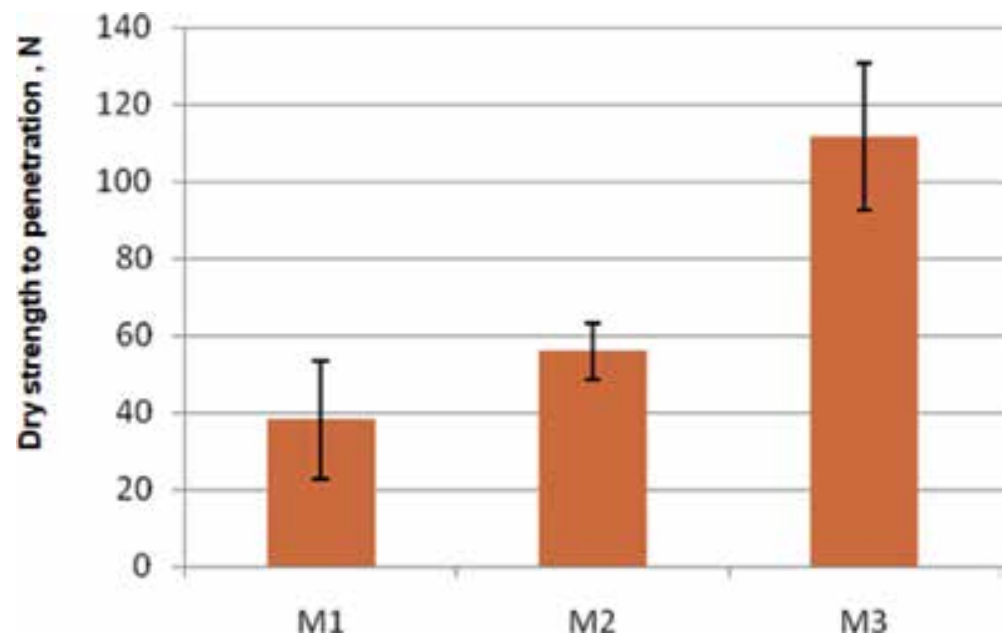

Figure 10.

Dry strength of biodegradable nutritive pots.

Strength tests were carried out both on samples conditioned in the standard atmosphere $\left(23^{\circ} \mathrm{C}\right.$, moisture $\left.50 \% \mathrm{RH}\right)$ and wetted by immersion in water at $23^{\circ} \mathrm{C}$ for 15 minutes. 


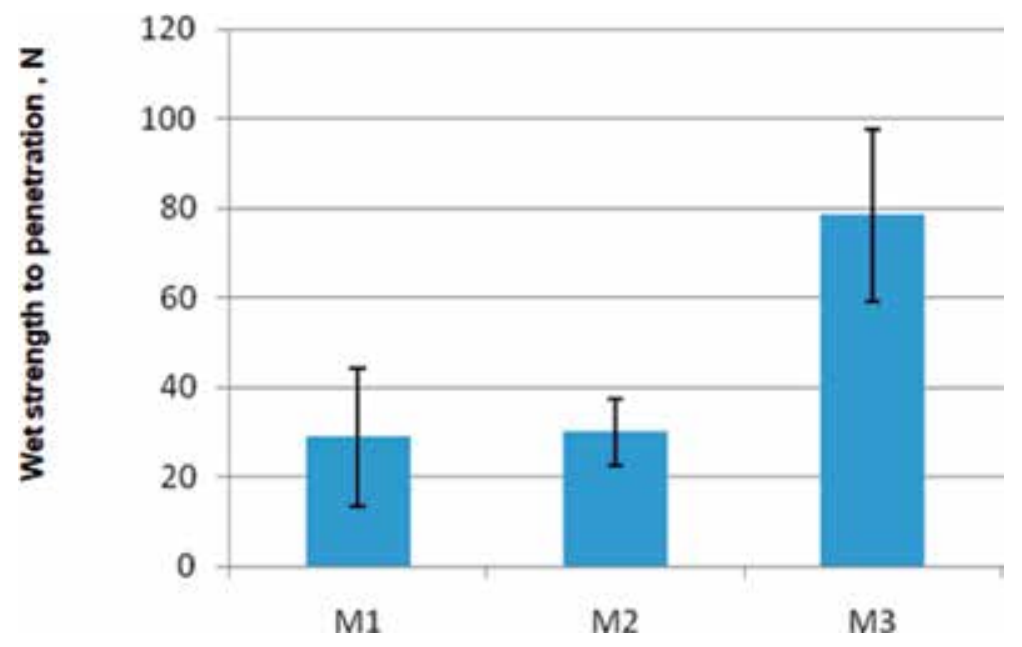

Figure 11.

Wet strength of biodegradable nutritive pots.

In Figures 10 and 11, the results obtained after the strength tests of those three versions of biodegradable nutritive pots are presented.

As it can be observed, the M3 version exhibits the best strength properties, both in dry and wet state. Values obtained for the M3 pots were of two and three times higher than those registered for the M1 and M2 versions. It seems that in case of the M1 version, the nutrient charge as salts affected resin retention and crosslinking, as it is known that resin adsorption on fibers decreases significantly, at the same time, increasing the valence of metallic ions and their stock concentration $[28,29,30]$. In case of the M2 version, the charge of residue from grape processing breaks the continuity of the fibrous network and introduces fine and colloidal anionically charged material. Nevertheless, in both cases (M1 and M2), the obtained strength exceeds the strength requirement for handling and transport in the seedling manufacturing process.

\subsection{Assessment of nutritive pots biodegradability during seedling manufacturing process}

To assess the biodegradability of nutritive pots, the cellulosic degradation rate was determinated $[31,32]$. Based on this evaluation method, the nutritive pot samples (dried at $105^{\circ} \mathrm{C}$ ) were incubated in a nutritive substrate commonly used for producing seedlings. During incubation, the nutritive pots were introduced in a previously weighed synthetic bag, in order to totally recover the fibrous material contained in it. During the entire experimenting period (141 days), the effective substrate moisture was maintained in the range of $60-65 \%$ relative humidity, and temperature in the range of $24-28^{\circ} \mathrm{C}$. The biodegradation rate (degradation degree) was calculated as weight loss of initial and after soil incubation of pots.

The capability to create a favorable environment for developing a typical microflora for soil and culture substrates was evaluated by microflora respiration intensity, having in view that microflora are involved in cellulosic material degradation [33]. The experiments were carried out on both experimental nutritive pots and the current process for the production of lettuce (Lactuca sativa, var. Capitata) and tomatoes (Lycopersicon esculentum) seedlings [27].

Analyzing the obtained results (Figure 12), it is observed that during the experimental program, the pots from M1 version showed the lowest biodegradation 


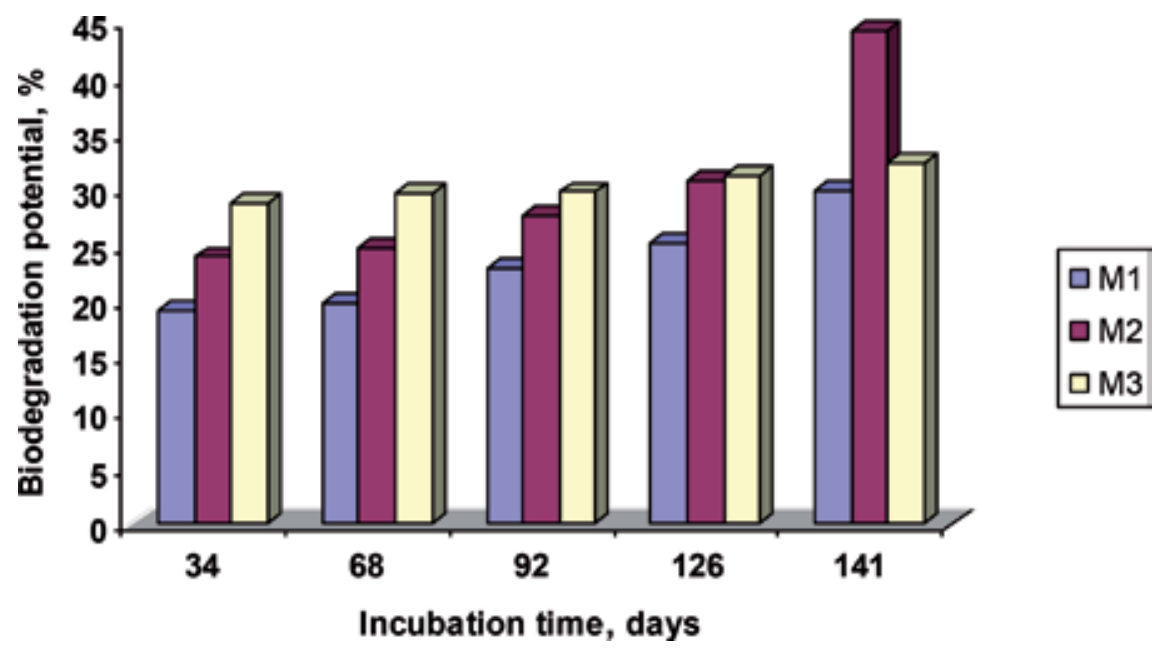

Figure 12.

Biodegradation potential of nutritive biodegradable pots [27].

\begin{tabular}{ccccc}
\hline \multirow{2}{*}{ Pot version } & \multicolumn{2}{c}{ Effective biodegradation rate (\%) } & \multicolumn{2}{c}{ Daily biodegradation rate (\%) } \\
\cline { 2 - 5 } & Tomatoes & Lettuce & Tomatoes & Lettuce \\
\hline M1 & 16.484 & 12.391 & 0.32 & 0.34 \\
\hline M2 & 15.351 & 13.657 & 0.30 & 0.38 \\
\hline M3 & 16.312 & 13.008 & 0.32 & 0.36 \\
\hline
\end{tabular}

Table 3.

The biodegradability of nutritive pots with cultivated seedling.

potential; though at the first analysis time (after 34 days), the M3 version pots showed a higher degradation rate $(28.76 \%)$ than the M1 and M2 pots. In the last analysis period (after 141 days), the biodegradation potential was the highest for the M2 version pots (44.19\%); this behavior can be explained by the fact that the pots obtained with this composition contained a lower amount of fibrous material (85\%) compared with the M1 and M3 pots; in the composition of these pots, the waste from grape processing acts as a filler, increasing the distance between fibers and reducing bonding forces in the fibrous network. The obtained results are correlated with the wet strength of the M2 version pots, also.

Regarding the effective biodegradation rate measured during seedlings manufacturing process (tomatoes-Lycopersicon esculentum and lettuce-Lactuca sativa), the obtained results showed that all of three tested versions of pots behaved differently according to the seedling type (Table 3 ). Therefore, in case of tomatoes seedlings (after 51 days), the M1 pots exhibited the highest biodegradation rate (16.48\%) and the M2 version showed the lowest rate (15.35\%). When the lettuce seedlings are produced, the highest biodegradation rate was obtained in M2 (13.65\%) and the lowest in M1 (12.39\%).

The reason is that tomatoes naturally have a stronger root system than lettuce, though the latter develops its roots faster. As a result, the rhizosphere effect is more intense for tomatoes, and biodegradation conditions are modified both in the culture substrate and in the pots.

Analyzing the average daily biodegradation rate, it is noticed that this is more intense when pots are not planted with seedling compared to seedling production 
Use of Recycled Cellulose Fibers to Obtain Sustainable Products for Bioeconomy Applications DOI: http://dx.doi.org/10.5772/intechopen.86092

\begin{tabular}{lcccccc}
\hline Pot version & $\begin{array}{c}\text { Height of } \\
\text { plant }(\mathbf{c m})\end{array}$ & $\begin{array}{c}\text { Length of } \\
\text { roots }(\mathbf{c m})\end{array}$ & $\begin{array}{c}\text { Plant/roots } \\
\text { ratio }\end{array}$ & $\begin{array}{c}\text { Number of } \\
\text { leaves }\end{array}$ & $\begin{array}{c}\text { Leaves frequency } \\
(\text { no./plant height })\end{array}$ & $\begin{array}{c}\text { Roots volume } \\
\left(\mathbf{c m}^{3}\right)\end{array}$ \\
\hline M1 & 20.3 & 18.1 & 1.12 & 6.6 & 0.32 & 10.0 \\
\hline M2 & 14.2 & 23.8 & 0.60 & 5.4 & 0.38 & 7.0 \\
\hline M3 & 14.0 & 16.8 & 0.83 & 4.6 & 0.32 & 8.4 \\
\hline Jiffy pot & 24.8 & 21.8 & 1.13 & 7.2 & 0.29 & 10.2 \\
\hline & & & Lettuce & & 1.24 & 9.6 \\
\hline M1 & 5.3 & 9.6 & 0.55 & 6.6 & 1.24 & 8.6 \\
\hline M2 & 5.0 & 9.8 & 0.51 & 6.2 & 1.39 & 8.8 \\
\hline M3 & 4.6 & 7.4 & 0.62 & 6.4 & 1.37 & 9.5 \\
\hline Jiffy pot & 5.1 & 5.1 & 1.00 & 7.0 & & \\
\hline
\end{tabular}

Table 4.

Comparative morphological characteristics of seedlings planted in biodegradable pots with different compositions.
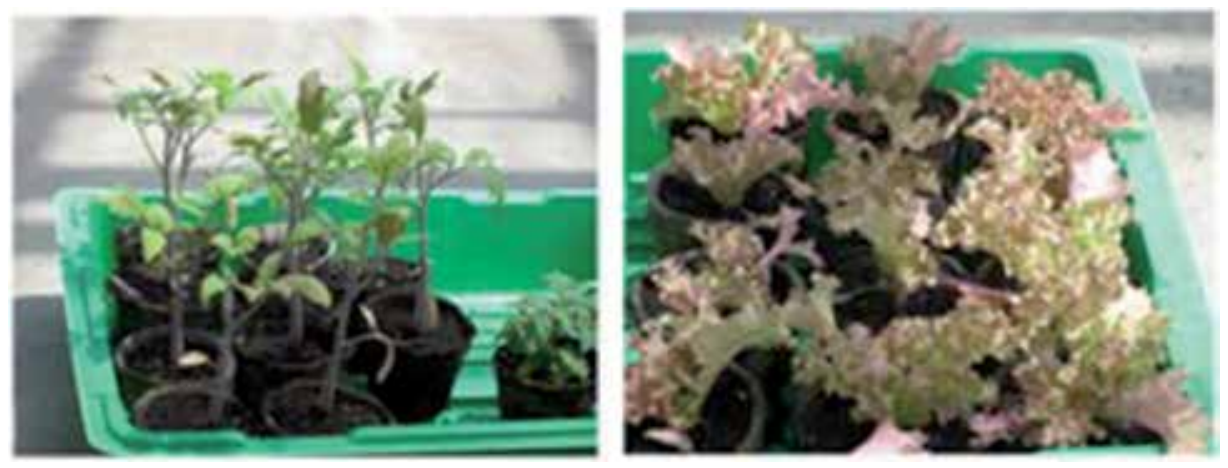

Figure 13.

Tomatoes and lettuce plants obtained using the experimental nutritive biodegradable pots.

when the pots benefit by rhizosphere effect of seedling. In these circumstances, there are differences between the two types of tested seedlings. Therefore, the daily biodegradation rate of lettuce seedling is with $0.02-0.08 \%$ higher than tomatoes seedling. This is based on the existence of an initial rate of roots growth which is more intense in lettuce than tomatoes.

From the results presented in the Table 4 and Figure 13 regarding the growth and development of lettuce and tomatoes seedlings, it can be observed that for all the studied versions, the growth indicators have values that allow the framing within the favorable limits according to the data from specialty literature. The mass indicators show accumulations that have allowed normal growth. The experiences have shown that for both the lettuce and tomatoes, the type of pots used for seedling and transplanting strongly influences the number of leaves and roots volume. By visual appreciation, it has been found that the good development of the seedlings is also related to the good penetration of the roots through the walls of the pots, even if their effective biodegradation was quite small. This aspect is mainly related to the mechanical properties of the nutritive pots, especially the penetration resistance. It is also observed that the morphological properties of the plants raised in the experimentally pots are comparable to those of the plants developed in currently existing Jiffy pots. 


\section{Conclusions}

In our experimental programs, three compositional versions of biodegradable nutritive pots based on 50 and $70 \%$ peat, $30 \%$ recycled cellulose fibers, and organic and mineral nutritive materials between 0 and $2 \%$ were tested; these biodegradable nutritive pots were tested on production of lettuce and tomatoes seedlings.

The results on mechanical strengths (wet and dry) demonstrated the importance of fibrous composition and chemistry relative to the formation and integrity of biodegradable nutritive pots for the seedling production process.

The additional nutrients (mineral or organic) stimulate the pulp degradation; therefore, the pots containing both chemical (for nutrient contribution) and natural (waste from grape processing) additives-M2 version — showed the highest biodegradation potential.

For all the studied versions of pots, the specific indicators of plant growth have values that allow them to be framed within the limits of favorability, ensuring a normal growth of plants.

The obtained results are promising and the biodegradable nutritive pots based on lignocellulosic materials can be used in the seedlings manufacturing process; based on their composition, these products can be considered a good reserve of organic materials for soil. These materials are nontoxic and biodegradable, according to the provisions of European Directives, concerning reduction of environmental pollution with plastics from agricultural sources. Furthermore, it represents a real opportunity to stimulate transition towards a circular economy.

\section{Future recommendations}

The experiments will be continued with testing of biodegradable pots on other types of seedling as well as for optimization of wet strength additives content aiming to ensure an adequate biodegradation according with the duration of seedling development.

\section{Acknowledgements}

The author thanks for support of Research and Consultancy Centre for Environmental and Agriculture "Lunca” from Dunărea de Jos University of Galați, Romania.

\section{Conflict of interests}

The author declares no potential conflicts of interest with respect to the research, authorship, and/or publication of this chapter. 
Use of Recycled Cellulose Fibers to Obtain Sustainable Products for Bioeconomy Applications DOI: http://dx.doi.org/10.5772/intechopen.86092

\section{Author details}

Petronela Nechita

Department of Environmental, Applied Engineering and Agriculture, "Dunărea de Jos" University of Galați, Romania

*Address all correspondence to: petronela.nechita@ugal.ro

\section{IntechOpen}

(C) 2019 The Author(s). Licensee IntechOpen. This chapter is distributed under the terms of the Creative Commons Attribution License (http://creativecommons.org/licenses/ by/3.0), which permits unrestricted use, distribution, and reproduction in any medium, provided the original work is properly cited. (cc) BY 


\section{References}

[1] Carrión C, Abad M, Maquieira A, Puchades R, Fornes F, Noguera V. Leaching of composts from agricultural wastes to prepare nursery potting media. Acta Horticulturae (ISHS). 2005;697:117-112

[2] Hurley S. Postconsumer Agricultural Plastic Report. California Integrated Waste Management Board; Published by California Environmental Protection Agency; 2008

[3] Levitan L, Barros A. Recycling agricultural plastics in New York state. In: A Research Report Prepared for the Environmental Risk Analysis Program. Ithaca, New York: Cornell University; 2003

[4] Treinytea J, Grazulevicienea V, Bridziuviene D, Svediene J. Properties and behaviour of starch and rapeseed cake based composites in horticultural applications. Estonian Journal of Ecology. 2014;63(1):15-27. DOI: 10.3176/ eco.2014.1.02

[5] Welleman JCC. Fytocell, an increasingly popular substrate. Acta Horticulturae (ISHS). 2005;697:195-198

[6] Evans MR, Taylor M, Kuehny J. Physical properties of biocontainers for greenhouse crops production. HortTechnology. 2010;20(3):549-555

[7] Nambuthiri S, Schnelle R, Fulcher A, Geneve R, Koeser A, Verlinden S, et al. Alternative containers for a sustainable greenhouse and nursery crop production. Agriculture \& Natural Resources. 2013;1(11)

[8] Seiichiro I, Hongkang Z. Products Based on Corn Gluten Meal and Other Agro Byproducts, World Conference and Exhibition on Oilseed and Vegetable Oil Utilization. Istanbul, Turkey; 2006
[9] Robinson T. Containers evolve to satisfy industry, retailer, and consumer needs. GMPro. 2008;28(1):35-40

[10] Environment Australia.

Biodegradable Plastics - Developments and Environmental Impacts, Ref: 311101/ October 2002, Prepared by NOLANITU Pty Ltd in Association with ExcelPlas Australia; 2002. pp. 37-40

[11] Yue C, Hall CR, Behe BK, Campbell BL, Dennis JH, Lopez RG. Are consumers willing to pay more for biodegradable containers than for plastic ones? Evidence for hypothetical conjoint analysis and nonhypothetical experimental auctions. Journal of Agricultural and Applied Economics. 2010;42(4):757-772

[12] Camberato D, Lopez R.

Biocontainers for Long-Term Crops. Greenhouse Grower; 2010. Available from: https://www.greenhousegrower. com/production/pots-trays/ biocontainers-for-long-term-crops/

[13] Abaecherli A, Popa VI. Lignin in crop cultivations and bioremediation. Environmental Engineering and Management Journal. 2005;4(3): 273-292. DOI: $10.30638 /$ eemj.2005.030

[14] United States Patent, No. 6,490,827 B2. 2002

[15] Kirchhoff MM. Promoting sustainability through green chemistry. Conservation and Recycling, Resources. 2005;44:237-243

[16] Bobu E. Improving the effectiveness of papermaking chemicals by controlling the aggregation mechanisms. In: PIRA International Conferenece- Scientific and Technical Advances in Wet End Chemistry. 2004; 1-12 May, Nice, France 
[17] Zhu S, Wu Y, Cheng Q, Yu Z, Wang C, Jen S, et al. Dissolution of cellulose with ionic liquids and its application: A minireview. Green Chemistry. 2006;8:325

[18] Maljanen M, Sigurdsson BD, Guðmundsson J, Skarsson H, Huttunen JT, Martikainen P. Greenhouse gas balances of managed peatlands in the Nordic countries ñ present knowledge and gaps. Biogeosciences. 2010;7:2711-2738

[19] Verhoeven JTA, Setter TL. Agricultural use of wetlands: Opportunities and limitations. Annals of Botany. 2010;105:155-163

[20] Ingram DL, Nambuthiri S. Using plantable containers for selected groundcover plant production. Hortscience. 2012;47(9). (Supplement) SR-ASHS Annual Meeting-February 3-6, 2012

[21] Maljanen M, Sigurdsson BD, Guðmundsson J, Óskarsson H, Huttunen JT, Martikainen PJ. Greenhouse gas balances of managed peatlands in the Nordic countries, present knowledge and gaps. Biogeosciences. 2010;7:2711-2738

[22] Evans MR, Taylor M, Kuehny J. Physical properties of biocontainers for greenhousec rops production. HortTechnology. 2010;20:549-555

[23] Wang X, Fernandez T, Cregg B, Fulcher A, Geneve R, Niu G, et al. Performance of alternative containers and plant growth and water use of Euonymus fortune. Hortscience. 2012;47(9):S2.(Abstr.)

[24] Taylor M, Evans M, Kuehny J. The beef on biocontainers: Strenght, water use, biodegradability and greenhouse performance. OFA Bulletin. 2010;3:923

[25] Orliac O, Rouilly A, Silvestre F, Rigal L. Effects of various plasticizers on the mechanical properties, water resistance and aging of thermomoulded films made from sunflower proteins. Industrial Crops and Products. 2003;18:91-100

[26] Nechita P, Bobu E, Ciolacu F, Dobrin E, Biocomposites from renewable resources - biodegradable nutritive support for containerized seedling manufacturing. 2009; National Research Programme, BIOSUN project Contract no. 51-090, stage 3

[27] Nechita et al. Biodegradable pots for planting. BioResources. 2010;5(2):1102-1113

[28] Ampulski RS, Neal CW. The effect of inorganic ions on the adsorption and ion exchange of Kymene $557 \mathrm{H}$ by bleached northern softwood Kraft pulp. Nordic Pulp \& Paper Research Journal. 1989;2:155-163

[29] Roberts JC. Wet-strength additives. In: Roberts JC, editor. Paper Chemistry. 2nd ed. Blackie Academic \& Professional; 1996. pp. 104-107. Available from: https://www.springer. com/la/book/9780751402360

[30] Yoon SH. Adsorption kinetics of polyamide-epichlorohydrin on cellulosic fibres suspended in aqueous solution. Journal of Industrial and Engineering Chemistry. 2006;12(6):877-881

[31] Ştefanic G. Probleme de agrofitotehnie teoretică şi aplicată. 1999;XXVIII(Supplement):45-50

[32] Bourtoom T. Plasticizer effect on the properties of biodegradable blend film from rice starch.Chitosan. Songklanakarin Journal of Science and Technology. 2008;30(Suppl. 1):149-155

[33] Szegi J. Cellulose Decomposition and Soil Fertility. Budapest: Akademiai Kiado; 1988. pp. 65-68 

Section 2

Non-Woven Fabrics

Technology 



\title{
Characteristics of Eco-friendly Kenaf Fiber-Imbedded Nonwoven for Automotive Application
}

\author{
Seung Jin Kim and Hyun Ah Kim
}

\begin{abstract}
This study examined the physical properties of kenaf fiber-imbedded nonwoven for automotive pillar trim according to the blend ratio of the fibers and needle-punching process conditions. Kenaf-imbedded nonwoven specimens mixed with polypropylene (PP) and low-melt PET (LM PET) fibers were prepared via needle-punching, and their physical properties such as air permeability, water absorption, sound absorption coefficient, and porosity were investigated according to the various processing conditions. The kenaf-imbedded nonwoven treated with high needle depth in the needle-punching process and/or mixed with a large amount of LM PET exhibited the highest breaking and tearing strengths, due to the high weight of the nonwoven specimens. A high blend percentage of LM PET fibers reduced the pore size, which resulted in low air permeability and water absorption. The sound absorption coefficient of the kenaf-imbedded nonwoven specimens was highly dependent on its weight and thickness. Regarding the lamination treatment, the laminated nonwoven exhibited higher breaking and tearing strengths, thermal conductivity, and sound absorption coefficient than the non-treated one. In addition, the HDPE powder-treated nonwoven exhibited lower breaking and tearing strengths, air permeability, water absorption, and sound absorption, due to the reduced pore size.
\end{abstract}

Keywords: kenaf, needle-punching, low-melt PET, sound absorption coefficient porosity, fogging

\section{Introduction}

The scientific name of kenaf is Hibiscus cannabinus L. The principal ingredients of kenaf fiber are cellulose, lignin, and pectin, and the hemicellulose distribution ranges between 10 and 22\% according to the type of kenaf fiber. Research on the application to fashion textile materials with soft tactile hand by retting treatment of kenaf stem has been conducted by Ramaswamy et al. [1], Tao et al. [2], and Lee et al. $[3,4]$. In particular, many studies have examined the spinning and fabric manufacturing technology using mixed fibers with cotton and kenaf, including Bel-Berger et al. [5], Weiying et al. [6], and Zhang [7]. Advanced composite materials mixed with kenaf and natural fibers with light weight, VOC-free, and good abrasion resistance are needed nowadays and have been studied for eco-friendly automotive materials [8-10]. In addition, the use of kenaf fiber in nonwoven 
was investigated by Moreau et al. [11], Yang et al. [12], and Tao et al. [13, 14] . Nonwoven has been used in the various industries because of its advantages of fast processing and competitive price. Recently, nonwoven has become one of the most common textile products in the automotive industry with sound absorption properties. The nonwoven fabrics used in the automotive industry require high functional quality and reliability. Many studies have examined the sound absorption property, including physical properties such as air permeability and wicking, of nonwovens. The studies carried out using natural jute [15] and coconut coir [16] fibers yielded good sound absorption properties. Kenaf, jute, and cotton fiber-imbedded nonwovens with PET and polypropylene (PP) fibers were used as industrial automotive padding materials and have significantly improved the sound absorption properties [17]. Nick et al. [18] investigated the acoustic behavior using three different composite materials: (1) cotton, bicomponent PET, and PP fibers; (2) flax, hemp, and PP fibers; and (3) lyocell, bicomponent PET, and PP fibers. The third composite material with lyocell fibers of 0.9 dtex exhibited the best sound absorption property. Lou et al. [19] studied the sound absorption property of nonwoven composed of low-melt PET (LM PET) and recycled PET particles mixed with PP fibers. The thick and low-density nonwoven specimens exhibited high sound absorption coefficients at low- and mid-frequency sound ranges. Lee et al. [20] examined the relationship between the acoustic absorption values of the recycled polyester nonwovens and the nonwoven processing conditions, including fiber and web properties. Byun et al. [21] investigated the sound absorption property of the PET nonwoven for automotive application according to the variation of the fiber fineness, density, and thickness of the three-layer nonwoven by substituting glass wool in order to improve the environmental and recycled capability. Kücük and Korkmaz [22] examined the effects of the physical parameters on the sound absorption properties of natural fiber-mixed nonwoven fabrics. They concluded that an increased thickness and decreased air permeability resulted in an increase of sound absorption properties. In addition, an increased amount of fiber per unit area resulted in an increase in sound absorption. On the other hand, Dubrovski and Brezocnik [23] studied the effects of the content of viscose and PET fibers and the porosity of the nonwoven structure on the vertical wicking rate of nonwovens. The results showed that higher-volume porosity gives higher vertical wicking rate. Soukupova et al. [24] studied the effect of the blend ratio of viscose and PET fibers on the wicking of the nonwoven and found that the capillary rise was higher for nonwoven fabrics containing more viscose fibers. Dubrovski and Brezocnik [25] predicted the model for the vertical wicking rate using the fiber density, fiber fineness, and nonwoven fabric density. Das et al. [26] and Tascan and Vaughn [27] examined the influence of fiber cross-sectional shape on the air permeability of nonwoven. Das et al. [26] found that the air permeability decreased with a higher proportion of noncircular fibers in the nonwoven fabrics, which was similar to Tascan and Vaughn's results [27].

In previous studies, LM PET and PP fibers as nonwoven materials were mixed with natural fibers such as cotton, lyocell, flax, jute, and coconut coir to enhance their physical properties such as the wicking rate, air permeability, and sound absorption property for automotive-acoustic materials. However, no detailed study has yet examined the physical properties of the kenaf fiber-imbedded nonwoven. Therefore, in this study, kenaf fiber-imbedded nonwoven specimens were produced with different processing conditions such as number of carding treatments, web layers, needle depth, and content ratio of LM PET, and their physical properties such as air permeability, water absorption, and sound absorption coefficient were measured in order to optimize the processing conditions for automotive pillar trim. Furthermore, the correlation between the breaking and tearing strengths and the 
structural factors of the nonwoven were investigated according to the processing conditions. In addition, the effect of different processing conditions on the fogging value of the nonwoven was investigated.

\section{Experimental}

\subsection{Specimen preparation}

Kenaf, PP, and LM PET were used as raw materials of the nonwoven. Table 1 presents the physical properties of the kenaf, PP, and LM PET staple fibers used. Ten kinds of kenaf-imbedded nonwoven specimen as a first batch of specimen were made with different processing conditions, as shown in Table 2.

Figure 1 shows the needle-punching nonwoven process to prepare the specimens. Figure 2 shows an image of the nonwoven machinery used. Three types of staple fiber supplied from material supply equipment were mixed and blended in the mixing tank shown in Figure 1. Specimen 1 in Table 1 was mixed and blended by single opener in the mixing tank, and specimens $2-10$ were prepared by multi-opener.

As shown in Table 2, the basic blend ratio of kenaf, PP, and LM PET staple fibers was 40 , 40, and $20 \%$, respectively (specimens $1-9$ ). The blend ratio of specimen 10 was changed to 30,30 , and $40 \%$. The mixed and blended fibers were delivered to the first and second carding processes. The basic carding treatment was conducted twice, but specimen 4 underwent only one treatment. Lap forming was performed after the carding process. The layering of the carding lap was changed from two to four layers, as shown in Table 2. The needle-punching process was followed by the second web-forming process, as shown in Figure 1. The basic needle depth was $16 \mathrm{~mm}$, but specimens 7 and 8 had a needle depth of 18.6 and $14.4 \mathrm{~mm}$, respectively. The specimens underwent thermo-compression bonding after the needlepunching process, as shown in Figure 1. Polyethylene (PE) powder was added after the thermo-bonding process to enhance coherence between the fabric and PP foam when automotive pillar trim was fabricated, as shown in Figure 3. Figure 3 shows the pillar trim in automotive interior. Kenaf-imbedded nonwoven is located between PP foam and fabric, which is placed on the inside of automotive pillar trim. Fabric is usually made by polyester (cation dyeable polyester).

Hot melt film was inserted between the fabric and the kenaf-imbedded nonwoven to enhance the adhesive force between them. In addition, the reason why low-melting (LM) PET is mixed to make nonwoven is to enhance the adhesive force among hot melt film, fabric, and kenaf-imbedded nonwoven.

\begin{tabular}{lccc}
\hline Physical properties & Kenaf & $\begin{array}{c}\text { Low-melting PET } \\
\text { (LM PET) }\end{array}$ & Polypropylene (PP) \\
\hline Fiber length (mm) & 64.8 & $51.8 \pm 5.0$ & 64 \\
\hline Linear density (d) & 8 & $4.53 \pm 0.41$ & $8 \pm 0.5$ \\
\hline Maker/origin & Bangladesh & Toray Chemical & $\begin{array}{c}\text { Han Kook Fiber } \\
\text { Co. Ltd }\end{array}$ \\
\hline Breaking strength (gf/d) & 4 & $3.52 \pm 0.42$ & $4 \pm 0.5$ \\
\hline Breaking strain (\%) & 200 & $44.0 \pm 8.7$ & $200 \pm 20$ \\
\hline Moisture regain (\%) & 11.8 & - & 0.1 \\
\hline
\end{tabular}

Table 1.

Physical properties of staple fibers used. 


\begin{tabular}{|c|c|c|c|c|c|c|c|}
\hline \multirow{2}{*}{$\begin{array}{l}\text { No. } \\
\\
1\end{array}$} & \multicolumn{2}{|c|}{$\begin{array}{c}\text { Blend ratio } \\
\text { (kenaf:PP:LM PET) }\end{array}$} & \multirow{2}{*}{$\begin{array}{c}\begin{array}{c}\text { No. of } \\
\text { carding } \\
\text { treatment }\end{array} \\
3 \text { Layers }\end{array}$} & \multirow{2}{*}{$\begin{array}{c}\begin{array}{c}\text { Layer of } \\
\text { web }\end{array} \\
3 \text { Layers }\end{array}$} & \multirow{2}{*}{$\begin{array}{c}\begin{array}{c}\text { Needle } \\
\text { depth }\end{array} \\
16 \mathrm{~mm}\end{array}$} & \multirow{2}{*}{ 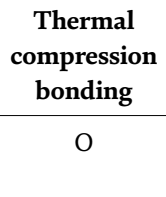 } & \multirow{2}{*}{$\begin{array}{c}\text { Powder } \\
\text { treatment }\end{array}$} \\
\hline & $\begin{array}{l}\text { Single } \\
\text { opener }\end{array}$ & $40: 40: 20$ & & & & & \\
\hline 2 & \multirow{9}{*}{$\begin{array}{l}\text { Multi- } \\
\text { opener }\end{array}$} & $40: 40: 20$ & 3 Layers & 3 Layers & $16 \mathrm{~mm}$ & $\mathrm{O}$ & $\mathrm{O}$ \\
\hline 3 & & $40: 40: 20$ & 3 Layers & 3 Layers & $16 \mathrm{~mm}$ & $\mathrm{O}$ & $\mathrm{X}$ \\
\hline 4 & & $40: 40: 20$ & 3 Layers & 3 Layers & $16 \mathrm{~mm}$ & $\mathrm{O}$ & $\mathrm{O}$ \\
\hline 5 & & $40: 40: 20$ & 4 Layers & 4 Layers & $16 \mathrm{~mm}$ & $\mathrm{O}$ & $\mathrm{O}$ \\
\hline 6 & & $40: 40: 20$ & 2 Layers & 2 Layers & $16 \mathrm{~mm}$ & $\mathrm{O}$ & $\mathrm{O}$ \\
\hline 7 & & $40: 40: 20$ & 3 Layers & 3 Layers & $18.6 \mathrm{~mm}$ & $\mathrm{O}$ & $\mathrm{O}$ \\
\hline 8 & & $40: 40: 20$ & 3 Layers & 3 Layers & $14.4 \mathrm{~mm}$ & $\mathrm{O}$ & $\mathrm{O}$ \\
\hline 9 & & $40: 40: 20$ & 3 Layers & 3 Layers & $16 \mathrm{~mm}$ & $\mathrm{X}$ & $\mathrm{O}$ \\
\hline 10 & & $30: 30: 40$ & 3 Layers & 3 Layers & $16 \mathrm{~mm}$ & $\mathrm{O}$ & $\mathrm{O}$ \\
\hline
\end{tabular}

Table 2.

Processing conditions for ten kinds of kenaf-imbedded specimen.

Therefore, to examine the effect of the polyurethane (PU)-laminating film treatment on the thermal conductivity, water absorption, and sound absorption properties of the kenaf-imbedded nonwoven, a second batch of specimens was prepared by the same procedure as that for the first batch. Table 3 presents the eight types of nonwoven specimen as a second batch of specimens. Two types of specimen were prepared as nonlaminated (1-4) and laminated (5-8) by PU film. The blend ratio of kenaf, PP, and LM PET staple fibers was 40,40 , and $20 \%$ as a fixed blend ratio. The carding treatment was conducted twice, and the number of layers of the carding lap was fixed at three. The needle depth was fixed at $16 \mathrm{~mm}$. In the thermo-compression bonding process, the surface temperature of the bonding roller was set at $170^{\circ} \mathrm{C}$, and its velocity was fixed at $7.2 \mathrm{~m} / \mathrm{min}$. Specimens 1 and 3 were treated with powder after the thermo-compression bonding process and have different weight. Specimens 2 and 4 were non-treated and also have different weight. Specimens 5-8 were laminated by PU film after the needle-punching nonwoven process. The temperature of the laminating roller was $129^{\circ} \mathrm{C}$, and the

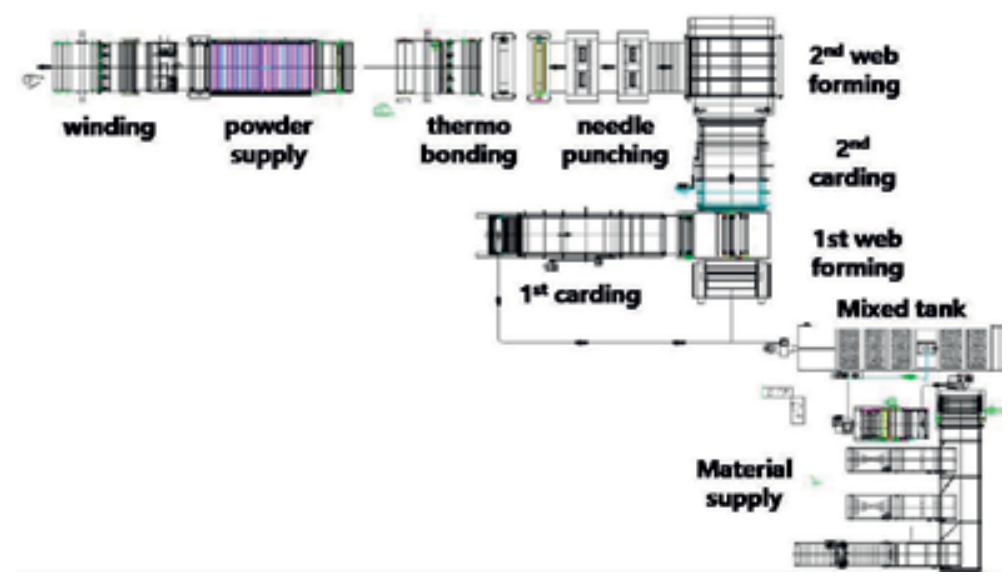

Figure 1.

Needle-punching nonwoven process. 


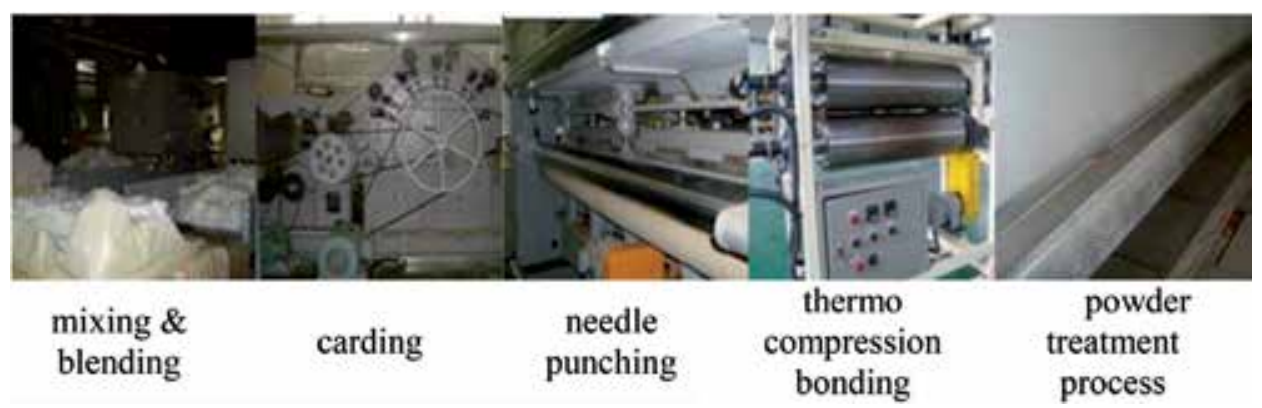

Figure 2.

Image of the nonwoven machinery.

doting temperature on the melting apparatus was set at $126^{\circ} \mathrm{C}$ and the feed speed of the laminating roller at $3.7 \mathrm{~m} / \mathrm{min}$. After laminating by PU film, aging was carried out at $60 \%$ of $\mathrm{RH}$ in the aging room for 24 hours.

\subsection{Measurement of physical properties}

\subsubsection{Tensile and tearing strengths}

The breaking strength and strain of the nonwoven specimens were measured using Testometric apparatus (Model Micro 350, England) according to KSK ISO 90733: 2009. A specimen of width $50 \mathrm{~mm}$ and length $200 \mathrm{~mm}$ was prepared and elongated at a speed of $100 \mathrm{~mm} / \mathrm{min}$. The tearing strength of the nonwoven specimens was measured using Testometric apparatus (Model Micro 350, England) according to KSK ISO 9073-4: 2010. A specimen of width 75 and length $150 \mathrm{~mm}$ was prepared. In addition, the breaking strength, strain, and initial modulus of the nonwoven specimens prepared at machine direction (MD) intervals of 30 degrees were measured. The preparation of the specimens is shown in Figure 4. Furthermore, the orientation factor of fibers in the nonwoven specimens was calculated as the measured inclined angle $(\theta)$ of the 500 fibers in the nonwoven fabric as shown in Figure 5, and the distribution of the measured angles was analyzed in relation to the measured tensile property.

\subsubsection{Thickness}

The thickness of the ten (first batch specimen) and eight (second batch specimen) different nonwoven specimens was measured using the FAST-1 system. Figure 6 shows an image and schematic diagram of the compression meter by FAST- 1 system [28]. The thickness $(\mathrm{mm})$ at a compression force of $2 \mathrm{gf} / \mathrm{cm}^{2}$ was measured, and 30 assessments of each specimen were carried out for calculating the mean thickness.

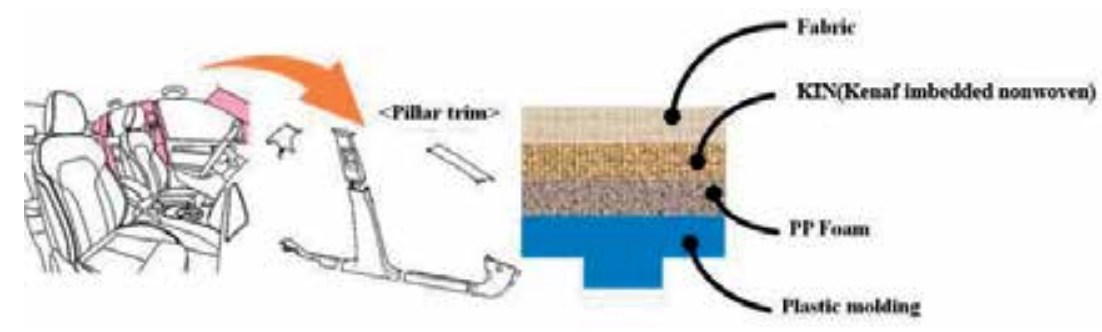

Figure 3.

Schematic diagram of pillar trim. 


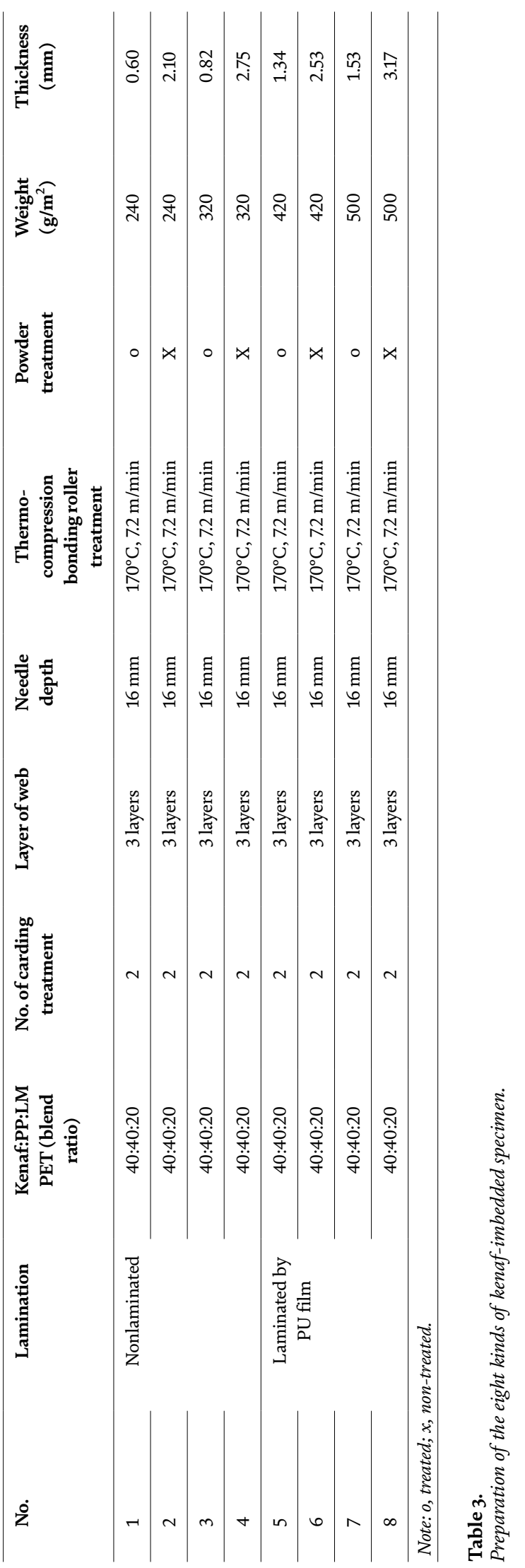




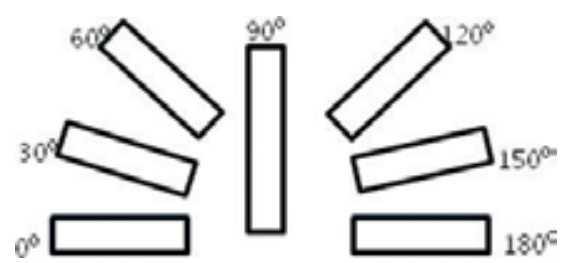

Figure 4.

Preparation of specimens for measuring tensile property of nonwoven fabric.

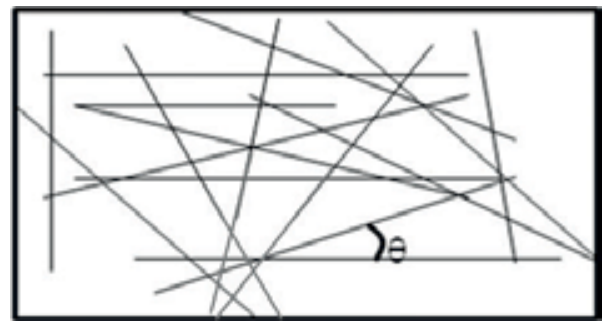

Figure 5.

Measured orientation angle of the fibers in the nonwoven.

\subsubsection{Porosity}

The pore size (diameter, $\mathrm{D}, \mu \mathrm{m}$ ) was measured using a capillary flow porometer (CFP-1200AE PMI Co., USA). The measured pore diameter (D) was calculated using Eq. (1) with the median value of the graph between the air flow and pressure. The mean and largest pore diameters were measured for each specimen:

$$
\text { Pore diameter }(\mathrm{D})=\frac{\mathrm{C} \tau}{\rho}
$$

where $C$ is a constant, $\tau$ the surface tension of the liquor $($ dyne/cm), and $\rho$ the pressure $\left(1 \mathrm{~b} /(\text { in })^{2}\right)$. Figure 7 shows the capillary flow porometer.

\subsubsection{Air permeability}

The air permeability (R) was measured using Fx3300 (TEXTEST, Switzerland) according to the KSK ISO 9237 method. An air pressure of $100 \mathrm{~Pa}$ was applied to a $20 \mathrm{~cm}^{2}$ area of the specimen, and the air permeability was calculated using the following Eq. (2). Figure 8 shows the air permeability measuring apparatus:

$$
\text { Air permeability }(\mathrm{R}, \mathrm{cm} 3 / \mathrm{cm} 2 / \mathrm{g})=\frac{\mathrm{Q}}{\mathrm{A}} \times 167
$$

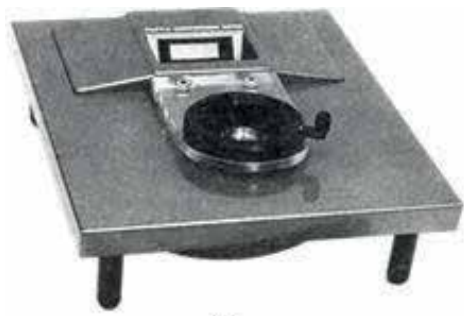

(a)

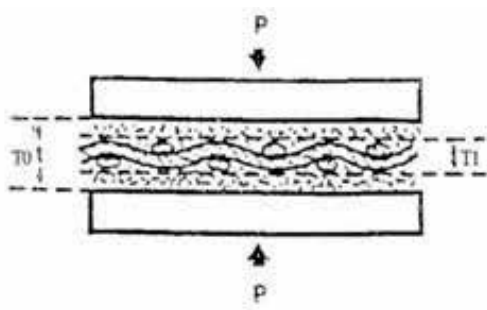

(b)

Figure 6.

FAST-1 system for measuring compressibility [28]. (a) Image of FAST-1 and (b) Schematic diagram. 


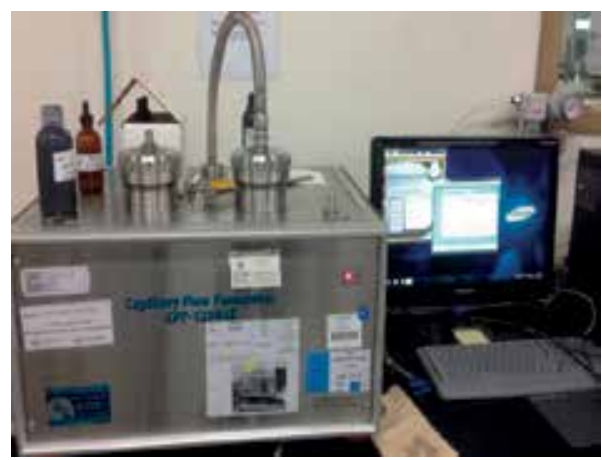

Figure 7.

Image of capillary flow porometer, CFP-1200AE.

where $Q$ is the arithmetic mean of air flow $\left(\mathrm{cm}^{3} / \mathrm{min}\right)$, A the area of the specimen $\left(\mathrm{cm}^{2}\right)$, and 167 the conversion constant.

\subsubsection{Water absorption property}

The water absorption property was assessed by KSK ISO 9073-6. The liquid absorption capacity (LAC) was calculated by Eq. (3):

$$
\text { LAC }=\frac{\text { weight of specimen absorbed }(B)-\text { weight of dried specimen }(A)}{\text { weight of dried specimen }(A)} \times 100
$$

A square specimen of dimensions $100 \mathrm{~mm} \times 100 \mathrm{~mm}$ was prepared and conditioned under $20 \pm 1^{\circ} \mathrm{C}$ and $65 \pm 5 \% \mathrm{RH}$. After its dry weight (A) was measured, the specimen was submersed to a depth of $20 \mathrm{~mm}$ in the water bath for $60 \mathrm{~s}$, then taken out, and hung horizontally for $120 \mathrm{~s}$, and finally its weight (B) was measured again, and LAC was calculated by Eq. (3) as the average value of five measurements.

\subsubsection{Sound absorption property}

The sound absorption coefficient of the nonwoven specimen was measured using acoustic duct (SCIEN-9301, USA) according to KSF2814-2: 2002. Figure 9 shows the acoustic duct apparatus.

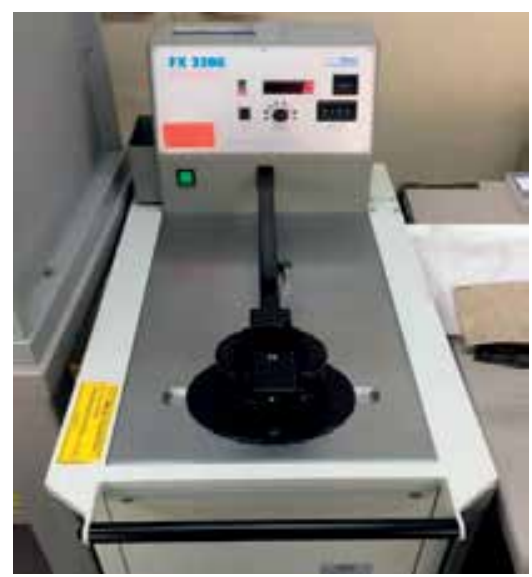

Figure 8.

Image of $F X 3300$. 


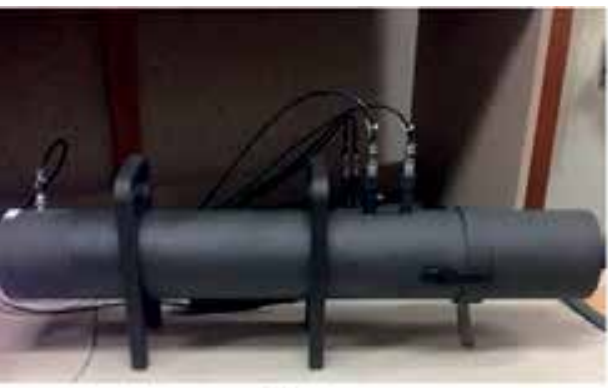

(a)

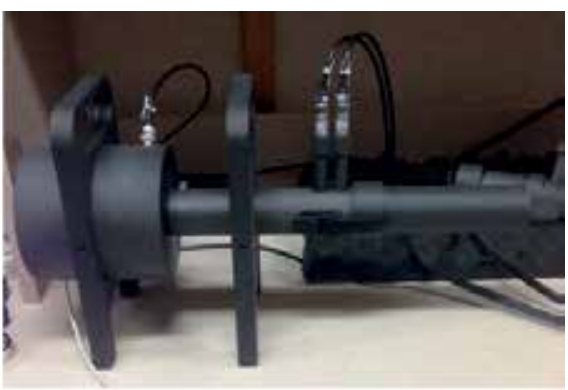

(b)

Figure 9.

Acoustic duct, SCIEN-9301. (a) Low Frequency and (b) High Frequency.

The specimen was fastened at the impedance tube's left wall, and a loudspeaker was attached at its right wall. Sound waves of well-defined frequencies were emitted by a loudspeaker. The nodes and antinodes of the standing waves emitted from the loudspeaker and those reflected from the specimens were detected by two small microphones, from which the sound absorption coefficient was calculated by frequency response transfer function from two microphone channels. The frequency used was between 100 and $1600 \mathrm{~Hz}$ for low frequency and between $500 \mathrm{~Hz}$ and $6.3 \mathrm{kHz}$ for high frequency.

\subsubsection{Measurement of thermal conductivity}

The thermal conductivity $(\mathrm{K})$ of the nonwoven specimen was measured using KES-F7 (Thermolabo, Kato Tech. Co. Ltd., Japan) and calculated using Eq. (4):

$$
\mathrm{Q}=\mathrm{K} \frac{\mathrm{A} \cdot \triangle \mathrm{T}}{d}
$$

where $Q$ is the heat loss $\left(\mathrm{W} / \mathrm{cm}^{2}\right), \mathrm{d}$ the specimen thickness $(\mathrm{cm}), \mathrm{A}$ the area of the specimen $\left(\mathrm{cm}^{2}\right)$, and $\Delta \mathrm{T}$ the temperature difference. Figure 10 shows an image of the KES-F7 measuring apparatus.

\subsubsection{Fogging test}

A fogging test of the nonwoven specimen was performed to examine the emission of volatile organic compounds (VOC) using the gravimetric method according to KSM ISO 6452. A circular specimen of diameter $80 \pm 1 \mathrm{~mm}$ was prepared and put

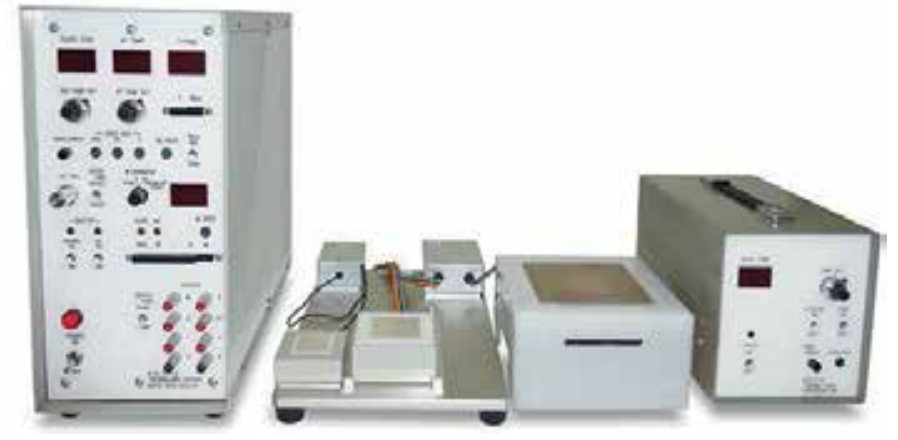

Figure 10.

Image of the KES-F7 measuring apparatus. 
into a thermostatic bath covered with aluminum foil which was boiled for 16 hours at $100^{\circ} \mathrm{C}$. The fogging value was calculated using the mass of aluminum foil wrapped on the beaker in the thermostatic bath before and after the experiment.

\subsubsection{Measurement of the surface texture of the nonwoven}

The surface texture of the nonwoven specimen was measured by SEM (S-4300, Hitachi Co., Japan) and optical microscopy (I Camscope 305A, Korea).

\section{Results and discussion}

\subsection{Physical properties of kenaf-imbedded nonwoven according to the processing conditions}

\subsubsection{Breaking and tearing strengths of the nonwoven}

Table 4 lists the physical properties of the ten kinds of nonwoven specimen.

Figure 11(a) and (b) shows the breaking and tearing strengths of the nonwoven specimens. Specimens 3 and 10 showed the highest breaking and tearing strengths. As shown in Table 4, specimens 3 and 10 had a smaller mean pore size and higher weight than the other specimens. Therefore, the effect of the mean pore size and weight on the breaking and tearing strengths of the nonwoven was investigated. Figure 12 shows a diagram of the breaking and tearing strengths according to the weight of the nonwoven specimens.

The breaking and tearing strengths of the MD and CD direction of the nonwoven specimen were increased with increasing weight of the nonwoven. This was attributed to the more numbers of fibers per unit area in the nonwoven specimens according to the increase of weight, which results in higher breaking and tearing strengths due to the more contribution of the fibers to the resistance from external load. Figure 13 shows a diagram of the breaking and tearing strengths according to the mean pore size. The breaking and tearing strengths of the nonwoven specimens were decreased with increasing mean pore size of the nonwoven specimen, possibly due to the weakened resistance from external force due to the large pore size in the nonwoven. In addition, the breaking and tearing strengths of nonwoven specimen 2, as shown in Figure 11, were the lowest, which was attributed to its lowest weight and largest mean pore size as shown in Table 4.

On the other hand, the orientation factor and the distribution of the fibers in the nonwoven specimens were measured and discussed to examine their effect on the breaking and tearing strengths of the nonwoven. Figure 14 presents the fiber orientation distribution of the ten types of nonwoven specimen.

As shown in Figure 14, the fiber orientation distributions of specimens 1, 2, 6, and 8 exhibited the shape of a quasi-Gaussian distribution, whereas that of specimens 3 and 10 exhibited a double quasi-normal distribution. Furthermore, specimens 4, 5, 7, and 9 exhibited a random distribution of fiber orientation in the nonwoven, i.e., the number of fibers according to the orientation angle was randomly distributed. As shown previously in Figure 11, specimens 3 and 10 exhibited the highest tearing and breaking strengths, respectively, whereas specimen 2 showed the lowest breaking and tearing strengths. This means that the fiber distribution in the nonwoven does not directly affect the breaking and tearing strengths, because specimen 2 with high distribution of fibers between $60^{\circ}$ and $120^{\circ}$ as a normal distribution exhibited low breaking strength, but specimens 1,6 , and 8 with the same normal distribution as specimen 2 showed higher breaking strength than that of the specimen 2. Furthermore, it was assumed 


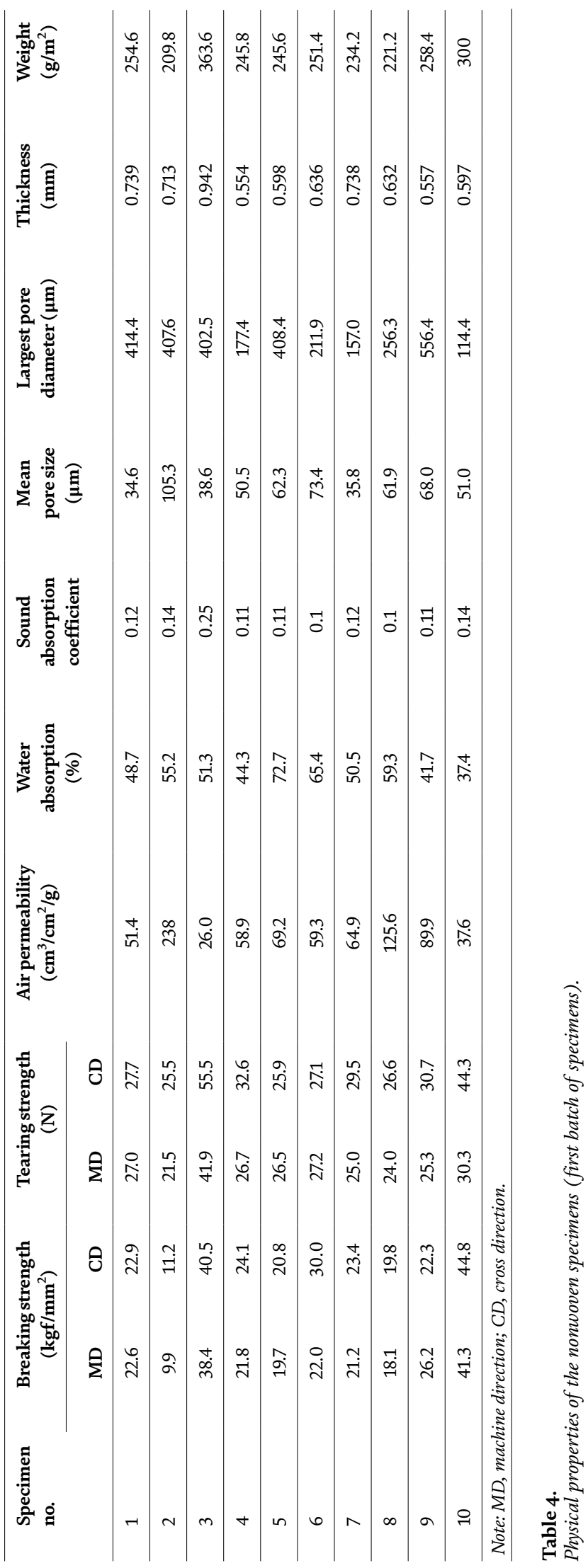




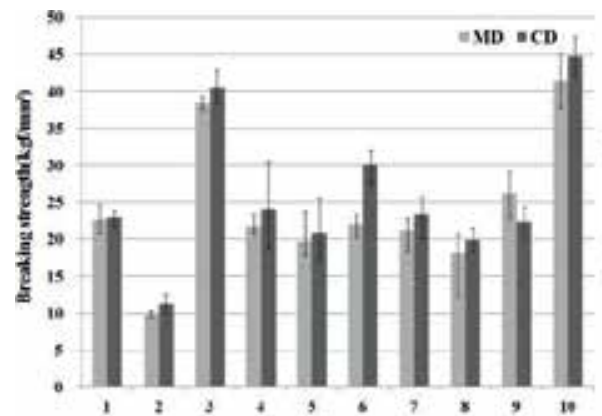

(a)

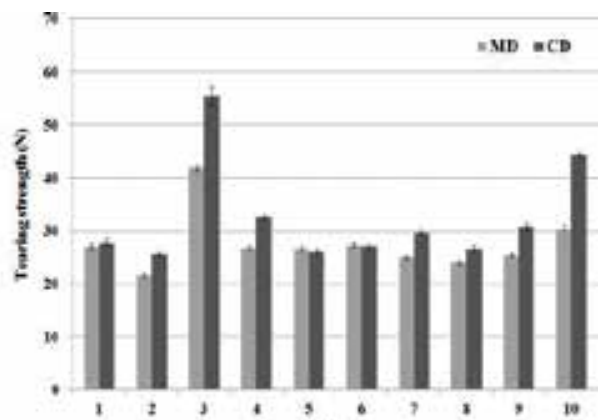

(b)

Figure 11.

Breaking and tearing strengths of the nonwoven specimens. (a) Breaking strength and (b) Tearing strength.

that high breaking and tearing strengths of specimens 3 and 10, which showed a double quasi-normal distribution, were attributed to the processing conditions of nonwoven. In addition, the breaking and tearing strengths of nonwoven specimen 2 were measured and discussed according to the cut direction of the nonwoven specimens. Figure 15 shows the tensile property of specimen 2 according to the cut direction of the specimen. The breaking strength, breaking strain, and initial modulus of the specimens cut along $\mathrm{MD}$, i.e., perpendicular to the cross direction (CD), exhibited maximum values, which was attributed to the many fibers distributed and oriented perpendicular to the CD.

\subsubsection{Air permeability}

Figure 16(a) presents the air permeability and mean pore size of the nonwoven specimens. Specimens 2 and 8 showed high air permeability, which was attributed to the large pore size and low weight of the nonwoven, as shown in Table 4. These specimens were processed under the double-carding treatment in the multi-opener with three

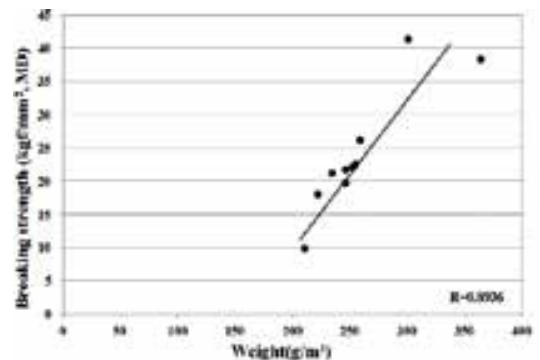

(a)

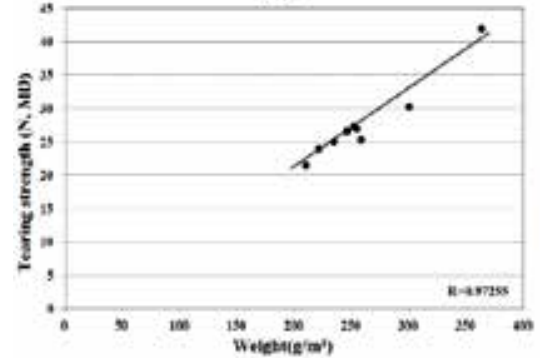

(c)

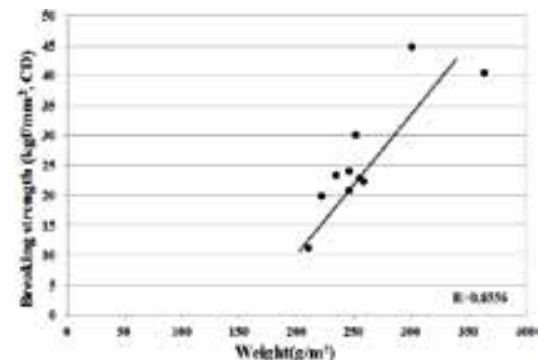

(b)

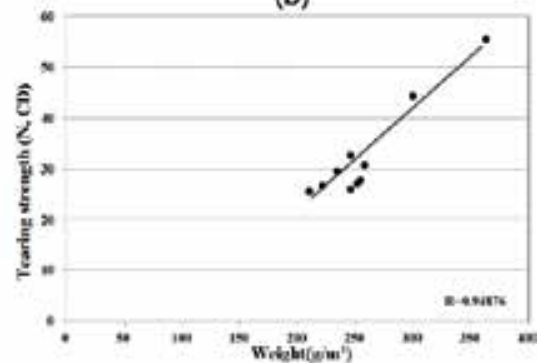

(d)

Figure 12.

Diagram of the breaking and tearing strengths according to the weight of the nonwoven specimens. (a) Breaking strength (MD) vs weight, (b) Breaking strength (CD) vs weight, (c) Tear strength $(M D)$ vs weight and (d) Tear strength $(C D)$ vs weight. 


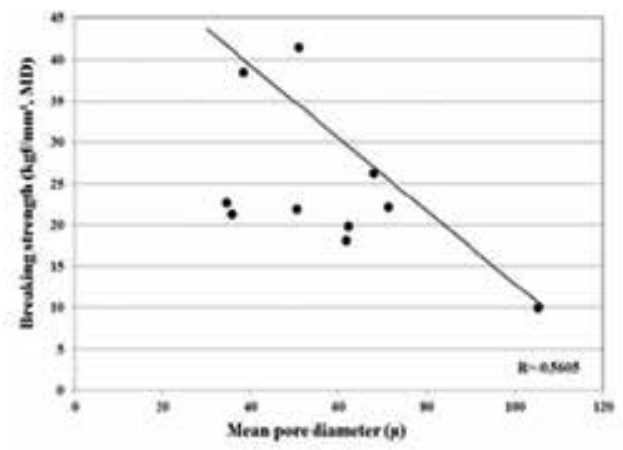

(a)

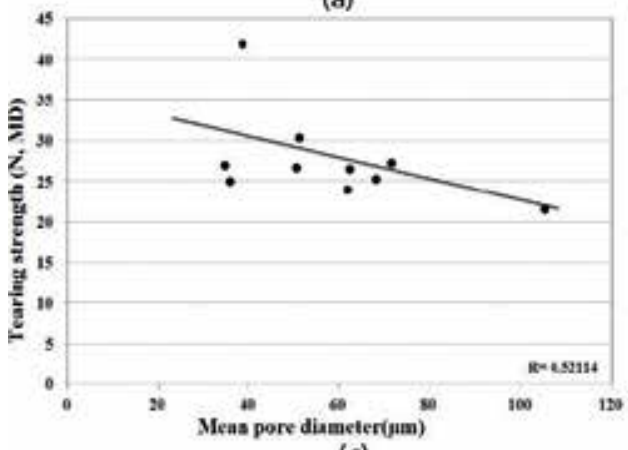

(c)

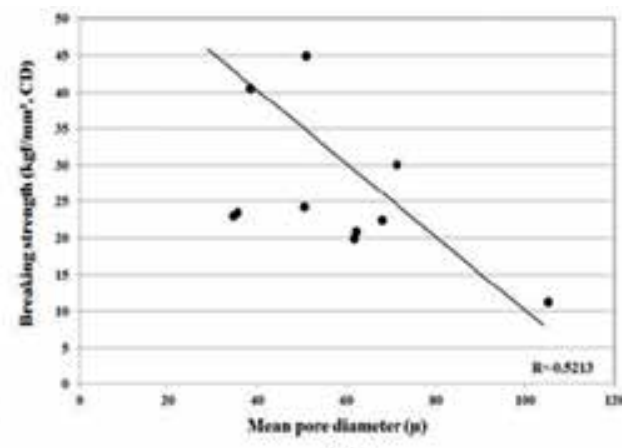

(b)

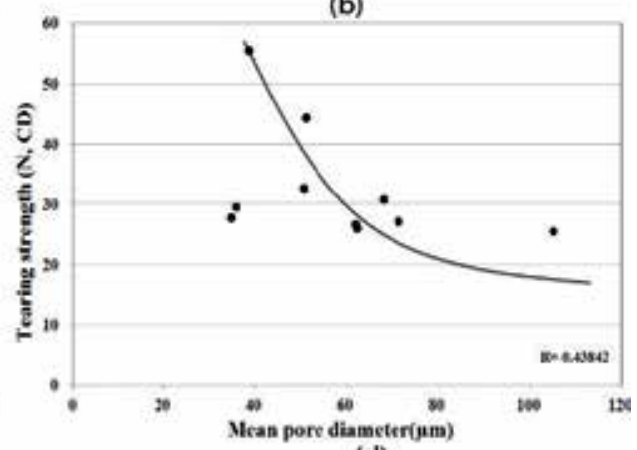

(d)

Figure 13.

Diagram of the breaking and tearing strengths according to the mean pore size of the nonwoven specimens. (a) Breaking strength $(M D)$ vsmean pore size, (b) Breaking strength $(C D)$ vsmean pore size, $(c)$ Tear strength $(M D)$ vsmean pore size and $(d)$ Tear strength $(C D)$ vsmean pore size.

layers of web and needle depth of 16 or $14.4 \mathrm{~mm}$. According to two previous studies $[26,27]$, nonwoven prepared using circular cross-sectional fibers exhibited the highest air permeability than nonwoven with noncircular fiber cross section, which was attributed to the highest pore diameter of nonwoven with circular fibers. These results were similar to our own. Figure 16(b) shows a correlation diagram between the mean pore diameter and air permeability of the ten different nonwoven specimens. The air permeability was highly dependent on the mean pore diameter of the nonwoven, and the correlation coefficient between the two parameters was 0.85 , which was relatively high.

\subsubsection{Water absorption}

Figure 17 shows the LAC of the nonwoven specimens. Specimens 2, 5, 6, and 8 showed high liquid absorption, which was related with their large mean pore size. Furthermore, specimens 2, 5, 6, and 8 had larger pore diameter than specimens 4, 7, and 9, as shown in Table 4. In particular, the air permeability (Figure 16) and liquid absorption (Figure 17) of specimen 10 were the lowest, which was attributed to its high percentage of LM PET, i.e., the voids in the nonwoven were blocked by the LM PET that was heat melted on the thermo-compression bonding roller, which shrunk the voids and reduced the air and water flows and hence reduced the air permeability and liquid absorption. According to a previous study [27], high-volume porosity gives high vertical wicking rate, which was a similar result to our own.

\subsubsection{Sound absorption coefficient}

Figure 18(a) and (b) presents the sound absorption coefficient according to the high frequency between 500 and $6300 \mathrm{~Hz}$ and the average sound absorption coefficient 


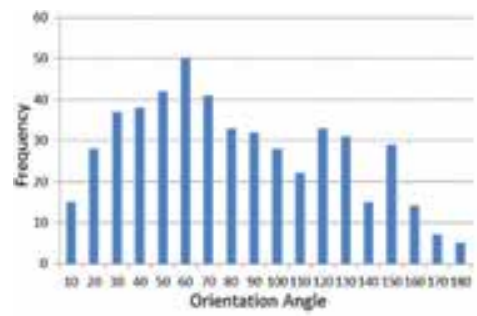

(a)

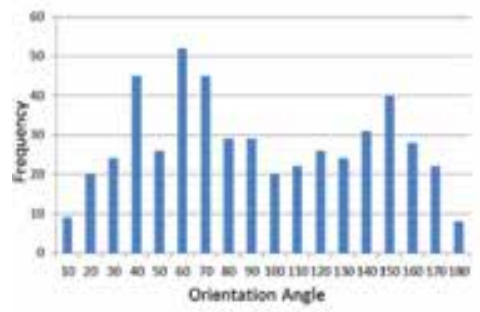

(c)

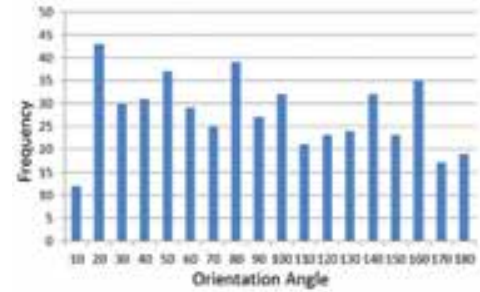

(c)

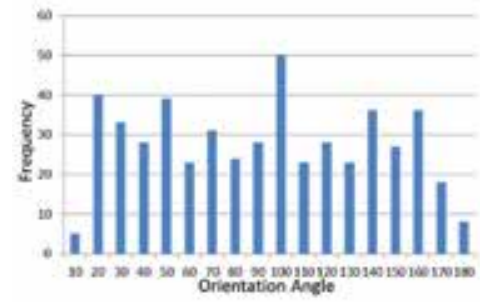

(g)

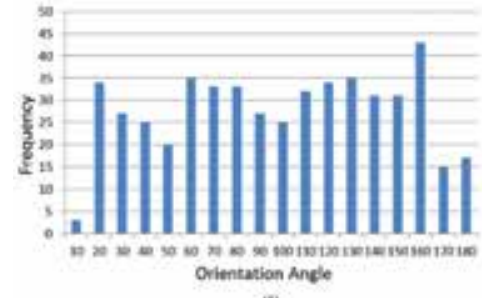

(i)

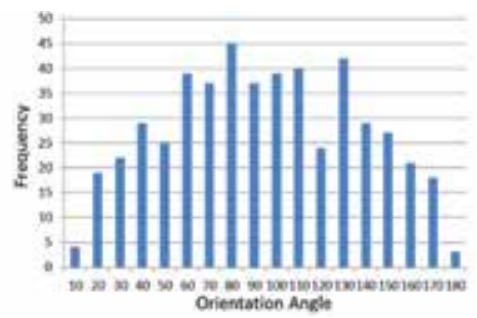

(b)

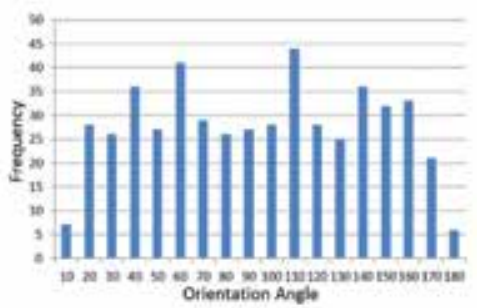

(d)

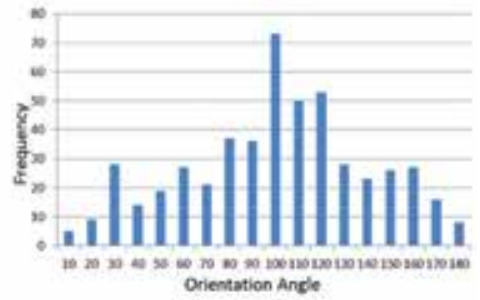

(1)

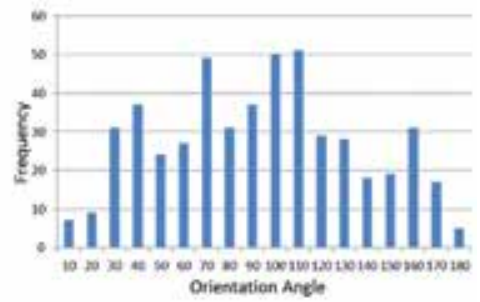

(h)

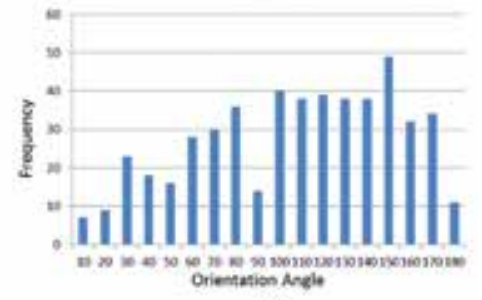

(i)

Figure 14.

Orientation of the fibers in the nonwoven specimens. (a) specimen 1, (b) specimen 2, (c) specimen $3,(d)$ specimen 4, (e) specimen $5,(f)$ specimen 6, $(g)$ specimen $7,(h)$ specimen $8,(i)$ specimen 9 and $(j)$ specimen 10.

of the nonwoven specimens, respectively. Specimens 2, 3, and 10, which had either high thickness and low weight or low thickness and high weight, showed a high sound absorption coefficient. The sound absorption coefficient under high frequency was highly dependent on the thickness and weight of the nonwoven and also partly affected by the pore diameter [19-21]. The sound absorption coefficient of specimen 3 was the largest, which was attributed to its high weight and low pore diameter. 
Characteristics of Eco-friendly Kenaf Fiber-Imbedded Nonwoven for Automotive Application DOI: http://dx.doi.org/10.5772/intechopen.85367

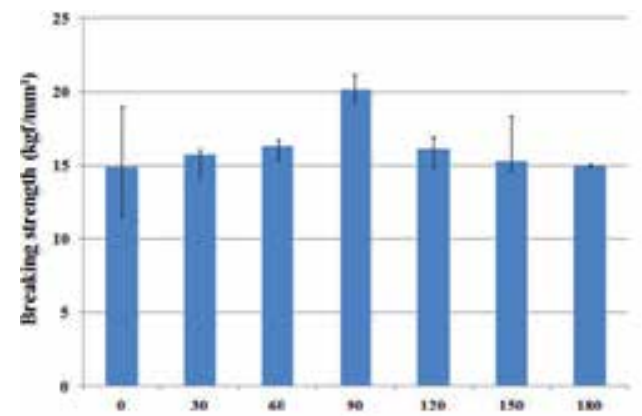

(a)

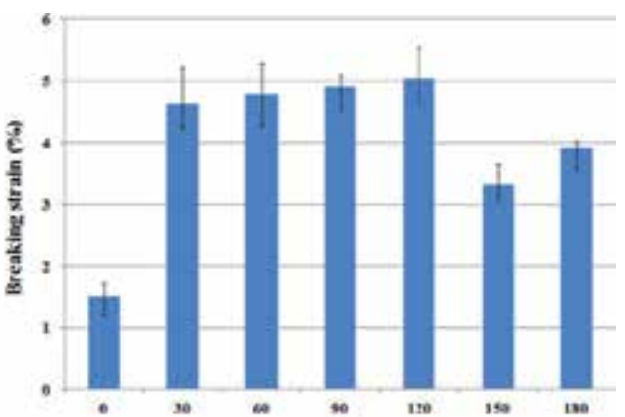

(b)

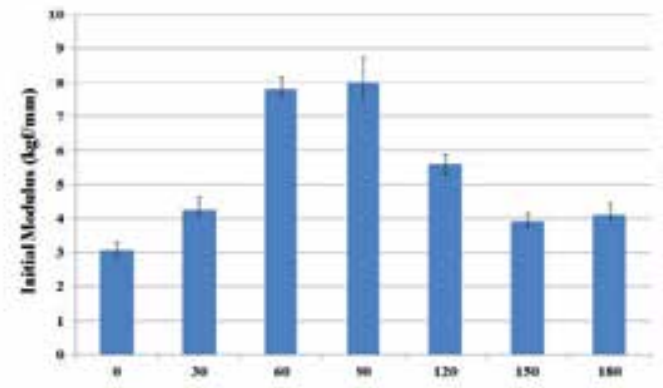

(c)

Figure 15.

Tensile property of the specimen (no. 2). (a) Breaking strength, (b) Breaking strain and (c) Initial modulus.

Table 5 shows the correlation coefficient between the sound absorption coefficient under high frequency and the thickness and weight of the kenaf-imbedded nonwoven specimens. The sound absorption coefficient was highly correlated with

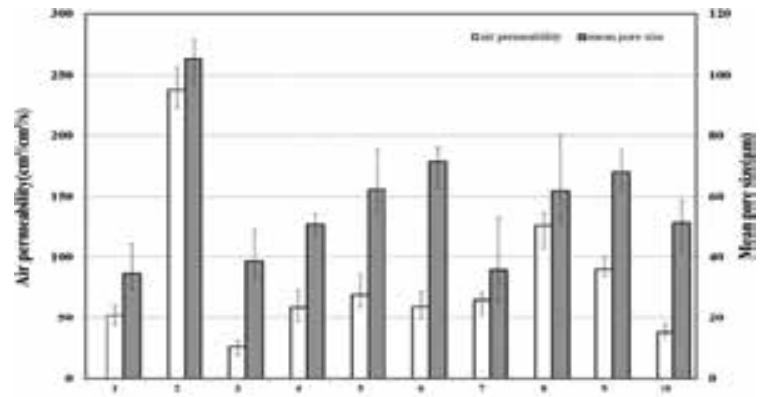

(e)

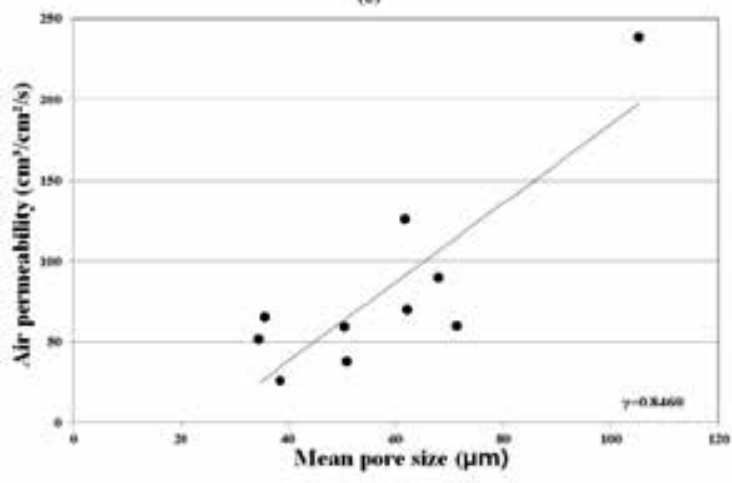

(b)

Figure 16.

Air permeability of the nonwoven specimens. (a) Air permeability of each specimens and (b) Air permeability vs Mean pore size. 


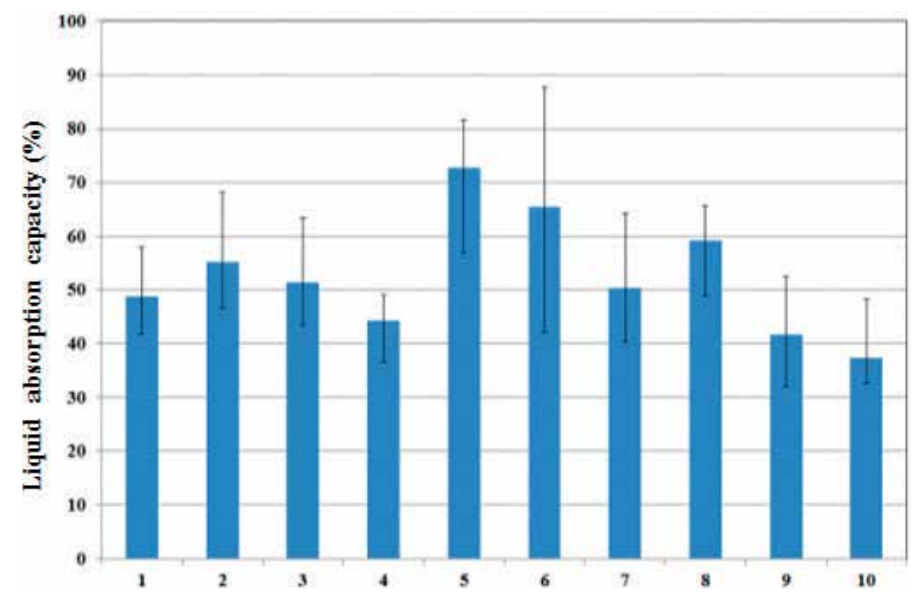

Figure 17.

Liquid absorption of specimens.

the thickness and weight, indicating that the nonwoven specimens with high thickness, high weight, and small pore size have a high sound absorption coefficient. In addition, these nonwoven specimens were made under manufacturing conditions of high needle depth or high blend ratio of LM PET. Lee and Joo [20] found that the sound absorption coefficient of nonwoven mixed with a large amount of fine fibers is high due to the friction of viscosity through the vibration of the air. Another study [21] attributed the increases in thickness and in the amount of the fiber per unit area to an increase in the sound absorption property of the nonwoven. These previous results were similar to our own.

\subsubsection{Fogging property}

A fogging test was carried out to determine the emission of volatile organic compounds (VOC) from automotive interior materials with increasing interior temperature during the summer time. Figure 19 presents the fogging values of the nonwoven specimens. Specimen 1 treated with a single opener, specimen 4 treated with the one-time carding process, and specimen 5 treated with four layers of web showed high fogging values, whereas specimens 2,6 , and 8 , with large mean pore size and high air permeability and water absorption, exhibited low fogging values. This was attributed to the easy flow of VOC gases developed from the nonwoven due to their large pores.

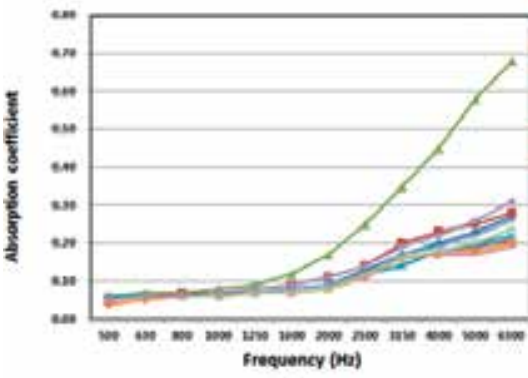

(a)

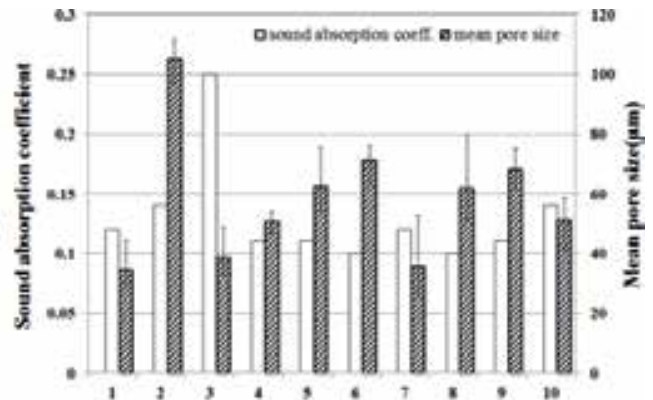

(b)

Figure 18.

Sound absorption coefficient of the nonwoven specimens. (a) Sound absorption coefficient and $(b)$ Average sound absorption coefficients. 


\begin{tabular}{cccc}
\hline & & Thickness $(\mathbf{m m})$ & Weight $\left(\mathbf{g} / \mathbf{m}^{2}\right)$ \\
\hline Sound absorption coefficient & High frequency & 0.91 & 0.83 \\
\hline
\end{tabular}

Table 5.

Correlation coefficient between physical properties and sound absorption coefficient of nonwoven.

\subsection{Physical properties of the kenaf-imbedded nonwoven according to powder treatment and laminated PU coating}

\subsubsection{Breaking and tearing strengths}

Table 6 shows the physical properties of the kenaf-imbedded nonwoven specimens treated with powder and laminated by PU film, respectively.

Figure 20 presents the breaking and tearing strengths of the kenaf-imbedded nonwoven specimens treated and non-treated with laminated PU film. The breaking and tearing strengths of the laminated specimens were higher than those of the non-treated specimens, which was attributed to the PU film laminated on the nonwoven surface, resulting in higher weight and thickness. In addition, as shown in Figure $\mathbf{2 0}(\mathbf{b})$ and (d), the non-powder-treated specimens (6 and 8) exhibited higher breaking and tearing strengths than the powdertreated specimens ( 5 and 7 ), which were assumed to be weakened by adhesion between the PE powder and PU film by the heat on the laminating roller. On the other hand, as shown in Figure 20(a), powder-treated specimens (1 and 3) exhibited higher breaking strength than the non-treated specimens ( 2 and 4$)$, which was attributed to the enhancement of coherence between PE powder and LM PET fibers that were heat melted on the thermo-compression bonding roller.

Figure 21 presents a diagram of the fiber orientation of the nonlaminated nonwoven specimens (1-4). The degree of fiber orientation in the nonwoven was calculated as the mean of $\cos ^{2} \theta$ of each specimens, i.e., unity of this value means orientation of fiber along the machine direction (MD) in the nonwoven, whereas zero value means fiber orientation along the cross direction (CD) in the nonwoven. Of these specimens, specimen 3 showed the highest value as a 0.46 , and specimen 4 exhibited the lowest value as a 0.33 , which resulted in the high difference between $\mathrm{MD}$ and $\mathrm{CD}$ in the breaking strength of this specimen 4 as shown in Figure 20(a) and (c).

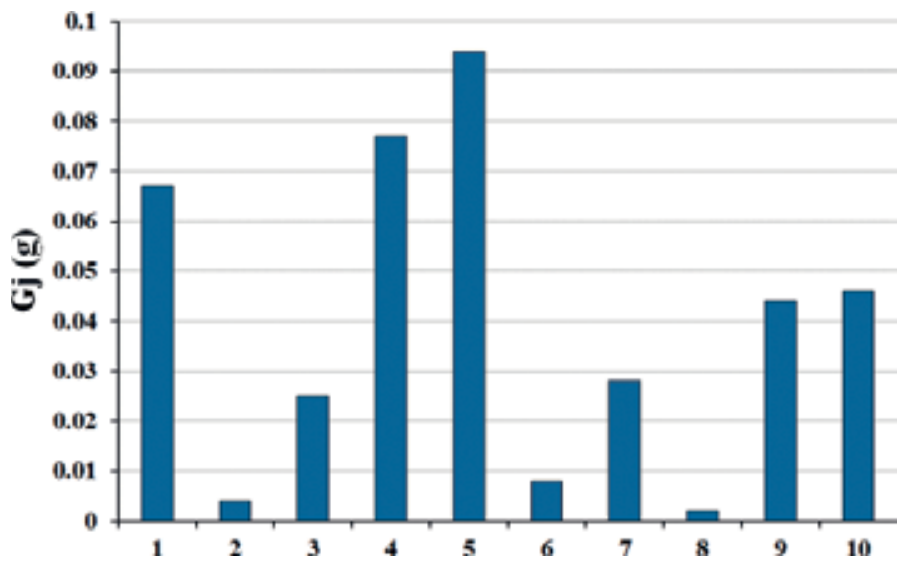

Figure 19.

Fogging values of the nonwoven specimens. 


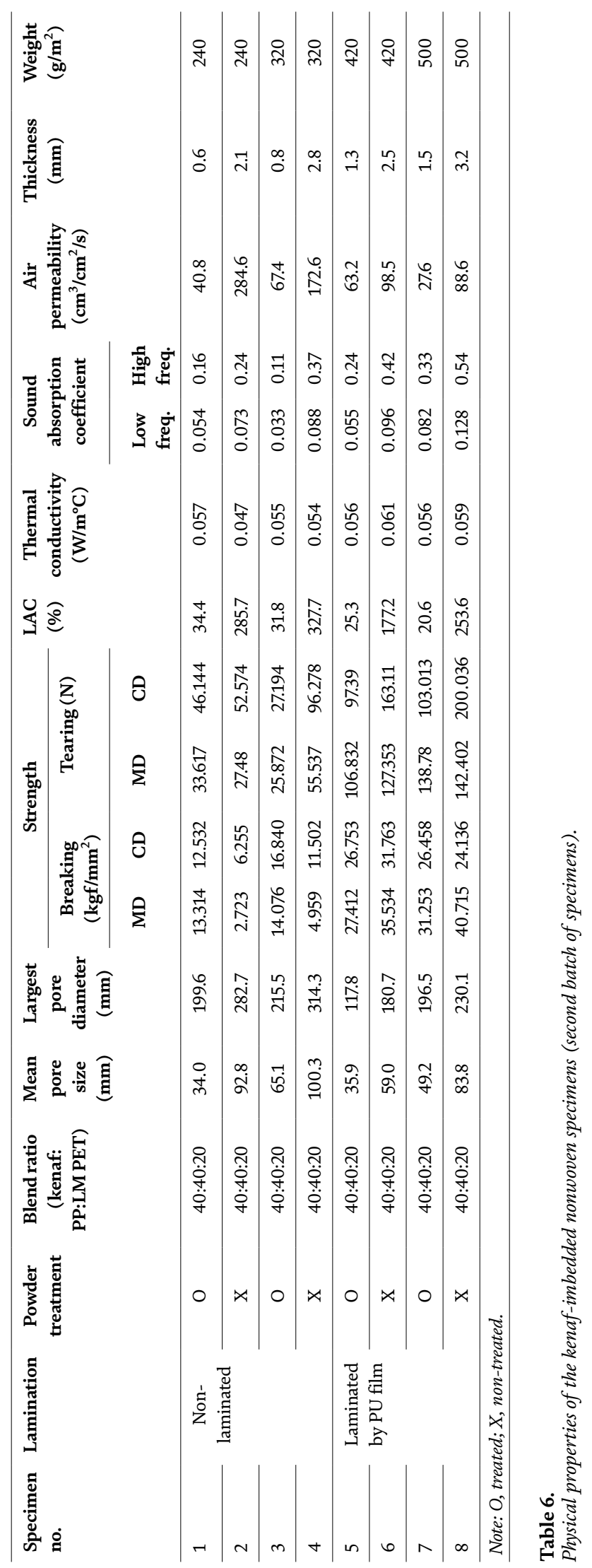


Characteristics of Eco-friendly Kenaf Fiber-Imbedded Nonwoven for Automotive Application DOI: $h$ ttp://dx.doi.org/10.5772/intechopen. 85367

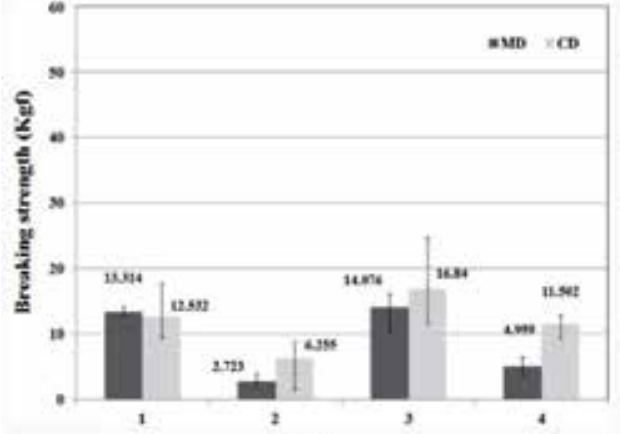

(a)

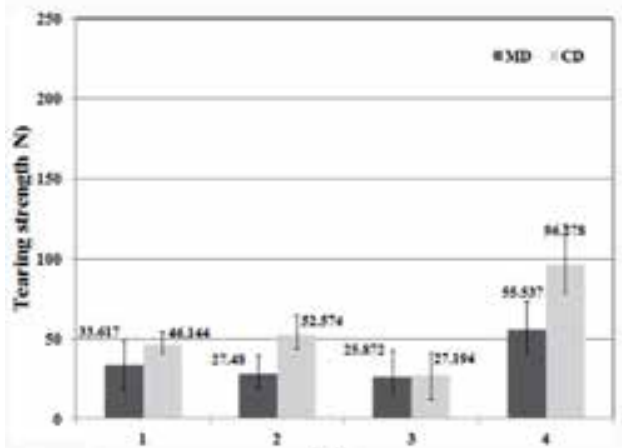

(c)

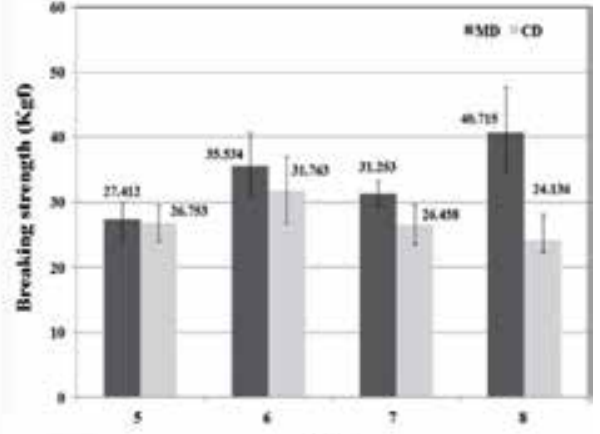

(b)

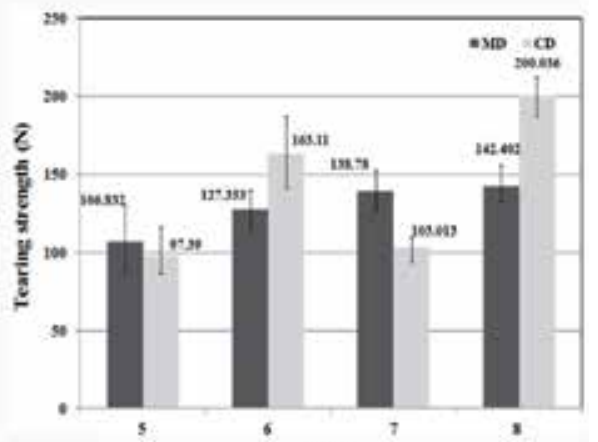

(d)

Figure 20.

Breaking and tearing strengths of the kenaf-imbedded nonwoven specimens (second group of specimens). (a) Breaking strength of nonlaminated specimens, (b) Breaking strength of laminated specimens, $(c)$ Tearing strength of nonlaminated specimens and $(d)$ Tearing strength of laminated specimens.

\subsubsection{Air permeability and water absorption}

Figure 22 shows the air permeability and water absorption of the kenafimbedded nonwoven specimens treated and nonlaminated with laminated PU film.

The differences of the air permeability and water absorption between the laminated and nonlaminated specimens were much lower than those between the

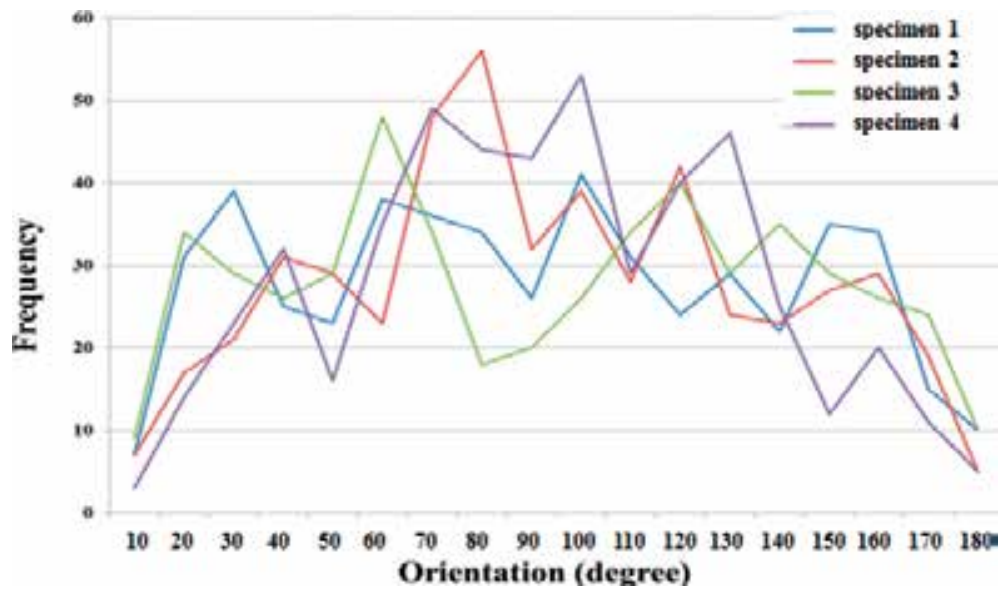

Figure 21.

Orientation of nonlaminated nonwoven specimens. 


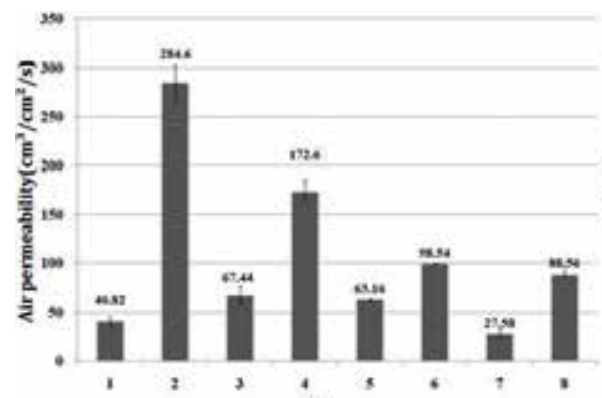

(a)

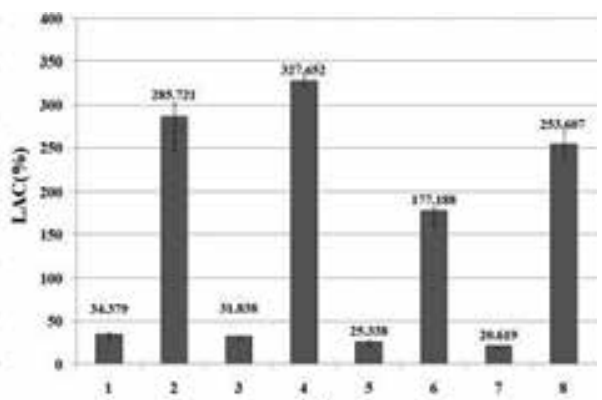

(b)

Figure 22.

Air permeability and water absorption of the kenaf-imbedded nonwoven treated and non-treated with laminated PU film. (a) Air permeability and (b) Water absorption.

powder-treated and non-treated specimens, i.e., the air permeability and water absorption of the non-powder-treated specimens $(2,4,6$, and 8$)$ were much higher than those of the powder-treated specimens $(1,3,5$, and 7$)$. Furthermore, the nonlaminated specimens (1-4) exhibited higher air permeability and water absorption than did the laminated specimens (5-9). This was attributed to the small pore size of the powder-treated and laminated specimens, which was caused by the blockage of the pores in the nonwoven by melted powder in the thermo-compression bonding process and partly melted $\mathrm{PU}$ in the laminating process. This was verified by the mean pore and largest pore diameters of the kenaf-imbedded nonwoven specimens, as shown in Figure 23.

The mean pore and largest pore diameters of the non-powder-treated $(2,4,6$, and 8$)$ and nonlaminated (1,2,3, and 4) specimens were much larger than those of the powder-treated (1, 3, 5, and 7) and laminated (5, 6, 7, and 8) specimens, respectively.

\subsubsection{Thermal conductivity}

Figure 24 shows the thermal conductivity of the kenaf-imbedded nonwoven specimens treated and non-treated with laminated PU film. The thermal conductivities of the powder-treated (1,3,5, and 7) and laminated (5-8) nonwoven specimens were higher than those of the non-powder-treated $(2,4,6$, and 8$)$ and nonlaminated (1-4) specimens, respectively, which was attributed to less obstruction of heat particles' flow due to less air film in the smaller pores due to blockage of pores in the nonwoven by melted powder in the thermo-compression bonding process.

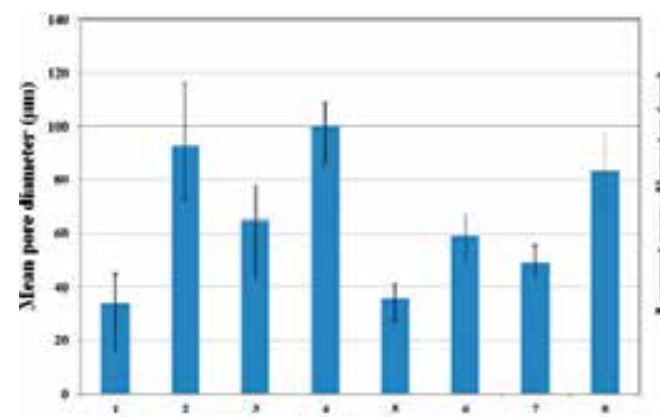

(a)

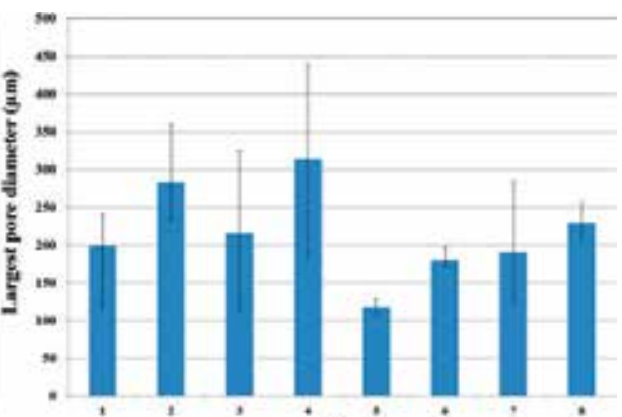

(b)

Figure 23.

Mean pore and largest pore diameters of the nonwoven specimens. (a) Mean pore dia and (b) Largest pore dia. 
Characteristics of Eco-friendly Kenaf Fiber-Imbedded Nonwoven for Automotive Application DOI: $h$ ttp://dx.doi.org/10.5772/intechopen. 85367

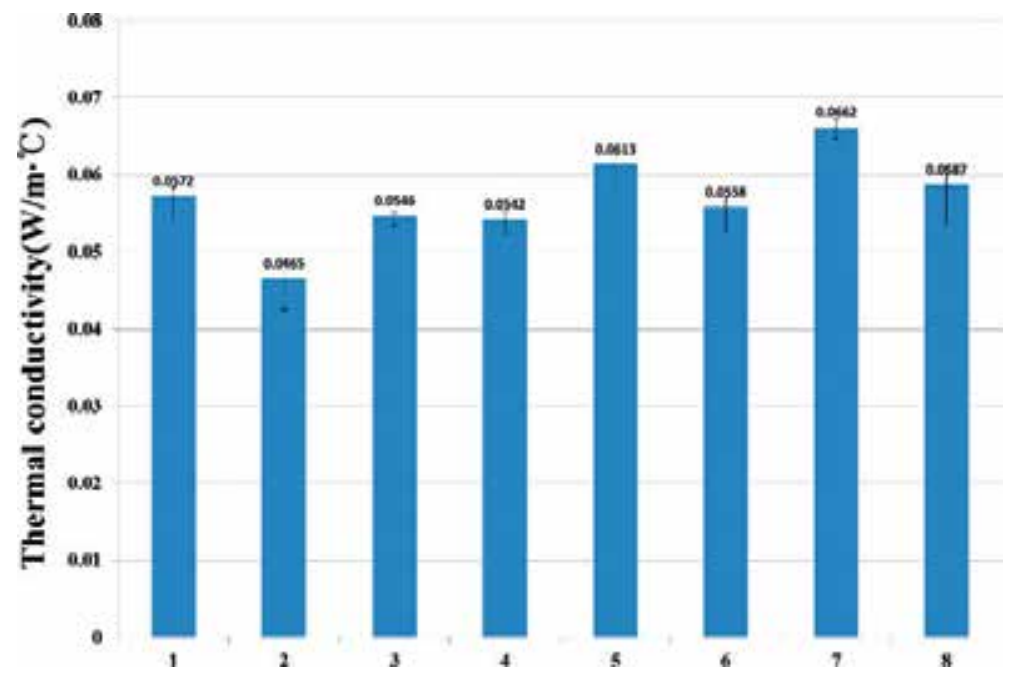

Figure 24.

Thermal conductivity of the laminated and nonlaminated nonwoven specimens.

\subsubsection{Sound absorption}

Figure 25 shows the sound absorption coefficients of the laminated and nonlaminated nonwoven specimens at low and high frequencies. The sound absorption coefficients of the laminated specimens $(5,6,7$, and 8$)$ were higher than those of the nonlaminated specimens $(1,2,3$, and 4$)$, which was attributed to the increased thickness of the nonwoven due to the laminated film on its surface. Furthermore, the sound absorption coefficients of the powder-treated specimens $(1,3,5$, and 7$)$

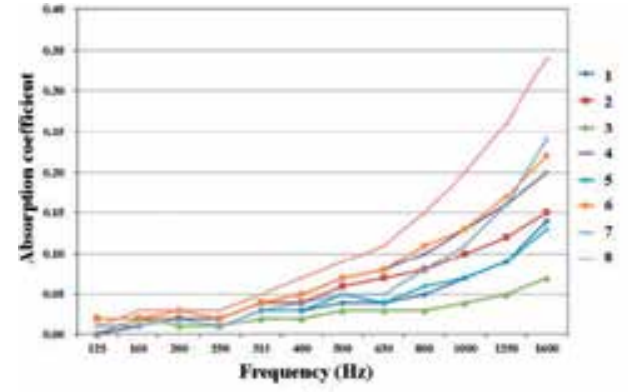

(a)

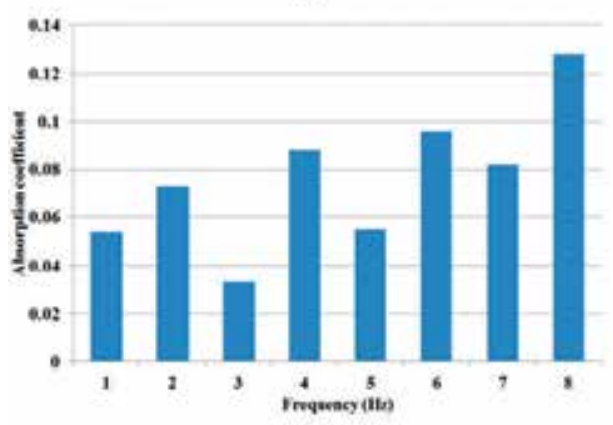

(c)

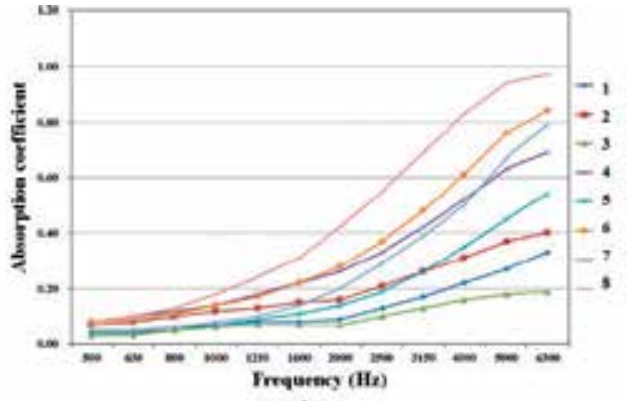

(b)

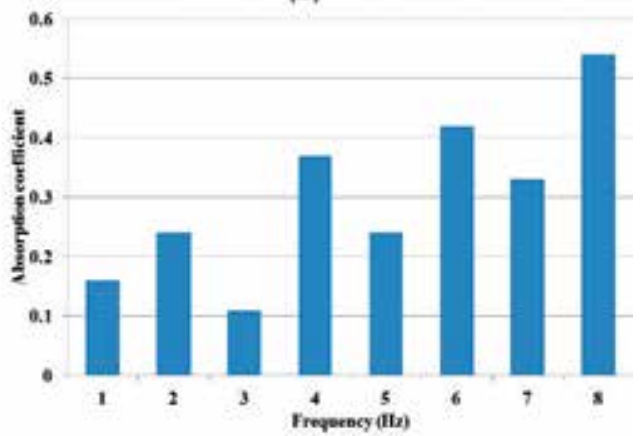

(d)

Figure 25.

Sound absorption coefficients of the kenaf-imbedded nonwoven specimens. (a) low frequency, (b) high frequency, (c) low frequency and (d) high frequency. 
were lower than those of the non-treated ones $(2,4,6$, and 8$)$, which was attributed to the thinner nonwoven and partly affected by its smaller pores due to blockage of the pores in the nonwoven by melted powder in the thermo-compression bonding process. In addition, the sound absorption coefficient of thick and heavy specimen 8, which was non-powder-treated and PU-laminated, was the highest, whereas those of thin and light specimens 1 and 3, which were powder-treated and nonPU-treated, exhibited lower value than others. The sound absorption coefficients of the laminated and nonlaminated nonwoven specimens according to the sound frequency during measurement exhibited a rapid increase around $630 \mathrm{~Hz}$ in the low-frequency experiment but showed a rapid increase around $1,600 \mathrm{~Hz}$ in the high-frequency experiment.

\subsubsection{Correlation between the physical properties and structural parameters of the kenaf-imbedded nonwoven specimens}

Table 7 presents the correlation coefficient between physical properties and structural parameters of the kenaf-imbedded nonwoven specimens.

The breaking and tearing strengths of the kenaf-imbedded nonwoven specimens were highly correlated with weight of the nonwoven and inversely correlated with mean pore diameter in the kenaf-imbedded nonwoven and the orientation factor of its fibers. In particular, tensile property of the nonwoven according to the orientation factor exhibited a similar result to that of Rawal et al. [29]. The air permeability was highly correlated with the mean pore diameter as a porosity in the kenaf-imbedded nonwoven, which can be compared with those of the previous findings $[26,30]$. The water absorption was also highly correlated with the mean pore diameter of the kenaf-imbedded nonwoven, and the thickness of the kenaf-imbedded nonwoven strongly affected its water absorption. This is in accordance with that of Das et al. [23]. They analyzed that more air trapped within the nonwoven with high porosity allows faster movement of water through pores. Furthermore, they suggested that this is in accordance with the theory of capillarity. The thermal conductivity of the nonwoven was dependent on its weight and was inversely correlated with its mean pore diameter. In addition, the sound absorption was highly correlated with thickness of the kenaf-imbedded nonwoven, and its

\begin{tabular}{|c|c|c|c|c|c|c|}
\hline & & \multicolumn{2}{|c|}{ Porosity } & \multirow{2}{*}{$\begin{array}{c}\text { Thickness } \\
(\mathbf{m m})\end{array}$} & \multirow{2}{*}{$\begin{array}{l}\text { Weight } \\
\left(\mathrm{g} / \mathrm{m}^{2}\right)\end{array}$} & \multirow{2}{*}{$\begin{array}{l}\text { Orientation } \\
\text { factor }\end{array}$} \\
\hline & & $\begin{array}{c}\text { Mean } \\
\text { pore } \\
\text { diameter } \\
(\mu \mathrm{m})\end{array}$ & $\begin{array}{c}\text { Largest } \\
\text { pore } \\
\text { diameter } \\
(\mu \mathrm{m})\end{array}$ & & & \\
\hline \multicolumn{2}{|c|}{ Breaking strength } & -0.55 & & 0.25 & 0.88 & -0.59 \\
\hline \multicolumn{2}{|c|}{ Tearing strength } & -0.48 & & 0.59 & 0.98 & -0.55 \\
\hline \multicolumn{2}{|c|}{ Air permeability } & 0.85 & 0.49 & 0.44 & -0.65 & \\
\hline \multicolumn{2}{|c|}{ Water absorption } & 0.91 & 0.68 & 0.84 & & \\
\hline \multicolumn{2}{|c|}{ Thermal conductivity } & -0.62 & & & 0.75 & \\
\hline \multirow[t]{2}{*}{$\begin{array}{l}\text { Sound } \\
\text { absorption }\end{array}$} & $\begin{array}{l}\text { Low } \\
\text { frequency }\end{array}$ & 0.43 & 0.60 & 0.90 & 0.65 & \\
\hline & $\begin{array}{l}\text { High } \\
\text { frequency }\end{array}$ & 0.41 & 0.48 & 0.91 & 0.83 & \\
\hline
\end{tabular}

Table 7.

Correlation coefficient between physical properties and structural parameters of the kenaf-imbedded nonwoven specimens. 


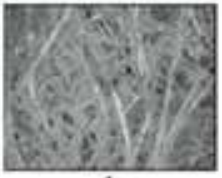

1

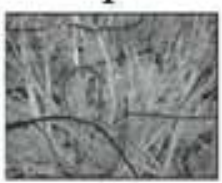

5

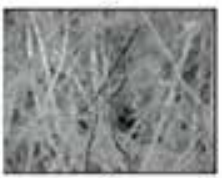

9

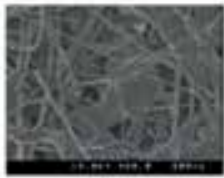

1

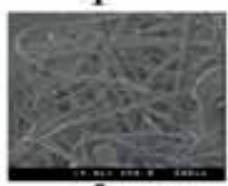

5

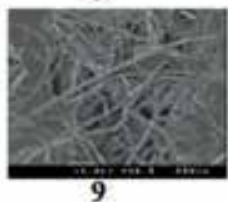

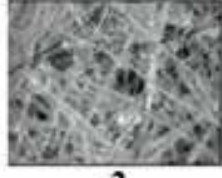

2

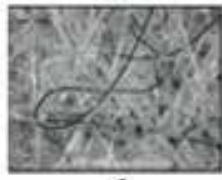

6

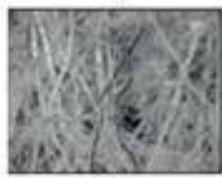

10

(a)

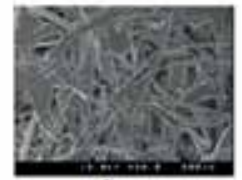

2

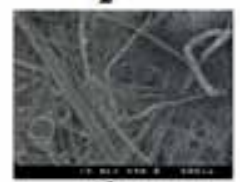

6

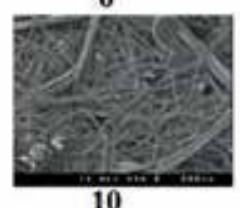

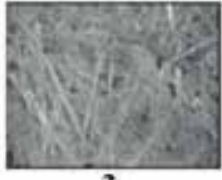

3

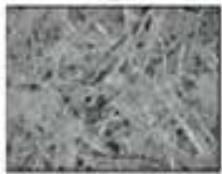

7

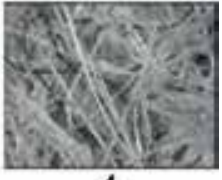

4

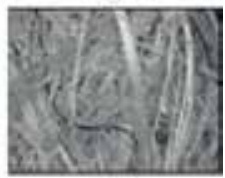

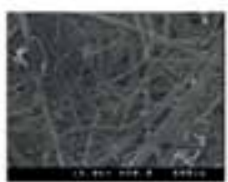

3

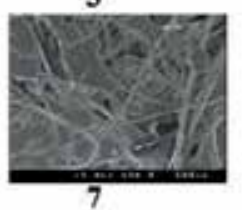

7

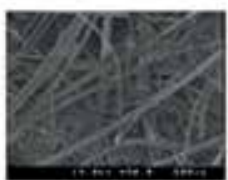

4

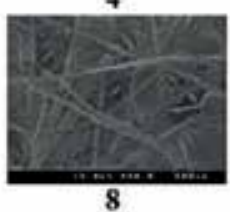

(b)

Figure 26.

Surface images of the kenaf-imbedded nonwoven specimens. (a) Optical microscopy (x100) and (b) SEM (x50).

weight affected the sound absorption, but its mean pore diameter did not. This was a similar result to those of previous studies $[20,21]$.

\subsubsection{Surface images of the kenaf-imbedded nonwoven specimens}

Figure 26 presents surface images of the kenaf-imbedded nonwoven specimens taken by SEM and optical microscopy.

The large pores observed for specimens 2, 6, and 9 resulted in high air permeability and water absorption, and these large pore diameters affected the breaking and tearing strengths. In addition, the thermal conductivity was inversely affected by the pore diameter. Specimens 1, 3, and 7 had small pore.

\section{Conclusion}

This study examined the relationship between the physical properties of kenafimbedded nonwoven and its structural factors according to the needle-punching 
nonwoven processing conditions. The physical properties of kenaf fiber-imbedded nonwoven were measured and compared according to the blend ratio of the constituent fibers and the different nonwoven processing conditions. The results are summarized as follows.

The breaking and tearing strengths of the kenaf-imbedded nonwoven were dependent on its weight and its mean pore size. Nonwoven specimens with high needle depth and/or a large amount of LM PET exhibited high breaking and tearing strengths. The air permeability was highly dependent on the mean pore diameter of the kenaf-imbedded nonwoven. Nonwoven specimens processed with double carding, three layers of web, and with a needle depth of $16 \mathrm{~mm}$ exhibited high air permeability, which was due to high mean pore diameter and low weight. The water absorption of the kenaf-imbedded nonwoven was highly correlated with its mean pore diameter and thickness. A high blend percentage of LM PET fibers reduced the pore size, which resulted in low air permeability and water absorption. The sound absorption coefficient of the kenaf-imbedded nonwoven under high frequency was highly dependent on its thickness and weight and was also partly affected by the pore diameter, i.e., the kenaf-imbedded nonwoven with high thickness and weight exhibited a high sound absorption coefficient, and small-pore nonwoven showed a low sound absorption coefficient, manufactured with high needle depth and/or a high blend ratio of LM PET. In addition, the large-pore nonwoven specimen with high air permeability and water absorption exhibited a low fogging value, which was attributed to the easy flow of VOC gases developed from the nonwoven due to its large pores. Regarding the effects of powder and laminated PU treatment on the physical properties of the kenaf-imbedded nonwoven fabric, the breaking and tearing strengths of the laminated specimens were higher than those of the nonlaminated specimens, and the non-powder-treated specimens exhibited higher breaking and tearing strengths than the powder-treated specimens after PU laminating. The air permeability and water absorption of the non-powder-treated specimens were much higher than those of the powder-treated specimens. Moreover, the laminated and non-powder-treated specimens exhibited higher sound absorption coefficient than did the nonlaminated and powder-treated specimens. On the other hand, the thermal conductivities of the powder-treated and PU-laminated specimens were higher than those of the non-powder-treated and nonlaminated ones.

\section{Author details}

Seung Jin $\mathrm{Kim}^{1 *}$ and Hyun Ah $\mathrm{Kim}^{2}$

1 Department of Fiber System Engineering, Yeungnam University, Gyeongsan, Korea

2 Korea Research Institute for Fashion Industry, Daegu, Korea

*Address all correspondence to: sjkim@ynu.ac.kr

IntechOpen

(C) 2019 The Author(s). Licensee IntechOpen. This chapter is distributed under the terms of the Creative Commons Attribution License (http://creativecommons.org/licenses/ by/3.0), which permits unrestricted use, distribution, and reproduction in any medium, provided the original work is properly cited. (cc) BY 


\section{References}

[1] Ramaswamy GN, Craft S, Wartelle L. Uniformity and softness of kenaf fibers for textile products. Textile Research Journal. 1995;65:765-770. DOI: $10.1177 / 004051759506501210$

[2] Tao W, Moreau JP, Calamari TA. Properties of nonwoven mats from kenaf fibers. Technical Association of Pulp \& Paper. Industry Journal. 1995;78:165-169

[3] Lee H, Ahn C, Kim J, Yoo H, Han Y, Song K. The characteristics of kenaf/ rayon fabrics. Journal of the Korean Society of Clothing and Textiles. 2004;20:1282-1291

[4] Lee H, Yoo H, Han Y. The properties of kenaf/polyester blended nonwovens. Journal of the Korean Society of Clothing and Textiles. 2007;31:1696-1706

[5] Bel-Berger P, Hoven TV, Ramaswamy GN, Kimmel L, Boylston E. Textile technology cotton/kenaf fabrics: A viable natural fabrics. The Journal of Cotton Science. 1999;3:60-70

[6] Weiying T, Calamari TA. Preparing and characterizing kenaf/cotton blended fabrics. Textile Research Journal. 1999;69:720-724

[7] Zhang X. Investigation of biodegradable nonwoven composite based on cotton, bagasse and other annual plants [thesis]. Louisiana: Louisiana State University; 2004

[8] Jung JS, Song KH, Kim SH. Mechanical properties and biodegradability of enzyme-retted kenaf fiber composites. Textile Research Journal. 2018. DOI: 10.1177/0040517518779996

[9] Dunne R, Desai D, Sadiku R, Jayaramudu J. A review of natural fibers, their sustainability and automotive applications. Journal of Reinforced Plastics \& Composites. 2016;35:1041-1050

[10] Thilagavathi G, Pradeep E, Kannaian T, Sasikala L. Development of natural fiber nonwovens for application as car interiors for noise control. Journal of Industrial Textile. 2010;39:267. DOI: 10.1177/1528083709347124

[11] Moreau JP, Bel-Berger P, Tao W. Mechanical Processing of Kenaf for Nonwovens. Tappi Journal. 1995;78:96-105

[12] Yang JQ, Morisawa J, Sameshima YQ. Kenaf bast fiber treatment for nonwoven fabrics. Sen'l Gakkaichi. 2001;57:88-93

[13] Tao W, Calamari TA, Shih FF, Cao C. Characterization of kenaf fiber bundles and their nonwoven mats. Tappi Journal. 1997;80:162-166

[14] Tao W, Calamari TA, Crook L. Carding kenaf for nonwovens. Textile Research Journal. 1998;68:402-406. DOI: $10.1177 / 004051759806800603$

[15] Fatima S, Mohanty AR. Acoustical and fire-retardant properties of jute composite materials. Applied Acoustic. 2011;72:108-114. DOI: $10.1016 /$ j. apacoust.2010.10.005

[16] Fouladi MH, Ayub M, Nor MJM. Analysis of coir fiber acoustical characteristics. Applied Acoustic. 2011;72:35-42. DOI: 10.1016/j. apacoust.2010.09.007

[17] Parikh VD, Chen Y, Sun L. Reducing automotive interior noise with natural fiber nonwoven floor covering systems. Textile Research Journal. 2006;76:813-820. DOI: $10.1177 / 0040517506063393$

[18] Nick A, Becker U, Thoma W. Improved acoustic behavior of interior 
parts of renewable resources in the automotive industry. Journal of Polymers and the Environment. 2002;10:115-118. DOI: 10.1023/A:1021124214818

[19] Lou CW, Lin JH, Su KH. Recycling polyester and polypropylene nonwoven selvages to produce functional sound absorption composites. Textile Research Journal. 2005;75:390-394. DOI: $10.1177 / 0040517505054178$

[20] Lee YN, Joo CW. Sound absorption properties of recycled polyester fibrous assembly absorbers. AUTEX Research Journal. 2003;3:78-84

[21] Byun HS, Lee TG. A study on the characteristic of sound absorption of the polyester non-woven fabrics used for the automobile sound absorption material. POLYMER-KOREA. 2001;25:427-434

[22] Kücük M, Korkmaz Y. The effect of physical parameters on sound absorption properties of natural fiber mixed nonwoven composites. Textile Research Journal. 2012;82:2043-2053. DOI: $10.1177 / 0040517512441987$

[23] Dubrovski PD, Brezocnik M. Porosity and nonwoven fabric vertical wicking rate. Fibers and Polymers. 2016;17:801-808. DOI: 10.1007/ s12221-016-6347-5

[24] Soukupova V, Boguslavsky L, AnandJiwala RD. Studies on the properties of biodegradable wipes made by the hydroentanglement bonding technique. Textile Research Journal. 2007;77:301-311

[25] Dubrovski PD, Brezocnik M. The modelling of porous properties regarding $\mathrm{PES} / \mathrm{CV}$-blended nonwoven wipes. Fibers and Polymers. 2012;13:363-370. DOI: 10.1177/0040517507078239

[26] Das D, Ishtiaque SM, Das S. Influence of fiber cross-sectional shape on air permeability of nonwovens.
Fibers and Polymers. 2005;16:79-85. DOI: $10.1007 / \mathrm{s} 12221-015-0079-9$

[27] Tascan M, Vaughn EA. Effects of total surface area and fabric density on the acoustical behavior of needlepunched nonwoven fabrics. Textile Research Journal. 2008;78:289-296. DOI: $10.1177 / 0040517507084283$

[28] CSIRO Division of Wool

Technology. The FAST system for the objective measurement of fabric properties. Operation. Interpretation and Application, CDW Technology. Geelong, Australia; 1989

[29] Rawal A, Lomov S, Ngo T, Verpoest I, Vankerre brouck J. Mechanical behavior of thru-air bonded nonwoven structures. Textile Research Journal. 2007;77:417-431

[30] Das D, Ishtiaque SM, Ajab Rao SV, Pourdeyhimi B. Modelling and experimental studies of air permeability of nonuniform nonwoven fibrous porous media. Fibers and Polymers. 2013;14:494-499 


\title{
3D Nonwoven Fabrics for Biomedical Applications
}

\author{
Mahesh Kumar Joshi, Rajeshwar Man Shrestha \\ and Hem Raj Pant
}

\begin{abstract}
Fibrous materials are attractive for biomedical applications owing to their structural superiorities, which include large surface-area-to-volume ratio, high porosity, and pore interconnectivity in a controlled manner. Among the various methods of fiber fabrication, electrospinning has emerged as an attractive nanotechnology to produce ultrafine fibrous materials for myriad applications, including tissue scaffolding. In this technique, processing parameters, such as the solution properties, tip-to-collector distance, applied voltage, etc., can be tailored to obtain the fibers of the desired morphology and physicochemical properties. Ideal scaffolds should meet the basic requirements, such as three-dimensional (3D) architecture, proper mechanical properties and biodegradability, and the sufficient surface characteristics for cell adhesion and proliferation. However, most of the electrospun nanofiber-based scaffolds have densely packed two-dimensional (2D) array which hinders the cell infiltration and growth throughout the scaffolds, thereby limiting their applicability in tissue regeneration. To overcome this problem, several attempts have been made to develop a biomimetic three-dimensional, nanofibrous scaffold. This chapter deals with noble techniques including gas foaming (GF), charge repulsion-assisted fabrication, post-processing, liquid-assisted collection, collector modification, and porogen-assisted methods for the fabrication of 3D nanofibrous scaffold for biomedical applications.
\end{abstract}

Keywords: electrospinning, tissue engineering, nano-/microfiber, 3D scaffold, biomaterials

\section{Introduction}

The fields of tissue engineering and regenerative medicine aim at promoting the regeneration of tissues or replacing the malfunctioning organs using a scaffold material. The development of scaffolds that mimic the composition and structure of natural extracellular matrix (ECM) is highly demanded in biomedical sciences. A scaffold used for tissue engineering is considered as an artificial extracellular matrix that provides mechanical support for neo-tissue formation in vitro and/or through the initial period after implantation during cell proliferation and differentiation. In addition to contributing to mechanical integrity, the ECM has an important role in signaling and regularity functions in development, maintenance, and regeneration of tissues [1]. It has long been demonstrated that the composition and architecture of a scaffold influence the cell-environment interactions that determine the effectiveness 
of the scaffold [2]. The scaffold material must be able to interact with cells in three dimensions and should facilitate the communication. The main goal of tissue engineering is to enable the body to heal itself by regenerating "neo-native" functional tissues [3, 4]. A highly porous scaffold is necessary to control tissue formation in three-dimensional (3D) architecture in a typical tissue engineering approach. The scaffolds provide the microenvironment (synthetic temporary extracellular matrix) for cell attachment, proliferation, differentiation, and neo-tissue genesis. Therefore, the material used for tissue scaffolding must function without interrupting other physiological processes, that is, the scaffold must not promote or initiate any adverse tissue reaction [5]. Furthermore, the scaffold must have an ability to promote normal cell growth and differentiation while maintaining a three-dimensional orientation/ space for the cells.

Recently, various materials including ceramics, metals, and polymers have been exploited to develop the scaffolds for tissue regeneration. Although the inorganic/ ceramic materials such as hydroxyapatite (HAP) or calcium phosphates are excellent choices for medical implants due to their good osteoconductivity and studied for mineralized tissue engineering, they are disadvantageous due to poor processability into highly porous structures and brittleness. Certain metals have superior mechanical properties and are preferred for medical implants. However, the lack of degradability in a biological environment limits their applications for tissue scaffolding [6]. In contrast, polymers have been extensively studied in various tissue engineering applications, including bone tissue engineering, due to the great design flexibility and structure which can be tailored to the specific needs $[6,7]$.

Recently, researches in biomaterials have turned to nanotechnology, specifically nanofibers, as the solution to the development of tissue engineering scaffolds and wound repair/care products. At present, few processing techniques are successful in producing nonwoven fibers and subsequent scaffolds on the nanoscale [8]. In basic terms, a nonwoven is a fabric or web composed of fibers. The orientation and properties of the fibers and fabric can be controlled to mimic the native cellular structures, such as collagen fibers of the extracellular matrix. Development and characterization of these nanofibrous structures for tissue engineering applications is crucial in understanding the cell-ECM interactions. Conventional polymer processing techniques are efficient in producing fibers, which are several orders of magnitude larger than the native ECM. Therefore, there has been a concerted effort to develop methods of producing nanofibers that closely mimics to the ECM geometry. In this endeavor, five distinct techniques have proven successful in producing nanofibrous tissue engineering structures: self-assembly, phase separation, melt blowing, drawing, and electrospinning.

Melt blowing and spunbond nonwovens are composed of continuous fiber filaments fabricated by forcing molten thermoplastic polymer through very fine orifices arranged in a spin beam. Melt blowing is a simple, versatile, and one-step process for the production of polymeric fibers in micrometer and smaller scale. During melt blowing and spunbond process, fibers are produced in a single step by extruding a polymer melt through an orifice die. In the melt blowing process, the filaments are drawn and accelerated toward the collector screen via hot air knives, keeping the filaments in a molten state, allowing for fine fiber attenuation. Collected fibers are still in a tacky state, allowing self-bonding between fibers. Conversely, in the spunbond process, as the filaments exit the spin beam, they are rapidly solidified by cool air before being drawn pneumatically. Spunbond and melt blowing techniques can be implemented from lab, pilot, and full production scale. Another method for generation of nonwoven fabric is carding technology. This is a mechanical process that disentangles, cleans, and intermixes fibers to produce a continuous web. In the carding process, short fibers of a few inches 
in length (staple fibers) are separated and entangled by a series of specialized combed rollers to form an unbonded web. Unlike spunbond and melt-blown processing that require a thermoplastic polymer for melt spinning, a variety of fiber materials can be processed via carding technology, including natural and synthetic polymers, glass, and metal fibers. The high-speed, repeatable, economical production capabilities of these techniques make them attractive candidates for the commercial production of nonwoven-based tissue engineering scaffolding materials. The main disadvantages of nonwoven webs generated by these techniques are their large fiber diameters which hinder the cell attachment, proliferation, and neotissue generation, thereby limiting their application as tissue scaffolding material.

Among the various techniques, electrospinning is the facile nonwoven manufacturing method and has recently gained significant interest as a method of scaffold fabrication. The size scale of electrospun fibers mimics to the native ECM and provides an ideal environment for cell proliferation, attachment, and differentiation into the target tissue. However, the fabrication of large-scale electrospun scaffolds using conventional technique is time-consuming and difficult to generate 3D microstructures. This chapter focuses on recent advances in the fabrication of the three-dimensional electrospun nanofibrous scaffolds.

\section{Electrospinning}

Electrospinning employs electrostatic force to draw a fiber from a spinneret. This fiber solidifies and lies down on a collector in the form of a nonwoven fibrous mesh. Recently, electrospinning has attracted much attention because of its low processing cost and tailorable fiber morphology and fiber diameter. Furthermore, synthetic and natural polymers can be processed into the fiber of different diameters at ambient conditions. However the electrospinning technology has been known for a long time; the practice of this technology remained largely dormant until the 1970s. Morton received the first US patent for the electrospinning of artificial fibers in 1902. Zeleny presented one of the earliest studies of the electrified jetting phenomenon in 1914 [9]. Later on, Formhals filed a series of patents on the processing and apparatus in the decades of the 1930s and 1940s to produce electrospun fibers. Only a few publications appeared in electrospinning research during the 1970s and 1980s, notably by Baumgarten and by Larrondo and St. John Manley $[10,11]$.

The electrospinning research has gained significant interest when Doshi and Reneker prepared submicron fibers in the 1990s [12]. Since then it has been demonstrated that almost all materials that can be spun from melt or solution by conventional methods can be electrospun into fibers. On account of the remarkable simplicity, versatility, and potential applications of this technique in a variety of fields, the number of publications in this field has been increasing exponentially during the past decade.

The principle of electrospinning involves a high voltage applied between a pendant polymer droplet and a metal target as the counter electrode [13]. Under the electrostatic force, the pendant polymer droplet is deformed from a hemispherical shape to a conical shape which is called as Taylor cone [14]. A thin polymer jet is initiated and travels toward the metal target once the electrostatic force reaches a critical value to overcome the surface tension of the polymer droplet. The charged thin polymer jet is elongated and undergoes a bending instability region where it whips swiftly in the air by the electric field [15]. The thin polymer jet is further stretched due to the evaporation of the solvent during this period and finally deposits on the metal target as a randomly oriented nanofibrous membrane as shown in Figures $\mathbf{1}$ and 2. 


\section{(+) charge}

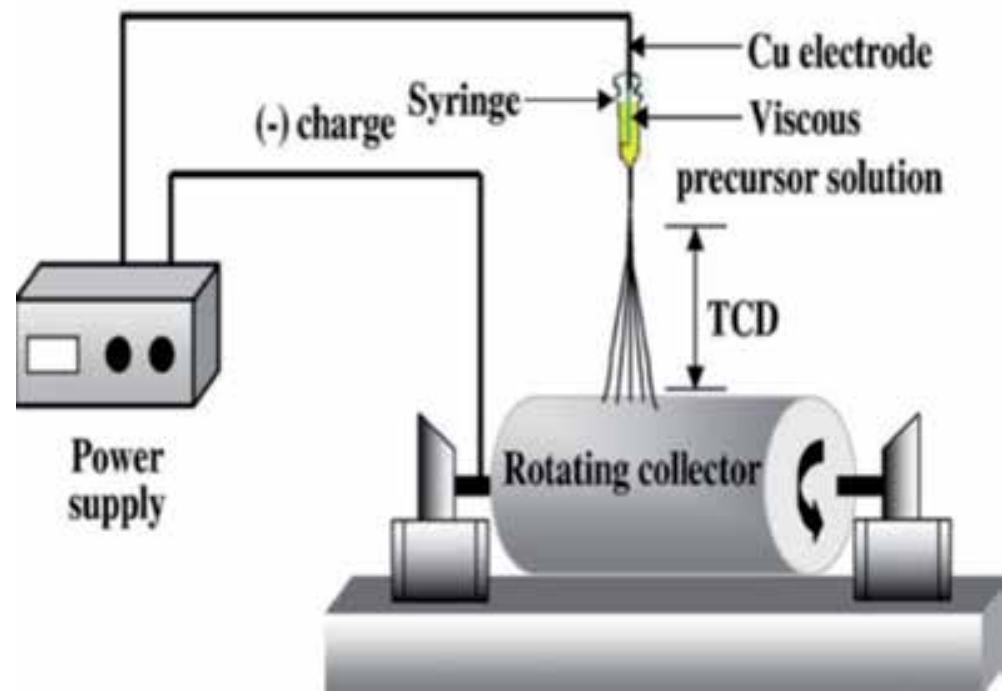

Figure 1.

Schematic illustration of electrospinning setups.

(a)

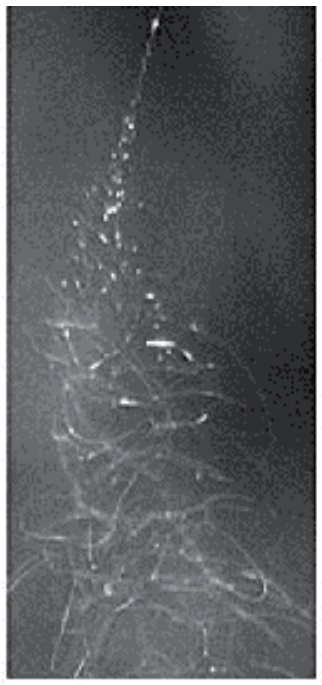

(b)

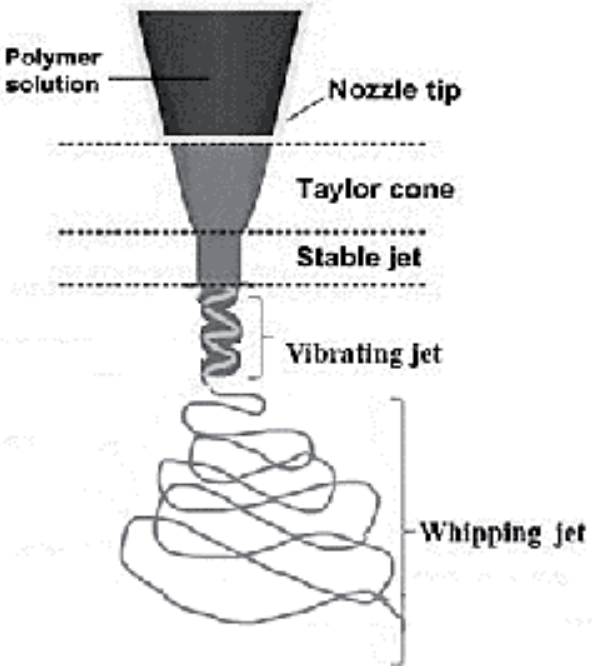

Figure 2.

(a) Photograph of electrospinning jet. (b) Schematic representation for the formation of electrospun nanofibers.

The electrospinning process is characterized by three major regions: (1) the cone region, (2) the steady jet region, and (3) the instability region. A pendant drop of a fluid is charged at the tip of the nozzle at the initial stage of electrospinning which deforms the droplet into a conical shape, just before jetting occurs. The conical shape is called the Taylor cone, named after G. Taylor who has studied this electrified fluid phenomenon [14]. At a critical electrical stress, a fluid jet is ejected from the apex of the cone. The diameter of the jet at the apex is about 100 micrometers. In the steady jet region, the jet can travel in a straight path anywhere from 1 to 20 centimeters. For a fluid that is a solution, real-time spectroscopic data shows that the loss of solvent due to evaporation in this portion of the jet is negligible. In the 
final region, the jet deviates from its straight path and undergoes an instability called bending or whipping instability (Figure 2) [15].

Several parameters influence the electrospinning process: polymer solution parameters, processing parameters, and ambient parameters. Extensive polymer chain entanglement is necessary for the fiber formation during electrospinning process; otherwise the polymer solution is electrosprayed into small droplets or forms fibers with large beaded polymer aggregates. Low molecular weight polymers are often difficult to electrospun because of their inability for chain entanglements, while higher molecular weight polymers often cause large changes in solution viscosity, thus increasing the surface tension of the droplet and limiting the ability to electrospun. The choice of solvent is another important processing parameter; the solvent should be nontoxic and should evaporate within the distance from the spinneret to the grounded collector. The processing parameters such as distance between spinneret and collector, solution flow rate, humidity, and voltage intensity ( a few $\mathrm{kV}-40 \mathrm{kV}$ ) have substantial influence on the morphology, fiber size and uniformity, and porosity.

\section{Development of 3D scaffolds}

The tissue engineering scaffolds should closely resemble to native extracellular matrices (ECMs) that provide structural support to cells. The primary role of the scaffold is to provide the temporary support until the neo-tissue formation. The scaffolds that closely mimics to the topographies and spatial structures of ECM are efficient for the cell proliferation and differentiation. The morphologies of ECMs vary according to the functions of the target tissues. Fibrous structures with 3D orientation and random distribution are found in native ECMs in the breast, liver, bladder, lung, and many other organs and tissues [16]. Therefore, it is reasonable to fabricate scaffolds with particular morphologies and structures according to categories and functions of the original native tissues [17].

Electrospinning is a simple method to fabricate the nano-/microfibers in a continuous process. The electrospinning parameters and instrumental setups can be tailored to fabricate micro-/nanofibers with desired morphologies, such as aligned fibrous array, fiber diameter, and fibrous patterns. Therefore, electrospinning has gained significant attention to fabricate tissue engineering scaffolds composed of nano- or submicrometer fibers from numerous materials [18]. However, the conventional electrospinning method produces two-dimensional (2D) sheet-like membranes with small pore and tightly packed fibrous layers that limits the cell infiltration and growth to the depth of the scaffolds [19-22]; cells mainly spread and distribute on the surface of 2D nanofibrous membrane [23]. Since most human tissues and organs possess three-dimensional microgeometry holding intrinsic functionality, developing three-dimensional structure has drawn a great interest in the search of the tissue surrogates. 3D fibrous scaffolds with macroporous, open structure facilitate the neo-tissue formation, thereby providing biomimetic environment for the cell infiltration, the cell proliferation, and the transportation of nutrients and waste.

\section{Gas-foaming technique}

Among the process technologies that have been developed and successfully implemented for the design of TE scaffolds, gas foaming (GF) has recently attracted much attention. The gas-foaming technique utilizes the nucleation and 
growth of gas bubbles dispersed into a viscous polymer solution for the creation of porosity [24]. The gas bubbles are generated in situ either via chemical reaction or by adding inert gases to the polymer phase at different physical environments. The gas-foaming agents are generally released from a pre-saturated gas-polymer mixture resulting in the formation of 3D porous architectures [24]. A supercritical fluid, that is, a fluid above its critical point, such as carbon dioxide, is commonly used for gas-foaming purpose because of its non-flammability, non-toxicity, and moderate critical point $\left(31.1^{\circ} \mathrm{C}\right.$ and $\left.73.8 \mathrm{bar}\right)$. Supercritical fluids can be used to form gas-saturated polymer phase by varying the temperature and pressure [25]. In the process, high-pressure $\mathrm{CO} 2$ gas is subjected to solid polymer disks to allow saturation of $\mathrm{CO} 2$ in the polymer. In this process, the nucleation and growth of $\mathrm{CO} 2$ gas bubbles in the material creates the thermodynamic instability and yields mostly a nonporous surface with closed-pore structure. The main limitation of this technique is that it produces the nonporous surface with closed-pore structure with only $10-30 \%$ of interconnected pores [26]. Recently, particulate leaching technique has been combined with the gas-foaming process to improve the inter-pore connectivity, although completely eliminating closed pores remains challenging [26].

Recently, Joshi et al. have developed the novel gas-foaming technique to modify the densely packed 2D electrospun membranes into low-density three-dimensional nanofibrous scaffolds $[19,27]$. In this technique, authors put the electrospun nanofibrous mat in an aqueous sodium borohydride (SB) solution where the interconnected pores of a mat were filled with the SB solution. The SB solution undergoes the hydrolysis in situ in the nano-/micropores of the nanofibrous mat and produces the hydrogen gas. As generated $\mathrm{H} 2$ gas molecules nucleated to form clusters that reorganize the nanofibers into multilayered 3D scaffold with low-density, macroporous spongy structure (Figure 3). In their study, nanofibrous membranes of various polymers were prepared via electrospinning and treated with sodium borohydride solution that was prepared in different solvents. They demonstrate that the solvent for sodium borohydride (either water or methanol) plays a crucial role in the fabrication of 3D scaffolds. The electrospun membranes of polar polymers were processed into 3D architecture in aqueous SB solution, while methanolic solution of SB can be used for both polar and nonpolar polymers. The fabrication process is fast in methanol solution compared to an aqueous solution which is attributed due to the
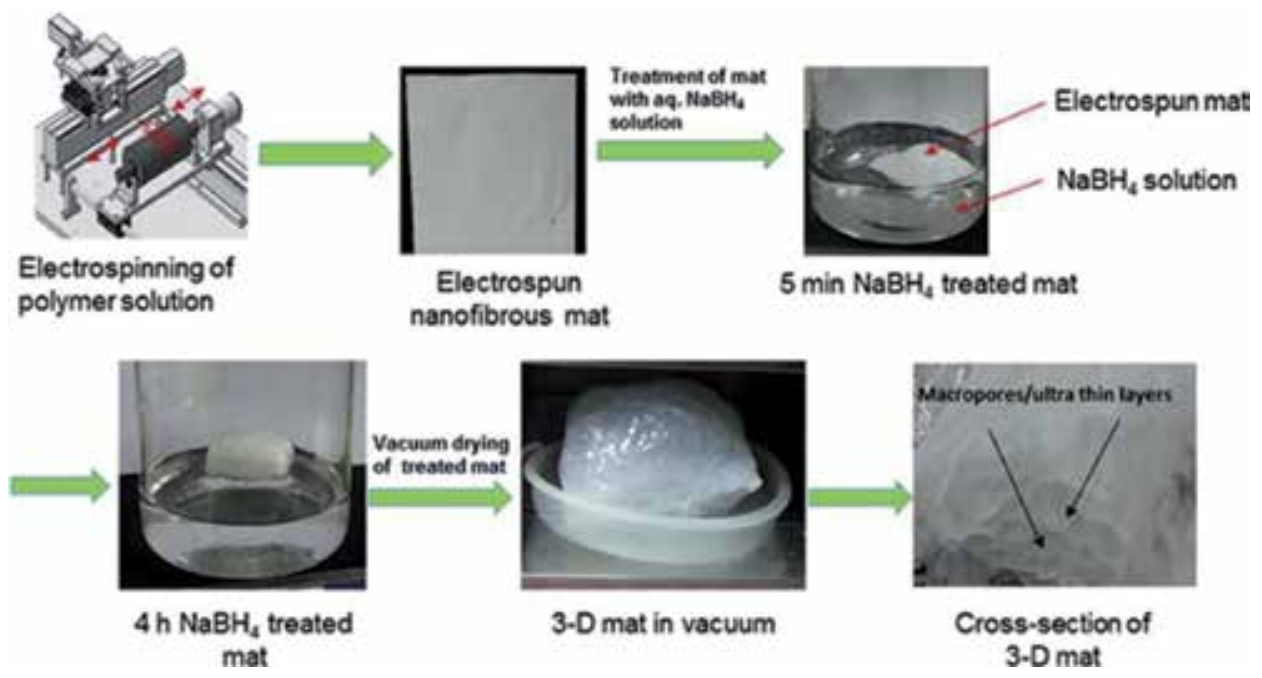

Figure 3.

Schematic illustration for the formation of low-density, macroporous, spongy, and multilayered ${ }_{3} D$ scaffolds. Reproduced with permission from Ref. [19]. 
rapid evolution of hydrogen gas from the methanolysis reaction compared to the hydrolysis reaction. This method forms the large pores with multilayered structure that mimics to the ECM. Similarly, Zhao et al. immersed the 2D PCL nanofibrous mat in a $\mathrm{NaBH} 4 /$ methanol solution inside a 3D-printed mold and obtained the 3D nanofibrous scaffolds with controllable geometric shapes [28]. Xie et al. also used the NaBH4 solution as gas source to expand the 2D PCL electrospun mat followed by freeze-drying and obtained 3D PCL scaffolds with highly ordered architecture with controllable gas widths and layered structure as a result [29]. Lee et al. combined electrospinning with salt leaching/gas foaming and developed micro-sized pores in poly(L-lactic acid) (PLLA)/montmorillonite (MMT) nanocomposite fibrous scaffold [30].

\section{Multilayering electrospinning}

The thickness of the electrospun can be increased by increasing the spinning time during the conventional electrospinning process, leading to the 3D fibrous structure. 3D multilayered fibrous membranes of different materials can be fabricated by a sequential electrospinning or co-electrospinning, and post-processing and sometimes an auxiliary electric field is even used to converge the collected fibers into a confined space to produce 3D fibrous structures [19] (Figure 4). Pham et al. [32] prepared layer-on-layer stacks including alternating layers of PCL microfibers and PCL nanofibers. This proposed 3D structure combined the beneficial properties of nanofibers with that of microfibers. The thickness of the nanofiber layers is modulated by electrospinning the nanofiber layers for different lengths of time. They demonstrated that cell infiltration and growth in a multilayered scaffold depends upon the thickness of each layer; increasing the thickness of the nanofiber layer reduced the cell infiltration of the scaffold. Han et al. [33] fabricated the electrospun 3D scaffold of cellulose acetate with three different layers (dense layer, cellular layer, and porous layer) by varying the solutions and processing parameters. In this technique, the total number of layers in multilayered scaffold can be controlled. Furthermore, the composition, the fiber diameter, and the porosity of each electrospun fiber layer can be tailored that affects cell proliferation, migration, and/or differentiation on a scaffold. Erisken et al. [34] reported the functionally graded electrospun PCL and $\beta$-tricalcium phosphate ( $\beta$-TCP) nanocomposites using a hybrid twin-screw extrusion/electrospinning process. Soliman et al. [35] fabricated 3D scaffolds of layered composites with mixed nano- and microscale PCL fibers by modifying the electrospinning setup with two parallel syringes and an actuated collector (co-electrospinning with scalability and modularity from an industrial perspective).
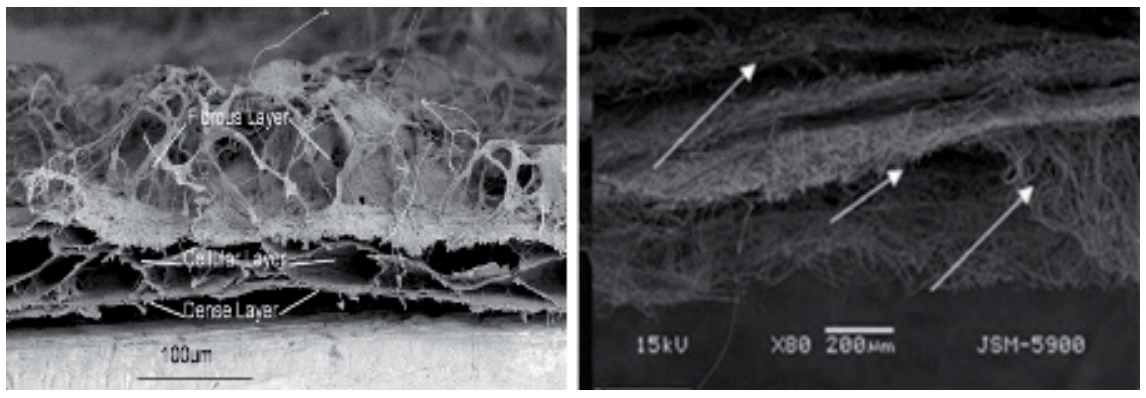

Figure 4.

SEM images showing the cross-sectional view of the multilayered scaffold. Reproduced with permission from [31] and right [19]. 


\section{Post-processing after electrospinning}

With a subsequent post-process after electrospinning such as folding/rolling up, the aforementioned 3D multilayer fibrous structures, even the as-spun 2D layer-on-layer mats, can turn into a desired morphology for further application. Recently, Duan et al. [37] reported the ultralight highly porous 3D polymer sponges of extremely low-density and low-specific surface area from dispersions of short electrospun fibers in an attempt to mimic the design principle of natural sponges. Short electrospun fibers were first prepared by cutting of electrospun nonwoven and then dispersed in dioxin in different concentrations. Sponges of different densities were prepared from these dispersions by freeze-drying. Such sponge showed tunable cellular infiltration and growth. Ryu et al. [36] developed a three-dimensional scaffolds of carbonized polyacrylonitrile for bone tissue regeneration. PAN fibers were formed by electrospinning onto a Petri dish containing water, and PAN/water was lyophilized for $48 \mathrm{~h}$. Performing the lyophilization step prior to the carbonization process created the micro-sized pores between the electrospun PAN fibers leading to the cotton ball-like 3D scaffolds (Figure 5). The scaffolds were carbonized under $800^{\circ} \mathrm{C}$ in argon atmosphere and then further modified into a 3D cylindrical geometry. Wang et al. [38] fabricated the electrospun chitosan nano-/microfiber mesh tubes by controlling the spinning parameters. The nonwoven or oriented fibers of the chitosan were deposited and reeled on the bar as the drum rotates. Furthermore, by folding the aligned electrospun nanofibrous meshes several times, a 3D nonwoven macroporous nanofibrous scaffold was manufactured. However, 3D structures generated by this method usually cannot put into use as scaffolds directly because they often have a large space or distance between adjacent fibrous surfaces. 3D electrospun poly(L-lactic acid) (PLLA) microfibrous scaffolds with $5 \mathrm{~mm}$ in thickness were fabricated by using a subsequent mechanical expansion process [39]. 3D scaffolds demonstrated a high level of osteoblast proliferation (1.8-fold higher than nanofibrous membranes in a week), actively penetrated the inside of the 3D scaffold, and showed a spatial cell distribution. Sintering after electrospinning is another way to fabricate 3D macrostructures. 3D electrospun scaffolds of pure PLGA and composites of PLGA/hydroxyapatite were

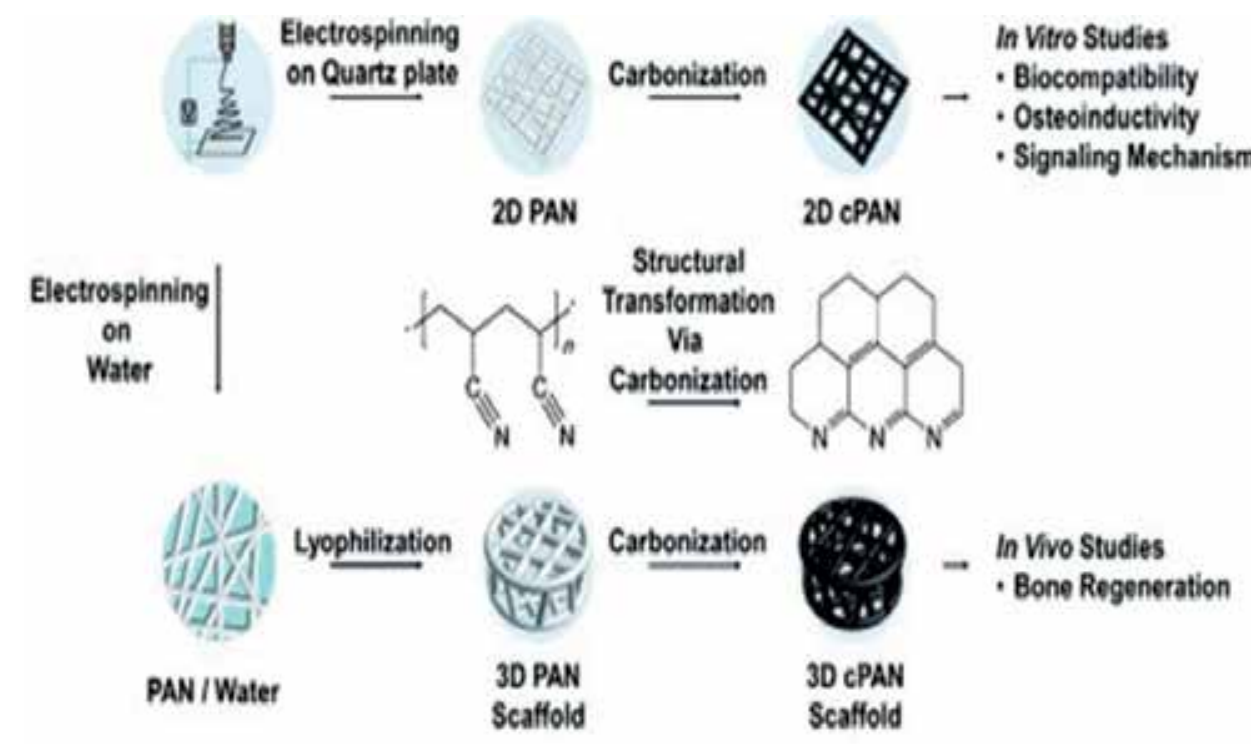

Figure 5.

Schematic illustration showing the fabrication process of cPAN scaffolds. Reproduced with permission from Ref. [36]. 
fabricated by a two-step process: electrospun meshes were first stacked and then sintered using pressurized gas which improved the mechanical properties and porosity.

\section{Charge repulsion-assisted fabrication}

Fabrication of fluffy nanofibrous mesh using the cosolvent that induces the charge repulsion during the spinning has been employed in recent studies [40, 41]. Lee et al. developed a novel strategy to fabricate highly porous poly(L-lactide) (PLLA)-based fibrous scaffold for bone tissue engineering. Blending of PLLA with its monomer, lactic acid (LA) produced the fluffy-type highly porous nanofibrous mesh (Figure 6). Their study revealed that the LA component in the blend solution assisted the formation of the macroporous spongy fibrous scaffold. The repulsion between the as-spun fibers occurs due to the interaction between the electric field formed by high voltage and the negative charge on LA due to the functional group $(\mathrm{COOH})$, thereby generating fluffy fibrous mesh [40-42]. Similarly, Xu et al. fabricated a fluffy-type nanofibrous mesh by electrospinning the blend solution of PCL and polystyrene (PS) [42]. In another study, Lee et al. fabricated a core-sheath-type fibrous scaffold (PCL as the core and PS as shell) with fluffy-type architecture using coaxial electrospinning. The PS in the sheath was removed out to avoid its drawbacks associated with scaffold activity [43]. They reported that the negative charge accumulated on the surface of the nanofiber due to the PS (sheath) caused the repulsion between nanofibers under the influence of the strong electric field, thereby generating the fluffy-type nanofibrous mesh [43].

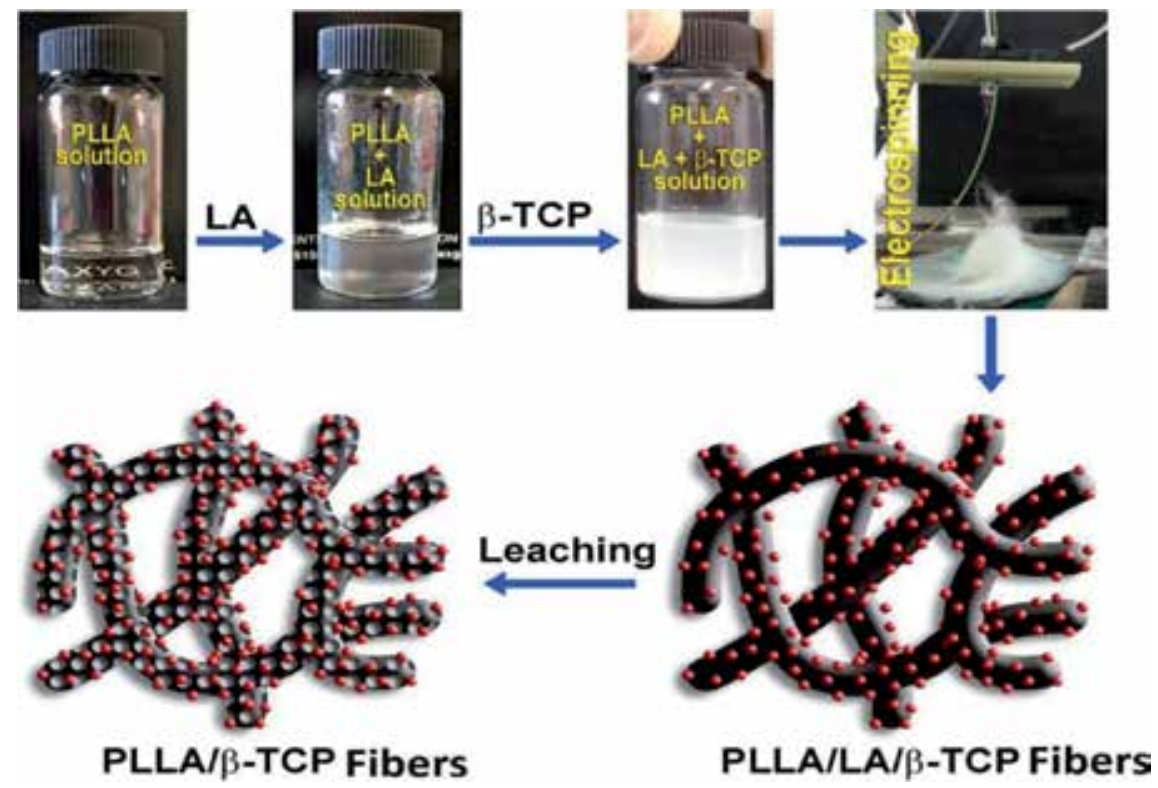

Figure 6.

Diagrammatic representation showing the fabrication of three-dimensional fluffy fibrous scaffolds. Reproduced with permission from Ref. [40].

\section{Liquid-assisted collection}

The highly porous three-dimensional nanofibrous scaffolds can be obtained using bath collectors containing a low surface tension solvent, and this technique 
is also helpful for fabricating 3D fibrous macrostructures. It is known that aligned electrospun micro-/nanofibrous arrays can be collected with the help of a water reservoir collector or a water vortex. Teo et al. [44] fabricated hierarchically organized 3D nanofibrous meshes of PCL using a water vortex. As-collected 3D PCL nanofibrous meshes were either freeze-dried or dried in a mold under ambient condition. The freeze-dried 3D meshes showed visible pores on the surface of the mesh, while the 3D meshes dried in room condition were densely packed without any apparent pores on the surface. Yokoyama et al. [45] fabricated the poly (glycolic acid) (PGA) 3D spongy nanofibrous mesh by combining electrospinning with wet spinning. The spongy-type 3D PGA nanofiber fabric showed a low apparent density and high porosity compared to the usual PGA nanofiber nonwoven mats prepared by conventional electrospinning method.

\section{Collector modification}

3D fibrous macrostructures fabricated by modifying collector are common. Zhang et al. [47] obtained tubular structures through designing the collectors. The collectors used in fabricating the electrospun fibrous tubes are static 3D columnar collectors. The schematic illustration and the photos of the relevant fibrous tubes are separately shown in Figure 7A ( $\mathbf{a}$ and $\mathbf{b}$ ). Tubes with different patterned architectures can also be obtained using collectors with two different patterns as displayed in Figure $7 \mathbf{B}(\mathbf{c}-\mathbf{g})$. Moreover, crossing tubes with interconnected tubular structures are made using this static collecting method, which are difficult to obtain by other strategies. Similar to 2D assembly, the 3D collecting template is also based on the manipulation of electric field and electric
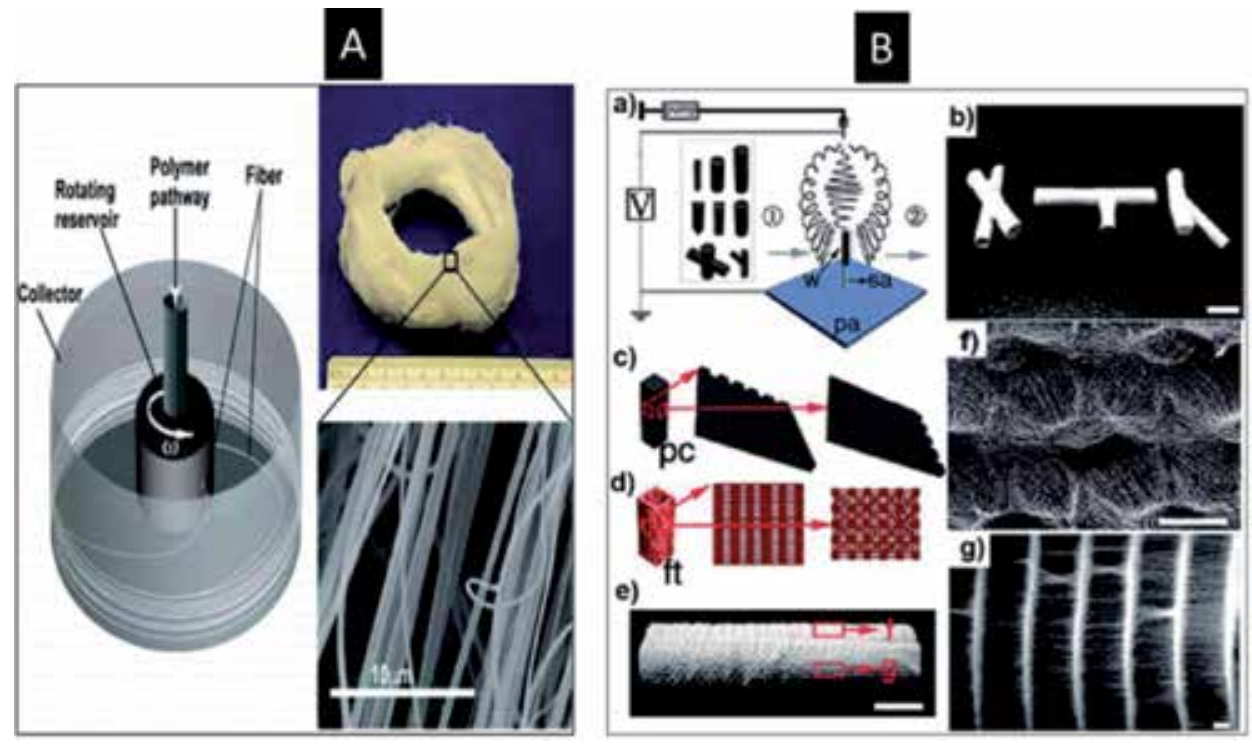

Figure 7.

(A) Schematics of rotary jet-spinning process. Rotary jet spinning consisted of a perforated reservoir. Photographic image of $3 D$ nanofiber structure produced by rotary jet spinning and corresponding SEM image. (B) (a) schematic illustration of collecting process using a cylindrical collector with equally spaced circular protrusions. (b) a fibrous tube with patterned architectures (scale bar $=5 \mathrm{~mm}$ ). (c) Magnified image of panel $b($ scale bar $=200 \mu \mathrm{m})$. (d) Schematic illustration of collectors with two different patterns and relevant fibrous tube ( $p$, patterned collector; ft., fibrous tube). (e) a fibrous tube with two different patterns (scale bar $=5 \mathrm{~mm}) .(f, g)$ Magnified images of two different patterns of panel. Reproduced with permission from Refs. [46, 47]. 
force. Some key factors, especially the design and configurations of the collector, should be well-tailored, which are critical for tubular structures. Moreover, feasible strategies for fabricating 3D structures are still in demand. Blakeney et al. [20] designed a collector with a network of stainless steel needles on the concave side of a foam half-sphere shell. The fibers were collected randomly between the arrays of needles, thereby generating 3D fluffy, "cotton ball-like" PCL scaffolds. As-fabricated scaffolds showed enhanced cellular infiltration compared with 2D scaffolds produced using traditional collectors [20]. Badrossamay et al. [46] prepared 3D fibrous structure using a rotary jet spinning combined with the hydrostatic pressure with centrifugal pressure, 3D nanofiber structures from poly(lactic acid) (PLA) have been fabricated under a proper rotation speed, and the contained aligned nanofibers were similar to that of the conventional 2D mats (Figure 7A). The rotating collector assists the collection of 3D nanofibrous tubular scaffolds. Cai et al. [16] fabricated 3D zein and PEG electrospun scaffolds with three-dimensionally and randomly oriented fibers and large interconnected pores by reducing surface resistivity of materials. The 3D structures are also fabricated via a hybrid technique that combines traditional electrospinning with other methods such as prototyping, polymer/fiber deposition, melt electrospinning, and so on. Park et al. [48] developed a nano- and microhybrid process incorporating direct polymer melt deposition (DPMD) and an electrospinning process. DPMD process was employed to prepare the microfiber layer with computer-aided design modeling data considering some structural points such as pore size, pore interconnectivity, and fiber diameter. The polycaprolactone/collagen nanofiber matrices were deposited between the layers of the three-dimensional structure via an electrospinning process. They found that the polymeric scaffolds with nanofiber matrices provided favorable conditions for cell adhesion and proliferation.

\section{Porogen leaching}

Another technique for the fabrication of highly porous 3D structure is the use of porogens. Materials such as ice crystals, salt particles, polymers (e.g., poly(ethylene oxide) (PEO)), which acts as porogens, usually are mixed simultaneously with the precursor during electrospinning to enable rapid buildup of the nanofibrous volume and then washed away or dried after a desired thickness is reached [49]. For example, Baker et al. [50] demonstrated that inclusion and subsequent removal of a sacrificial fiber population within a fiber-aligned fibrous scaffold enhance cellular infiltration. Poly ( $\varepsilon$-caprolactone) (a slow-degrading polyester) and poly(ethylene oxide) (a water-soluble polymer) were co-electrospun from two separate spinnerets to form dual-polymer composite fiber-aligned scaffolds, and PEO is washed out. Removal of these sacrificial elements (PEO fibers) preserved structural and mechanical anisotropy and tuned to generate composites with varying mechanical properties. Kim et al. [51] fabricated a 3D macroporous and nanofibrous hyaluronic acid (HA) scaffold by combining the electrospinning process with a salt leaching technique (Figure 8). The salt particulates, as a porogen, deposited during electrospinning were leached which produced water-soluble HA-based scaffold with macroporous and nanofibrous geometry. Ki et al. [52] developed 3D nanofibrous fibroin scaffold with high porosity by electrospinning. The electrospun SF nanofiber dispersion was collected in 1,4-dioxane having $\mathrm{NaCl}$ particles $(300-500 \mu \mathrm{m})$ as porogen. The scaffold was cross-linked, lyophilized, and washed with PBS solution several times that was effective for cell addition and proliferation. 
A
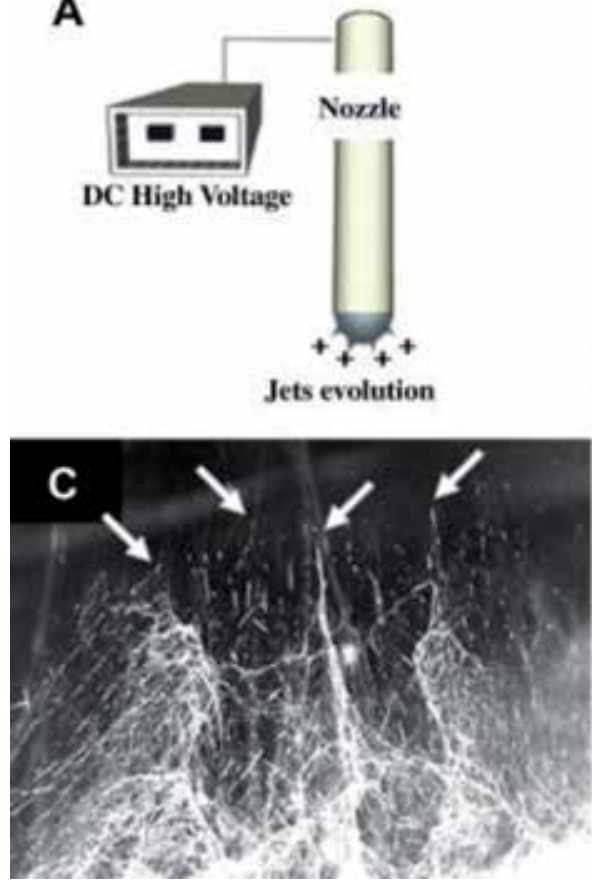
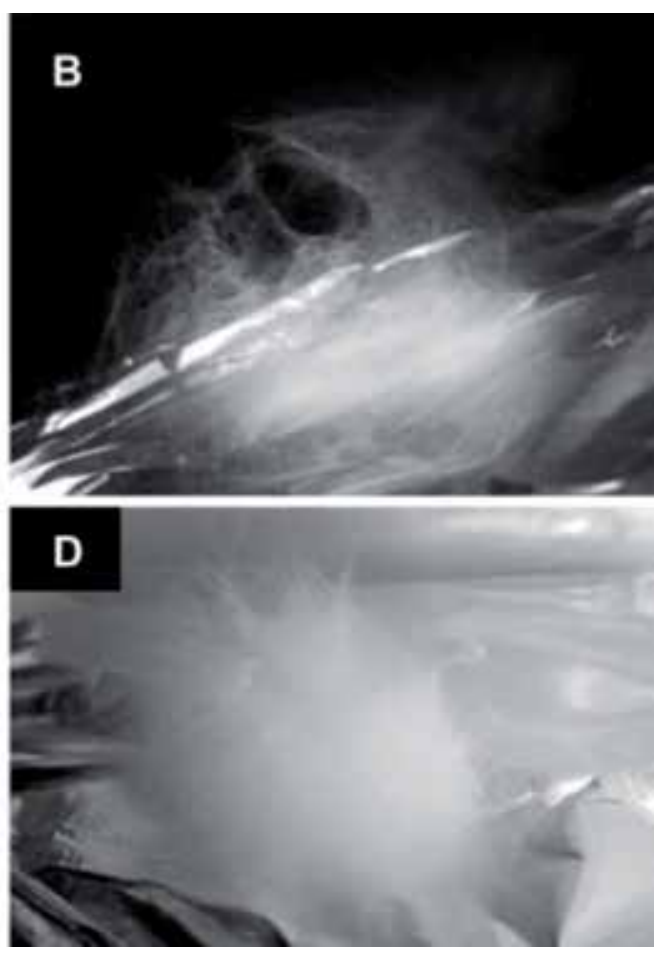

Figure 8.

(A) Diagrammatic illustration showing the polymer jet evolution; (B) digital image showing the vertical growth of solidified fibers; $(C)$ the polymer solution from the needle tip was immediately split into minijets (arrows indicate minijets); and (D) fluffy-type nanofiber mesh. Reproduced with permission from Ref. [50].

\section{Conclusion}

In conclusion, it is evident from the foregoing examples that the diversity in biomaterials is immense. The utilization of electrospun nanofibers as tissue scaffold is challenging. A great deal of effort has been put in to prepare the biomimetic 3D nonwoven scaffolds based on natural as well as synthetic polymers. Different processing routes have been proposed to produce 3D nanofibrous scaffolds with a great variety of architectures. Many clever approaches to mimicking the structure and, more importantly, the function of the ECM have been devised. Different fabrication methods have their own merits and demerits. However, despite all the extensive literature containing references to the so-called biomimetic three-dimensional scaffolds, it is the authors' opinion that much work is still needed to obtain clinically successful materials. Various types of bioactive components, such as peptides (e.g., RGD) and hydroxyapatite, may be incorporated/integrated to enhance the cellular response and biocompatibility of the 3D nanofibrous scaffolds. More importantly, the real-time monitoring/control systems may be established by integrating either electronic components or magnetic responsive elements with 3D nanofibrous mesh, enabling remote actuation and thus with an active role in the modulation of the host response on implantation that can revolutionize human therapies toward successful regeneration. It is imperative that these important technologies continue to be investigated for their ability to interact in biological systems. It will be most interesting to follow the further progress and the expected and unexpected leaps forward that will be shaping the field in the coming years. 


\section{Author details}

Mahesh Kumar Joshi* ${ }^{1 *}$ Rajeshwar Man Shrestha ${ }^{2}$ and Hem Raj Pant ${ }^{2 *}$

1 Department of Chemistry, Trichandra Multiple Campus, Tribhuvan University, Kathmandu, Nepal

2 Department of Applied Sciences, Institute of Engineering, Tribhuvan University, Kathmandu, Nepal

*Address all correspondence to: joshimj2003@yahoo.com and hempant@ioe.edu.np

\section{IntechOpen}

(C) 2020 The Author(s). Licensee IntechOpen. This chapter is distributed under the terms of the Creative Commons Attribution License (http://creativecommons.org/licenses/ by/3.0), which permits unrestricted use, distribution, and reproduction in any medium, provided the original work is properly cited. (cc) BY 


\section{References}

[1] Lavik E, Langer R. Tissue engineering: Current state and perspectives. Applied Microbiology and Biotechnology. 2004;65(1):1-8

[2] Joshi MK et al. In situ generation of cellulose nanocrystals in Polycaprolactone nanofibers: Effects on crystallinity, mechanical strength, biocompatibility, and biomimetic mineralization. ACS Applied Materials \& Interfaces. 2015;7(35):19672-19683

[3] Barnes CP et al. Nanofiber technology: Designing the next generation of tissue engineering scaffolds. Advanced Drug Delivery

Reviews. 2007;59(14):1413-1433

[4] Maharjan B et al. In-situ synthesis of AgNPs in the natural/synthetic hybrid nanofibrous scaffolds: Fabrication, characterization and antimicrobial activities. Journal of the Mechanical Behavior of Biomedical Materials. 2017;65:66-76

[5] Kidoaki S, Kwon IK, Matsuda T. Mesoscopic spatial designs of nano- and microfiber meshes for tissue-engineering matrix and scaffold based on newly devised multilayering and mixing electrospinning techniques. Biomaterials. 2005;26(1):37-46

[6] Liu XH, Ma PX. Polymeric scaffolds for bone tissue engineering. Annals of Biomedical Engineering. 2004;32(3):477-486

[7] Huang LH et al. Synthesis and characterization of electroactive and biodegradable ABA block copolymer of polylactide and aniline pentamer. Biomaterials. 2007;28(10):1741-1751

[8] Tiwari AP et al. Formation of lipophilic drug-loaded human serum albumin nanofibers with the aid of glutathione. Chemical Engineering Journal. 2017;313:753-758
[9] Zeleny J. The electrical discharge from liquid points, and a hydrostatic method of measuring the electric intensity at their surfaces. Physical Review. 1914;3(2):69-91

[10] Baumgart P. Electrostatic spinning of acrylic microfibers. Journal of Colloid and Interface Science. 1971;36(1):71

[11] Larrondo L, St. John Manley R. Electrostatic fiber spinning from polymer melts. I. Experimental observations on fiber formation and properties. Journal of Polymer Science: Polymer Physics Edition. 1981;19(6):909-920

[12] Doshi J, Reneker DH.

Electrospinning process and applications of electrospun fibers. Journal of Electrostatics. 1995;35(2-3):151-160

[13] Han SW, Joshi MK, Kim CS. Fabrication and characterization of silver nanoparticle-incorporated bilayer electrospun-melt-blown micro/ nanofibrous membrane AU - Kim, Han Joo. International Journal of Polymeric Materials and Polymeric Biomaterials. 2017;66(10):514-520

[14] Taylor G. Disintegration of water drops in an electric field. Proceedings of the Royal Society of London A: Mathematical, Physical and Engineering Sciences. 1964;280(1382):383-397

[15] Reneker DH et al. Bending instability of electrically charged liquid jets of polymer solutions in electrospinning. Journal of Applied Physics. 2000;87(9):4531-4547

[16] Cai S et al. Novel 3D electrospun scaffolds with Fibers oriented randomly and evenly in three dimensions to closely mimic the unique architectures of extracellular matrices in soft tissues: 
Fabrication and mechanism study. Langmuir. 2013;29(7):2311-2318

[17] Pant HR et al. Chitin butyrate coated electrospun nylon- 6 fibers for biomedical applications. Applied Surface Science. 2013;285:538-544

[18] Wang S et al. Electrospun laponitedoped poly(lactic-co-glycolic acid) nanofibers for osteogenic differentiation of human mesenchymal stem cells. Journal of Materials Chemistry. 2012;22(44):23357-23367

[19] Joshi MK et al. Multi-layered macroporous three-dimensional nanofibrous scaffold via a novel gas foaming technique. Chemical Engineering Journal. 2015;275:79-88

[20] Blakeney BA et al. Cell infiltration and growth in a low density, uncompressed three-dimensional electrospun nanofibrous scaffold. Biomaterials. 2011;32(6):1583-1590

[21] Tiwari AP et al. pH/NIR-responsive Polypyrrole-functionalized fibrous localized drug-delivery platform for synergistic cancer therapy. ACS Applied Materials \& Interfaces. 2018;10(24):20256-20270

[22] Liao $\mathrm{N}$ et al. Fabrication, characterization and biomedical application of two-nozzle electrospun polycaprolactone/zein-calcium lactate composite nonwoven mat. Journal of the Mechanical Behavior of Biomedical Materials. 2016;60:312-323

[23] Xu T et al. Electrospun Polycaprolactone 3D Nanofibrous scaffold with interconnected and hierarchically structured pores for bone tissue engineering. Advanced Healthcare Materials. 2015;4(15):2238-2246

[24] Annabi N et al. Controlling the porosity and microarchitecture of hydrogels for tissue engineering.
Tissue Engineering Part B-Reviews. 2010;16(4):371-383

[25] Ji C et al. Fabrication of poly-DLlactide/polyethylene glycol scaffolds using the gas foaming technique. Acta Biomaterialia. 2012;8(2):570-578

[26] Harris LD, Kim BS, Mooney DJ. Open pore biodegradable matrices formed with gas foaming. Journal of Biomedical Materials Research. 1998;42(3):396-402

[27] Joshi MK et al. Three-dimensional cellulose sponge: Fabrication, characterization, biomimetic mineralization, and in vitro cell infiltration. Carbohydrate Polymers. 2016;136:154-162

[28] Gao Q et al. Fabrication of electrospun nanofibrous scaffolds with 3D controllable geometric shapes. Materials \& Design. 2018;157:159-169

[29] Jiang J et al. Expanding twodimensional electrospun nanofiber membranes in the third dimension by a modified gas-foaming technique. ACS Biomaterials Science \& Engineering. 2015;1(10):991-1001

[30] Lee YH et al. Electrospun dual-porosity structure and biodegradation morphology of montmorillonite reinforced PLLA nanocomposite scaffolds. Biomaterials. 2005;26(16):3165-3172

[31] Woodfield TBF et al. Polymer scaffolds fabricated with pore-size gradients as a model for studying the zonal organization within tissueengineered cartilage constructs. Tissue Engineering. 2005;11(9-10):1297-1311

[32] Pham QP, Sharma U, Mikos AG. Electrospun poly(epsilon-caprolactone) microfiber and multilayer nanofiber/ microfiber scaffolds: Characterization of scaffolds and measurement of cellular infiltration. Biomacromolecules. 2006;7(10):2796-2805 
[33] Han D, Gouma P-I. Electrospun bioscaffolds that mimic the topology of extracellular matrix. Nanomedicine: Nanotechnology, Biology and Medicine. 2006;2(1):37-41

[34] Erisken C, Kalyon DM, Wang HJ. Functionally graded electrospun polycaprolactone and beta-tricalcium phosphate nanocomposites for tissue engineering applications. Biomaterials. 2008;29(30):4065-4073

[35] Soliman S et al. Multiscale three-dimensional scaffolds for soft tissue engineering via multimodal electrospinning. Acta Biomaterialia. 2010;6(4):1227-1237

[36] Ryu S et al. Three-dimensional scaffolds of carbonized Polyacrylonitrile for bone tissue regeneration. Angewandte Chemie International Edition. 2014;53(35):9213-9217

[37] Duan G et al. Ultralight, soft polymer sponges by self-assembly of short electrospun Fibers in colloidal dispersions. Advanced Functional Materials. 2015;25(19):2850-2856

[38] Wang W et al. Influences of mechanical properties and permeability on chitosan nano/microfiber mesh tubes as a scaffold for nerve regeneration. Journal of Biomedical Materials Research Part A. 2008;84A(2):557-566

[39] Shim IK et al. Novel threedimensional scaffolds of poly(L-lactic acid) microfibers using electrospinning and mechanical expansion: Fabrication and bone regeneration. Journal of Biomedical Materials Research Part B: Applied Biomaterials. 2010;95B(1):150-160

[40] Lee $\mathrm{S}$ et al. Lactic acid assisted fabrication of bioactive threedimensional PLLA/ $\beta$-TCP fibrous scaffold for biomedical application. Chemical Engineering Journal. 2018;347:771-781
[41] Hwang TI et al. Facile fabrication of spongy nanofibrous scaffold for tissue engineering applications. Materials Letters. 2018;219:119-122

[42] Sun B et al. Self-assembly of a three-dimensional fibrous polymer sponge by electrospinning. Nanoscale. 2012;4(6):2134-2137

[43] Lee S et al. Highly Moldable electrospun clay-like fluffy nanofibers for three-dimensional scaffolds. ACS Applied Materials \& Interfaces. 2014;6(2):1082-1091

[44] Teo WE et al. Remodeling of threedimensional hierarchically organized Nanofibrous assemblies. Current Nanoscience. 2008;4(4):361-369

[45] Yokoyama Y et al. Novel wet electrospinning system for fabrication of spongiform nanofiber 3-dimensional fabric. Materials Letters. 2009;63(9-10):754-756

[46] Badrossamay MR et al. Nanofiber assembly by rotary jet-spinning. Nano Letters. 2010;10(6):2257-2261

[47] Zhang D, Chang J. Electrospinning of three-dimensional Nanofibrous tubes with controllable architectures. Nano Letters. 2008;8(10):3283-3287

[48] Park SH et al. Development of dual scale scaffolds via direct polymer melt deposition and electrospinning for applications in tissue regeneration. Acta Biomaterialia. 2008;4(5):1198-1207

[49] Sun B et al. Advances in threedimensional nanofibrous macrostructures via electrospinning. Progress in Polymer Science. 2014;39(5):862-890

[50] Baker BM et al. The potential to improve cell infiltration in composite fiber-aligned electrospun scaffolds by the selective removal of sacrificial fibers. Biomaterials. 2008;29(15):2348-2358 
$3 D$ Nonwoven Fabrics for Biomedical Applications

DOI: http://dx.doi.org/10.5772/intechopen.88584

[51] Kim TG, Chung HJ, Park TG.

Macroporous and nanofibrous

hyaluronic acid/collagen hybrid

scaffold fabricated by concurrent

electrospinning and deposition/leaching

of salt particles. Acta Biomaterialia.

2008;4(6):1611-1619

[52] Ki CS et al. Development

of 3-D nanofibrous fibroin

scaffold with high porosity by

electrospinning: Implications for bone

regeneration. Biotechnology Letters.

2008;30(3):405-410 


\section{Edited by Mudassar Abbas and Han-Yong Jeon}

This book covers natural fibers at the basic level as well as a few advanced approaches for recent trends in natural fibers. The core chapters include an introduction to cellulosic fibers like cotton, protein fibers like silk, and other natural fibers. Overall the book provides comprehensive knowledge of natural fibers.

\section{IntechOpen}

